\title{
Targeting the Hedgehog and PI3K/AKT/mTOR signaling pathways in rhabdomyosarcoma
}

\author{
Doctoral Thesis \\ In partial fulfillment of the requirements for the degree \\ "Doctor rerum naturalium (Dr. rer. nat.)" \\ in the Molecular Medicine Study Program \\ at the Georg-August University Göttingen
}

submitted by

Natalie Geyer

born in Darmstadt

Göttingen 2018 
Members of the Thesis Committee:

Supervisor

Prof. Dr. Heidi Hahn

Institute of Human Genetics, University Medical Center Göttingen

Second member of the thesis committee

Prof. Dr. Matthias Dobbelstein

Institute of Molecular Oncology, University Medical Center Göttingen

Third member of the thesis committee

Prof. Dr. Dieter Kube

Department of Haematology and Oncology, University Medical Center Göttingen

Date of Disputation: 


\section{Affidavit}

Here I declare that my doctoral thesis entitled "Targeting the $\mathrm{HH}$ and PI3K/AKT/mTOR signaling pathways in rhabdomyosarcoma" has been written independently with no other sources and aids than quoted.

Natalie Geyer

Göttingen, May 2018 


\section{Table of Contents}

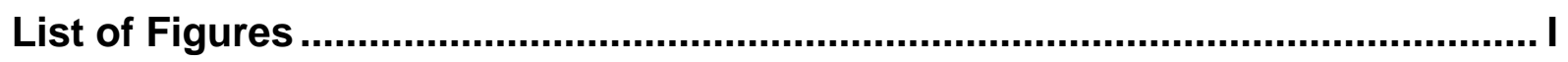

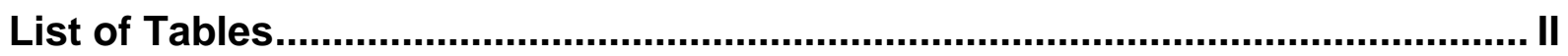

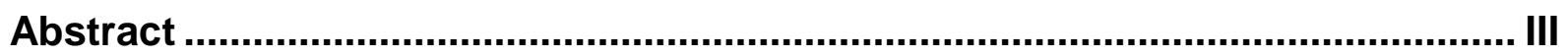

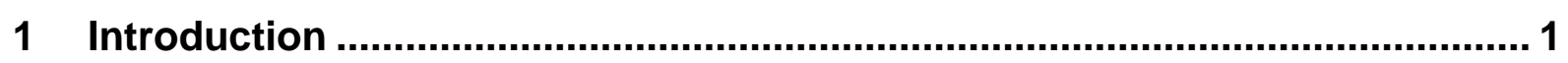

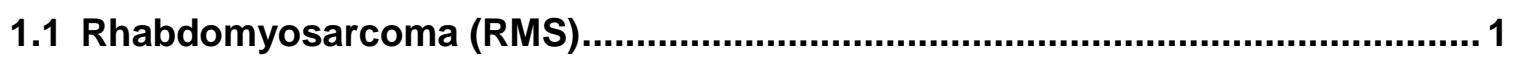

1.1.1 Current clinical trials for RMS .................................................................

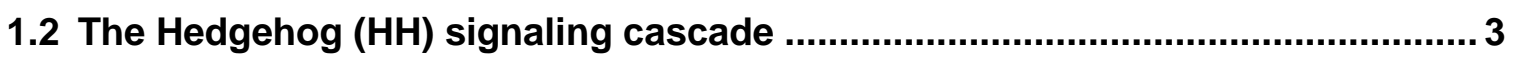

1.2.1 Canonical HH signaling ............................................................................

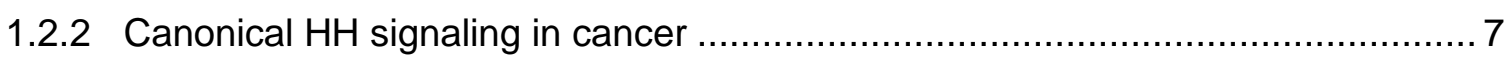

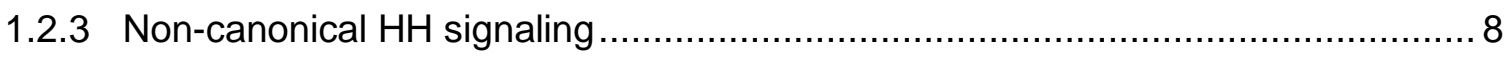

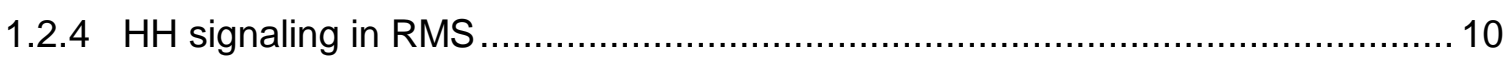

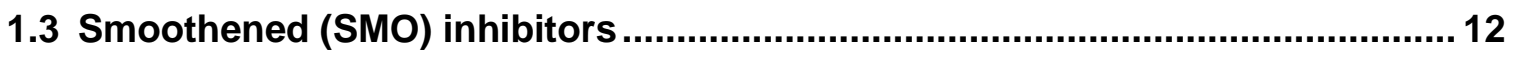

1.3.1 Cyclopamine, vismodegib, sonidegib and HhAntag....................................... 12

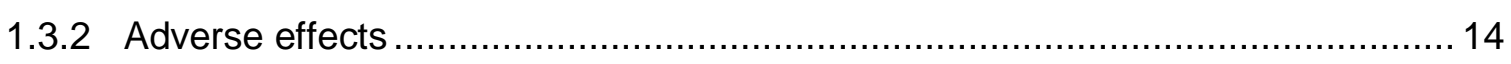

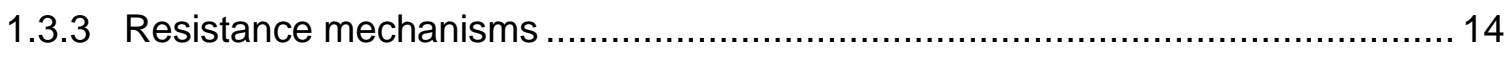

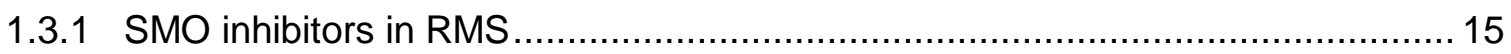

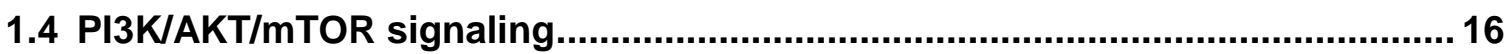

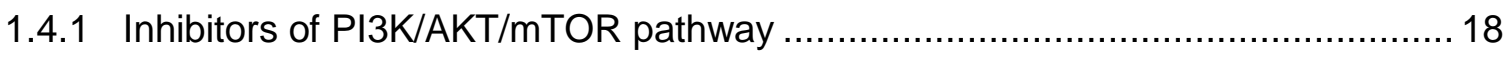

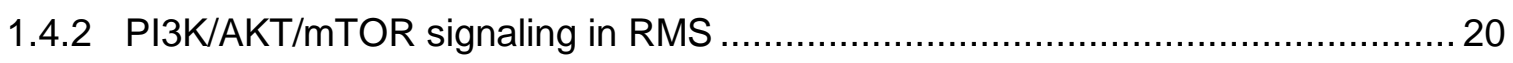

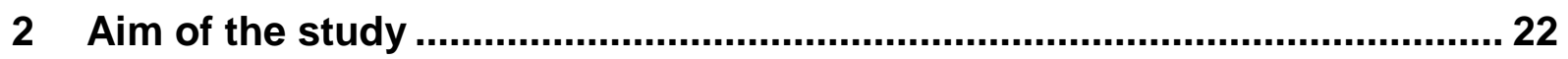

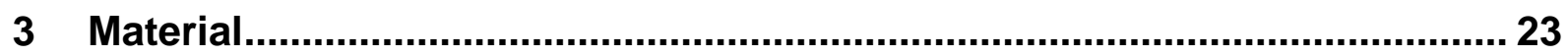

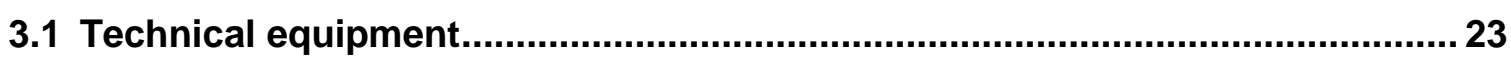

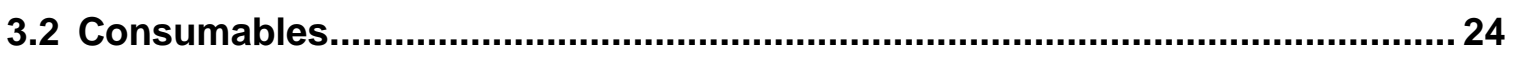

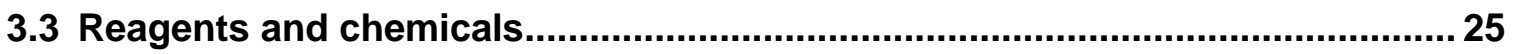

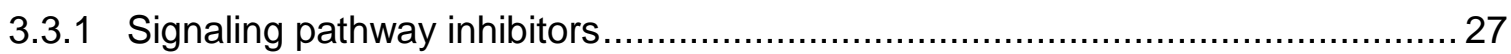




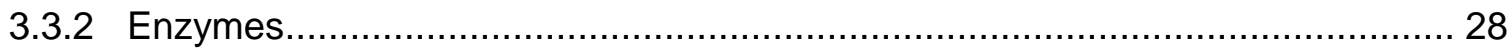

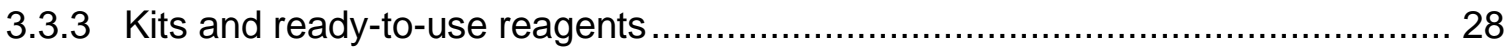

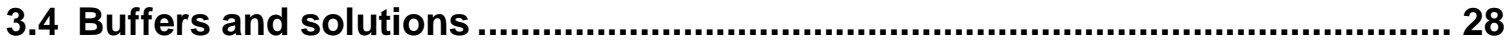

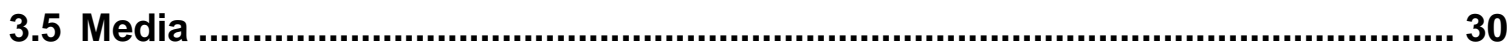

3.5.1 Media for prokaryotic cell cultivation .................................................... 30

3.5.2 Media and reagents for eukaryotic cell cultivation ........................................ 31

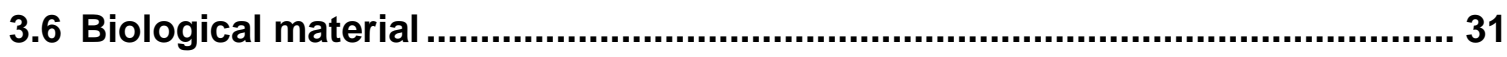

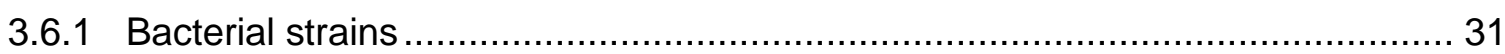

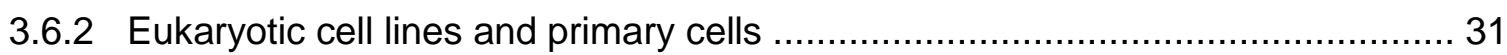

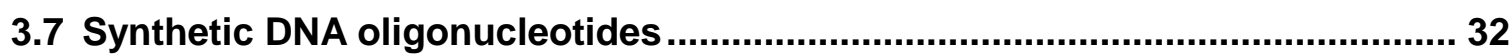

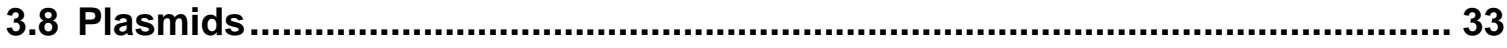

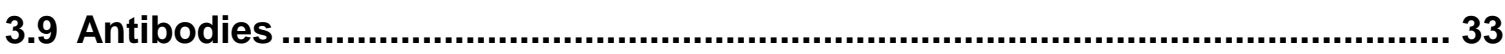

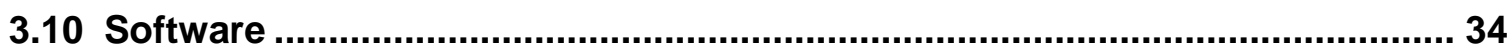

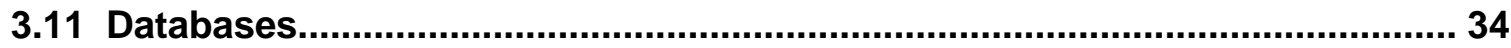

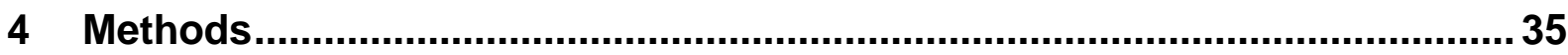

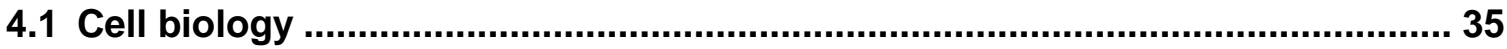

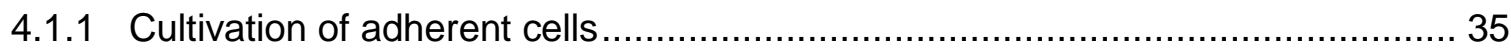

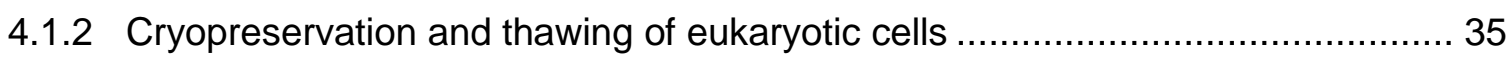

4.1.3 Generation of $\mathrm{SHH}$ conditioned medium (SHH-CM) ...................................... 36

4.1.4 Isolation and cultivation of primary murine RMS cells ................................... 36

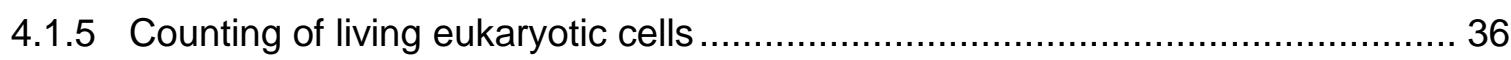

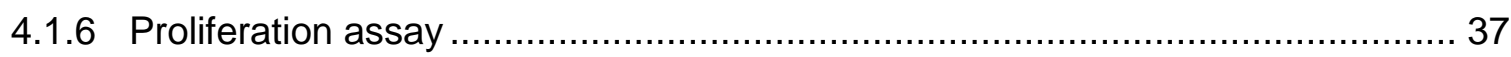

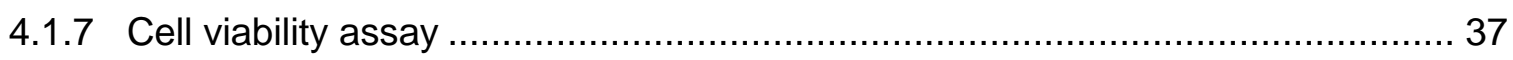

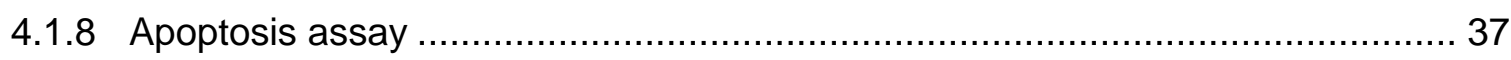

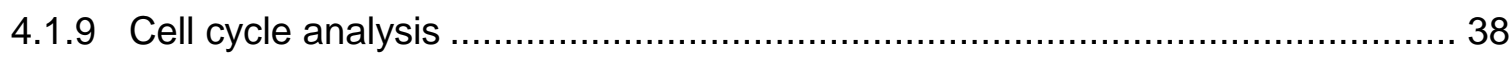

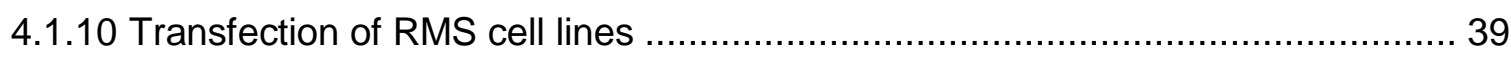

4.1.11 Transfection of RD cells with a Gli reporter system.................................... 39

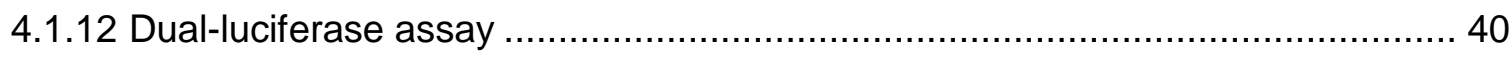

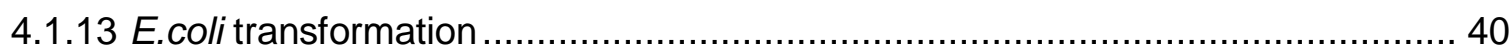




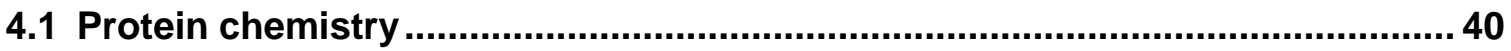

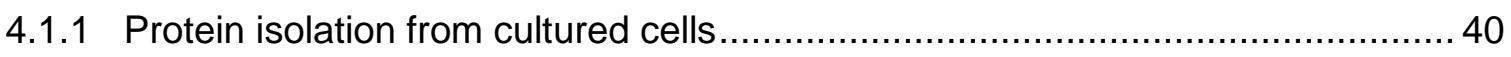

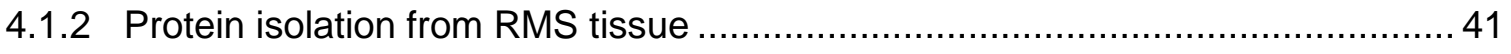

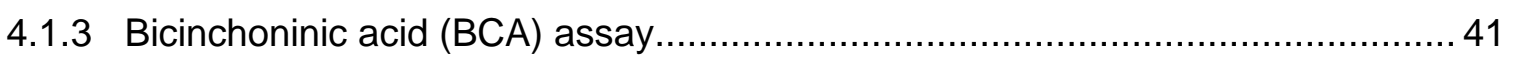

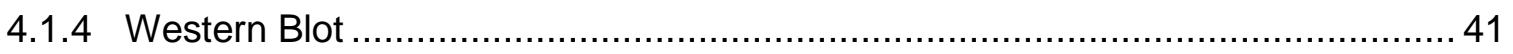

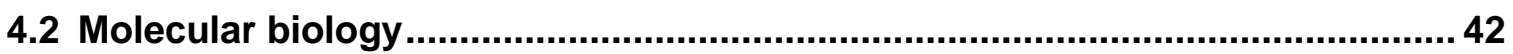

4.2.1 Genomic DNA (gDNA) isolation from mouse tail biopsies ............................... 42

4.2.2 Total RNA isolation from cell culture .......................................................... 43

4.2.3 Total RNA isolation from RMS tissue ....................................................... 43

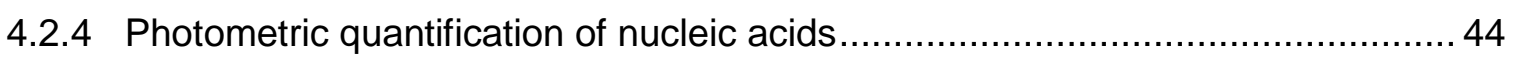

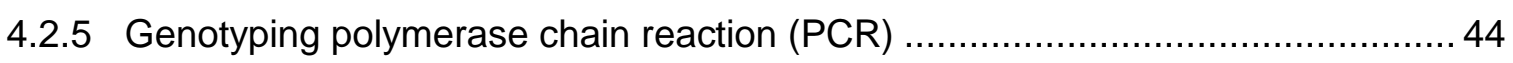

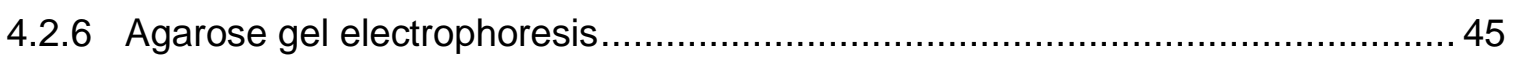

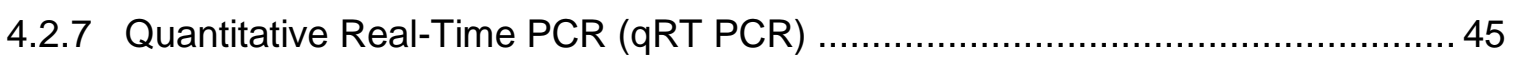

4.2.8 Plasmid DNA amplification, isolation and purification .................................... 47

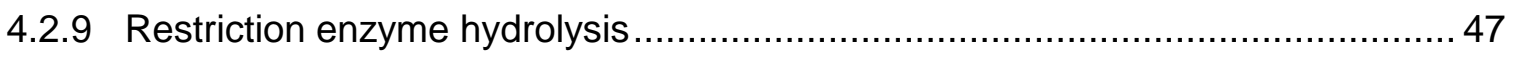

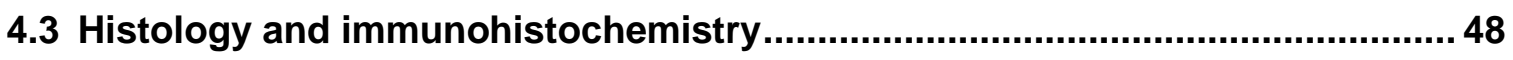

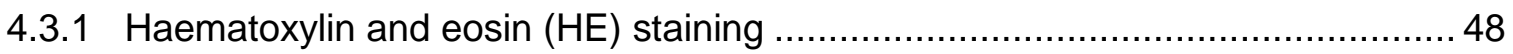

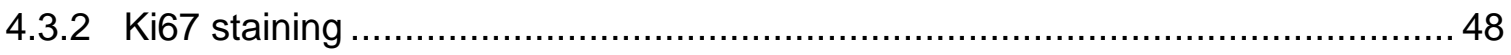

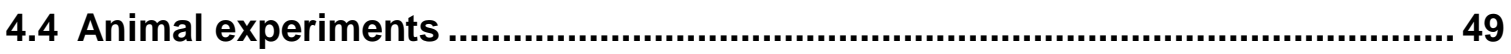

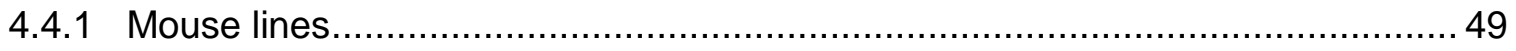

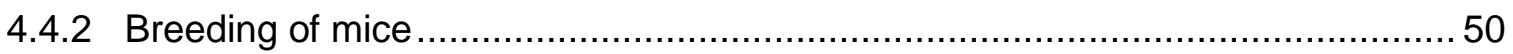

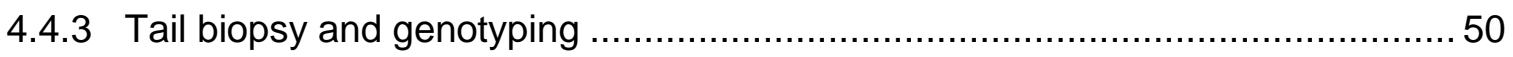

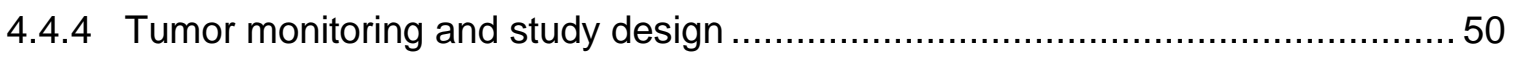

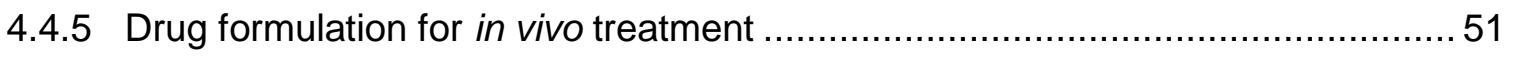

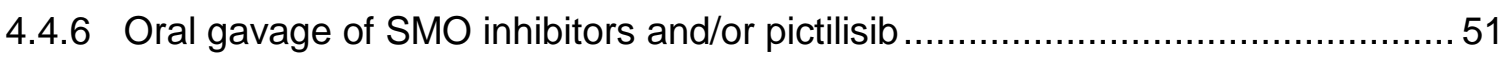

4.4.7 Tumor size assessment by in vivo micro computed tomography $(\mu \mathrm{CT})$............... 52

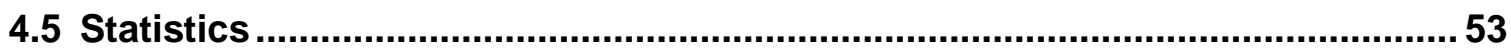

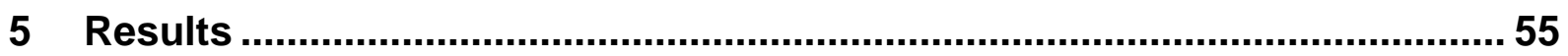

5.1 Targeting $\mathrm{HH}$ and PI3K/AKT/mTOR signaling pathways in human ERMS cell lines..................................................................................................... 55

5.1.1 Cyclopamine, sonidegib or HhAntag, but not vismodegib, enhance antiproliferative effects of cells with a low SMO expression level ..... 
5.1.2 HhAntag, but not cyclopamine, vismodegib or sonidegib, induces a moderate G2/M arrest although it does not affect $\mathrm{HH}$ signaling activity

5.1.3 Non-canonical regulation of $\mathrm{HH}$ signaling in ERMS cell lines

5.1.4 SMO inhibitors can induce cooperative anticancer effects when combined with $\mathrm{PI} / \mathrm{K} / \mathrm{AKT} / \mathrm{mTOR}$ inhibitors

5.1.5 Chapter summary

5.2 Targeting $\mathrm{Hh}$ and Pi3k/Akt/mTor signaling pathways in murine Ptch $^{\text {+/ }}$ ERMS cells

5.2.1 SMO inhibitors as well as pictilisib efficiently inhibit Gli1 expression

5.2.2 Pictilisib inhibits Akt phosphorylation and induces cleavage of caspase 3

5.2.3 Synergistic anti-proliferative effects of SMO inhibitors in combination with pictilisib.

5.2.4 Chapter summary

5.3 Targeting $\mathrm{Hh}$ and Pi3k/Akt/mTor signaling pathways in ERMS of $\mathrm{Ptch}^{+/}$ mice

5.3.1 SMO inhibitors and pictilisib can reduce ERMS tumor growth and their combination can enhance the antitumoral effects

5.3.2 SMO inhibitors and/or pictilisib can reduce the number of $\mathrm{Ki} 67^{+}$tumor cells ...... 90

5.3.3 SMO inhibitors, but not pictilisib, strongly reduce Gli1 expression.

5.3.4 Effects of SMO inhibitors and pictilisib on Pi3k/Akt/mTor signaling and

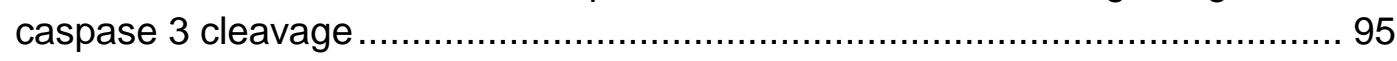

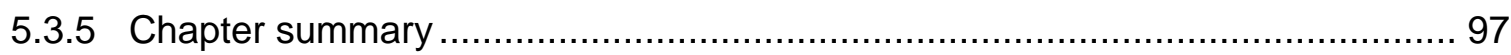

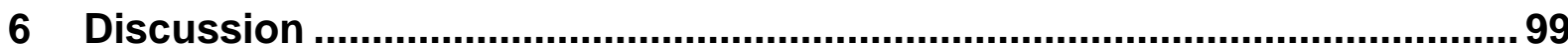

6.1 Effectiveness of SMO inhibitors on ERMS cell lines with low HH activity ....... 99

6.2 Modulation of canonical HH signaling in ERMS cell lines 101

\subsection{Non-canonical modulation of $\mathrm{HH}$ signaling via PI3K/AKT/mTOR in ERMS} cell lines

6.4 Effects of SMO and/or PI3K/AKT/mTOR inhibitors in ERMS cell lines. 103

6.4.1 Functionality of PI3K/AKT/mTOR signaling inhibitors depends on feedback regulatory loops.....

6.4.2 Anticancer effects of SMO inhibitors alone and in combination with $\mathrm{PI} \mathrm{KK} / \mathrm{AKT} / \mathrm{mTOR}$ inhibitors 
6.5.1 Effects of different SMO inhibitors in vitro and in vivo.................................. 106

6.5.2 Pictilisib-mediated effects on Hh signaling and growth of $\mathrm{Ptch}^{+/}$ERMS ........... 108

6.5.3 Combination effects of SMO inhibitors plus pictilisib .................................. 110

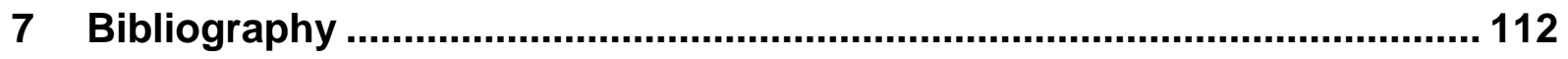

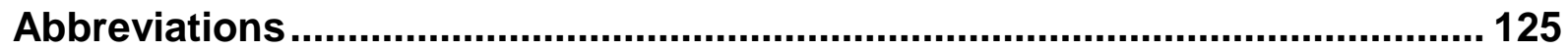

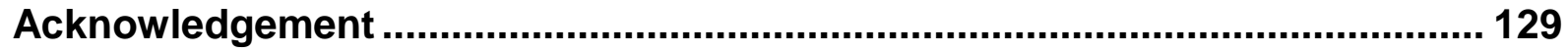

Curriculum Vitae ........................................................................................... 130 


\section{List of Figures}

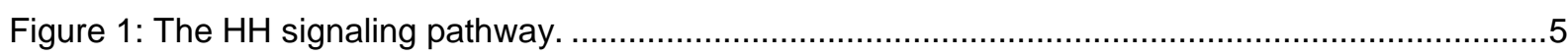

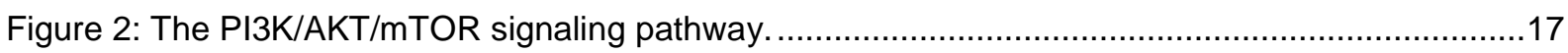

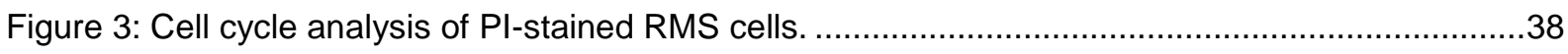

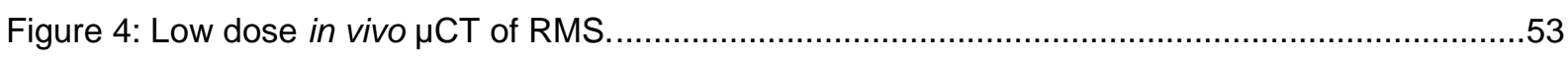

Figure 5: RD SMOlow cells show a clear but incomplete downregulation of SMO .............................56

Figure 6: RD SMOlow cells are sensitiver towards cyclopamine, sonidegib or HhAntag compared

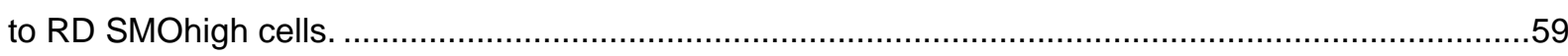

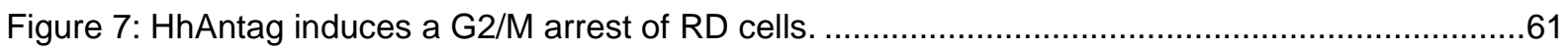

Figure 8: SMO inhibitors do not alter GLI reporter activity in RD cells.............................................62

Figure 9: SHH may, if at all, only moderately regulate HH signaling in ERMS cell lines. .....................64

Figure 10: Proof of functionality of PI3K/AKT/mTOR and RAS/MEK/ERK inhibitors............................66

Figure 11: UO126 enhances and PI3K/AKT/mTOR inhibitors reduce $\mathrm{HH}$ activity..............................67

Figure 12: Overexpression of AKT variants in RD and HEK293 cells. ............................................68

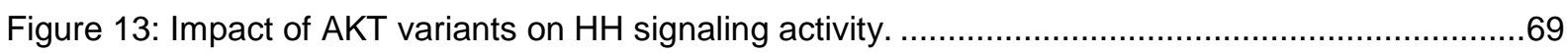

Figure 14: Impact of SMO and PI3K/AKT/mTOR inhibitors on $\mathrm{HH}$ signaling activity. ...........................71

Figure 15: Impact of SMO and PI3K/AKT/mTOR inhibitors on phosphorylation of AKT, S6 and the

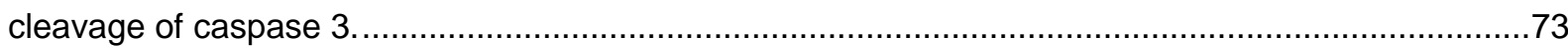

Figure 16: Impact of SMO and PI3K/AKT/mTOR inhibitors on proliferation. ......................................75

Figure 17: Synergistic anti-proliferative effects of combined SMO and PI3K inhibition. .......................77

Figure 18: Impact of SMO and PI3K/AKT/mTOR inhibitors on apoptosis.........................................79

Figure 19: SMO inhibitors reduce Gli1 and can rescue the upregulation of Hhip occurring upon

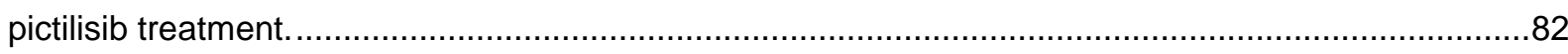

Figure 20: Impact of Smo and Pi3k inhibition on Pi3k/Akt/mTor activity and caspase 3 cleavage in

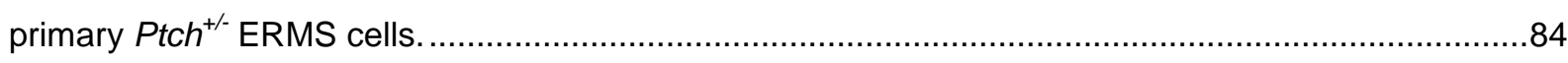

Figure 21: Synergistic anti-proliferative effects of SMO and PI3K inhibitors in Ptch $^{+/}$ERMS cells.......87

Figure 22: Impact of SMO inhibitors and/or pictilisib on ERMS tumor growth. ...................................89

Figure 23: Percentage of $\mathrm{Ki} 67^{+}$cells in $\mathrm{Ptch}^{+/}$ERMS treated with SMO inhibitors and/or pictilisib. .....91

Figure 24: Effect of SMO and/or PI3K inhibitors on Hh signaling activity. .......................................92

Figure 25: Vismodegib and sonidegib, but not pictilisib, reduce tumor growth in $\mathrm{Ptch}^{+/}$mice in

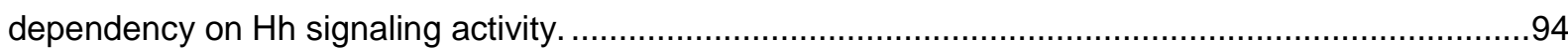

Figure 26: Impact of vismodegib, sonidegib, HhAntag and/or pictilisib on Pi3k/Akt/mTor activity

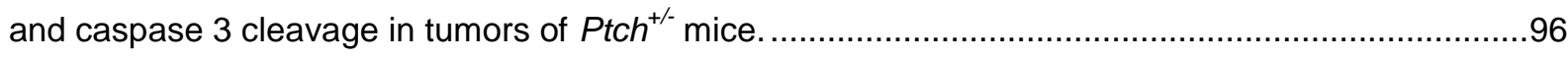

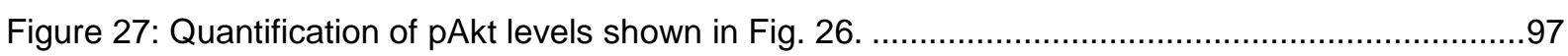




\section{List of Tables}

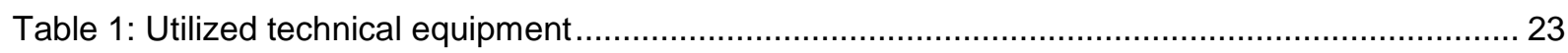

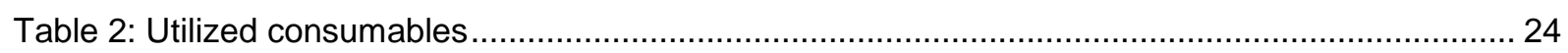

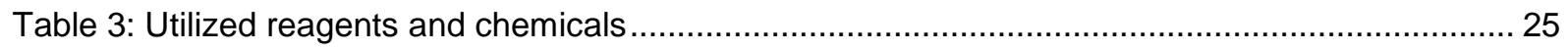

Table 4: Utilized small molecule inhibitors for in vitro experiments ................................................. 27

Table 5: Utilized small molecule inhibitors for in vivo experiments ..................................................... 27

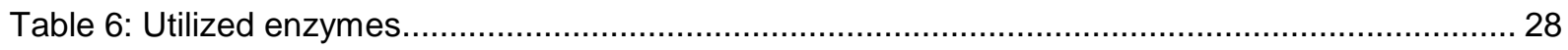

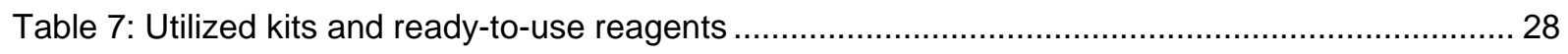

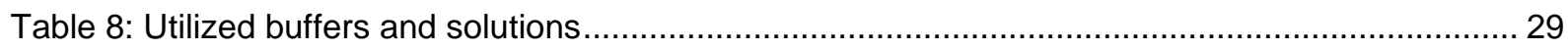

Table 9: Utilized media and reagents for eukaryotic cell cultivation.................................................. 31

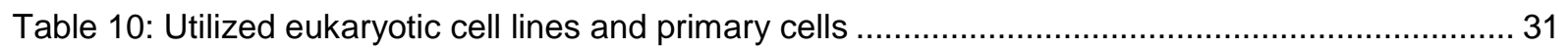

Table 11: Utilized synthetic DNA oligonucleotides for genotyping PCR of $\mathrm{PtCh}^{+/-}$mice........................ 32

Table 12: Utilized synthetic DNA oligonucleotides for qRT PCR .................................................... 32

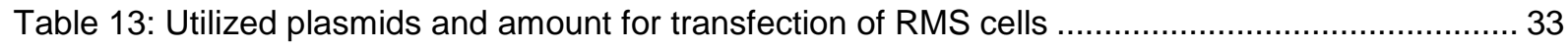

Table 14: Utilized antibodies for Western Blot analysis and immunohistochemistry ........................... 33

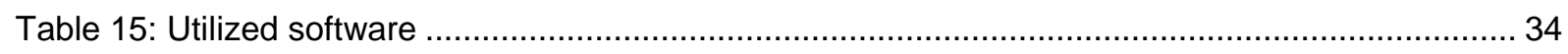

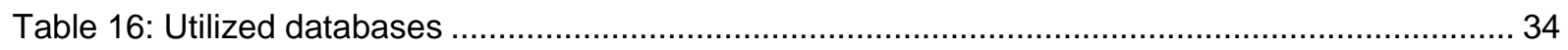

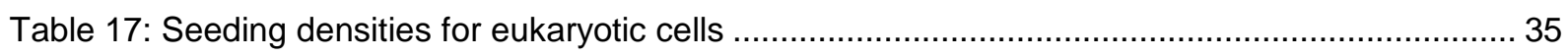

Table 18: Analysis of data shown in Figs. 22A - 22C according to RECIST analysis..........................90 


\section{Abstract}

Rhabdomyosarcoma (RMS) is the most common pediatric soft tissue sarcoma with poor prognosis. RMS, and especially the embryonal subtype (ERMS), show activation of Hedgehog $(\mathrm{HH})$ signaling. In patients with Gorlin syndrome, who have an increased susceptibility to ERMS, activation of the $\mathrm{HH}$ pathway is due to mutations in the $\mathrm{HH}$ receptor PATCHED $(P T C H)$. This is different in sporadic RMS, in which mutations in components of the $\mathrm{HH}$ pathway are very rare.

Because the $\mathrm{HH}$ pathway seems to be a good target for RMS therapy, we tested the effects of several SMOOTHENED (SMO) inhibitors on cell lines derived from sporadic human RMS. The response of the cells was very heterogeneous and some drugs paradoxically induced proliferation at certain concentrations or showed anti-proliferative effects without inhibition of $\mathrm{HH}$ signaling activity. Therefore we hypothesized that the antitumoral effects of SMO inhibitors may rely on off-target effects. In addition, our group found evidence for an interaction between $\mathrm{HH}$ and $\mathrm{PI} 3 \mathrm{~K} / \mathrm{AKT} / \mathrm{mTOR}$ signaling in RMS.

Since the majority of RMS show phosphorylation of AKT or S6 and since an interaction between the $\mathrm{PI3K} / \mathrm{AKT} / \mathrm{mTOR}$ and $\mathrm{HH}$ signaling pathways is well described in the literature, this thesis elucidated the importance of PI3K/AKT/mTOR signaling in RMS and in regulation of $\mathrm{HH}$ signaling activity. Furthermore the effectiveness of PI3K/AKT/mTOR inhibitors alone and in combination with SMO inhibitors was analyzed. For this purpose cell lines from sporadic human ERMS and the $\mathrm{Ptch}^{+/}$mouse model for ERMS were employed. In addition, we tried to unravel if the anti-cancer effects of SMO inhibitors that were not associated with a downregulation of $\mathrm{HH}$ signaling activity were off-target effects.

The data show that cell lines from sporadic human ERMS are rather unresponsive to stimulation by the SHH ligand or SMO agonist. They are also only moderately responsive to SMO inhibitors, which apparently can exert off-target effects. However, they are highly responsive to $\mathrm{PI} 3 \mathrm{~K} / \mathrm{AKT} / \mathrm{mTOR}$ inhibitors, especially to the $\mathrm{PI} \mathrm{K}$ inhibitor pictilisib. Furthermore, PI3K/AKT/mTOR inhibitors can inhibit $\mathrm{HH}$ signaling activity in ERMS cells and when combined with SMO inhibitors they can induce cooperative anti-cancer effects.

Because the investigated human ERMS cell lines in most likelihood do not harbor mutations that cause activation of $\mathrm{HH}$ signaling upstream of SMO and because the cells were only moderately responsive to SMO inhibitors, we hypothesized that SMO inhibitors alone are only useful in those ERMS that are caused by mutations upstream of SMO. To approach this hypothesis, we made use of ERMS-like tumors of Ptch mutant mice. Indeed, cultured Ptch ${ }^{+/}$ 
ERMS cells respond to SMO inhibitors, which goes along with efficient reduction of $\mathrm{Hh}$ signaling activity. In addition, and as in human ERMS cells, efficient reduction of $\mathrm{Hh}$ signaling activity and antitumor effects are also seen with the PI3K inhibitor pictilisib. Furthermore, the combination of SMO inhibitors plus pictilisib synergistically induces anti-cancer effects. When applied orally to tumor bearing $\mathrm{Ptch}^{+/}$mice, SMO inhibitors stop tumor growth and downregulate Gli1 expression, which correlates with reduction of tumor size. Tumor growth is also stopped by pictilisib. However, in contrast to cultured $\mathrm{Ptch}^{+-}$ERMS cells and human ERMS cell lines and probably due to microenvironmental factors, pictilisib does not affect Gli1 expression.

In summary, the experiments of this thesis demonstrate that SMO inhibitors and concomitant reduction of $\mathrm{HH}$ signaling activity exhibit strong antitumoral effects in ERMS that harbor mutations upstream of SMO, whereas their antitumoral activity in cell lines derived from sporadic human ERMS (which most likely do not harbor mutations upstream of SMO) is very variable and not always associated with $\mathrm{HH}$ signaling inhibition. In contrast, PI3K/AKT/mTOR inhibitors e.g. pictilisib induce a strong antitumoral response irrespective of the mutational status of the $\mathrm{HH}$ pathway and in some cases also may allow for lowering the dose of SMO inhibitors. Together, these data suggest that PI3K/AKT/mTOR inhibitors are in general a better and probably a more secure therapeutic option in patients with sporadic ERMS and that a treatment with SMO inhibitors requires either pretesting e.g. in patient-derived short-term RMS cultures or a screen for $\mathrm{PTCH}$ mutations. 


\section{Introduction}

\subsection{Rhabdomyosarcoma (RMS)}

RMS is the most common pediatric soft tissue sarcoma with an annual incidence rate of 5.4 (males) and 4.2 (females) cases per one million children at the age of 0-19 years ${ }^{1,2}$. Originally RMS was supposed to develop from the skeletal muscle lineage. However, these tumors can also arise from non-skeletal muscle progenitor cells ${ }^{3,4}$. Hence, primary sites of RMS are not only skeletal muscle tissue i.e. the muscles of the limbs, but also the head and neck area, the genitourinary tract and the peritoneum ${ }^{1,5}$.

The two major histological subtypes are embryonal RMS (ERMS, account for approx. $50 \%$ of cases) and alveolar RMS (ARMS, account for approx. $40 \%$ of cases). In addition, spindle cell RMS and botryoid RMS have been classified as the third and fourth accepted subtype ${ }^{6}$.

On a molecular basis ARMS are further characterized by chromosomal reciprocal translocations of chromosome 13 and chromosome 2 or 1 . These translocations, $t(2 ; 13)$ (q35$37 ; q 14)$ and $t(1 ; 13)(p 36 ; q 14)$, result in the expression of PAX3/FOXO1 and PAX7/FOXO1 fusion proteins, respectively. Approximately $70 \%$ of ARMS are fusion protein-positive tumors and the expression of the fusion proteins is associated with a poorer outcome ${ }^{7-9}$. In contrast, ERMS don't show unique chromosomal alterations. However, they frequently show a loss of heterozygosity $(\mathrm{LOH})$ at $11 \mathrm{p} 15$ locus $^{10-12}$. Additionally ERMS often accumulate copy number variations and structural variants in typical cancer associated genes like NRAS, KRAS, TP53, FGFR4 and PIK3CA. For example, RAS pathway mutations occur in $75 \%$ of high-risk ERMS $^{13}$. In addition, $10 \%$ of ERMS carry a c.365T>G mutation within the MYOD 1 gene, which results in a p.Leu122Arg substitution that alters the DNA binding domain of this myogenic transcription factor and which is associated with a worse outcome ${ }^{14}$.

Risk stratification for RMS is predicted based on age, tumor subtype and stage, primary site and number/sites of metastatic disease. Hence, the 10-year overall survival ranges between $20 \%$ for fusion gene-positive ARMS, $65 \%$ for ERMS and $75 \%$ for fusion gene-negative ARMS $^{15}$. The current therapy of RMS consists of radiotherapy or surgery in combination with a multi-agent chemotherapy that includes vincristine, actinomycin $D$ and cyclophosphamide (VAC). A trial with 617 intermediate-risk RMS patients receiving X-rays and VAC treatment resulted in a mean 4-year failure-free survival in $73 \%$ of the patients. However, this therapeutic approach is highly toxic and can result in febrile neutropenia (85\%), anemia (55 $\%$ ), infectious diseases (54\%), leukopenia (60\%), lymphopenia (22\%), neutropenia (63\%) and thrombopenia (51\%). Besides, secondary hematologic malignancies or secondary solid 
tumors can occur ${ }^{16}$. As these adverse effects of chemotherapy are especially detrimental for children, other therapy approaches including targeted therapy are highly requested.

\subsubsection{Current clinical trials for RMS}

Even though the 3-year failure-free survival for low-risk RMS with the current treatment options is $>90 \%$, patients with high-risk metastatic RMS have a long-term failure-free survival of $<30 \%$. Hence, clinical trials for low-risk RMS aim to sustain the effectiveness of current treatments while at the same time reducing toxicities. In contrast, clinical trials for intermediate- and high-risk RMS aim to improve the therapy effectiveness of the current chemotherapy ${ }^{17}$. In addition, trials for refractory or relapsed RMS after standard therapy often assess the effectiveness of alternative novel targeted therapies.

Ongoing or recently completed clinical trials can be found in the ClinicalTrials.gov database (provided by the U.S. National Library of Medicine) and will be summarized in the following section.

Currently, many clinical trials test agents targeting receptor tyrosine kinases or their ligands, either as single agent therapy or in combination with a chemotherapy backbone. Examples are the trials NCT01222715 and NCT00643565, which investigate the effectiveness of the monoclonal antibody bevacizumab, which targets the vascular endothelial growth factor (VEGF). However, the treatment did not show any benefits compared to the current therapy $^{18}$. Other examples are the studies NCT01055314, NCT00642941 and NCT03041701, which investigate the effectiveness of cixutumumab, R1507 and ganitumab, which are three different monoclonal antibodies against insulin-like growth factor 1 receptor (IGF-1R). Whereas cixutumumab is applied in combination with a chemotherapy backbone, R1507 is applied as single drug and ganitumab is applied in combination with the tyrosine kinase inhibitor dasatinib. The study results are already published for R1507 and show that the drug is well tolerated but is not efficient in refractory or relapsed $\mathrm{RMS}^{19}$.

Besides antibodies targeting receptors or ligands, small molecules are employed in RMS. Examples are the fibroblast growth factor receptor (FGFR) inhibitor erdafitinib (NCT03210714) and the epidermal growth factor receptor (EGFR) inhibitors erlotinib and afatinib (NCT00077454, NCT02689336 and NCT 02372006). Additionally, VEGF signaling is repressed with multi-target receptor tyrosine kinase inhibitors that target its receptors (VEGFRs), e.g. regorafenib (NCT02048371 and NCT02085148), sorafenib (NCT01502410), cabozantinib (NCT02867592) and lanvatinib (NCT03245151).

Additionally, several RMS clinical trials target more downstream kinases of common oncogenic pathways, which are the phosphatidylionsitide 3-kinase (PI3K) / protein kinase B 
(AKT) / mammalian target of rapamycin (mTOR) signaling pathway. For instance the mTOR inhibitor temsirolimus, which is approved by the FDA and EMEA for renal cell carcinoma, entered a phase III clinical trial in combination with a chemotherapy backbone for intermediate-risk RMS patients (NCT02567435). Two additional mTOR inhibitors, rapamycin and everolimus, are also under investigation (NCT01331135, NCT02574728 and NCT01216839). Furthermore, the dual mTOR and PI3K inhibitor LY302314 as well as the PI3K inhibitor copanlisib are investigated (NCT03123678 and NCT03458728). Finally, results for a clinical phase II trial with perifosine, which supposedly inhibits AKT and also the MAPK and JNK pathways, have been published and show that this drug is not effective in $\mathrm{RMS}^{20}$.

Together these data show that the effectiveness of the currently completed targeted therapy treatments using inhibitors of receptor tyrosine kinases or the PI3K/AKT/mTOR pathway stayed somewhat behind the expectations. Therefore current research also focuses on other therapy options. One pathway, which apparently is activated in RMS, but silenced in most adult human cells, is the Hedgehog $(\mathrm{HH})$ signaling cascade ${ }^{21,22}$. Recently, results of a phase I clinical trial with the Smoothened (SMO) inhibitor sonidegib for pediatric and adult RMS, medulloblastoma, neuroblastoma, hepatoblastoma, glioma or astrocytoma were posted (NCT01125800). The maximal tolerated dose was $680 \mathrm{mg} / \mathrm{m}^{2}$ and oral application induced dose-limiting toxicities in only 1 of 60 pediatric participants who was is the group receiving $372 \mathrm{mg} / \mathrm{m}^{2}$ sonidegib. Results from another phase II clinical trial using a SMO inhibitor called vismodegib (oral application of $150 \mathrm{mg}$ per day) in combination with the $\gamma$-secretase/notch signaling pathway inhibitor RO4929097 were posted in 2016 (NCT01154452). The shortterm results (4 month) show that addition of vismodegib is of no benefit. However the results about the long-term effects are not available yet. Even though $\mathrm{HH}$ signaling plays an important role in tumorigenesis and tumor maintenance of RMS (see section 1.2.4), no further clinical trials targeting this pathway are under investigation.

\subsection{The Hedgehog $(\mathrm{HH})$ signaling cascade}

The importance of $\mathrm{HH}$ proteins became obvious upon a mutational screen in Drosophila melanogaster larvae, performed back in $1980^{23}$. The screen discovered a set of genetic mutations leading to segmentation defects. One of these larvae had duplicated denticles ${ }^{24}$. As this phenotype - in the view of the authors - resembled a hedgehog, the responsible gene in Drosophila melanogaster was called hedgehog as was the resulting protein.

\subsubsection{Canonical HH signaling}

In vertebrates, three $\mathrm{Hh}$ homologs exist, which are Desert hedgehog (DHH), Indian hedgehog $(\mathrm{IHH})$ and Sonic hedgehog $(\mathrm{SHH}) . \mathrm{SHH}$ is the most important $\mathrm{HH}$ protein and 
plays a crucial role in several key developmental processes in the human embryo including patterning of the neural tube, the ventral somites and the anterior-posterior limb axis ${ }^{24}$. In addition, $\mathrm{HH}$ signaling is very important for regulation of tissue homeostasis and stem cell maintenance as well as for differentiation processes in the adult organism. As dysregulated cell growth is associated with the development of cancer, it is not surprising that aberrant $\mathrm{HH}$ signaling can induce tumorigenesis ${ }^{25}$.

Although the mechanism of canonical $\mathrm{HH}$ signal transduction within eukaryotic cells is not fully understood, the main factors are known and a simplified scheme of the pathway is depicted in Fig. 1. Today it is known that binding of any of the three $\mathrm{HH}$ ligands to the transmembrane protein Patched $1(\mathrm{PTCH})$ that is located in the primary cilium and represses $\mathrm{SMO}$, releases the inhibition of SMO. The mechanism of SMO repression by PTCH in the absence of $\mathrm{HH}$ is not completely understood, but upon $\mathrm{HH}$ binding $\mathrm{PTCH}$ disappears from the primary cilium and subsequently SMO translocates into the primary cilium ${ }^{26}$. Accumulation of SMO in the primary cilium triggers an intracellular signaling cascade, which finally leads to conversion of the Glioma-associated Oncogene Homolog (GLI) transcription factors GLI2 and GLI3 into their active state. As a consequence GLI2/3 are translocated into the nucleus where they recognize and bind to specific promoter sequences. The latter process activates transcription of $\mathrm{HH}$ target genes, which are amongst others GLI1, PTCH and $H H I P^{27,28}$. Whereas expression of GLI1 amplifies the signal in a positive feedback loop, expression of the two negative regulators $P T C H$ and HHIP reflect negative feedback loops. $\mathrm{HHIP}$ is the abbreviation for $\mathrm{HH}$ interacting protein, which is a membrane protein that can compete with $\mathrm{PTCH}$ for binding of all three $\mathrm{HH}$ ligands $^{29}$.

Besides positive and negative feedback regulation, GLI proteins can regulate the expression of factors that are related to cell cycle progress, proliferation and cell survival, e.g. CyclinD1, IGF2 and N-Myc. However the cellular response upon GLI activation highly depends on the cell type, age, state and time ${ }^{28,30}$.

Within the following, the three main components of $\mathrm{HH}$ signal transduction in a recipient cell, $\mathrm{PTCH}, \mathrm{SMO}$ and $\mathrm{GLI}$, are described in more detail, because they play an important role in cancers associated with aberrant $\mathrm{HH}$ signaling activity.

PTCH is a 12-pass transmembrane protein with the $\mathrm{N}$ - and C-terminal parts located within the cytoplasm and six extracellular as well as five intracellular loops. The extracellular parts of $\mathrm{PTCH}$ interact with the three SHH co-receptors growth arrest-specific 1 (GAS1), cell adhesion molecule-related/down-regulated by oncogenes (CDO) and brother of CDO (BOC), which are essential for proper signal activation ${ }^{31,32}$. 
A

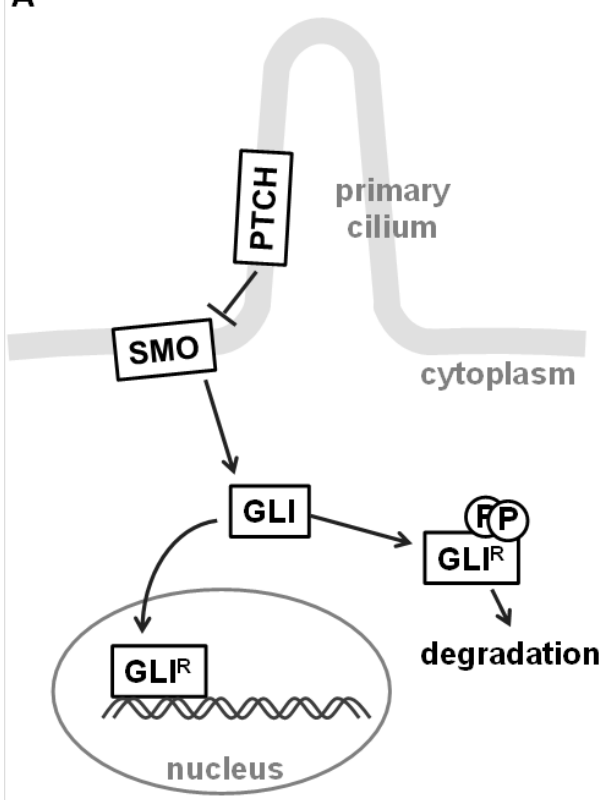

B

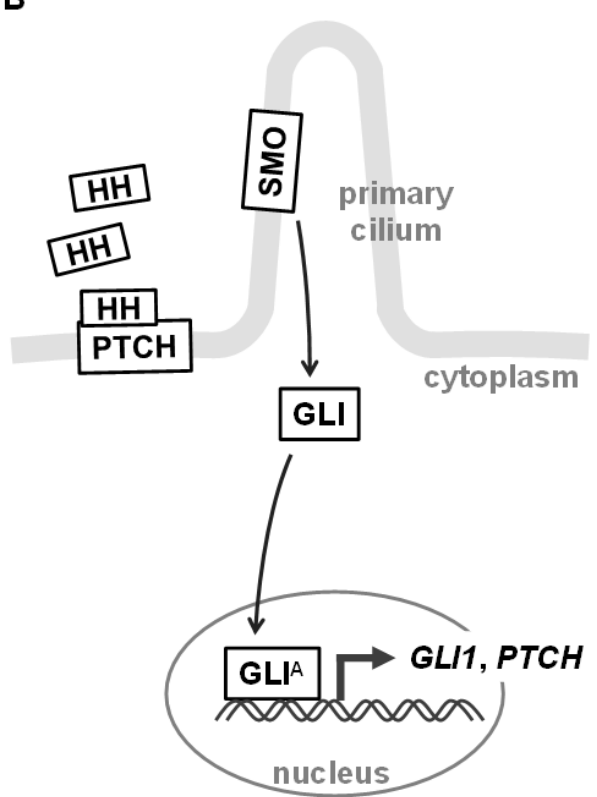

Figure 1: The HH signaling pathway. (A) In absence of $\mathrm{HH}$ ligands, the transmembrane protein PTCH withholds SMO from entering the primary cilium. This triggers an intracellular signaling cascade resulting in the phosphorylation of GLI transcription factors. As a result GLI proteins are processed into their truncated repressor forms $\left(\mathrm{GLI}^{\mathrm{R}}\right)$ which enter the nucleus to inhibit target gene expression or are further degraded by the proteasome. (B) Upon binding of $\mathrm{HH}$ ligands to $\mathrm{PTCH}$, the transmembrane protein exits the primary cilium and the repression of SMO is released. Hence SMO enters the primary cilium and the GLI transcription factors are activated and translocate into the nucleus where they induce the expression of $\mathrm{HH}$ target genes, e.g. GLI1 and PTCH. A more detailed description of the $\mathrm{HH}$ signaling pathway can be found in the main text.

The mechanism of signal transduction from $\mathrm{PTCH}$ to SMO is not well understood. Nevertheless the N-terminal part of PTCH is important for ligand binding as well as SMO inhibition and the C-terminal cytosolic tail of PTCH is sufficient for localization of the protein within the primary cilium. In addition, the removal of $\mathrm{PTCH}$ from the primary cilium, in contrast to binding of $\mathrm{HH}$ ligands to $\mathrm{PTCH}$, seems to be uncoupled from the activation of $\mathrm{SMO}$. As a consequence, it is supposed that removal of PTCH from the primary cilium might rather enhance than induce the response to $\mathrm{HH}$ ligands ${ }^{33}$.

PTCH plays a pivotal role in developmental processes and in cancer. Thus, in humans, germline mutations in $\mathrm{PTCH}$ result in Gorlin syndrome that is characterized by developmental anomalies and a variety of tumors (see section 1.2.2 for description). In mice, the homozygous deletion of Ptch leads to neural tube closure defects and Ptch mutants do not survive beyond embryonic day 9.0. Heterozygous deletion of Ptch can result in developmental anomalies like polydactyly and overgrowth ${ }^{34}$. In addition, these animals are prone to develop basal cell carcinoma, medulloblastoma and $\mathrm{RMS}^{34,35}$. 
SMO is a $\mathrm{G}$ protein-coupled receptor that consists of 7 transmembrane domains, 3 extracellular and 3 intracellular loops, an extracellular $\mathrm{N}$ - and an intracellular C-terminus. Although in research focus since several years, the mechanism of SMO repression by PTCH and the identity of cell endogenous SMO ligands remains elusive, as reviewed $\mathrm{in}^{36}$. However, it is known that $\mathrm{HH}$ ligands induce phosphorylation of SMO at the C- terminus ${ }^{37}$ that leads to a conformation change resulting in SMO activation ${ }^{38}$. In Drosophila melanogaster it was shown that Smo activation leads to ubiquitination and degradation of $\mathrm{Ptch}^{39}$.

The transmembrane domain of SMO carries a binding pocket, which is accessible for small molecule inhibitors. The first described inhibitor was the natural SMO antagonist cyclopamine. Discovery of this drug began more than 50 years ago, when a series of lamb cyclops were born in sheep ranches in the United States. Within the following decades a causative compound was found in wildflowers. Offspring of sheep fed with these wildflowers developed malformations of the head and in the worst case were born as cyclops. Hence, the compound was named cyclopamine. Cyclopamine was shown to be the first SMO antagonist inhibiting $\mathrm{HH}$ signaling and evoking developmental problems ${ }^{40}$. Besides cyclopamine several SMO antagonists and agonists, which can bind to different sites of SMO's binding pocket have been developed ${ }^{41}$. The SMO inhibitors that are used in this thesis are described in detail in section 1.3.1.

In addition, the extracellular N-terminus of SMO possesses a cysteine-rich domain that is accessible to oxysterol binding. Interaction of oxysterols with this domain, albeit not fully understood on mechanistic basis, can modulate SMO activation as well ${ }^{42}$.

The importance of SMO in development was discovered in Smo knock-out mouse embryos. These embryos suffer from severe developmental defects like holoprosencephaly, cyclopia and heart defects and do not survive beyond embryonic day $9.5^{43}$. Opposite, activating SMO mutations result in activation of $\mathrm{HH}$ signaling and lead to basal cell carcinoma and other tumors both in humans and mice ${ }^{44,45}$.

In vertebrates, three members of the GLI zinc-finger transcription factor family exist, which are GLI1, GLI2 and GLI3. Whereas GLI2/3 can occur in a repressor or activator form and serve as a first line of $\mathrm{HH}$ signal sensors, GLI1 is expressed when GLI2/3 activate its transcription. It therefore amplifies the initial response to the $\mathrm{HH}$ signal.

GLI transcription factors consist of five zinc-finger DNA binding domains that recognize the DNA motif 5'-GACCACCCA-3' 46,47 . In the absence of $\mathrm{HH}$ ligands, GLI2/3 bind to a cytoplasmatic protein called Suppressor of Fused (SUFU), which represses the nuclear transport of GLI activator forms. Upon activation of the pathway, SUFU-bound GLI2/3 
translocate into the primary cilium and their activator forms are released from SUFU at the tip of the cilium. Subsequently GLI2/3 translocate into the nucleus where they induce HH target gene expression ${ }^{48,49}$. Homozygous Sufu mutant embryos suffer from severe developmental abnormalities resulting in open fore-, mid- and hindbrain and neural tube closure defects as well as cardiac malformations. Sufu mutants die in utero at embryonic day $9.5^{50-52}$, which is similar to Ptch mutant embryos that show a comparable phenotype as described above. This indicates the importance of SUFU's function in proper $\mathrm{HH}$ signaling regulation. Hence it is not surprising that SUFU mutations were also found in patients with Gorlin syndrome and sporadic medulloblastoma ${ }^{53}$ and that $S u f u^{+-} p 53^{+/}$animals are prone to medulloblastoma and $\mathrm{RMS}^{52}$.

The regulation of transcriptional activity of $\mathrm{GLI}$ proteins is conducted by several posttranslational modification steps. Depending on the availability of $\mathrm{HH}$ ligands, GLI2/3 are phosphorylated at two different phosphorylation clusters, one $\mathrm{N}$-terminal and the other $\mathrm{C}$ terminal of the zinc-finger DNA binding domains ${ }^{54}$. In the absence of $\mathrm{HH}$ ligands, protein kinase $A(P K A)$, glycogen synthase kinase $3 \beta(G S K 3 \beta)$ and casein kinase 1 (CK1) phosphorylate GLI2/3 at the C-terminus, triggering their ubiquitination and proteasomal degradation into the truncated repressor forms. Dephosphorylation of the C-terminus and additional phosphorylation at the $\mathrm{N}$-terminus is essential for pathway activation in the presence of $\mathrm{HH}$ ligands. In this case, full length activator forms of GLI2/3 are stabilized, released from SUFU binding and translocate into the nucleus, where they activate target gene expression. The sensitive equilibrium between the activator and repressor form of GLI2/3 depends on the quantitative availability of ligands and is referred to as the GLI code ${ }^{55}$. Signal quantification is achieved by stepwise phosphorylation and dephosphorylation of $\mathrm{GLI} / \mathrm{3}^{28,55}$ and regulates fate decision of $\mathrm{HH}$ morphogen recipient cells in developmental processes. GLI1, in contrast to GLI2/3, misses the N-terminal region that is necessary for the repressor form and can therefore only act as an activating transcription factor.

\subsubsection{Canonical HH signaling in cancer}

The first link between $\mathrm{HH}$ signaling and cancer was the discovery of $\mathrm{PTCH}$ mutations in patients with Gorlin syndrome. Gorlin patients develop basal cell carcinoma at high incidence and are prone to medulloblastoma, RMS and meningioma ${ }^{56-58}$. Nowadays it is clear that the $\mathrm{HH}$ signaling pathway is also active in the majority of sporadic basal cell carcinoma and a subset of sporadic medulloblastoma. In many of these tumors, $\mathrm{HH}$ pathway activation is due to inactivating mutations in $P T C H$ or SUFU or activating mutations in $S M O^{44,53,59}$.

In addition, $\mathrm{HH}$ signaling is activated in several cancers that are not associated with Gorlin syndrome. In glioblastoma, $\mathrm{HH}$ signaling plays an important role in cancer stem cell 
maintenance and tumorigenesis ${ }^{60-62}$. In breast cancer $\mathrm{HH}$ signaling activity caused by $\mathrm{HH}$ ligand overexpression is associated with an unfavorable outcome ${ }^{63,64}$. Similarly, overexpression of the $\mathrm{HH}$ ligands plays a role in formation of pancreatic cancer ${ }^{65-67}$. In this tumor entity, ligand expression by the tumor cells has a paracrine function as it activates $\mathrm{HH}$ signaling in the tumor stroma, which can promote invasion and metastasis ${ }^{68,69}$. In prostate cancer, paracrine as well as autocrine pathway activation seems to be important and $\mathrm{HH}$ target gene expression is associated with loss of the negative regulator SUFU or HH ligand overexpression ${ }^{70-75}$. In melanoma, $\mathrm{HH}$ signaling is also active and exome sequencing detected mutations in PTCH, SUFU, SMO, GLI1, GLI2 or GLI3 $3^{76,77}$.

\subsubsection{Non-canonical HH signaling}

Besides the canonical $\mathrm{HH} / \mathrm{PTCH} / \mathrm{SMO} / \mathrm{GLI}$ axis, several non-canonical regulation mechanisms of the pathway have been described in cancer. In many types of cancer that show an expression of components of classical $\mathrm{HH}$ signaling, non-canonical interactions play an additional role in tumorigenesis, maintenance or metastasis. First, $\mathrm{HH}, \mathrm{PTCH}$ or SMO can regulate processes independently of the GLI transcription factors. Second, the GLI transcription factors can be activated in a $\mathrm{HH} / \mathrm{PTCH} / \mathrm{SMO}$ independent way. This section will focus on a few examples for both regulation mechanisms and their implications in cancer.

\subsubsection{GLI-independent effects of $\mathrm{HH}, \mathrm{PTCH}$ and SMO}

The $\mathrm{HH}$ ligand sensor PTCH is a dependence receptor, meaning that it evokes pro-apoptotic effects when expressed in the absence of its ligands ${ }^{78,79}$. Thus, PTCH recruits a multiprotein complex including caspase 9 to its C-terminal intracellular region where the protein is cleaved and where further apoptotic events are initiated, e.g. caspase 3 cleavage. These effects are not impaired by SMO overexpression or treatment with SMO agonist (SAG), indicating that it is a SMO-independent process.

Additionally, it is known that SHH decreases intracellular cAMP levels in a PTCH/SMOdependent manner through the activation of $\mathrm{G}$ proteins associated with $\mathrm{SMO}^{80,81}$. Activation of $G$ proteins induces a calcium spike activity within the cell, which is necessary for several neuro-developmental processes ${ }^{82}$. Regulation of intracellular calcium signaling evokes different downstream effects, e.g. expression of neurotransmitters. It is however also part of a negative regulatory loop to the GLI transcription factors, as cAMP-dependent calcium spikes can trigger the activity of PKA, leading to the formation of GLI3 repressor forms and degradation of $\mathrm{GLI}^{83}$. Another effect of the calcium increase is a change in cellular metabolism ${ }^{84}$. These increased calcium levels go along with activation of AMP-activated protein kinase (AMPK) and trigger a rapid uptake of glucose especially in brown fat and muscle tissue. The SMO/calcium/AMPK axis has also an effect on neuronal precursor cells 
because AMPK activation via SMO leads to an enhanced amount of polyamine resulting in cellular proliferation ${ }^{85}$.

Finally, SMO activation can recruit PI3K, initiating the activation of the small GTPases RhoA and Rac1. This provokes remodeling of the actin cytoskeleton ${ }^{86}$. The activation of PI3K, RhoA and Rac1 occurs in the cytoplasm, independent of the cilial translocation of SMO.

\subsubsection{Non-canonical regulation of GLI}

GLI proteins can also be activated in a non-canonical way. This is especially important in the context of cancer where GLI protein interaction partners can either fully activate $\mathrm{HH}$ signaling autonomously or potentiate pathway activation ${ }^{59,87}$.

For example, transforming growth factor- $\beta$ (TGF $\beta$ ) signaling can control GLI activity on transcriptional level as the GLI2 promoter contains a TGF $\beta$-responsive element. Activation of TGF $\beta$ leads to binding of mothers against decapentaplegic homolog 3 (SMAD3) and $\beta$ catenin to the GLI2 promoter, which results in GLI2 transcription ${ }^{88,89}$. In addition, treatment of pancreatic cancer cell lines with TGF $\beta$ induces $G L / 1$ and $G L / 3$ expression ${ }^{90}$.

Furthermore, the tumor suppressor p53 can inhibit GLI activity by inducing its ubiquitination and proteasomal degradation ${ }^{91}$. Hence, p53-deficiency results in GLI1 activation in neural stem cells, medulloblastoma and glioblastoma. Furthermore, in cerebella lacking mouse double minute 2 homolog (MDM2), a negative regulator of $p 53$, the GLI2 protein level is reduced $^{92}$. This p53-GLI interaction is part of an inhibitory loop, as GLI1 activity itself triggers the ubiquitination and proteasomal degradation of p53 during tumorigenesis by activation of $\operatorname{MDM} 2^{93,94}$.

In addition, members of the dual-specificity tyrosine-phosphorylation-regulated kinase (DYRK) family can regulate GLI activity. Whereas DYRK2 can trigger the proteasomal degradation of $\mathrm{GLI} 2^{95}$, DYRK1A can induce GLI1 activity by phosphorylation at the $\mathrm{N}$ terminal part, inducing its nuclear localization ${ }^{96}$. In a more complex interaction network, DYRK1B was shown to evoke oppositional effects on GLI activity ${ }^{97,98}$. In medulloblastoma and basal cell carcinoma DYRK1B enhances the GLI transcriptional activity ${ }^{99}$. In contrast, DYRK1B negatively modulates GLI activity in pancreatic cancer cells in a non-canonical manner ${ }^{97}$. In contrast another study showed that DYRK1B can inhibit canonical GLI activation in fibroblasts but can simultaneously enhance GLI activation in a non-canonical (SMO-independent) way. Therefore the authors stated that the role of DYRK1B in regulation of $\mathrm{HH}$ signaling is strongly dependent on the DYRK1B expression level, the mode of $\mathrm{HH}$ pathway activation (canonical or non-canonical), the time point of analysis and on the investigated model ${ }^{98}$. 
Mitogen-activated protein (MAP) kinases are another group of kinases that regulate GLI protein activity by post-translational modifications. Extracellular signal-regulated kinases (ERKs) as well as c-Jun N-terminal kinases (JNKs) can directly phosphorylate GLI transcription factors at the $\mathrm{N}$-terminus ${ }^{100}$. This is seen in fibroblasts and pancreatic cancer, where activation of the RAS/RAF/MEK/ERK pathway stimulates GLI transcriptional activity ${ }^{101,102}$. In pancreatic cancer, basal cell carcinoma and gastric cancer the cross-reaction between RAS/RAF/MEK/ERK and HH signaling pathways is essential for tumor growth ${ }^{103-105}$. It was shown that the interaction between the two pathways cooperatively induces the expression of growth-related factors like SOX2 and SOX9104.

Finally, PI3K/AKT/mTOR signaling can act as a post-translational regulator of GLI proteins. Activation of this pathway antagonizes the $\mathrm{HH}$ signaling suppressors PKA and GSK3 $\beta$, which normally reduce the transcriptional activity of GLI2 by phosphorylation at different sites. As a consequence, activation of PI3K/AKT/mTOR induces $\mathrm{HH}$ signaling activity in $\mathrm{SHH}$ primed cells ${ }^{106}$. AKT additionally enhances the nuclear localization and transcriptional activity of GLI1 in melanoma ${ }^{76}$ and also stabilizes and thus activates GLI2 during osteoblast differentiation ${ }^{107}$. In esophageal adenocarcinoma, the downstream effector of active $\mathrm{PI3K} / \mathrm{AKT} / \mathrm{mTOR}$ signaling S6K1 phosphorylates GLI1 resulting in its release from SUFU and its transcriptional activity ${ }^{108}$. In contrast, PI3K/AKT2 signaling can also negatively regulate GLI1 transcriptional activity in neuroblastoma cells, in which GLI1 has a tumorsuppressive role ${ }^{109}$.

\subsubsection{HH signaling in RMS}

As already mentioned, $\mathrm{PTCH}$ germline mutations in patients with Gorlin syndrome result in an enhanced susceptibility to RMS. Similarly, $\mathrm{Ptch}^{+-}$mice develop RMS, which resemble the human embryonal phenotype ${ }^{34,110}$. This is indicated by strong expression of terminal myogenic differentiation markers and of the two $\mathrm{HH}$ target genes Gli1 and Igf2. Indeed, Igf2 expression was shown to be indispensable for the formation of $\mathrm{Ptch}^{+/} \mathrm{RMS}^{110,111}$. Similarly, human ERMS are associated with overexpression of $I G F 2^{12,112}$. In addition, constitutive activation of Smo can drive RMS tumorigenesis in the mouse ${ }^{3}$.

However, the importance of genetic mutations in $\mathrm{HH}$ signaling components in patients with sporadic RMS is still controversial. Whole-genome and RNA sequencing of 32 RMS did not find any mutations in genes associated with $\mathrm{HH}$ signaling ${ }^{13}$ and also sequencing of $P T C H$ and SMO in 6 RMS with active $\mathrm{HH}$ signaling (high GL/1 and PTCH expression levels) did not reveal any mutations ${ }^{113}$. Similarly, another study on 147 RMS samples did not detect any tumors with mutations in the $\mathrm{HH}$ signaling pathway ${ }^{114}$. In contrast, $\mathrm{PTCH}$ and SUFU missense mutations were found in 4 out of 22 highly differentiated, fusion gene-negative 
cases of $\mathrm{RMS}^{115}$. Furthermore, fluorescence in situ hybridization and comparative genomic hybridization of 12 ERMS samples revealed chromosomal loss of 9q22, which includes the PTCH locus, in 4 cases $^{116}$. Additionally, another study described LOH in PTCH or SUFU in 4 of 9 RMS cases ${ }^{22}$. Finally, another study showed LOH in 1 tumor out of 14 RMS samples ${ }^{117}$. Together, the aforementioned studies indicate that $\mathrm{HH}$ pathway mutations can occur, but are rare in sporadic cases of RMS.

Although data on $\mathrm{HH}$ pathway mutations in RMS are controversial, several studies have provided strong and clear evidence of $\mathrm{HH}$ signaling activation in RMS, indicated by $\mathrm{HH}$ target gene overexpression. For example, in situ hybridization of formalin-fixed tumors showed strong expression of $P T C H$ and GLI1 in almost all of the 43 analyzed RMS ${ }^{22}$. Similar results were obtained in a microarray analysis performed by our working group showing that ERMS express high levels of $\mathrm{GL} / 1 / 3$ and $\mathrm{PTCH}$. Moreover, expression of $\mathrm{HH}$ target genes was significantly elevated in ERMS and fusion gene-negative ARMS compared to fusion genepositive ARMS and high expression of $P T C H$ was associated with a poor overall survival ${ }^{21}$. In line with these results, immunohistochemical staining of GLI1 in 91 ERMS samples showed that increased GLI1 protein levels predict poor outcome ${ }^{118}$. The higher abundance of $\mathrm{HH}$ signaling in the ERMS subtype was also shown by quantification of GL/1 and PTCH1 expression, which is found in 15 out of 70 ERMS but in none out of $20 \mathrm{ARMS}^{113}$. In addition, comparative RNA sequencing analysis of ARMS and ERMS showed higher expression levels of GLI2/3 and SMO in the latter subtype ${ }^{13}$. Together, all study data agree with an upregulation of $\mathrm{HH}$ signaling activity in RMS and with higher expression levels of $\mathrm{HH}$ target genes in the embryonal subtype.

Because mutations in $\mathrm{HH}$ signaling components were only rarely found in RMS patients (see above), several studies investigated whether $\mathrm{HH}$ ligands may activate $\mathrm{HH}$ signaling in RMS. A japanese study used immunohistochemical staining to show that 14 out of 18 RMS samples express $\mathrm{SHH}^{119}$. In addition, it has been shown that RMS cell lines and tissue samples express $\mathrm{HH}$ ligands. But in contrast to the aforementioned results, the two ligands $\mathrm{IHH}$ and DHH were predominantly expressed, indicated by Western Blot analysis, qRT PCR and immunohistochemical staining ${ }^{120}$. The same study also revealed that $\mathrm{HH}$ ligand expression correlates with GLI1 expression in patient samples and that depletion of either $\mathrm{SHH}, \mathrm{IHH}$ or $\mathrm{DHH}$ significantly decreases tumor growth in a xenograft RMS model. Another recent study showed that patient-derived xenograft tumors intrinsically express $I H H$ and $D H H$, whereas only a minority expresses $S H H^{18}$.

Due to the importance of $\mathrm{HH}$ signaling in RMS, our group recently analyzed the effects of $\mathrm{HH}$ antagonists on the growth of RMS cell lines. The data showed that SMO inhibitors evoke a 
very heterogeneous response in these cells. Thus, the drugs sonidegib and HhAntag can reduce GLI1 expression in the ERMS cell lines RD and $\mathrm{RUCH}-2$, which is however concentration-dependent. Vismodegib only reduces the GL/1 level in RD cells, whereas cyclopamine does induce the expression of GL/1. In addition, sonidegib and HhAntag can evoke strong anti-cancer effects on ERMS cell lines, but these effects are not always accompanied by a downregulation of $\mathrm{HH}$ signaling activity ${ }^{121}$.

Together, these data show that $\mathrm{HH}$ signaling is active in RMS. The way of pathway activation in these tumors is not fully understood. However, the better understanding of pathway activation is of uppermost interest for further preclinical and clinical investigations with $\mathrm{HH}$ antagonists, e.g. SMO inhibitors.

\subsection{Smoothened (SMO) inhibitors}

Since the discovery of cyclopamine (see above), $\mathrm{HH}$ signaling inhibitors are under investigation for targeted therapy of $\mathrm{HH}$-associated cancers. These drugs are especially small molecule inhibitors targeting SMO or GLI. The GLI1/2 inhibitor GANT-61 is effective in preclinical models for RMS, osteosarcoma, neuroblastoma and ovarian cancer ${ }^{122-126}$ and has the potential to inhibit both canonical and non-canonical $\mathrm{HH}$ signaling activity. However, this drug is not used in clinical trials, because it is not stable ${ }^{127}$. In contrast, vismodegib and sonidegib that target the $\mathrm{HH}$ pathway at the level of SMO and thus inhibit canonical $\mathrm{HH}$ signaling, have been approved by the FDA for treatment of basal cell carcinoma (reviewed in $^{128}$ ). Since these tumors harbor mutations in $P T C H$ in the vast majority of cases ${ }^{129}$, SMO inhibitors are especially effective. Vismodegib and sonidegib and also other available SMO inhibitors are currently under clinical investigation ranging from phase I to IV for several other cancers, which are listed in the ClinicalTrials.gov database. For the treatment of RMS, we here used the SMO inhibitors cyclopamine, vismodegib, sonidegib and HhAntag.

\subsubsection{Cyclopamine, vismodegib, sonidegib and HhAntag}

Cyclopamine was the first discovered natural SMO inhibitor with the potential to block $\mathrm{HH}$ signaling (reviewed in ${ }^{130}$ ). In a preclinical mouse model for pancreatic cancer, which shows $\mathrm{HH}$ signaling activation in nearly all cases, cyclopamine inhibits the $\mathrm{HH}$ pathway very efficiently and prolongs the median survival of the animals ${ }^{131}$. Nevertheless, cyclopamine was never used in clinical trials because of its poor aqueous solubility, suboptimal pharmacokinetic properties and acid lability. Instead, several derivatives of cyclopamine were developed. One example is saridegib (also known as IPI-926), which shows a similar effectiveness but better pharmacokinetics than cyclopamine. Saridegib was also a very promising agent in a preclinical model for pancreatic cancer ${ }^{132}$. Because of its success a few 
clinical trials with saridegib were initiated. However, in phase II studies for chondrosarcoma and myelofibrosis it was ineffective ${ }^{133,134}$ and studies with this drug were discontinued.

The pyridine derivative vismodegib (also known as GDC-0449, Genentech) is a SMO inhibitor with remarkable effectiveness. It also has better pharmacokinetic properties compared to cyclopamine. Preclinical and clinical trials on basal cell carcinoma and medulloblastoma, which both show active $\mathrm{HH}$ signaling due to $\mathrm{PTCH}$ mutations, proved safety and efficiency of vismodegib ${ }^{135-138}$. Therefore the compound was approved by the FDA and EMA (European Medicines Agency) for treatment of locally advanced and metastatic basal cell carcinoma. In a study assessing long-term effects of vismodegib, approximately 70 $\%$ of patients suffering from advanced basal cell carcinoma responded to this drug $^{139}$. Additionally, vismodegib is under investigation for therapy of other cancer entities, including ovarian cancer, B-cell lymphoma, chronic lymphocytic leukemia and medulloblastoma. However, in a small study enrolling prostate cancer patients, vismodegib efficiently reduced $\mathrm{HH}$ signaling activity but did not reduce tumor size $\mathrm{i}^{140}$. Similarly, patients with metastatic colorectal cancer did not benefit from vismodegib compared to standard therapy ${ }^{141}$. The drug was also not effective in maintenance treatment of patients with ovarian cancer in remission ${ }^{142}$.

Besides cyclopamine, saridegib and vismodegib several other small molecule inhibitors targeting SMO were developed, among them sonidegib (also called LDE225, Novartis). Sonidegib shows preclinical and clinical effectiveness in the treatment of basal cell carcinoma and medulloblastoma ${ }^{143-146}$. Hence, it is the second SMO inhibitor, which was approved by the FDA for treatment of locally advanced basal cell carcinoma with response rates of up to $58 \%{ }^{147,148}$. Currently, sonidegib is in a clinical phase lb trial in combination with a cyclin-dependent kinase $4 / 6$ inhibitor for $P T C H$ mutant medulloblastoma in children (NCT03434262). Additionally sonidegib is in clinical trials for several types of other solid cancers and is efficient in preclinical models for $\mathrm{HH}$-associated glioblastoma and melanoma ${ }^{149,150}$. Finally, sonidegib is efficient in a preclinical model for chronic myeloid leukemia when combined with the tyrosine kinase inhibitor nilotinib ${ }^{151}$.

Another drug screening discovered HhAntag, which is a benzimidazol derivative. This drug binds to and inhibits SMO in a way different from vismodegib or sonidegib. In addition this compound is effective in SMO mutant cells that developed resistance against vismodegib or sonidegib $^{152}$. In a mouse model for medulloblastoma, HhAntag reduced tumor growth, which was associated with anti-proliferative and pro-apoptotic effects and a massive infiltration of host immune cells, especially macrophages ${ }^{153}$. Despite its high effectiveness in preclinical cancer models, HhAntag is not investigated in clinical trials due to its poor pharmacokinetics. 


\subsubsection{Adverse effects}

In general, SMO inhibitors are well tolerated. Nevertheless, clinical trials and every day clinical practice reported that up to $36 \%$ of vismodegib-receiving patients discontinue treatment due to high grade adverse effects ${ }^{139,154,155}$. The most common adverse effects are muscle spasms, alopecia, fatigue, nausea and weight loss ${ }^{138,156,157}$.

The observed muscle spasms are thought to be caused by non-canonical effects of $\mathrm{HH}$ signaling on cellular calcium influx triggered by SMO in a GLI-independent manner (see above). As a consequence the effects of calcium channel blockers were investigated in a small group of basal cell carcinoma patients. Even though the addition of calcium channel blockers during therapy resulted in a significant reduction in muscle cramps, further trials with larger patient cohorts are required ${ }^{84,158}$.

\subsubsection{Resistance mechanisms}

Besides interruption of therapy due to severe adverse effects, another drawback of SMO inhibitors in the clinics is development of resistance. In a patient with metastatic medulloblastoma, vismodegib therapy showed a remarkable first response, but after 3 month of treatment the patient relapsed and died approximately 2 month later ${ }^{159}$. Sequencing of a metastatic biopsy found a $\mathrm{D} 473 \mathrm{H}$ mutation in $S M O$, which was not present in the primary tumor or in the metastasis before treatment. This amino acid substitution is located within one of the transmembrane sites of SMO. The corresponding murine residue 477 was also mutated in a vismodegib-resistant allograft model for medulloblastoma and the mutation was suggested to impair vismodegib-binding to $\mathrm{Smo}^{160}$. More recently, another case report of a medulloblastoma patient with an initial PTCH mutation first showed a substantial response to vismodegib treatment ${ }^{161}$. However, also this patient developed metastases carrying the SMO mutations G477L or L412P. Acquired SMO mutations also occur in basal cell carcinoma after treatment with SMO inhibitors. Besides mutations that prevent the binding of the drugs to SMO, other mutations induce a conformational shift of SMO towards a constitutive active form $^{162-164}$

As SMO inhibitors interact with different sites of the SMO binding pocket, resistance towards one drug may be overcome by subsequent treatment with another SMO inhibitor. For example, it was shown that HhAntag treatment of a vismodegib-resistant (D477G amino acid substitution) allograft model for medulloblastoma effectively reduced tumor growth and Gli1 expression within the tumor tissue ${ }^{152}$.

With help of the $\mathrm{Ptch}^{+/} \mathrm{p} 53^{-/}$mouse model for medulloblastoma, additional resistance mechanisms towards SMO inhibitors were identified ${ }^{152,165}$. Treatment of medulloblastoma- 
bearing mice with sonidegib leads to resistance development in nearly all animals, but only a small number of resistant tumors show point mutations within Smo. However, $50 \%$ of them show chromosomal amplification of Gli2. The degree of gene amplification correlates with Gli2 expression levels, indicating an activation of $\mathrm{Hh}$ signaling downstream of Smo. Interestingly, the sonidegib-resistant tumors that neither have a point mutation in Smo nor an amplification of Gli2 show activation of the Pi3k/Akt/mTor pathway. As a consequence a combined treatment with sonidegib and PI3K/AKT/mTOR inhibitors delayed resistance acquisition and in a few cases indeed completely prevented resistance ${ }^{165}$.

In summary, SMO inhibitor resistance is a common phenomenon occurring during treatment of cancer cells with vismodegib or sonidegib. To antagonize resistance, secondary treatment options are crucial. In case of an acquired SMO mutation, the use of alternative SMO antagonists seems to be an option. In contrast, downstream pathway activation by GL/2 amplification or non-canonical $\mathrm{HH}$ signaling activation cannot be antagonized with SMO inhibitors. In these cases, the usage of GLI inhibitors or the combination of SMO inhibitors with inhibitors targeting the effectors of non-canonical pathway activation might be an option.

\subsubsection{SMO inhibitors in RMS}

As mentioned above, RMS show aberrant activation of the HH signaling cascade. However, so far only a few clinical trials with SMO inhibitors are listed in the ClinicalTrials.gov database. In 2012 a clinical phase I trial for the SMO inhibitor LY2940680 as single agent therapy in pediatric RMS or medulloblastoma was set up. Unfortunately, this trial was resigned as not enough patients could be recruited. Another phase I study, which was completed in 2014, investigated dose finding and safety of sonidegib in children with RMS (NCT01125800) and other tumor entities. $50 \%$ of participants were suffering from serious adverse effects like vomiting, headache, general physical health deterioration, convulsion, decreased appetite, nausea and fatigue. A follow-up trial to assess the effectiveness of sonidegib in RMS was not conducted. Furthermore, in 2016 a phase I/II trial for combination treatment of RMS with vismodegib and a Notch signaling inhibitor was completed (NCT01154452). Unfortunately, no clinical activity was observed even though $\mathrm{HH}$ and Notch signaling were efficiently inhibited within the tumors.

In addition, the effectiveness of SMO inhibitors is also investigated in different preclinical RMS models. Treatment of RMS cell lines with cyclopamine decreased cell growth in a concentration-dependent manner ${ }^{166}$. In contrast, cyclopamine treatment did not reduce tumor growth of full-blown RMS in vivo even though Hh signaling activity was efficiently blocked in this model ${ }^{167}$. A more recent analysis of our group with the SMO inhibitors cyclopamine, vismodegib, sonidegib and HhAntag revealed that the drugs can induce anticancer effects in 
human RMS cell lines. However, these effects are not necessarily associated with inhibition of $\mathrm{HH}$ signaling ${ }^{121}$. Among the investigated compounds, sonidegib and HhAntag are more effective than the others. Surprisingly, cyclopamine and vismodegib even enhance cell growth of certain RMS cell lines. The lack of association between GLI1 levels and cellular proliferation might point to a non-canonical regulation of GLI in some RMS and shows that the anticancer effects caused by SMO inhibitors are most likely off-target effects. This hypothesis is strengthened by another group showing that cyclopamine is less effective than the GLI1/2 inhibitor GANT-61 in blocking HH signaling activity and proliferation of several ERMS cell lines ${ }^{168}$. In contrast, a more recent study investigating the impact of vismodegib, sonidegib and GANT-61 on spheroid cultures of ERMS cell lines resulted in potent anticancer effects of all three drugs ${ }^{118}$. These results suggest that canonical $\mathrm{HH}$ signaling regulates ERMS self-renewal and thus tumor initiation. Because modulation of $\mathrm{HH}$ signaling did not result in changes in cell cycle, cell viability or proliferation, the authors hypothesized that tumor regression may not be an appropriate endpoint to estimate treatment effectiveness.

Together, the effects of SMO inhibitors on RMS cell lines remain uncertain.

\section{$1.4 \mathrm{PI} 3 \mathrm{~K} / \mathrm{AKT} / \mathrm{mTOR}$ signaling}

The PI3K/AKT/mTOR signaling pathway is a major regulator of cell growth and survival under physiological and pathological conditions. Its aberrant activation is a hallmark of many different cancers. The pathway senses activation of receptor tyrosine kinases (RTKs) and translates the information into a cellular response like proliferation, differentiation, apoptosis or regulation of cell metabolism ${ }^{169}$. In the context of cancer, PI3K/AKT/mTOR signaling is often aberrantly activated by mutations in RTKs, e.g. EGFR, in the negative regulator phosphatase and tensin homolog (PTEN), in PI3K or in $\mathrm{AKT}^{170}$. Additionally, aberrant growth factor expression or interaction with other oncogenic pathways like RAS/RAF/MEK/ERK signaling can activate PI3K/AKT/mTOR signaling in cancer. A simplified scheme of the pathway is depicted in Fig. 2. 


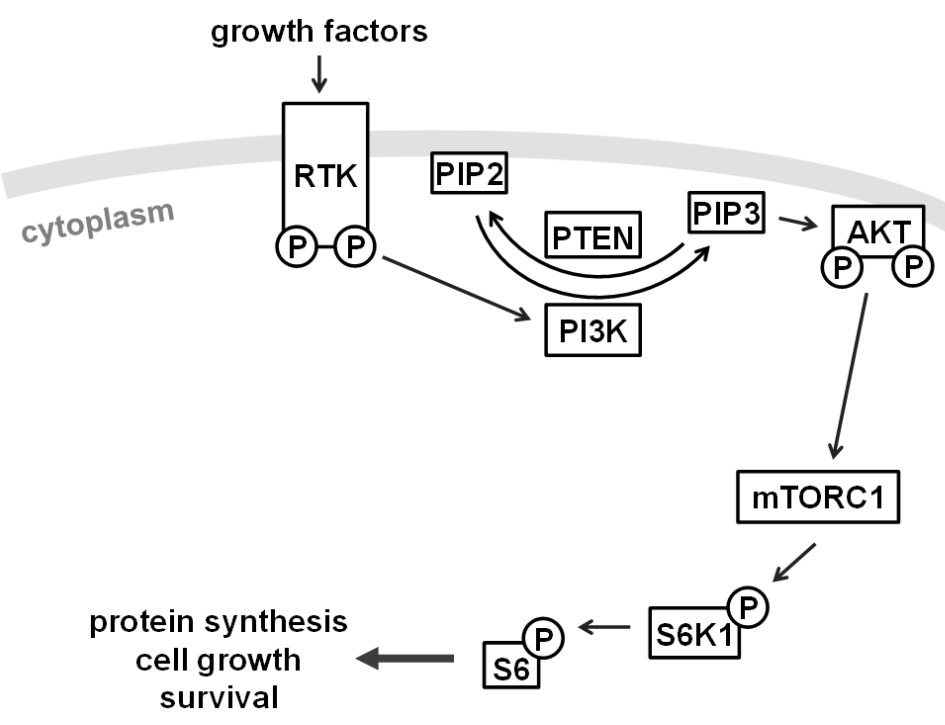

Figure 2: The PI3K/AKT/mTOR signaling pathway. RTKs induce autophosphorylation of the intracellular domain. PI3K binds to the phosphorylated RTK and triggers the formation of PIP3. This reaction can be reversed by the tumor suppressor PTEN. PIP3 further recruits AKT to the cell membrane where it gets phosphorylated. Fully activated AKT induces several downstream reactions resulting in the activation of $\mathrm{mTORC} 1$. As a consequence mTORC1 phosphorylates S6K1, which in turn phosphorylates ribosomal protein S6. This induces protein synthesis, cell growth and survival. A more detailed description of the PI3K/AKT/mTOR signaling pathway can be found in the main text.

Activation of RTKs by e.g. IGF1, IGF2 or EGF results in RTK autophosphorylation. This recruits the regulatory subunit of PI3K to the intracellular domain of the activated RTK. In turn, the catalytic subunit of PI3K phosphorylates the inositol ring structure of phosphatidylinositol-4,5-bisphosphate (PIP2), which is anchored in the cell membrane by its lipid chains. This results in the formation of phosphatidylinositol-3,4,5-trisphosphate (PIP3). Subsequently, this enzymatic reaction can be reversed by the tumor suppressor PTEN that thus blocks signal transduction. PIP3 recruits proteins with a pleckstrin homology $(\mathrm{PH})$ domain to the cell membrane, e.g. AKT and 3-phosphoinositide-dependent protein kinase-1 (PDK1). PDK1 then phosphorylates Thr308 of AKT. Full activation of AKT is accomplished by the mTOR complex 2 (mTORC2), which phosphorylates AKT at Ser473 in the C-terminal region. AKT itself is a Ser/Thr protein kinase and serves as a central cell fate regulator. This kinase phosphorylates many different proteins, mostly resulting in their inactivation. AKT can for example inactivate the complex of tuberous sclerosis protein 1 (TSC1) and 2 (TSC2), which is a negative regulator of $m T O R C 1^{171}$. In addition, AKT can inactivate another mTORC1 suppressor called proline-rich AKT substrate of $40 \mathrm{kDa}$ (PRAS40), which results in activation of $\mathrm{mTORC} 1^{172,173}$. This in turn results in phosphorylation of ribosomal protein $\mathrm{S} 6$ kinase 1 (S6K1) at Thr389. Full activation of S6K1 is then accomplished by phosphorylation at Thr229 by PDK1. S6K1 further phosphorylates ribosomal protein S6, potentiating ribosome function, protein synthesis and cell growth. Simultaneous phosphorylation of AKT, 
S6K1 and/or S6K can be detected with phospho-specific antibodies and serves as readout for activation of the PI3K/AKT/mTOR signaling pathway.

The pathway contains several negative feedback loops. For example, S6K1 and mTORC1 phosphorylate and negatively regulate insulin receptor substrate 1 (IRS1), which normally mediates signal activation from RTKs to $\mathrm{PI}^{1} \mathrm{~K}^{174-176}$. In addition, S6K1 inhibits mTORC2 and thus AKT signaling, which links mTORC1 and mTORC2 together ${ }^{177}$.

As already mentioned, AKT represents a central regulatory factor of the PI3K/AKT/mTOR pathway, which - besides mTORC1 activation - can trigger many cellular responses ${ }^{178}$. Amongst others, AKT mediates cell survival by direct phosphorylation and inactivation of $B A D$, inhibiting its pro-apoptotic effects on proteins of the Bcl-2 family ${ }^{179,180}$. In addition, AKT phosphorylates and inactivates the kinase GSK3 $\beta$ and the transcription factor FOXO, resulting in a decreased expression of pro-apoptotic genes. On the other hand it activates MDM2, which is a negative regulator of the tumor suppressor $\mathrm{p} 53^{181-183}$.

As mentioned above, several interactions between PI3K/AKT/mTOR and $\mathrm{HH}$ signaling have been described. For example a positive interaction between AKT and $\mathrm{HH}$ signaling exists in esophageal and breast cancer ${ }^{184,185}$. As a consequence the effectiveness of combination treatments with inhibitors of $\mathrm{HH}$ and $\mathrm{PI} / 3 \mathrm{~K} / \mathrm{AKT} / \mathrm{mTOR}$ signaling is investigated in several preclinical models. In cell culture and mouse models for glioblastoma and pancreatic cancer the combination of sonidegib with PI3K inhibitors induces synergistic anticancer effects ${ }^{149,186}$. Furthermore, the combination of sonidegib with the dual PI3K and mTOR inhibitor BEZ235 synergistically inhibits the self-renewal capacity of pancreatic cancer cells in vitro and in vivo $^{186}$. In a clinical study on advanced solid tumors, the combination therapy of sonidegib and the $\mathrm{PI} 3 \mathrm{~K}$ inhibitor buparlisib is generally tolerable ${ }^{187}$.

\subsubsection{Inhibitors of PI3K/AKT/mTOR pathway}

Several drugs targeting the PI3K/AKT/mTOR pathway have been developed for cancer therapy ${ }^{169,188,189}$. Within this work the two mTOR inhibitors everolimus and rapamycin, the dual PI3K and mTOR inhibitor PI-103, the class I PI3K inhibitor pictilisib and the AKT inhibitor MK-2206 were used.

The naturally occurring mTOR inhibitor rapamycin was first isolated back in 1975 from an Easter Island soil sample ${ }^{190}$. A few years later it was shown to evoke anticancer effects ${ }^{191}$ and as a consequence this drug, which was originally used as an immunosuppressant agent in organ transplantation, has entered clinical phase III trials for a range of different cancer types. These include bladder cancer, lymphoma, leukemia, renal cell carcinoma and breast cancer. Several structurally very similar derivatives were developed and the first inhibitor of 
mTOR that was approved in 2007 by the FDA was temsirolimus for renal cell carcinoma ${ }^{192}$. Only a few years later, a second mTOR inhibitor, everolimus, was approved for the treatment of advanced renal cell carcinoma and for subependymal giant-cell astrocytoma in patients with Tuberous Sclerosis. Tuberous Sclerosis is a hereditary disease, which is characterized by mutations in TSC1/2 resulting in constitutive activation of mTOR. Patients suffering from this disease develop nonmalignant tumors in different organs, e.g. the brain, skin or kidneys ${ }^{193}$. In addition, temsirolimus and everolimus have entered phase III clinical trials for mantle cell lymphoma, neuroendocrine tumors, breast cancer and large B-cell lymphoma. The latter phase III trial on 742 patients with relapsed large B-cell lymphoma showed that everolimus does not improve disease-free survival compared to placebo ${ }^{194}$. In contrast, everolimus improves the progression-free survival of patients with advanced, progressive neuroendocrine tumors ${ }^{195}$.

In addition to mTOR inhibitors, several drugs targeting PI3K or AKT have been developed and have entered phase II clinical trials. The PI3K inhibitor buparlisib was supposed to enter a phase III clinical trials for breast cancer but due to a lack of efficiency, the trial was stopped $^{196}$. In addition, buparlisib also did not improve the progression-free survival of patients with non-small cell lung cancer, hence the authors suggested using the drug in combination treatments rather than as monotherapy ${ }^{197}$. Clinical phase II trials with buparlisib are also ongoing for the treatment of prostate cancer, thyroid cancer, breast cancer, glioblastoma, melanoma and leukemia.

The dual PI3K and mTOR inhibitor $\mathrm{PI}-103$ did not reach any clinical trial due to its unfavorable pharmacokinetics ${ }^{198}$. However, it was further developed to a drug called pictilisib, which is in clinical phase II trials for lung cancer, breast cancer and glioblastoma. The results of a phase I clinical trial with 60 patients suffering from advanced solid tumors were published in 2015. The trial showed that pictilisib administration is safe and has favorable pharmacokinetic and pharmacodynamic properties ${ }^{199}$. Additionally, the results of three clinical phase II trials with breast cancer patients were reported in 2016. Two of them did not show any benefits of pictilisib addition to standard therapy ${ }^{200,201}$. In the third one, however, addition of pictilisib resulted in a significant reduction of proliferative cells within the tumor even though no clinical outcome was reported ${ }^{202}$.

In addition, the AKT inhibitor MK-2206 has entered several phase II clinical trials. In colorectal cancer patients the effectiveness of MK-2206 was investigated in combination with a MEK inhibitor. However, the combination did not reach the expectations of target inhibition $^{203}$. This was the same in trials for lung cancer and renal cell carcinoma ${ }^{204,205}$. 
Nevertheless, clinical phase II trials on colon cancer, hepatocellular carcinoma, lymphoma, breast cancer, melanoma and lung cancer are ongoing.

\subsubsection{PI3K/AKT/mTOR signaling in RMS}

The activation of PI3K/AKT/mTOR signaling is a hallmark of many different cancer entities. This is also the case for primary RMS samples, which show phosphorylation of AKT and thus pathway activation in $82.5 \%$ of cases $^{206-208}$. In addition, phosphorylation of AKT, S6K1 and S6 is associated with a poor overall survival of RMS patients ${ }^{209}$. However, mutations in components of the core pathway are relatively rare. Thus, PIK3CA, which encodes the catalytic subunit of PI3K, is mutated in $7.4 \%$ and FGFR4, encoding the fibroblast growth factor receptor 4 , is mutated in $9.6 \%$ of fusion gene-negative $\mathrm{RMS}^{114}$. Therefore, activation of PI3K/AKT/mTOR signaling is rather based on other mechanisms. Indeed, $91 \%$ of ERMS show hypermethylation of PTEN. In addition, activation of the FGFR/RAS/AKT axis has been observed in $40 \%$ of cases $^{114,210}$.

Therefore, several preclinical and clinical trials with PI3K/AKT/mTOR inhibitors in patients with RMS have been launched. The data show that treatment of RMS cell lines with the PI3K inhibitor LY294002 induces apoptosis under hypoxic conditions ${ }^{211}$. Furthermore, the mTOR inhibitor temsirolimus effectively reduces tumor growth in xenograft models of $\mathrm{RMS}^{209}$. However, when applied as monotherapy, temsirolimus did not meet the expectations in a clinical phase II trial for $\mathrm{RMS}^{212}$. In addition, chemotherapy in combination with either rapamycin or everolimus entered clinical phase II trials and the combination temsirolimus with chemotherapy entered a clinical phase III trial, which is currently recruiting.

$\mathrm{PI} 3 \mathrm{~K} / \mathrm{AKT} / \mathrm{mTOR}$ inhibitors are also combined with RAS/RAF/MEK/ERK inhibitors in preclinical RMS studies and the results are promising. Thus, the combination of the mTOR inhibitor AZD8055 with the MEK inhibitor AZD6244 induces synergistic anticancer effects in human RMS cell lines and in RMS xenografts ${ }^{206}$. Furthermore, combination of the dual PI3K and mTOR inhibitor PI-103 with the MEK inhibitor UO126 cooperatively induces apoptosis ${ }^{213}$. Surprisingly, targeting one pathway separately activates the other pathway, e.g. PI-103 induces phosphorylation of ERK and UO126 enhances phosphorylation of AKT, indicating cross-reactivity in RMS.

The $\mathrm{HH}$ signaling pathway is another interaction partner of PI3K/AKT/mTOR signaling, as described above. Hence, the effectiveness of temsirolimus or rapamycin plus GANT-61 (GLI1/2 inhibitor) in RMS cells was investigated and indeed, the combinations efficiently enhanced anticancer effects ${ }^{125}$. 
In summary, the $\mathrm{PI} 3 \mathrm{~K} / \mathrm{AKT} / \mathrm{mTOR}$ signaling pathway seems to be a promising target for RMS therapy. In addition, the current research shows that the combination of $\mathrm{PISK} / \mathrm{AKT} / \mathrm{mTOR}$ inhibitors with drugs targeting its interaction partners such as the $\mathrm{HH}$ signaling pathway efficiently enhances anticancer effects. Nevertheless, no clinical trials for these combinations have been launched. 


\section{Aim of the study}

RMS is the most common soft tissue sarcoma in children and it is currently treated with a combination of surgery or radiotherapy and multi-agent chemotherapy. However, because advanced RMS have a very poor prognosis, new therapeutic options for the disease are required.

It has been shown that RMS, especially ERMS, show strong $\mathrm{HH}$ signaling activity. Therefore we tested the effectiveness of SMO inhibitors in preclinical ERMS models. So far, data of our group showed that some SMO inhibitors induce anticancer effects in ERMS cell lines. However, these effects are drug- and cell line-dependent and are not generally accompanied by downregulation of $\mathrm{HH}$ signaling activity. In addition, our group found evidence for an interaction between $\mathrm{HH}$ and PI3K/AKT/mTOR signaling in RMS.

The aim of this thesis was to analyze whether SMO inhibitors can produce off-target effects in ERMS. Secondly, it was analyzed whether SMO inhibitors only exert reliable anticancer effects in those ERMS, which harbor mutations upstream of SMO in e.g. PTCH. Finally, the relevance of $\mathrm{PI} 3 \mathrm{~K} / \mathrm{AKT} / \mathrm{mTOR}$ signaling in regulation of $\mathrm{HH}$ signaling activity in ERMS was investigated. To achieve these aims, the effectiveness of SMO inhibitors and/or $\mathrm{PIOK} / \mathrm{AKT} / \mathrm{mTOR}$ inhibitors was investigated in ERMS tumor cells with and without PTCH mutations. 


\section{Material}

\subsection{Technical equipment}

Table 1: Utilized technical equipment

\begin{tabular}{|c|c|}
\hline Technical Equipment & Supplier \\
\hline$-20^{\circ} \mathrm{C}$ Freezer & Liebherr GmbH, Bulle, Switzerland \\
\hline$-80^{\circ} \mathrm{C}$ Freezer & Sanyo Electric Co., Ltd., Osaka, Japan \\
\hline $4^{\circ} \mathrm{C}$ Fridge & Robert Bosch GmbH, Stuttgart \\
\hline $\begin{array}{l}\text { Agarose gel electrophoresis chambers } \\
\text { (PerfectBlue }{ }^{\mathrm{TM}} \text { Gel Systems) }\end{array}$ & VWR International, Radnor, USA \\
\hline Autoclave (Sanoclave) & Sanoclav, Bad Überkingen \\
\hline Autoclave (Systec DX-150) & Systec $\mathrm{GmbH}$, Linden \\
\hline $\begin{array}{l}\text { Biological safety cabinet (Clean Air Euroflow } \\
\text { Class II, Type A2) }\end{array}$ & Telstar, Terrassa, Spain \\
\hline $\begin{array}{l}\text { Centrifuges (Heraeus Biofuge pico, fresco, } \\
\text { primo, Multifuge } 3 \mathrm{LR} \text { ) }\end{array}$ & Thermo Fisher Scientific Inc., Waltham, USA \\
\hline $\mathrm{CO}_{2}$ Incubator (6000, BBD 6220) & Thermo Fisher Scientific Inc., Waltham, USA \\
\hline $\mathrm{CO}_{2}$ Incubator (CB220-230V-G) & Binder GmbH, Tuttlingen \\
\hline Cooling Plate (EG $1150 \mathrm{C}$ ) & Leica Microsystems GmbH, Wetzlar \\
\hline Digital monochrome printer (P91D) & Mitsubishi Electric Corp., Chiyoda, Japan \\
\hline Dispersing tool for homogenizer (DS-8/P) & MICCRA GmbH, Heitersheim \\
\hline Dissecting tools & Karl Hammacher GmbH, Solingen \\
\hline Electronic pipette (Accu-jet) & Brand GmbH \& Co.KG, Wertheim \\
\hline $\begin{array}{l}\text { Electrophoresis System (XCell4 SureLock }{ }^{\mathrm{TM}} \\
\text { Midi-Cell) }\end{array}$ & Thermo Fisher Scientific Inc., Waltham, USA \\
\hline FACSCalibur $^{\mathrm{TM}}$ & BD Biosciences Corp., Franklin Lakes, USA \\
\hline Freezing Container (Mr. Frosty ${ }^{\mathrm{TM}}$ ) & Thermo Fisher Scientific Inc., Waltham, USA \\
\hline Gas burner (Campingaz) & Newell Brands, Hoboken, USA \\
\hline Heating shaker (Thermomixer®) & Eppendorf AG, Hamburg \\
\hline Heating stirrer (MR 3000/3001) & $\begin{array}{l}\text { Heidolph Instruments GmbH \& Co.KG, } \\
\text { Schwabach }\end{array}$ \\
\hline Homogenizer (Miccra D-1) & MICCRA GmbH, Heitersheim \\
\hline Hybridization oven (HB-1000 Hybridizer) & VWR International, Radnor, USA \\
\hline Inverted microscope (Axiovert 25) & Carl Zeiss AG, Oberkochen \\
\hline Liquid nitrogen tank & Air Liquide S.A., Paris, France \\
\hline $\begin{array}{l}\text { Micro-computed tomography }(\mu \mathrm{CT}) \text { scanner } \\
\text { (Quantum FX) }\end{array}$ & PerkinElmer Health Sciences, Hopkinton, USA \\
\hline Microplate reader (SynergyMx) & BioTek Instruments, Inc., Winooski, USA \\
\hline Microscope (Olympus BX 60) & Olympus Corp., Shinjuku, Japan \\
\hline Microtome (HN 40) & Leica Microsystems GmbH, Wetzlar \\
\hline Microwave Oven (Dimension 4) & Panasonic Corp., Kadoma, Japan \\
\hline Mini centrifuge (Rotilabo®) & Carl Roth GmbH \& Co.KG, Karlsruhe \\
\hline
\end{tabular}




\begin{tabular}{|c|c|}
\hline Mixer (Vortex-Genie® 2) & Scientific Industries, Inc., Bohemia, USA \\
\hline Neon Transfection System & Thermo Fisher Scientific Inc., Waltham, USA \\
\hline Paraffin dispenser (Dispenser PAG 12) & Medite $\mathrm{GmbH}$, Burgdorf \\
\hline Paraffin tissue floating bath (Round model) & Medax GmbH \& Co.KG, Neumünster \\
\hline $\begin{array}{l}\text { PCR cycler (Mastercycler }{ }^{\circledR} \text {, Mastercycler }{ }^{\circledR} \\
\text { Gradient S) }\end{array}$ & Eppendorf AG, Hamburg \\
\hline pH meter (inoLab pH Level 1) & Xylem Inc., Rye Brook \\
\hline Pipettes (Multipette, one-channel) & Eppendorf AG, Hamburg \\
\hline Platform shaker (Unimax 1010) & $\begin{array}{l}\text { Heidolph Instruments GmbH \& Co.KG, } \\
\text { Schwabach }\end{array}$ \\
\hline Power supply for electrophoresis (E835) & Consort, Turnhout, Belgium \\
\hline $\begin{array}{l}\text { Power supply for Western Blot analysis (CS- } \\
\text { 300V) }\end{array}$ & Cleaver Scientific Ltd., Rugby, UK \\
\hline Precision scales (Sartorius Basic ${ }^{\text {plus }}$ ) & Sartorius AG, Göttingen \\
\hline qRT PCR system (ABI Prism 7900HT) & Thermo Fisher Scientific Inc., Waltham, USA \\
\hline Tissue processor (TP 1020) & Leica Microsystems GmbH, Wetzlar \\
\hline UV-VIS spectrophotometer (NanoDrop ${ }^{\mathrm{TM}} 8000$ ) & Thermo Fisher Scientific Inc., Waltham, USA \\
\hline UV transilluminator & Intas Science Imaging GmbH, Göttingen \\
\hline Vacuum pump system (EcoVac) & Schuett-Biotec GmbH, Göttingen \\
\hline Water purification system (Arium® 611 VF) & Sartorius AG, Göttingen \\
\hline Western Blot imaging system (FluorChem ${ }^{\mathrm{TM}} \mathrm{Q}$ ) & Bio-Techne Corp., Minneapolis, USA \\
\hline $\begin{array}{l}\text { Western Blot transfer system (Trans-Blot@ SD } \\
\text { Semi-Dry Transfer Cell) }\end{array}$ & Bio-Rad Laboratories, Inc., Hercules, USA \\
\hline
\end{tabular}

\subsection{Consumables}

\section{Table 2: Utilized consumables}

\begin{tabular}{|c|c|}
\hline Consumables & Supplier \\
\hline $1.5 \mathrm{~mL}$ reaction tubes & Ochs GmbH, Bovenden/Lenglern \\
\hline $1.5 \mathrm{~mL}$ safeseal microtubes & Sarstedt AG \& Co., Nürnberg \\
\hline $2.0 \mathrm{~mL}$ reaction tubes & Sarstedt AG \& Co., Nürnberg \\
\hline $15 \mathrm{~mL}$ Greiner centrifuge tubes & Merck KGaA, Darmstadt \\
\hline 12-well tissue culture plates & Sarstedt AG \& Co., Nürnberg \\
\hline 24-well tissue culture plates & Sarstedt AG \& Co., Nürnberg \\
\hline 384-well PCR plates (Framestar) & 4titude Ltd., Berlin \\
\hline $50 \mathrm{~mL}$ Greiner centrifuge tubes & Merck KGaA, Darmstadt \\
\hline 6-well tissue culture plates & Sarstedt AG \& Co., Nürnberg \\
\hline 96-well assay plates (transparent) & Corning, Inc., Corning, USA \\
\hline 96-well reaction plates (black) & Thermo Fisher Scientific Inc., Waltham, USA \\
\hline $\begin{array}{l}\text { BD Discardit }{ }^{\mathrm{TM}} \text { II }(2,10,20 \mathrm{~mL}) \text {, disposable } \\
\text { syringes }\end{array}$ & BD Biosciences GmbH, Franklin Lakes, USA \\
\hline BD Microfine + Demi Pen Needles & BD Biosciences GmbH, Franklin Lakes, USA \\
\hline BD Plastipak $^{\mathrm{TM}}(100 \mathrm{~mL})$, disposable syringe & BD Biosciences GmbH, Franklin Lakes, USA \\
\hline
\end{tabular}




\begin{tabular}{|c|c|}
\hline Blotting paper (GB 33 B003) & Heinemann Labortechnik GmbH, Duderstadt \\
\hline Cell scrapers & Sarstedt AG \& Co., Nürnberg \\
\hline Cell strainers $(40 \mu \mathrm{m})$ & BD Biosciences GmbH, Franklin Lakes, USA \\
\hline Coverslips & Menzel GmbH \& Co.KG, Braunschweig \\
\hline CryoPure tubes & Sarstedt AG \& Co., Nürnberg \\
\hline Disposable needles (Sterican $\varnothing 0,45 \times 12 \mathrm{~mm}$ ) & B. Braun Medical AG, Emmenbrücke \\
\hline $\begin{array}{l}\text { Eppendorf® Combitips advanced® pipette tips } \\
(0.2,0.5,2.5,5,10,25,50 \mathrm{~mL})\end{array}$ & Merck KGaA, Darmstadt \\
\hline Feeding tubes $(1.0 \times 60 \mathrm{~mm})$ & Unimed SA, Lausanne, Schweiz \\
\hline Filter tips $(10,100,200,1000 \mu \mathrm{L})$ & Kisker Biotech GmbH \& Co. KG, Steinfurt \\
\hline Flow cytometry tubes & Sarstedt AG \& Co., Nürnberg \\
\hline Fluted filters & Sartorius AG, Göttingen \\
\hline Glass slides & Thermo Fisher Scientific Inc., Waltham, USA \\
\hline Glassware & Schott AG, Mainz \\
\hline Neubauer counting chamber & Brand GmbH \& Co KG, Wertheim \\
\hline $\begin{array}{l}\text { Nitrocellulose (NC) membrane (Hybond ECL), } \\
0.2 \mu \mathrm{m} \text { pore size }\end{array}$ & GE Healthcare Europe GmbH, Freiburg \\
\hline Nunc $^{\mathrm{TM}}$ cell culture dishes $(\varnothing 10 \mathrm{~cm})$ & Thermo Fisher Scientific Inc., Waltham, USA \\
\hline Nunc $^{\mathrm{TM}}$ cell culture dishes $(\varnothing 6 \mathrm{~cm})$ & Thermo Fisher Scientific Inc., Waltham, USA \\
\hline NuPAGE Novex $4-12 \%$ Bis-Tris Midi Gels & Thermo Fisher Scientific Inc., Waltham, USA \\
\hline Pasteur pipettes & Brand GmbH \& Co.KG, Wertheim \\
\hline Petri dishes & Ochs GmbH, Bovenden/Lenglern \\
\hline Pipette tips $(10,20,100,200,1000 \mu \mathrm{L})$ & Sarstedt AG \& Co., Nürnberg \\
\hline $\begin{array}{l}\text { Polyvinylidene difluoride (PVDF) membrane } \\
\text { (Immobilon®-P), } 0.45 \mu \mathrm{m} \text { pore size }\end{array}$ & Merck KGaA, Darmstadt \\
\hline QPCR adhesive clear seals & 4titude Ltd., Berlin \\
\hline Scalpel blades $(10,24)$ & Aesculap AG \& Co.KG, Tuttlingen \\
\hline Serological pipettes $(2,5,10,25,50 \mathrm{~mL})$ & Sarstedt AG \& Co., Nürnberg \\
\hline Sterile filters & Omnilab-Krannich, Göttingen \\
\hline Superfrost glass slides (SuperFrost Plus ${ }^{\mathrm{TM}}$ ) & Thermo Fisher Scientific Inc., Waltham, USA \\
\hline Syringe $1,30,50 \mathrm{~mL}$ & Terumo Medical Corp., Elkton, MD, USA \\
\hline
\end{tabular}

\subsection{Reagents and chemicals}

All chemicals, which are not listed in Table 3 were purchased from Merck KGaA, Darmstadt.

Table 3: Utilized reagents and chemicals

\begin{tabular}{|c|c|}
\hline Reagents and chemicals & Supplier \\
\hline 50 bp, 100 bp plus, 1 kb DNA ladder & Thermo Fisher Scientific Inc., Waltham, USA \\
\hline Acetic acid & Carl Roth GmbH \& Co.KG, Karlsruhe \\
\hline Agarose & Bio-Budget Technologies GmbH, Krefeld \\
\hline Ampicillin & Carl Roth GmbH \& Co. KG, Karlsruhe \\
\hline BD Bacto $^{\mathrm{TM}}$ Tryptone & BD Biosciences GmbH, Franklin Lakes, USA \\
\hline
\end{tabular}




\begin{tabular}{|c|c|}
\hline Boric acid & Carl Roth GmbH \& Co.KG, Karlsruhe \\
\hline Bovine serum albumin (BSA) & Carl Roth GmbH \& Co.KG, Karlsruhe \\
\hline Chloroform & Carl Roth GmbH \& Co.KG, Karlsruhe \\
\hline Citric acid & Carl Roth GmbH \& Co.KG, Karlsruhe \\
\hline Collagen from rat tail & Merck KGaA, Darmstadt \\
\hline Collagenase $\mathrm{H}$ & Roche Diagnostic GmbH, Basel, Switzerland \\
\hline Contrast agent Imeron 300 & Bracco Imaging Deutschland GmbH, Konstanz \\
\hline Cresol Red & Merck KGaA, Darmstadt \\
\hline Deoxyribonucleotide triphosphates (dNTPs) & Roche Diagnostic GmbH, Basel, Switzerland \\
\hline Dimethyl sulfoxide (DMSO) & Thermo Fisher Scientific Inc., Waltham, USA \\
\hline Dithiothreitol (DTT) & Thermo Fisher Scientific Inc., Waltham, USA \\
\hline DNA Gel Loading Dye $(6 \mathrm{X})$ & Thermo Fisher Scientific Inc., Waltham, USA \\
\hline DNase/RNase-free $\mathrm{H}_{2} \mathrm{O}$ & Thermo Fisher Scientific Inc., Waltham, USA \\
\hline Eosin $Y$ & Merck KGaA, Darmstadt \\
\hline Ethanol (EtOH), $99 \%$ & Fisher Scientific, Schwerte \\
\hline Ethidium bromide (0.07\%) & $\begin{array}{l}\text { Inno-train Diagnostik GmbH, Kronberg im } \\
\text { Taunus }\end{array}$ \\
\hline Ethylendiaminetetraacetic acid (EDTA) & MP Biomedicals, Santa Ana, USA \\
\hline EtOH, $99 \%$, denatured & $\begin{array}{l}\text { CVH Chemie-Vertrieb GmbH \& Co. Hannover } \\
\text { KG, Hannover }\end{array}$ \\
\hline Glycergel mounting medium & Agilent Technologies Inc., Santa Clara, USA \\
\hline Haematoxylin, Mayer's & Merck KGaA, Darmstadt \\
\hline Hydrogen peroxide $\left(\mathrm{H}_{2} \mathrm{O}_{2}, 35 \%\right)$ & Carl Roth GmbH \& Co. KG, Karlsruhe \\
\hline Isoflurane (FORENE®) & Abbott Laboratories, North Chicago, USA \\
\hline Isopropyl alcohol & Carl Roth GmbH \& Co. KG, Karlsruhe \\
\hline Kanamycin & Carl Roth GmbH \& Co. KG, Karlsruhe \\
\hline Liquid Barrier Marker & Carl Roth GmbH \& Co. KG, Karlsruhe \\
\hline Methanol & Carl Roth GmbH \& Co. KG, Karlsruhe \\
\hline NuPAGE MES SDS Running Buffer (20X) & Thermo Fisher Scientific Inc., Waltham, USA \\
\hline Paraformaldehyde & Carl Roth GmbH \& Co. KG, Karlsruhe \\
\hline Pertex mounting medium & Medite $\mathrm{GmbH}$, Orlando \\
\hline $\begin{array}{l}\text { Phosphatase inhibitor cocktail tablets } \\
\text { (PhosSTOP }^{\mathrm{TM}} \text { ) }\end{array}$ & Roche Diagnostic GmbH, Basel, Switzerland \\
\hline Phosphate buffered saline (PBS) tablets & Thermo Fisher Scientific Inc., Waltham, USA \\
\hline Potassium aluminum sulfate & Merck KGaA, Darmstadt \\
\hline Powdered milk & Carl Roth GmbH \& Co. KG, Karlsruhe \\
\hline Propidium lodide $(\mathrm{PI})$ & Miltenyi Biotec $\mathrm{GmbH}$, Bergisch Gladbach \\
\hline $\begin{array}{l}\text { Protease inhibitor cocktail tablets (cOmplete }{ }^{\mathrm{TM}} \text {, } \\
\text { mini) }\end{array}$ & Roche Diagnostic GmbH, Basel, Switzerland \\
\hline Random hexamers & Thermo Fisher Scientific Inc., Waltham, USA \\
\hline S.O.C Medium & Thermo Fisher Scientific Inc., Waltham, USA \\
\hline SeeBlue® Plus2 Pre-Stained Protein Standard & Thermo Fisher Scientific Inc., Waltham, USA \\
\hline Sodiumdodecylsulfate (SDS) & Carl Roth GmbH \& Co. KG, Karlsruhe \\
\hline Trichloro acetaldehyde hydrate & Merck KGaA, Darmstadt \\
\hline
\end{tabular}




\begin{tabular}{|l|l|}
\hline Triton $^{\mathrm{TM}} \mathrm{X}-100$ & Merck KGaA, Darmstadt \\
\hline Trypan blue & Merck KGaA, Darmstadt \\
\hline Tween ${ }^{\circledR} 20$ & Scharlau Chemie S.A., Barcelona, Spain \\
\hline Tween ${ }^{8} 80$ & Merck KGaA, Darmstadt \\
\hline Xylene & Fisher Scientific, Schwerte \\
\hline Yeast extract & Merck KGaA, Darmstadt \\
\hline
\end{tabular}

3.3.1 Signaling pathway inhibitors

Table 4: Utilized small molecule inhibitors for in vitro experiments

\begin{tabular}{|l|l|l|l|}
\hline Inhibitor & Solvent & $\begin{array}{l}\text { Incubation } \\
\text { concentration }\end{array}$ & Supplier \\
\hline Cyclopamine & EtOH & $1-10 \mu \mathrm{M}$ & $\begin{array}{l}\text { Sigma-Aldrich Inc., St. Louis, USA (now Merck } \\
\text { KGaA, Darmstadt) }\end{array}$ \\
\hline Everolimus & EtOH & $50 \mathrm{nM}$ & $\begin{array}{l}\text { Sigma-Aldrich Inc., St. Louis, USA (now Merck } \\
\text { KGaA, Darmstadt) }\end{array}$ \\
\hline HhAntag & DMSO & $3.1-50 \mu \mathrm{M}$ & Genentech, San Francisco, USA \\
\hline MK-2206 & DMSO & $5 \mu \mathrm{M}$ & Selleckchem, Houston, USA \\
\hline Pictilisib & DMSO & $0.6-10 \mu \mathrm{M}$ & $\begin{array}{l}\text { Selleckchem, Houston, USA and Genentech, San } \\
\text { Francisco, USA }\end{array}$ \\
\hline Pl-103 & DMSO & $3 \mu \mathrm{M}$ & Alexis Biochemicals, San Diego, USA \\
\hline Rapamycin & DMSO & $100 \mathrm{nM}$ & Merck KGaA, Darmstadt \\
\hline $\begin{array}{l}\text { Smoothened } \\
\text { agonist } \\
\text { (SAG) }\end{array}$ & DMSO & $100 \mathrm{nM}$ & Cayman Chemical Company, Ann Arbor, USA \\
\hline Sonidegib & DMSO & $3.1-50 \mu \mathrm{M}$ & $\begin{array}{l}\text { Active Biochem LTD, Kowloon, Hong Kong and } \\
\text { Novartis AG, Basel, Switzerland }\end{array}$ \\
\hline UO126 & DMSO & $2-25 \mu \mathrm{M}$ & Cell Signaling Technology, Danvers, USA \\
\hline Vismodegib & DMSO & $3.1-50 \mu \mathrm{M}$ & $\begin{array}{l}\text { Selleckchem, Houston, USA and Genentech, San } \\
\text { Francisco, USA }\end{array}$ \\
\hline
\end{tabular}

Table 5: Utilized small molecule inhibitors for in vivo experiments

\begin{tabular}{|l|l|l|l|}
\hline Inhibitor & $\begin{array}{l}\text { Daily dose }[\boldsymbol{\mu g} / \mathbf{g} \\
\text { body weight] }\end{array}$ & $\begin{array}{l}\text { Stock concentration } \\
{[\mathbf{m g} / \mathbf{m L}]^{*}}\end{array}$ & Supplier \\
\hline HhAntag & 100 & 10 & Genentech, San Francisco, USA \\
\hline Pictilisib & 75 & 37.5 & Genentech, San Francisco, USA \\
\hline Sonidegib & 80 & 10 & Novartis AG, Basel, Switzerland \\
\hline Vismodegib & 100 & 10 & Genentech, San Francisco, USA \\
\hline
\end{tabular}

${ }^{*}$ All drugs for in vivo experiments were resuspended in vehicle as described in section 4.4.5. 


\subsubsection{Enzymes}

\section{Table 6: Utilized enzymes}

\begin{tabular}{|l|l|}
\hline Enzymes & Supplier \\
\hline BamHI & Thermo Fisher Scientific Inc., Waltham, USA \\
\hline Collagenase H & Roche Diagnostic GmbH, Basel, Switzerland \\
\hline EcoRI & Thermo Fisher Scientific Inc., Waltham, USA \\
\hline Hind III & Thermo Fisher Scientific Inc., Waltham, USA \\
\hline Hpal & Thermo Fisher Scientific Inc., Waltham, USA \\
\hline Kpnl & Thermo Fisher Scientific Inc., Waltham, USA \\
\hline Nhel & Thermo Fisher Scientific Inc., Waltham, USA \\
\hline Notl & Thermo Fisher Scientific Inc., Waltham, USA \\
\hline Proteinase K & Carl Roth GmbH \& Co. KG, Karlsruhe \\
\hline RNase A & Carl Roth GmbH \& Co.KG, Karlsruhe \\
\hline SuperScript ${ }^{\text {TM }}$ II Reverse Transcriptase & Thermo Fisher Scientific Inc., Waltham, USA \\
\hline Taq Polymerase (MolTaq basis) & Molzym GmbH \& Co. KG, Bremen \\
\hline
\end{tabular}

\subsubsection{Kits and ready-to-use reagents}

Unless stated otherwise all kits and ready-to-use reagents listed in Table 7 were used according to the manufacturer's instructions.

\section{Table 7: Utilized kits and ready-to-use reagents}

\begin{tabular}{|c|c|}
\hline Reaction system & Supplier \\
\hline FITC Annexin V Apoptosis Detection Kit I & BD Biosciences Corp., Franklin Lakes, USA \\
\hline $\begin{array}{l}\text { Cell Proliferation ELISA, BrdU } \\
\text { (chemiluminescent) }\end{array}$ & Roche Diagnostic GmbH, Basel, Switzerland \\
\hline Dako REAL ${ }^{\mathrm{TM}}$ EnVision $^{\mathrm{TM}}$ Detection System & Agilent Technologies Inc., Santa Clara, USA \\
\hline Dual-Luciferase® Reporter Assay System & Promega Inc., Fitchburg, USA \\
\hline Neon $^{\mathrm{TM}}$ Transfection System Kit & Thermo Fisher Scientific Inc., Waltham, USA \\
\hline Pierce BCA Protein Assay Kit & Thermo Fisher Scientific Inc., Waltham, USA \\
\hline Pierce ECL Plus Western Blot substrate & Thermo Fisher Scientific Inc., Waltham, USA \\
\hline Platinum SYBR Green qPCR Super Mix & Thermo Fisher Scientific Inc., Waltham, USA \\
\hline PureLink® HiPure Plasmid Midiprep kit & Thermo Fisher Scientific Inc., Waltham, USA \\
\hline QuantiTect SYBR Green PCR kit & Qiagen, Venlo, Netherlands \\
\hline TRIzol $^{\mathrm{TM}}$ Reagent & Thermo Fisher Scientific Inc., Waltham, USA \\
\hline Water soluble tetrazolium salt 1 (WST-1) reagent & Roche Diagnostic GmbH, Basel, Switzerland \\
\hline
\end{tabular}

\subsection{Buffers and solutions}

If not stated otherwise all buffers and solutions listed in Table 8 were made with ultrapure $\mathrm{H}_{2} \mathrm{O}$. 
Table 8: Utilized buffers and solutions

\begin{tabular}{|c|c|c|}
\hline Buffer or solution & Composition & \\
\hline \multirow{4}{*}{ 10X PBS, pH 7.4} & $1.4 \mathrm{M}$ & $\mathrm{NaCl}$ \\
\hline & $65 \mathrm{mM}$ & $\mathrm{Na}_{2} \mathrm{HPO}_{4}$ \\
\hline & $27 \mathrm{mM}$ & $\mathrm{KCl}$ \\
\hline & $15 \mathrm{mM}$ & $\mathrm{KH}_{2} \mathrm{PO}_{4}$ \\
\hline \multirow{3}{*}{$\begin{array}{l}\text { 10X Tris-boric acid-EDTA (TBE), pH } \\
8.0\end{array}$} & $890 \mathrm{mM}$ & Tris/HCl \\
\hline & $730 \mathrm{mM}$ & Boric acid \\
\hline & $12.5 \mathrm{mM}$ & EDTA \\
\hline \multirow{2}{*}{$\begin{array}{l}\text { 10X Tris-buffered saline (TBS), } \mathrm{pH} \\
7.4\end{array}$} & $1.5 \mathrm{M}$ & $\mathrm{NaCl}$ \\
\hline & $0.5 \mathrm{M}$ & Tris/HCl \\
\hline \multirow{5}{*}{$6 X$ SDS loading buffer } & $35 \%(v / v)$ & Glycerol \\
\hline & $9 \%(w / v)$ & SDS \\
\hline & $8.5 \%(w / v)$ & DTT \\
\hline & $0.1 \%(w / v)$ & Bromophenolblue \\
\hline & \multicolumn{2}{|c|}{ Dissolved in upper gel buffer } \\
\hline \multirow{4}{*}{ Blotting buffer } & $20 \%(v / v)$ & Methanol \\
\hline & $6 \%(w / v)$ & Tris \\
\hline & $3 \%(w / v)$ & Glycine \\
\hline & $0.0375 \%(v / v)$ & SDS \\
\hline \multirow{3}{*}{ BSA-azide } & $0.02 \%(v / v)$ & Sodium azide \\
\hline & $2 \%(w / v)$ & BSA \\
\hline & \multicolumn{2}{|c|}{ Dissolved in PBST } \\
\hline \multirow{2}{*}{ Casein } & $0.2 \%(w / v)$ & Casein \\
\hline & \multicolumn{2}{|c|}{ Dissolved in TBS } \\
\hline Collagen solution & $\begin{array}{l}0.1 \mathrm{M} \\
1 \mathrm{mg} / \mathrm{mL}\end{array}$ & $\begin{array}{l}\text { Acetic acid } \\
\text { Collagen from rat tail }\end{array}$ \\
\hline \multirow[b]{2}{*}{ Cresol } & $0.1 \%(\mathrm{w} / \mathrm{v})$ & Cresol Red \\
\hline & \multicolumn{2}{|c|}{ In saturated sucrose solution $\left(100 \%(\mathrm{w} / \mathrm{v})\right.$ sucrose in $\left.\mathrm{H}_{2} \mathrm{O}\right)$} \\
\hline \multirow{4}{*}{ dNTPs } & $10 \mathrm{mM}$ & dATP \\
\hline & $10 \mathrm{mM}$ & $\mathrm{dCTP}$ \\
\hline & $10 \mathrm{mM}$ & dGTP \\
\hline & $10 \mathrm{mM}$ & dTTP \\
\hline \multirow{2}{*}{ Eosin solution } & $80 \%(v / v)$ & $\mathrm{EtOH}$ \\
\hline & $1 \%(w / v)$ & Eosin $Y$ (water soluble) \\
\hline \multirow{5}{*}{ Haematoxylin solution } & $5 \%(w / v)$ & Potassium aluminum sulfate \\
\hline & $5 \%(w / v)$ & Trichloro acetaldehyde hydrate \\
\hline & $1 \%(w / v)$ & Citric acid \\
\hline & $0.1 \%(w / v)$ & Haematoxylin \\
\hline & $0.015 \%(w / v)$ & Sodium iodate \\
\hline \multirow{7}{*}{ Lysis buffer (RIPA) } & $50 \mathrm{nM}$ & Tris/HCl, $\mathrm{pH} 7.4$ \\
\hline & $1 \%(v / v)$ & NP-40 \\
\hline & $0.25 \%(v) v$ & Sodium deoxycholat \\
\hline & $150 \mathrm{mM}$ & $\mathrm{NaCl}$ \\
\hline & $1 \mathrm{mM}$ & EDTA \\
\hline & 1 tablet $/ 10 \mathrm{~mL}$ & Phosphatase inhibitor PhosSTOP ${ }^{\mathrm{TM}}$ \\
\hline & 1 tablet/ $10 \mathrm{~mL}$ & Protease inhibitor cocktail cOmplete ${ }^{\mathrm{TM}}$ \\
\hline
\end{tabular}




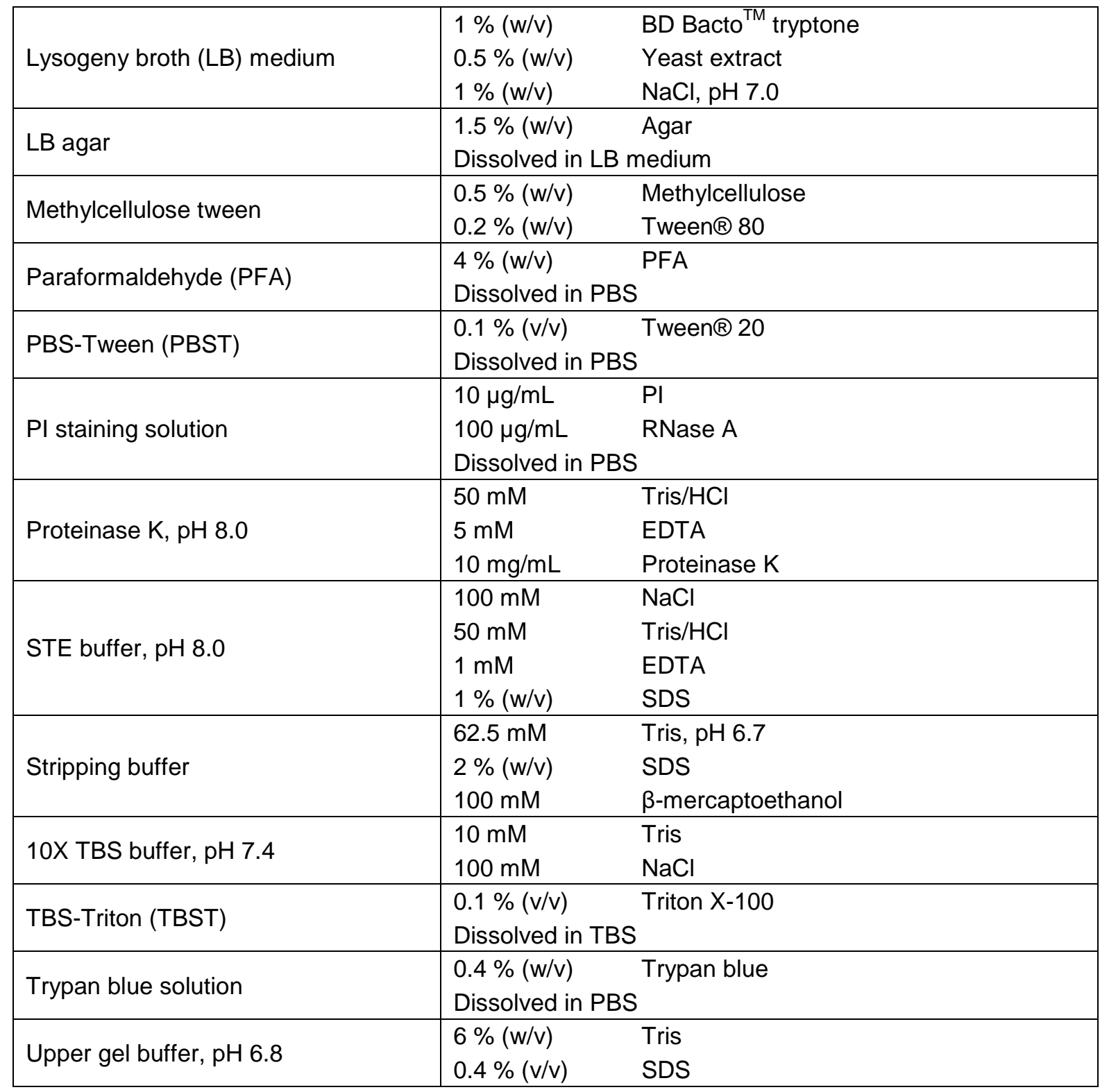

\subsection{Media}

\subsubsection{Media for prokaryotic cell cultivation}

The cultivation of bacterial cells was done in LB medium or on LB agar plates. The compositions of LB medium and LB agar are listed in Table 8. Medium was autoclaved before use. After cooling down of the medium, the antibiotic ampicillin (100 $\mu \mathrm{g} / \mathrm{mL})$ or kanamycin $(50 \mu \mathrm{g} / \mathrm{mL})$ was added. LB agar plates were poured into petri dishes afterwards and allowed to harden completely. LB medium and LB agar plates were stored at $4{ }^{\circ} \mathrm{C}$. 


\subsubsection{Media and reagents for eukaryotic cell cultivation}

Table 9: Utilized media and reagents for eukaryotic cell cultivation

\begin{tabular}{|c|c|}
\hline Medium or reagent & Supplier \\
\hline Accutase & GE Healthcare, Little Chalfont, UK \\
\hline Dulbecco's Modified Eagle Medium (DMEM) & Thermo Fisher Scientific Inc., Waltham, USA \\
\hline Fetal calf serum (FCS) & Thermo Fisher Scientific Inc., Waltham, USA \\
\hline G418 disulfate salt solution $(50 \mathrm{mg} / \mathrm{mL})$ & Merck KGaA, Darmstadt \\
\hline PBS (cell culture) ${ }^{*}$ & Thermo Fisher Scientific Inc., Waltham, USA \\
\hline $\begin{array}{l}\text { Penicillin, } 10000 \mathrm{U} / \mathrm{mL} \text {, and Streptomycin, } 10 \\
\mathrm{mg} / \mathrm{mL}(\mathrm{P} / \mathrm{S})\end{array}$ & Pan - Biotech GmbH, Aidenbach \\
\hline Puromycin dihydrochloride $(10 \mathrm{mg} / \mathrm{mL})$ & Merck KGaA, Darmstadt \\
\hline TrypLE Express & Thermo Fisher Scientific Inc., Waltham, USA \\
\hline
\end{tabular}

${ }^{*} 1$ PBS tablet was dissolved in $500 \mathrm{~mL}$ ultrapure $\mathrm{H}_{2} \mathrm{O}$, autoclaved before use and stored at $4{ }^{\circ} \mathrm{C}$.

\subsection{Biological material}

\subsubsection{Bacterial strains}

Plasmids were amplified by transformation and growth of chemical competent $\mathrm{DH} 5 \alpha$ Escherichia coli (E. coli) cells obtained from Thermo Fisher Scientific Inc., Waltham, USA.

\subsubsection{Eukaryotic cell lines and primary cells}

Table 10: Utilized eukaryotic cell lines and primary cells

\begin{tabular}{|c|c|c|c|}
\hline $\begin{array}{l}\text { Cell line / } \\
\text { Cells }\end{array}$ & Specification & $\begin{array}{l}\text { Medium and } \\
\text { supplements }\end{array}$ & Source or Reference \\
\hline B9 & $\begin{array}{l}\text { Murine adult fibroblasts, } \\
\text { Shh-responsive }\end{array}$ & $\begin{array}{l}\text { DMEM, } 10 \% \\
\text { FCS, } 1 \% \mathrm{P} / \mathrm{S}\end{array}$ & $\begin{array}{l}214 \text {, referred to as } \\
\text { Ptch }^{\text {floxfflox } E R T 2^{+/-}}\end{array}$ \\
\hline HEK293 & $\begin{array}{l}\text { Human embryonic kidney } \\
\text { cells, untransfected (control } \\
\text { cells for HEK293 Shh-N) }\end{array}$ & $\begin{array}{l}\text { DMEM, } 10 \% \\
\text { FCS, } 1 \% \mathrm{P} / \mathrm{S}\end{array}$ & ATCC*, Manassas, USA \\
\hline $\begin{array}{l}\text { HEK293 } \\
\text { Shh-N }\end{array}$ & $\begin{array}{l}\text { Human embryonic kidney } \\
\text { cells, stably transfected } \\
\text { with Shh- } N \text { expression } \\
\text { plasmid }\end{array}$ & $\begin{array}{l}\text { DMEM, } 10 \% \\
\text { FCS, } 1 \% \text { P/S, } \\
0.4 \mathrm{mg} / \mathrm{mL} \text { G418 }\end{array}$ & 215 \\
\hline $\mathrm{RD}$ & Human ERMS & $\begin{array}{l}\text { DMEM, } 10 \% \\
\text { FCS, } 1 \% \mathrm{P} / \mathrm{S}\end{array}$ & ATCC, Manassas, USA \\
\hline $\begin{array}{l}\text { RD } \\
\text { SMOlow }\end{array}$ & $\begin{array}{l}\text { Human ERMS, stably } \\
\text { transfected with shSMO }\end{array}$ & $\begin{array}{l}\text { DMEM, } 10 \% \\
\text { FCS, } 1 \% \mathrm{P} / \mathrm{S} \\
1 \mu \mathrm{g} / \mathrm{mL} \\
\text { puromycin }\end{array}$ & $\begin{array}{l}118 \text {, cells were kindly provided by } \\
\text { Prof. B. Schäfer (University } \\
\text { Children's Hospital of Zurich, } \\
\text { Switzerland) }\end{array}$ \\
\hline $\begin{array}{l}\text { RD } \\
\text { SMOhigh }\end{array}$ & $\begin{array}{l}\text { Human ERMS, stably } \\
\text { transfected with pLKO. } 1 \\
\text { (control cells for RD } \\
\text { SMOlow) }\end{array}$ & $\begin{array}{l}\text { DMEM, } 10 \% \\
\text { FCS, } 1 \% \mathrm{P} / \mathrm{S} \\
1 \mu \mathrm{g} / \mathrm{mL} \\
\text { puromycin }\end{array}$ & $\begin{array}{l}118 \text {, cells were kindly provided by } \\
\text { Prof. B. Schäfer (University } \\
\text { Children's Hospital of Zurich, } \\
\text { Switzerland) }\end{array}$ \\
\hline $\mathrm{RUCH}-2$ & Human ERMS & $\begin{array}{l}\text { DMEM, } 10 \% \\
\text { FCS, } 1 \% \mathrm{P} / \mathrm{S}\end{array}$ & ATCC, Manassas, USA \\
\hline
\end{tabular}




\begin{tabular}{|l|l|l|l|}
\hline $\begin{array}{l}\text { Primary } \\
\text { Ptch }^{+-} \text {cells }\end{array}$ & Murine ERMS-like & $\begin{array}{l}\text { DMEM, 10 \% } \\
\text { FCS, } 1 \% \mathrm{P} / \mathrm{S}\end{array}$ & RMS-bearing Ptch $^{+/}$mice \\
\hline
\end{tabular}

${ }^{*}$ ATCC: American Type Culture Collection

\subsection{Synthetic DNA oligonucleotides}

All DNA oligonucleotides listed in Table 11 and Table 12 were obtained from Eurofins Scientific SE, Luxemburg, Luxemburg.

Table 11: Utilized synthetic DNA oligonucleotides for genotyping PCR of Ptch $^{+/-}$mice

\begin{tabular}{|c|c|c|c|}
\hline Primer Name & Primer Sequence $\left(5^{\prime}-3^{\prime}\right.$ orientation) & $\begin{array}{l}\text { Amplification } \\
\text { product }\end{array}$ & Reference \\
\hline Exon 7-F & AGGAAGTATATGCATTGGCAGGAG & \multirow{2}{*}{$\begin{array}{l}950 \text { bp (mutant Ptch } \\
\text { allele) }\end{array}$} & \multirow{4}{*}{216} \\
\hline Neo-R & GCATCAGAGCAGCCGATTGTCTG & & \\
\hline mPTCNx_f & GGGAGGGGATTTCAGCAGAATGTT & \multirow{2}{*}{$\begin{array}{l}445 \text { bp (wild type } \\
\text { Ptch allele) }\end{array}$} & \\
\hline mPTCwt_r & TCAAGGAGCAGAGGCCCAA & & \\
\hline
\end{tabular}

Table 12: Utilized synthetic DNA oligonucleotides for qRT PCR

\begin{tabular}{|c|c|c|c|}
\hline Primer name & Primer sequence $\left(5^{\prime}-3^{\prime}\right.$ orientation) & Location & Transcript \\
\hline $\begin{array}{l}\text { 18S-fwd } \\
\text { 18S-rev2 }\end{array}$ & $\begin{array}{l}\text { CGCAAATTACCCACTCCCG } \\
\text { TTCCAATTACAGGGCCTCGAA }\end{array}$ & $\begin{array}{l}\text { exon } 1 \\
\text { exon } 1\end{array}$ & $18 S$ rRNA \\
\hline $\begin{array}{l}\text { hHPRT1_F1 } \\
\text { hHPRT1_R1 }\end{array}$ & $\begin{array}{l}\text { TGGCGTCGTGATTAGTGATG } \\
\text { CGAGCAAGACGTTCAGTCCT }\end{array}$ & $\begin{array}{l}\text { exon } 1+2 \\
\text { exon } 2+3\end{array}$ & HPRT \\
\hline $\begin{array}{l}\text { HsaGli } 1 \text { tq F } \\
\text { HsaGli1 tq R }\end{array}$ & $\begin{array}{l}\text { AGCTACATCAACTCCGGCCA } \\
\text { GCTGCGGCGTTCAAGAGA }\end{array}$ & $\begin{array}{l}\text { exon } 11 \\
\text { exon } 12\end{array}$ & GLI1 \\
\hline $\begin{array}{l}\text { HSA_Hhip_tq_FW1 } \\
\text { HSA_Hhip_tq_RV1 }\end{array}$ & $\begin{array}{l}\text { ATGGTGGGTTGTGCTTTCCA } \\
\text { CAGAAGCAGTTGTGTTTGTGCT }\end{array}$ & $\begin{array}{l}\text { exon } 3 \\
\text { exon } 4\end{array}$ & Hhip \\
\hline $\begin{array}{l}\text { mGli1-tq-f } \\
\text { mGli1-tq-r }\end{array}$ & $\begin{array}{l}\text { TACATGCTGGTGGTGCACATG } \\
\text { ACCGAAGGTGCGTCTTGAGG }\end{array}$ & $\begin{array}{l}\text { exon } 9 \\
\text { exon } 10\end{array}$ & Gli1 \\
\hline $\begin{array}{l}\text { mGli2F.1 } \\
\text { mGli2R.1 }\end{array}$ & $\begin{array}{l}\text { GCAAGGTCAAGACTGAGGCTGA } \\
\text { GCTGCTCCTGTGTGTCATACTCCTT }\end{array}$ & $\begin{array}{l}\text { exon } 8 \\
\text { exon } 9\end{array}$ & Gli2 \\
\hline $\begin{array}{l}\text { mHhipF.1 } \\
\text { mHhipR.2 }\end{array}$ & $\begin{array}{l}\text { GGAGCCTTACTTGGACATTCACAA } \\
\text { ACCGTTCCTGGTTGGTGGTATAA }\end{array}$ & $\begin{array}{l}\text { exon } 4 \\
\text { exon } 5\end{array}$ & Hhip \\
\hline $\begin{array}{l}\text { mTBP-Q-Fwd } \\
\text { mTBP-Q-Rev }\end{array}$ & $\begin{array}{l}\text { CACCAATGACTCCTATGACCCCTA } \\
\text { CAGTTGTCCGTGGCTCTCTTATTC }\end{array}$ & $\begin{array}{l}\text { exon } 3 \\
\text { exon } 5\end{array}$ & Tbp \\
\hline $\begin{array}{l}\text { hsPTC1F.2 } \\
\text { hsPTC1R.2 }\end{array}$ & $\begin{array}{l}\text { GAGGTTGGTCATGGTTACATGGA } \\
\text { TGCTGTTCTTGACTGTGCCACC }\end{array}$ & $\begin{array}{l}\text { exon } 6 \\
\text { exon } 7\end{array}$ & $\mathrm{PTCH}$ \\
\hline $\begin{array}{l}\text { hSMO-F1 } \\
\text { hSMO-R1 }\end{array}$ & $\begin{array}{l}\text { CAAGAACTACCGATACCGTGC } \\
\text { AGCATGGTCTCGTTGATCTTGC }\end{array}$ & $\begin{array}{l}\text { exon } 6 \\
\text { exon } 7\end{array}$ & SMO \\
\hline
\end{tabular}




\subsection{Plasmids}

Table 13: Utilized plasmids and amount for transfection of RMS cells

\begin{tabular}{|l|l|l|l|}
\hline Plasmid & Application & $\begin{array}{l}\text { DNA amount for } \\
\text { transfection }\end{array}$ & Reference or supplier \\
\hline pCR3.1 & Gli reporter assay & $0.5 \mu \mathrm{g}$ & $\begin{array}{l}\text { Thermo Fisher Scientific Inc., } \\
\text { Waltham, USA }\end{array}$ \\
\hline pCR3.1 mGli1 & Gli reporter assay & $0.5 \mu \mathrm{g}$ & 217 \\
\hline pGL-9xGli BS & Gli reporter assay & $5.5 \mu \mathrm{g}$ & 218 \\
\hline pHA-Akt-DN & $\begin{array}{l}\text { Overexpression of } \\
\text { dominant negative Akt }\end{array}$ & $6 \mu \mathrm{g}$ & 219 \\
\hline pmaxGFP ${ }^{\text {TM }}$ & Transfection control & $6 \mu \mathrm{g}$ & $\begin{array}{l}\text { Lonza Group AG, Basel, } \\
\text { Switzerland }\end{array}$ \\
\hline pMyrAkt $\triangle 4-129$ & $\begin{array}{l}\text { Overexpression of } \\
\text { constitutive active Akt }\end{array}$ & $6 \mu \mathrm{g}$ & $\begin{array}{l}220,221 \\
\text { Addgene, Cambridge, USA }\end{array}$ \\
\hline pRL-CMV & Gli reporter assay & $0.5 \mu \mathrm{g}$ & Promega Inc., Fitchburg, USA \\
\hline
\end{tabular}

\subsection{Antibodies}

For immunohistochemical staining of tissue paraffin sections the HRP-conjugated secondary antibody from the Dako REAL ${ }^{\mathrm{TM}}$ EnVision ${ }^{\mathrm{TM}}$ Detection System was used.

Table 14: Utilized antibodies for Western Blot analysis and immunohistochemistry

\begin{tabular}{|c|c|c|}
\hline \multicolumn{3}{|l|}{ Primary antibodies } \\
\hline Antibody & Dilution & Supplier \\
\hline $\begin{array}{l}\text { mAb mouse anti-AKT (Clone } \\
\text { 55/PKBa/Akt) }\end{array}$ & $1: 1000$ & $\begin{array}{l}\text { BD Biosciences Corp., } \\
\text { Franklin Lakes, USA }\end{array}$ \\
\hline mAb mouse anti-HSC70 (B-6) & $1: 10000$ & $\begin{array}{l}\text { Santa Cruz Biotechnology, } \\
\text { Santa Cruz, USA }\end{array}$ \\
\hline mAb mouse anti-Ki67 & $1: 50$ & $\begin{array}{l}\text { BD Biosciences Corp., } \\
\text { Franklin Lakes, USA }\end{array}$ \\
\hline mAb mouse anti-S6 (54D2) & $1: 1000$ & $\begin{array}{l}\text { Cell Signaling Technology, } \\
\text { Danvers, USA }\end{array}$ \\
\hline mAb rabbit anti- $\beta$-Actin (13E5) & $1: 1000$ & $\begin{array}{l}\text { Cell Signaling Technology, } \\
\text { Danvers, USA }\end{array}$ \\
\hline $\begin{array}{l}\text { mAb rabbit anti-pAKT (Ser473) } \\
(193 \mathrm{H} 12)\end{array}$ & $1: 1000$ & $\begin{array}{l}\text { Cell Signaling Technology, } \\
\text { Danvers, USA }\end{array}$ \\
\hline pAb rabbit anti-Caspase 3 & $\begin{array}{l}\text { 1:500 (Caspase } 3 \text { pro form) and } \\
1: 250 \text { (Caspase } 3 \text { cleaved) }\end{array}$ & $\begin{array}{l}\text { Cell Signaling Technology, } \\
\text { Danvers, USA }\end{array}$ \\
\hline pAb rabbit anti-ERK & $1: 1000$ & Merck KGaA, Darmstadt \\
\hline $\begin{array}{l}\text { pAb rabbit anti-pERK } \\
\text { (Thr202/Tyr204) }\end{array}$ & 1:1000 & $\begin{array}{l}\text { Cell Signaling Technology, } \\
\text { Danvers, USA }\end{array}$ \\
\hline pAb rabbit anti-pS6 (Ser240/244) & $1: 2000$ & $\begin{array}{l}\text { Cell Signaling Technology, } \\
\text { Danvers, USA }\end{array}$ \\
\hline pAb rabbit anti-SMO & $1: 1000$ & Abcam, Cambridge, UK \\
\hline
\end{tabular}




\begin{tabular}{|l|l|l|}
\hline \multicolumn{3}{|l|}{ Secondary antibodies } \\
\hline Antibody & Dilution & Supplier \\
\hline pAb goat anti-rabbit IgG & $1: 5000$ & Dianova, Hamburg \\
\hline pAb rabbit anti-mouse $\lg G$ & $1: 5000$ & Dianova, Hamburg \\
\hline
\end{tabular}

mAb/pAb: monoclonal/polyclonal antibody, HSC70: heat-shock protein 70, IgG: immunoglobulin G

\subsection{Software}

\section{Table 15: Utilized software}

\begin{tabular}{|l|l|}
\hline Software & Developer \\
\hline Adobe Photoshop CS5 & Adobe Systems Inc., San José, USA \\
\hline AlphaView Q SA 3.2.2 & Cell Bioscience, California, USA \\
\hline CellSens Dimension & Olympus GmbH, Hamburg \\
\hline CompuSyn & ComboSyn, Inc., Paramus, USA \\
\hline Flowing Software 2 & $\begin{array}{l}\text { Perttu Terho, Cell Imaging Core, Turku Centre } \\
\text { for Biotechnology, Finland }\end{array}$ \\
\hline FlowJo & Tree Star Inc, Oregon, USA \\
\hline Gen5 & BioTek Instriuments Inc., Bad Friedrichshall \\
\hline GraphPad Prism 6 & GraphPad Software Inc, La Jolla, USA \\
\hline Microsoft Office & Microsoft Co., Redmont, USA \\
\hline Quantum FX $\mu$ CT (SimpleViewer) & PerkinElmer Health Sciences, Hopkinton, USA \\
\hline Scry v6.0 & Kuchel \& Sautter UG, Bad Teinach-Zavelstein \\
\hline SDS 2.2 & Applied Biosystems, Darmstadt \\
\hline
\end{tabular}

\subsection{Databases}

\section{Table 16: Utilized databases}

\begin{tabular}{|l|l|}
\hline Database & Source \\
\hline Basic Local Alignment Search Tool (BLAST) & https://blast.ncbi.nlm.nih.gov/Blast.cgi \\
\hline $\begin{array}{l}\text { Catalogue Of Somatic Mutations In Cancer } \\
\text { (COSMIC) }\end{array}$ & https://cancer.sanger.ac.uk/cell_lines \\
\hline ClinicalTrials.gov & https://clinicaltrials.gov \\
\hline Ensembl genome browser & http://www.ensembl.org/index.html \\
\hline Genomics of Drug Sensitivity in Cancer Project & https://www.cancerrxgene.org/ \\
\hline Mouse Genome Informatics (MGl) & http://www.informatics.jax.org/ \\
\hline $\begin{array}{l}\text { National Center for Biotechnology Information } \\
\text { (NCBI) }\end{array}$ & http://www.ncbi.nlm.nih.gov/ \\
\hline
\end{tabular}




\section{Methods}

\subsection{Cell biology}

\subsubsection{Cultivation of adherent cells}

Table 10 contains a list of the used eukaryotic cell lines and their specific growth conditions. Cells were cultivated in $\varnothing 10 \mathrm{~cm}$ cell culture dishes in an atmosphere of $37^{\circ} \mathrm{C}, 5 \% \mathrm{CO}_{2}$ and $95 \%$ humidity. Cell culture medium was renewed every fourth day and cultures were split when they reached $>90 \%$ confluence. To passage cells, medium was removed, cells were washed with PBS and $2 \mathrm{~mL}$ of TrypLE Express was added. When all cells were detached, they were resuspended in $8 \mathrm{~mL}$ of cell culture medium and split 1:10 - 1:30 into fresh cell culture dishes. For inhibitor treatment, cell numbers were counted as described in section 4.1.5 and cells were seeded at the densities listed in Table 17.

Table 17: Seeding densities for eukaryotic cells

\begin{tabular}{|l|l|l|}
\hline Experimental endpoint & Cultivation format & Seeding density \\
\hline Cell cycle analysis & $\varnothing 6 \mathrm{~cm}$ cell culture dishes & $1 \times 10^{5}$ cells/dish \\
\hline $\begin{array}{l}\text { Proliferation (BrdU assay), } \\
\text { Viability (WST-1 assay) }\end{array}$ & 96-well plates & $\begin{array}{l}4 \times 10^{3} \text { cells/well } \\
1 \times 10^{4} \text { cells/well (RD SMOlow) }\end{array}$ \\
\hline Proliferation (cell counting) & 24-well plates & $\begin{array}{l}5 \times 10^{4} \text { cells/well (RD SMOlow) } \\
1 \times 10^{5} \text { cells/well (RD SMOhigh) }\end{array}$ \\
\hline qRT PCR, Apoptosis & 6-well plates & $1 \times 10^{5}$ cells/well \\
\hline Western Blot analysis & $\varnothing 10 \mathrm{~cm}$ cell culture dishes & $1 \times 10^{6}$ cells/dish \\
\hline
\end{tabular}

\subsubsection{Cryopreservation and thawing of eukaryotic cells}

Cells that were > $90 \%$ confluent were washed with PBS and detached as described in section 4.1.1. The cell suspension was transferred into a $15 \mathrm{~mL}$ reaction tube and centrifuged at $300 \times \mathrm{g}$ and $4^{\circ} \mathrm{C}$ for $5 \mathrm{~min}$. The supernatant was removed and cells were resuspended in $10 \mathrm{~mL}$ cell culture medium containing $5 \%$ DMSO. The cell suspension was distributed in ten CryoPure tubes, which were immediately placed in the freezing device Mr. Frosty $^{\mathrm{TM}}$. After $12 \mathrm{~h}$ aliquots were transferred into liquid nitrogen.

Aliquots with frozen cells were thawed by pipetting $1 \mathrm{~mL}$ of cell culture medium onto the frozen cells and gently resuspending them until they were completely thawed. Subsequently, cells were transferred into a $\varnothing 10 \mathrm{~cm}$ cell culture plate and resuspended in $20 \mathrm{~mL}$ fresh cell culture medium. The cells were allowed to attach for $24 \mathrm{~h}$ and afterwards cell culture medium was renewed. 


\subsubsection{Generation of SHH conditioned medium (SHH-CM)}

Stably transfected HEK293 Shh-N cells and untransfected HEK293 cells (for preparation of control conditioned medium, control-CM) were cultured until they reached $70 \%$ confluence. Then the cell culture medium was replaced by low-serum cell culture medium (DMEM with 2 $\%$ FCS and $1 \% \mathrm{P} / \mathrm{S}$ ). After $24 \mathrm{~h}$ the medium was transferred into a $50 \mathrm{~mL}$ reaction tube and filtered through a $0.2 \mu \mathrm{m}$ pore filter to remove cells and cell debris. $\mathrm{SHH}-\mathrm{CM}$ and control-CM were stored at $4{ }^{\circ} \mathrm{C}$ for up to one month.

\subsubsection{Isolation and cultivation of primary murine RMS cells}

For the cultivation of primary RMS cells, 12-well tissue culture plates were coated with collagen solution. Afterwards plates were allowed to dry under the sterile bench and either stored at $4{ }^{\circ} \mathrm{C}$ for up to one week or used immediately. Directly before use, plates were sterilized by UV exposure for $1 \mathrm{~h}$.

For the isolation of primary cells, RMS-bearing $\mathrm{Ptch}^{+/}$mice were euthanized, tumors were excised and washed in PBS. A small piece was fixed in $4 \%$ PFA for HE staining to confirm RMS histology. The rest of the tumor was chopped into very small pieces with a scalpel, transferred into $2 \mathrm{~mL}$ reaction tubes with pre-warmed DMEM containing $3 \mathrm{mg} / \mathrm{mL}$ collagenase $\mathrm{H}$ and incubated at $37{ }^{\circ} \mathrm{C}$ and $1000 \mathrm{rpm}$ for $50 \mathrm{~min}$ to allow for collagen cleavage. Afterwards the tissue was resuspended and transferred onto a cell strainer, which was placed onto a $50 \mathrm{~mL}$ reaction tube. By gentle rubbing with a pipette tip and washing with PBS, cells were separated through the strainer. Cell suspension was centrifuged at $300 \times \mathrm{g}$ and $4{ }^{\circ} \mathrm{C}$ for $10 \mathrm{~min}$. Supernatant was discarded, cells were resuspended in cell culture medium and transferred into the collagen-coated 12-well plates. Primary cells were cultivated in an atmosphere of $37^{\circ} \mathrm{C}, 5 \% \mathrm{CO}_{2}$ and $95 \%$ humidity. After $24 \mathrm{~h}$ of cultivation, cell cultures were washed several times with PBS to remove all floating cells and cell debris. The remaining adherent cells were incubated with fresh culture medium.

When cells were approximately $80-90 \%$ confluent, but latest 4 days after isolation, the medium was replaced with medium containing the respective drugs.

\subsubsection{Counting of living eukaryotic cells}

To count the number of living cells, adherent cell cultures were detached with TrypLE Express as explained in section 4.1.1. $10 \mu \mathrm{L}$ of cell suspension was mixed with $1 \mu \mathrm{L}$ of trypan blue solution, which only stains dead cells, and the number of living cells was counted in a Neubauer counting chamber. 


\subsubsection{Proliferation assay}

To assess the number of proliferating cells, DNA incorporation of the thymidine analog 5bromo-2'-deoxyuridine (BrdU) was measured using the Cell Proliferation ELISA. The procedure was performed according to the manufacturer's instructions. In brief, cells were seeded in a 96-well plate as described in section 4.1.1 and incubated with drugs for 24 - 48 h. For the last $24 \mathrm{~h}$, cells were co-incubated with drugs and $10 \mu \mathrm{M} B \mathrm{BdU}$. At the end of treatment, medium was removed and cells were fixed with Fix-Denat solution for $30 \mathrm{~min}$. Peroxidase-conjugated BrdU antibody was diluted 1:100 in antibody dilution solution, distributed onto the 96-well plate and the plate was incubated for $1 \mathrm{~h}$. Antibody solution was discarded and wells were washed three times for $5 \mathrm{~min}$ with washing buffer. In the meanwhile, peroxidase substrate was prepared. After the last washing step, substrate solution was added and the luminescence of all wells was measured in the SynergyMx microplate photometer with Gen5 software.

All experiments were performed in triplicates for human ERMS cell lines and in quadruplicates for primary RMS cells. Cells lacking either BrdU, BrdU antibody or peroxidase substrate were included as negative assay controls.

\subsubsection{Cell viability assay}

To assess cell viability, WST-1 was used, which is cleaved by viable cells into a formazan dye. Cells were seeded in a 96-well plate as described in section 4.1.1 and incubated with drugs for $24 \mathrm{~h} .4 \mathrm{~h}$ before the end of treatment $10 \mu \mathrm{L} /$ well WST-1 was added. At the end of treatment, the absorbance at a wavelength of $450 \mathrm{~nm}$ was measured in the SynergyMx microplate photometer with Gen5 software.

\subsubsection{Apoptosis assay}

The amount of apoptotic cells was quantified by Annexin $\mathrm{V}$ staining and flow cytometry. During apoptosis phosphatidylserine is translocated from the cytosolic side of the cell membrane to the cell surface. Annexin $\mathrm{V}$ can bind phosphatidylserine and mark apoptotic cells. The conjugation with a fluorescent dye like fluorescein isothiocyanate (FITC) allows for flow cytometric analysis. Thus, Annexin $V+$ cells are supposed to be apoptotic cells.

For apoptosis assay, cells were seeded in 6-well plates as described in section 4.1.1 and incubated with respective drugs for $48 \mathrm{~h}$. Afterwards, cells were washed with ice cold PBS and detached for $3 \mathrm{~min}$ with $1 \mathrm{~mL} /$ well accutase. To stop the reaction, $1 \mathrm{~mL} /$ well ice cold PBS was added and the cell suspension was transferred into a $15 \mathrm{~mL}$ reaction tube, which was pre-cooled on ice. The cell suspension was centrifuged at $300 \mathrm{xg}$ and $4{ }^{\circ} \mathrm{C}$ for $5 \mathrm{~min}$ and the supernatant was discarded. Cells were washed once with ice cold PBS following a second 
centrifugation and discarding of the supernatant. Cells were stained with FITC-Annexin V from the FITC Annexin V Apoptosis Detection Kit I according to the manufacturer's instructions. In brief, binding buffer (10X) was diluted with ultrapure $\mathrm{H}_{2} \mathrm{O}$ and mixed 1:50 with FITC-Annexin V solution. Cells were resuspended in $100 \mu \mathrm{L}$ of this staining solution, transferred to a $1.5 \mathrm{~mL}$ reaction tube and incubated for $10 \mathrm{~min}$ at room temperature in the dark. Another $200 \mu \mathrm{L}$ of $1 \mathrm{X}$ binding buffer were added to dilute the staining solution and flow cytometry was performed on a FACSCalibur ${ }^{\mathrm{TM}}$ device. The fluorescence of FITC-Annexin V was measured in channel FL-1 (FITC has an emission maximum at a wavelength of 519 $\mathrm{nm})$. Data acquisition was performed with FlowJo and GraphPad Prism 6 softwares.

\subsubsection{Cell cycle analysis}

To measure the cell cycle distribution, fixed cells were stained with the intercalating DNA dye $\mathrm{PI}$ and analyzed by flow cytometry. Fig. 3 shows an example of PI cell cycle analysis in RMS cells.

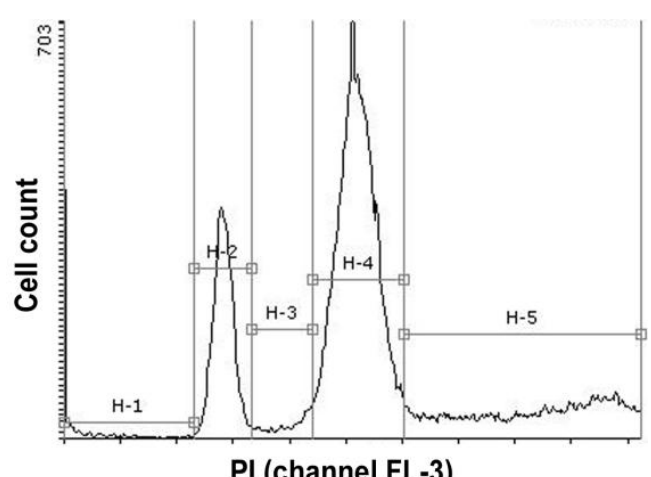

Figure 3: Cell cycle analysis of PI-stained RMS cells. Fixed RMS cells were stained with PI as described in the text. PI signal strength was measured by flow cytometry in the FL-3 channel of a FACSCalibur $^{\top M}$. Data analysis was performed with Flowing Software 2. Gating was performed as depicted. $\mathrm{H}-1, \mathrm{H}-2, \mathrm{H} 3, \mathrm{H}-4$ and $\mathrm{H}-5$ represent cells in the sub-G0, G0/G1, S, G2/M and super-G2/M phase of the cell cycle, respectively.

Cells were seeded in $\varnothing 6 \mathrm{~cm}$ cell culture dishes as described in section 4.1 .1 and incubated with respective drugs for $24 \mathrm{~h}$ (RD cells) or $72 \mathrm{~h}$ ( $\mathrm{RUCH}-2$ cells). At the end of treatment, cell culture medium was removed and cells were washed with PBS. To detach the cells, 2 $\mathrm{mL} /$ plate accutase were added and the plates were incubated at $37^{\circ} \mathrm{C}$ for $2 \mathrm{~min} .3 \mathrm{~mL}$ of cell culture medium were added to stop the accutase reaction. The cell suspension was transferred into a $15 \mathrm{~mL}$ reaction tube and centrifuged at $300 \times \mathrm{g}$ and $4{ }^{\circ} \mathrm{C}$ for $5 \mathrm{~min}$. The supernatant was discarded and cells were resuspended in $1 \mathrm{~mL}$ ice cold PBS. For fixation, $10 \mathrm{~mL} \mathrm{EtOH}$ were pre-cooled at $-80^{\circ} \mathrm{C}$ in a $15 \mathrm{~mL}$ reaction tube. While vortexing the $\mathrm{EtOH}$ containing reaction tube at medium speed, the cell suspension was injected into the alcohol 
and the tube was subsequently put back on dry ice. To fix the cells, they were incubated at $20{ }^{\circ} \mathrm{C}$ for at least $3 \mathrm{~h}$.

The fixed cells were centrifuged at $600 \times \mathrm{g}$ and $4{ }^{\circ} \mathrm{C}$ for $5 \mathrm{~min}$. The supernatant was discarded, cells were resuspended in $2 \mathrm{~mL}$ PBS and centrifuged again at $600 \mathrm{xg}$ and $4{ }^{\circ} \mathrm{C}$ for $5 \mathrm{~min}$. The supernatant was again discarded and cells were resuspended in $450 \mu \mathrm{L} \mathrm{PI}$ staining solution containing $10 \mu \mathrm{g} / \mathrm{mL} \mathrm{PI}$ and $100 \mu \mathrm{g} / \mathrm{mL}$ RNase A in PBS. The cell suspension was incubated at $37^{\circ} \mathrm{C}$ for $30 \mathrm{~min}$ and afterwards $\mathrm{PI}$ staining intensity was measured by flow cytometry on a FACSCalibur ${ }^{\mathrm{TM}}$ (channel FL-3 because PI has an emission maximum at a wavelength of $617 \mathrm{~nm}$ ). A minimum of $3 \times 10^{4}$ cells/sample were counted and data analysis was performed with Flowing Software 2.

\subsubsection{Transfection of RMS cell lines}

The ERMS cell line RD was transfected with the Neon Transfection System according to the manufacturer's instructions. In brief, RMS cells were washed with PBS and detached. After centrifugation at $300 \times \mathrm{g}$ and $4^{\circ} \mathrm{C}$ for $5 \mathrm{~min}$ the cells were resuspended in Resuspension Buffer $\mathrm{R}$ to a density of $4 \times 10^{6}$ cells $/ \mathrm{mL}$. For transfection, $4 \times 10^{5}$ cells were mixed with $6 \mu \mathrm{g}$ plasmid DNA (pDNA) in a final volume of $100 \mu \mathrm{L}$. The respective amounts of the used plasmids are listed in Table 13. To track transfection efficiency, control cells were transfected with an enhanced green fluorescent protein (EGFP) expression plasmid. Electroporation of the cells was performed with $1000 \mathrm{~V}$ in 2 pulses each lasting for $30 \mathrm{msec}$. Afterwards the cells were seeded in 6-well plates containing DMEM with $10 \%$ FCS. After $24 \mathrm{~h}$ of cultivation, cells were checked under a microscope for viability and EGFP expression. Protein or RNA isolation was performed $48 \mathrm{~h}$ after transfection.

\subsubsection{Transfection of RD cells with a Gli reporter system}

The transcriptional activity of Gli proteins in RMS cells was measured with a luciferase-based Gli reporter system. For this purpose cells were transfected with $2 \mu \mathrm{g}$ of the firefly luciferase reporter plasmid pGL-9xGli BS containing nine Gli protein binding sites. For normalization cells were co-transfected with $0.12 \mu \mathrm{g}$ of the Renilla luciferase reporter plasmid $\mathrm{pRL}-\mathrm{CMV}$. As positive assay control, cells were additionally co-transfected with $2 \mu \mathrm{g}$ of the Gli1 overexpression plasmid pCR3.1 mGli1. In all other settings pDNA amount was filled up to $4.12 \mu \mathrm{g}$ with $2 \mu \mathrm{g}$ of the respective empty pCR3.1 plasmid. As negative control cells were transfected with $4 \mu \mathrm{g} \mathrm{pCR3.1} \mathrm{and} 0.12 \mu \mathrm{g}$ pRL-CMV. The respective plasmids are listed in Table 13.

Transfection was performed as described in section 4.1.10 and cells were seeded in 6-well plates. After $48 \mathrm{~h}$ cells were detached and reseeded in a transparent 96-well plate at a 
density of $5 \times 10^{3}$ cells/well. Incubation with respective drugs was performed for $48 \mathrm{~h}$ and afterwards the dual-luciferase assay was performed as described below in section 4.1.12.

\subsubsection{Dual-luciferase assay}

The Dual-Luciferase ${ }^{\circledR}$ reporter assay system was used according to the manufacturer's instructions. In brief, transfected cells were washed. For cell lysis $20 \mu \mathrm{L} /$ well passive lysis buffer were added. Cell lysis was performed at room temperature while shaking at $250 \mathrm{rpm}$ for $15 \mathrm{~min}$. The plates were frozen at $-80^{\circ} \mathrm{C}$ for a minimum of $15 \mathrm{~min}$. LAR II and Stop'n'Glo solutions were prepared following the manufacturer's instructions and pre-warmed to room temperature before use. The firefly and Renilla luciferase activity was measured in a SynergyMx microplate photometer by serial injection of the two substrates and subsequent luminescence measurement with Gen5 software. The firefly luciferase activity was normalized to Renilla luciferase activity using GraphPad Prism 6 software.

\subsubsection{E.coli transformation}

To avoid contamination with undesired microorganisms, the glassware required for bacterial transformation was autoclaved in advance and all open bottles with the required solutions were sterilized with a gas flame.

The chemical competent DH5a E. coli strain was used for transformation and amplification of pDNA. The bacteria (stored in $50 \mu \mathrm{L}$ aliquots at $-80^{\circ} \mathrm{C}$ ) were thawed on ice and $100 \mathrm{ng}$ of pDNA was added. After incubation on ice for $20 \mathrm{~min}$, a heat shock at $42{ }^{\circ} \mathrm{C}$ for $30 \mathrm{sec}$ was performed. The transformation mix was again cooled down on ice for 1 min and mixed with $450 \mu \mathrm{L}$ S.O.C. medium. Bacteria were incubated at $37^{\circ} \mathrm{C}$ while shaking at $400 \mathrm{rpm}$ for 50 $\min .150 \mu \mathrm{L}$ of the mixture were plated on LB agar with ampicillin $(100 \mu \mathrm{g} / \mathrm{mL})$ or kanamycin $(50 \mu \mathrm{g} / \mathrm{mL})$ to select for transformed bacteria. The plate was incubated at $37^{\circ} \mathrm{C}$ overnight in upside down position. The next day, single colonies were picked for plasmid amplification.

\subsection{Protein chemistry}

\subsubsection{Protein isolation from cultured cells}

All steps were performed on ice and all required buffers were pre-cooled to $4^{\circ} \mathrm{C}$.

Cell culture medium was removed and cells were washed with PBS. Cells were covered with $2 \mathrm{~mL}$ PBS and scratched off with a cell scraper. Remaining cells were gently washed off with PBS and transferred to a $50 \mathrm{~mL}$ reaction tube. Cells were centrifuged at $1800 \mathrm{rpm}$ and $4{ }^{\circ} \mathrm{C}$ for $5 \mathrm{~min}$. Supernatant was discarded, cells were resuspended in $800 \mu \mathrm{L}$ PBS and transferred into a $1.5 \mathrm{~mL}$ reaction tube. Cells were again centrifuged at $1800 \mathrm{rpm}$ and $4{ }^{\circ} \mathrm{C}$ 
for $5 \mathrm{~min}$. The supernatant was discarded and the cells were shock-frozen in liquid nitrogen for mechanical cell lysis. Afterwards samples were thawed on ice for $20 \mathrm{~min}$ and suspended in $60-100 \mu \mathrm{L}$ lysis buffer. Samples were incubated on ice for $30 \mathrm{~min}$. Lysates were centrifuged at $13000 \mathrm{rpm}$ and $4^{\circ} \mathrm{C}$ for $30 \mathrm{~min}$ and the supernatant, which now contained all soluble cell proteins, was transferred into a fresh $1.5 \mathrm{~mL}$ reaction tube. Lysates were stored at $-80^{\circ} \mathrm{C}$.

\subsubsection{Protein isolation from RMS tissue}

For protein isolation, a piece of approximately $30 \mathrm{mg}$ RMS tissue was cut into small pieces while keeping it on ice. The tissue was transferred into a $2 \mathrm{~mL}$ reaction tube with $300 \mu \mathrm{L}$ lysis buffer. Tissue was homogenized at $20000 \mathrm{rpm}$ for 1 min while keeping the tube constantly on ice. Afterwards, samples were shock-frozen in liquid nitrogen for mechanical cell lysis. Lysates were thawed on ice for $20 \mathrm{~min}$ and centrifuged at $10000 \mathrm{rpm}$ and $4^{\circ} \mathrm{C}$ for $10 \mathrm{~min}$. The supernatant containing proteins was transferred into a $1.5 \mathrm{~mL}$ reaction tube and stored at $-80^{\circ} \mathrm{C}$.

To prevent sample contamination, the homogenizer was washed with $70 \% \mathrm{EtOH}$ and ultrapure $\mathrm{H}_{2} \mathrm{O}$. Afterwards it was dried in a $55{ }^{\circ} \mathrm{C}$ oven before the next sample was homogenized.

\subsubsection{Bicinchoninic acid (BCA) assay}

The BCA assay for protein quantification is based on two reactions. In alkaline solutions, peptide bonds reduce cupric ions $\left(\mathrm{Cu}^{2+}\right)$ resulting in the formation of $\mathrm{Cu}^{+}$ions. These in turn form a colored, water-soluble complex with BCA, which has an absorption maximum at a wavelength of $562 \mathrm{~nm}$. Absorbance shows linear correlation with the protein concentration 222 .

The Pierce BCA Protein Assay Kit was used to measure protein concentrations according to the manufacturer's instructions. In brief, triplicates of $1 \mu \mathrm{L} /$ well protein solution were transferred into a transparent 96-well assay plate and mixed with $200 \mu \mathrm{L} /$ well of substrate solution. A BSA dilution series was used as standard. The plate was incubated at $37^{\circ} \mathrm{C}$ for 15 - $30 \mathrm{~min}$. Subsequently, the absorbance at $540 \mathrm{~nm}$ was measured in a SynergyMx microplate photometer. Based on linear regression of the absorbance measured in the BSA dilution series, the concentration of protein samples was calculated with Gen5 software.

\subsubsection{Western Blot}

Protein lysates containing $20-35 \mu \mathrm{g}$ of protein were mixed with $2.5 \mu \mathrm{L}$ of SDS loading buffer (6X) and ultrapure $\mathrm{H}_{2} \mathrm{O}$ to a total volume of $15 \mu \mathrm{L}$. Proteins were denatured at $96{ }^{\circ} \mathrm{C}$ for 5 
min while shaking at $450 \mathrm{rpm}$. Then the tubes were centrifuged at low speed to collect all liquids and protein samples were loaded onto a NuPAGE ${ }^{\mathrm{TM}} 4-12 \%$ Bis-Tris Protein Gel. The protein ladder SeeBlue ${ }^{\circledR}$ Plus2 Pre-Stained was used to determine protein sizes. Electrophoresis was performed at $160 \mathrm{~mA}, 100 \mathrm{~V}$ and $100 \mathrm{~W}$ for $20 \mathrm{~min}$ in NuPAGE $^{\text {TM }}$ MES SDS running buffer. Afterwards voltage was raised to $160 \mathrm{~V}$ and electrophoresis ran for another $1.5 \mathrm{~h}$ until the protein ladder was separated. To avoid heat, the electrophoresis chamber was put on ice during the run.

After proteins were separated, they were blotted to a NC or PVDF membrane by the Semidry blotting method. Blotting was performed in a Trans-Blot@ SD Semi-Dry Transfer Cell at $120 \mathrm{~mA}, 20 \mathrm{~V}$ and $100 \mathrm{~W}$ for $1 \mathrm{~h} 20 \mathrm{~min}^{223-225}$.

Afterwards, the membrane was blocked with $5 \%(\mathrm{w} / \mathrm{v})$ milk in PBST buffer for $1 \mathrm{~h}$ and washed three times for 10 min with PBST buffer while shaking at room temperature. Primary antibodies were diluted in BSA-azide as described in Table 14. $3 \mathrm{~mL}$ of primary antibody dilution were transferred into a $50 \mathrm{~mL}$ reaction tube together with the membrane with proteins facing the interior. Incubation was done on a roller shaker at $4{ }^{\circ} \mathrm{C}$ overnight. Then the membrane was washed three times in PBST buffer for 10 min while shaking. Horse radish peroxidase (HRP)-conjugated secondary antibodies were prepared in $5 \%(\mathrm{w} / \mathrm{v})$ milk in PBST buffer as described in Table 14 and the membrane was incubated in the solution for $1 \mathrm{~h}$ at room temperature while gently shaking. Remaining antibodies were removed by washing the membrane in PBST buffer three times for $10 \mathrm{~min}$. The Pierce ECL Plus Western Blot substrate was prepared by mixing solution $A$ with solution $B$ in a ratio of $1: 1$. Membrane was put on a straight surface and the substrate was distributed on the membrane. After an incubation for $90 \mathrm{sec}$, the remaining substrate was removed and HRP signals were detected using a FluorChem $Q$ system. Picture acquisition and processing was done with AlphaView Q SA and Adobe Photoshop CS5 softwares.

If necessary, bound proteins were stripped off the membrane by incubation in stripping buffer at $55^{\circ} \mathrm{C}$ for $30 \mathrm{~min}$ while slowly rotating. Afterwards the membrane was washed thoroughly three times for 10 min with PBST buffer and blocked with $5 \%(w / v)$ milk in PBST buffer for 1 $\mathrm{h}$ while gently shaking at room temperature.

\subsection{Molecular biology}

\subsubsection{Genomic DNA (gDNA) isolation from mouse tail biopsies}

For PCR-based genotyping, gDNA was isolated from mouse tail biopsies. To digest the tissues, tail biopsies were incubated in $500 \mu \mathrm{L}$ STE buffer with $0.5 \mathrm{mg} / \mathrm{mL}$ Proteinase $\mathrm{K}$ 
overnight at $55^{\circ} \mathrm{C}$. Samples were centrifuged at $13000 \mathrm{rpm}$ for $10 \mathrm{~min}$ to remove tissue debris. The supernatant was transferred into a new reaction tube. $1 \mathrm{~mL}$ of $99 \%$ ice cold $\mathrm{EtOH}$ was added and mixture was shaken thoroughly to precipitate gDNA. After centrifugation at $13000 \mathrm{rpm}$ for $25 \mathrm{~min}$ the supernatant was discarded, gDNA was washed with $500 \mu \mathrm{L}$ of $70 \% \mathrm{EtOH}$ and centrifuged again at 13000 for $10 \mathrm{~min}$. The supernatant was discarded and gDNA was dried at $55{ }^{\circ} \mathrm{C}$ for $10 \mathrm{~min}$. Afterwards $125 \mu \mathrm{L}$ RNase/DNase-free $\mathrm{H}_{2} \mathrm{O}$ were added and gDNA was dissolved while shaking at $1400 \mathrm{rpm}$ and $42{ }^{\circ} \mathrm{C}$ for $10 \mathrm{~min}$. Solutions were stored at $-20^{\circ} \mathrm{C}$.

\subsubsection{Total RNA isolation from cell culture}

For total RNA isolation from cultured cells, the TRIzol ${ }^{\mathrm{TM}}$ reagent was used according to the manufacturer's instructions. This process is based on phenol-chloroform extraction ${ }^{226}$. To prevent RNA degradation, the whole isolation process was performed on ice if not stated otherwise.

Cells were washed once with ice cold PBS and subsequently $1 \mathrm{~mL} /$ well (6-well plates) or 0.5 $\mathrm{mL} /$ well (12-well-plates, 2 wells were pooled afterwards) of cold TRIzol ${ }^{\mathrm{TM}}$ reagent were added. Cells were resuspended thoroughly and transferred into a sterile $2 \mathrm{~mL}$ reaction tube. The cell suspension was vortexed at maximum speed for 2 min and incubated another 5 min at room temperature. Per $1 \mathrm{~mL}$ TRIzol ${ }^{\mathrm{TM}}$ reagent $200 \mu \mathrm{L}$ chloroform were added and the mix was again vortexed at maximum speed for $15 \mathrm{sec}$. Afterwards, phases were allowed to separate for $3 \mathrm{~min}$ at room temperature and by centrifugation at $4{ }^{\circ} \mathrm{C}$ and $12000 \mathrm{rpm}$ for 10 min. The lighter aqueous phase that contained the RNA was transferred into a new $1.5 \mathrm{~mL}$ reaction tube with $700 \mu \mathrm{L}$ of ice cold isopropanol and the mix was inverted several times. The remaining lower organic phase and the interphase, containing proteins and DNA, were discarded. For full RNA precipitation, samples were incubated at $-20{ }^{\circ} \mathrm{C}$ overnight or at -80 ${ }^{\circ} \mathrm{C}$ for $15 \mathrm{~min}$. Afterwards they were centrifuged at $12000 \mathrm{rpm}$ and $4{ }^{\circ} \mathrm{C}$ for $30 \mathrm{~min}$. Supernatant was discarded and RNA was washed twice with $500 \mathrm{~mL}$ of ice cold $70 \% \mathrm{EtOH}$ by centrifugation at $12000 \mathrm{rpm}$ and $4{ }^{\circ} \mathrm{C}$ for $10 \mathrm{~min}$. After the second washing step, the alcohol was discarded and the RNA was allowed to air dry. Afterwards the RNA was dissolved in $10-20 \mu \mathrm{L}$ of RNase/DNase-free $\mathrm{H}_{2} \mathrm{O}$ while shaking at $900 \mathrm{rpm}$ and $56{ }^{\circ} \mathrm{C}$ for 5 $10 \mathrm{~min}$. The exact volume was adjusted to the size of the visible RNA pellet. RNA samples were stored at $-80^{\circ} \mathrm{C}$.

\subsubsection{Total RNA isolation from RMS tissue}

A piece of approximately $20 \mathrm{mg}$ frozen RMS tissue was transferred into $1 \mathrm{~mL}$ of ice cold $\mathrm{TRIzol}^{\mathrm{TM}}$ reagent. Tissue was homogenized for $2 \mathrm{~min}$ at $20000 \mathrm{rpm}$ on ice until all visible 
tissue chunks were chopped. To avoid sample contamination, the homogenizer was carefully cleaned with forceps, washed in RNase/DNase-free $\mathrm{H}_{2} \mathrm{O}$ and dried before isolating RNA from the next sample. The homogenates were incubated at room temperature for $5 \mathrm{~min}$ and 200 $\mu \mathrm{L}$ of chloroform were added. All following steps were performed according to the description in section 4.2.2. RNA from RMS tissue was dissolved in $25 \mu \mathrm{L}$ of RNase/DNase-free $\mathrm{H}_{2} \mathrm{O}$ and stored at $-80^{\circ} \mathrm{C}$.

\subsubsection{Photometric quantification of nucleic acids}

For quantification of nucleic acids, the NanoDrop 8000 spectrophotometer was used. The sample absorbance at a wavelength of $260 \mathrm{~nm}\left(\mathrm{~A}_{260}\right)$ was measured and the following equation, which is based on the Beer-Lambert's law, was used for quantification.

$c=\frac{A \times \varepsilon}{b}=A \times f$

c: nucleic acid concentration in $\mathrm{ng} / \mu \mathrm{L}$,

A: absorbance in arbitrary units

$\varepsilon$ : wavelength-dependent extinction coefficient in $\mathrm{ng} \times \mathrm{cm} / \mu \mathrm{L}$

b: pathlength in $\mathrm{cm}$

f: factor for $\varepsilon$ and $b$ combined, $50 \mathrm{ng} / \mu \mathrm{L}$ for double-stranded DNA and $40 \mathrm{ng} / \mu \mathrm{L}$ for RNA

To detect sample contamination with proteins, $A_{280}$ was measured and the ratio $A_{260} / A_{280}$ was calculated. In general, ratios of 1.8 for DNA samples and 2.0 for RNA samples are considered as pure.

\subsubsection{Genotyping polymerase chain reaction (PCR)}

PCR for genotyping was performed in a total volume of $10 \mu \mathrm{L} .1 \mu \mathrm{L}$ of gDNA (corresponds to approximately $100 \mathrm{ng}$ ) was mixed with $1 \mu \mathrm{L}$ PCR buffer (10X, provided with MolTaq), $0.5 \mu \mathrm{L}$ forward primer $(10 \mu \mathrm{M}), 0.5 \mu \mathrm{L}$ reverse primer $(10 \mu \mathrm{M}), 0.2 \mu \mathrm{L}$ dNTPs (10 mM each), $1 \mu \mathrm{L}$ cresol, $5.7 \mu \mathrm{L} \mathrm{ddH_{2 }} \mathrm{O}$ and $0.1 \mu \mathrm{L}$ MolTaq.

PCR for the mutant Ptch alleles was performed in the following steps:

$\left.\begin{array}{ll}95^{\circ} \mathrm{C} & 5 \min \\ 95^{\circ} \mathrm{C} & 1 \min \\ 62{ }^{\circ} \mathrm{C} & 1 \mathrm{~min} \\ 72{ }^{\circ} \mathrm{C} & 3 \mathrm{~min} \\ 72{ }^{\circ} \mathrm{C} & 5 \mathrm{~min}\end{array}\right\} 35$ cycles


PCR for the wildtype Ptch alleles was performed in the following steps:

$\left.\begin{array}{ll}95^{\circ} \mathrm{C} & 5 \mathrm{~min} \\ 95^{\circ} \mathrm{C} & 20 \mathrm{sec} \\ 60^{\circ} \mathrm{C} & 20 \mathrm{sec} \\ 72^{\circ} \mathrm{C} & 45 \mathrm{sec} \\ 72^{\circ} \mathrm{C} & 5 \mathrm{~min}\end{array}\right\} 35$ cycles

PCR products were analyzed by agarose gel electrophoresis and afterwards stored at $4{ }^{\circ} \mathrm{C}$ (short-term) or $-20^{\circ} \mathrm{C}$ (long-term). When the PCR efficiency was low, the amount of $\mathrm{MgCl}_{2}$ in the reaction was increased (100 $\mathrm{mM} \mathrm{MgCl}_{2}$ solution was provided with MolTaq).

\subsubsection{Agarose gel electrophoresis}

Agarose gel electrophoresis was used for separation and visualization of DNA fragments, e.g. products of genotyping PCR. $1 \%(w / v)$ agarose was dissolved in TBE buffer by boiling for approximately $5 \mathrm{~min}$ in a microwave oven at $1000 \mathrm{~W}$. While stirring at room temperature for $10-15 \mathrm{~min}$, the solution was allowed to cool down to about $50{ }^{\circ} \mathrm{C}$ and 5 drops of ethidium bromide $(0.07 \%)$ were added per $100 \mathrm{~mL}$ gel volume. The agarose solution was poured into an electrophoresis gel tray and the comb was put in place. The gel was allowed to solidify at room temperature for approximately $30-45 \mathrm{~min}$. Afterwards it was transferred into the electrophoresis chamber filled with TBE buffer. DNA samples and a size ladder were loaded onto the gel and electrophoresis was run at $100 \mathrm{~V}$. DNA was visualized in an UV transilluminator.

\subsubsection{Quantitative Real-Time PCR (qRT PCR)}

\subsubsection{Reverse transcription}

The first step of qRT PCR is to reverse transcribe the mRNA in total RNA samples into cDNA. Reverse transcription was performed in a total volume of $20 \mu \mathrm{L}$ with the SuperScript ${ }^{\mathrm{TM}}$ II reverse transcriptase. $2 \mu \mathrm{g}$ of total RNA were diluted in $7 \mu \mathrm{L}$ of RNase/DNase-free $\mathrm{H}_{2} \mathrm{O}$, mixed with $5 \mu \mathrm{L}$ of $50 \mathrm{ng} / \mu \mathrm{L}$ random hexamer oligonucleotides and incubated at $70{ }^{\circ} \mathrm{C}$ for 10 min. Next, $2 \mu \mathrm{L}$ of $0.1 \mathrm{M}$ DTT and $1 \mu \mathrm{L}$ of dNTPs (10 mM each) were mixed with $4 \mu \mathrm{L}$ of $1^{\text {st }}$ strand buffer $(5 X)$. The mixture was added to the RNA sample and incubated at room temperature for $10 \mathrm{~min}$. After preheating at $42^{\circ} \mathrm{C}$ for $2 \mathrm{~min}, 100 \mathrm{U}$ of SuperScript ${ }^{\mathrm{TM}}$ II reverse transcriptase were added and reverse transcription was performed at $42{ }^{\circ} \mathrm{C}$ for $1 \mathrm{~h}$. To stop the reaction, the mixture was incubated at $70{ }^{\circ} \mathrm{C}$ for $10 \mathrm{~min}$. The yield of cDNA was estimated to be $50 \mathrm{ng} / \mathrm{LL}$ (a $50 \%$ reaction efficiency was assumed) and samples were stored at $-20^{\circ} \mathrm{C}$ 


\subsubsection{2 qRT PCR}

Gene expression levels were quantified with SYBR green-based qRT PCR. The primer pairs used for qRT PCR are listed in Table 12. For qRT PCR using samples from human cell culture experiments the Platinum SYBR Green qPCR Super Mix was employed and for samples of murine origin the QuantiTect SYBR Green PCR kit was used.

For qRT PCR with the Platinum SYBR Green qPCR Super Mix, $2 \mu \mathrm{L}$ of diluted template cDNA were mixed with $0.4 \mu \mathrm{L}$ forward primer $(10 \mu \mathrm{M}), 0.4 \mu \mathrm{L}$ reverse primer $(10 \mu \mathrm{M}), 4 \mu \mathrm{L}$ SYBR green mix $(5 X)$ and $3.2 \mu \mathrm{L}$ RNase-/DNase-free $\mathrm{H}_{2} \mathrm{O}$. PCR was performed in the following steps:

$\left.\begin{array}{ll}95^{\circ} \mathrm{C} & 2 \mathrm{~min} \\ 95^{\circ} \mathrm{C} & 15 \mathrm{sec} \\ 60^{\circ} \mathrm{C} & 1 \mathrm{~min}\end{array}\right\} 40$ cycles

For qRT PCR with the QuantiTect SYBR Green PCR kit, $2 \mu \mathrm{L}$ of diluted template cDNA were mixed with $0.4 \mu \mathrm{L}$ forward primer $(10 \mu \mathrm{M}), 0.4 \mu \mathrm{L}$ reverse primer $(10 \mu \mathrm{M}), 5 \mu \mathrm{L}$ SYBR green mix (4X) and 2.2 $\mu \mathrm{L}$ RNase-/DNase-free $\mathrm{H}_{2} \mathrm{O}$. PCR was performed in the following steps:

$\left.\begin{array}{ll}50{ }^{\circ} \mathrm{C} & 2 \mathrm{~min} \\ 95^{\circ} \mathrm{C} & 15 \mathrm{~min} \\ 95^{\circ} \mathrm{C} & 15 \mathrm{sec} \\ 60^{\circ} \mathrm{C} & 30 \mathrm{sec} \\ 72{ }^{\circ} \mathrm{C} & 30 \mathrm{sec}\end{array}\right\} 40$ cycles

When either qRT PCR was finished, a melting curve analysis was recorded to assess whether single, specific products had been produced.

For quantification of the gene expression level of a specific gene the standard curve method was applied. For this purpose a 5-fold dilution series starting with $10 \mathrm{ng} / \mu \mathrm{L}$ cDNA (gene of interest) or with $25 \mathrm{pg} / \mu \mathrm{L}$ cDNA (18S $r R N A$ ) was generated. For each gene one standard curve with cDNA from a source that is known to express the gene of interest was generated. The Ct values were plotted against the cDNA concentration and by nonlinear regression a standard curve was generated. With the help of the regression analysis the concentration of gene-specific cDNA in the samples of interest was calculated. These values were normalized to the corresponding values of the housekeeper gene ( $18 \mathrm{~S} r R N A, H P R T$ or Tbp). The results were normalized to control samples, e.g. solvent treated cells. Measurements were performed in triplicates on an ABI Prism $7900 \mathrm{HT}$ device with the help of SDS software 
(version 2.2.1). Standard curve generation with the semilog line equation as well as normalization was done with GraphPad Prism 6 software.

\subsubsection{Plasmid DNA amplification, isolation and purification}

Single colonies of transformed DH5a E. coli (transformation is described in section 4.1.13) were transferred into $100 \mathrm{~mL}$ of LB medium containing ampicillin $(100 \mu \mathrm{g} / \mathrm{mL})$ or kanamycin $(50 \mu \mathrm{g} / \mathrm{mL})$ and grown overnight at $37^{\circ} \mathrm{C}$ while shaking at $155 \mathrm{rpm}$.

Isolation of pDNA was performed with the PureLink® HiPure Plasmid Midiprep kit, which is based on anion-exchange chromatography in columns. Cells are lysed and lysates are loaded onto the column. Positively charged residues within the column material interact with the negative charges of DNA's phosphate groups. Unbound cell debris, proteins and RNA can be washed away with Wash buffer. Afterwards, salt concentrations within the column are raised with Elution buffer, DNA binding to the column material is released and the DNA is eluted.

The isolation process was performed according to the manufacturer's instruction. In brief, the bacteria suspension was transferred into $50 \mathrm{~mL}$ reaction tubes and centrifuged at $10000 \mathrm{rpm}$ and $4{ }^{\circ} \mathrm{C}$ for $10 \mathrm{~min}$. Supernatant was discarded and the cells were resuspended in $4 \mathrm{~mL}$ Resuspension Buffer. For lysis of the bacteria, $4 \mathrm{~mL}$ of Lysis Buffer were added, the mixture was inverted gently, incubated at room temperature for $5 \mathrm{~min}$ and $4 \mathrm{~mL}$ of Precipitation buffer were added. Afterwards, the mixture was centrifuged at $10000 \mathrm{rpm}$ and $4{ }^{\circ} \mathrm{C}$ for $10 \mathrm{~min}$. In the meanwhile, columns were equilibrated with $10 \mathrm{~mL}$ Equilibration buffer. When centrifugation was finished, the supernatant was transferred onto the columns and allowed to drain by gravity flow. Then the columns were washed twice with $10 \mathrm{~mL}$ of Wash buffer. Afterwards the bound pDNA was eluted with $5 \mathrm{~mL}$ Elution buffer and the flow-through was collected in a $15 \mathrm{~mL}$ reaction tube. The eluate was transferred in $1 \mathrm{~mL}$ aliquots to five $2 \mathrm{~mL}$ reaction tubes. $1 \mathrm{~mL}$ of pure isopropanol was added and the mixture was incubated at $-20^{\circ} \mathrm{C}$ overnight or at $-80{ }^{\circ} \mathrm{C}$ for $20 \mathrm{~min}$. Afterwards the precipitated pDNA was centrifuged at 13000 rpm and $4{ }^{\circ} \mathrm{C}$ for $30 \mathrm{~min}$. Supernatant was discarded and to wash the pDNA $200 \mu \mathrm{L}$ of $70 \%$ $\mathrm{EtOH}$ were added and the mixture was centrifuged at $13000 \mathrm{rpm}$ and $4{ }^{\circ} \mathrm{C}$ for $10 \mathrm{~min}$. Then supernatant was discarded and the pDNA was dried upside down at $55^{\circ} \mathrm{C}$ for $5 \mathrm{~min}$. The pDNA was resuspended in $20 \mu \mathrm{L}$ of RNase/DNase-free $\mathrm{H}_{2} \mathrm{O}$ while shaking at $1400 \mathrm{rpm}$ and $42{ }^{\circ} \mathrm{C}$ for $10 \mathrm{~min}$. All suspensions of one plasmid were pooled and stored at $-20^{\circ} \mathrm{C}$.

\subsubsection{Restriction enzyme hydrolysis}

Test-restriction analysis of the amplified pDNA was performed using two adequate restriction endonucleases. For this purpose $1 \mu \mathrm{g}$ of pDNA was mixed with 3 units of the respective 
restriction enzymes in $1 \mathrm{X}$ hydrolysis buffer in a total volume of $10 \mu \mathrm{L}$. Hydrolysis was performed at $37^{\circ} \mathrm{C}$ for $2 \mathrm{~h}$. Afterwards the reaction was stopped by incubation at $70{ }^{\circ} \mathrm{C}$ for 10 min. The used restriction enzymes and suppliers are listed in Table 6.

To analyze hydrolysis products, $2 \mu \mathrm{L}$ of $6 \mathrm{X}$ DNA Loading dye were added and the pDNA was separated by agarose gel electrophoresis. Depending on the expected product sizes, agarose concentrations were $0.5-2 \%(\mathrm{w} / \mathrm{v})$.

\subsection{Histology and immunohistochemistry}

\subsubsection{Haematoxylin and eosin (HE) staining}

For HE staining, RMS tissue fixed in 4 \% PFA was embedded in paraffin and cut into 4 - 5 $\mu \mathrm{m}$ sections. Sections were mounted onto glass slides and deparaffinized in xylene for 10 min and another $10 \mathrm{~min}$ in fresh xylene. Afterwards the tissue was hydrated in a descending EtOH series (100\%, $96 \%, 70 \% \mathrm{EtOH}$ for 1 min each while shaking). After a thorough washing step with ultrapure $\mathrm{H}_{2} \mathrm{O}$, the slides were incubated in haematoxylin for $15 \mathrm{~min}$ and rinsed with warm tap water until the draining water got clear. The tap water induces formation of haemalaun, which stains all basophile structures (e.g. DNA, ribosomes) blue. In the meanwhile a few drops of acetic acid were added to eosin solution, which helps to intensify the staining of the acid dye eosin. Slides were incubated for $20 \mathrm{sec}$ in eosin solution and shortly rinsed with ultrapure $\mathrm{H}_{2} \mathrm{O}$. Subsequently tissue slides were dehydrated in an ascending $\mathrm{EtOH} / x y l e n e$ series $(70 \%, 96 \%$ and $100 \% \mathrm{EtOH}$, two times xylene). Slides were mounted with pertex and dried at $55^{\circ} \mathrm{C}$ for at least $20 \mathrm{~min}$.

\subsubsection{Ki67 staining}

For Ki67 staining, paraffin embedded RMS tissue was cut into $4-5 \mu \mathrm{m}$ sections and mounted onto superfrost glass slides. Tissue was deparaffinized in xylene for $10 \mathrm{~min}$ and another $10 \mathrm{~min}$ in fresh xylene. Afterwards the tissue was hydrated in a descending $\mathrm{EtOH}$ series (2x $100 \%, 95 \%, 80 \%, 70 \% \mathrm{EtOH}$ for 2 min each). Slides were rinsed with ultrapure $\mathrm{H}_{2} \mathrm{O}$ and antigen-retrieval was performed by cooking the slides in citric acid buffer $(\mathrm{pH} 6)$ once for $4 \mathrm{~min}$ and three times for $3 \mathrm{~min}$ at $600 \mathrm{~W}$ in a microwave oven. Slides were cooled down to room temperature and rinsed two times in TBS buffer for 2 min. Endogenous peroxidases were blocked by incubating the slides for 20 min in $3 \% \mathrm{H}_{2} \mathrm{O}_{2}$ in TBS buffer while shaking. Afterwards slides were washed for $5 \mathrm{~min}$ in ultrapure $\mathrm{H}_{2} \mathrm{O}$ and rinsed in TBS buffer. Slides were placed in a moist chamber, the remaining liquid was removed and the tissue was blocked with $0.2 \%$ casein in TBS buffer for 20 min to prevent unspecific antibody binding. Primary antibody against Ki67 was diluted 1:50 in TBS buffer and distributed onto the tissue 
slides. Incubation was performed overnight at $4{ }^{\circ} \mathrm{C}$. The remaining antibody dilution was removed by washing the slides with TBST buffer for three times. HRP-conjugated secondary antibody and HRP substrate were used from the Dako REAL ${ }^{\mathrm{TM}}$ EnVision ${ }^{\mathrm{TM}}$ Detection System. Slides were incubated with the ready-to-use secondary antibody for $30 \mathrm{~min}$ and washed twice with TBS buffer. Diaminobenzidine (DAB) chromogen was diluted in substrate buffer 1:50 and transferred to the slides for $10 \mathrm{~min}$. To stop staining, slides were rinsed with TBST and washed with ultrapure $\mathrm{H}_{2} \mathrm{O}$ for $5 \mathrm{~min}$. Afterwards the slides were counterstained with haematoxylin for $5 \mathrm{sec}$, washed in warm tap water for 5 min and mounted with glycergel.

To count the number of $\mathrm{Ki}^{+} 7^{+}$nuclei, staining was analyzed on a microscope with a camera. From each tumor 5 pictures of randomly chosen regions within the tissue were taken at $200 \mathrm{x}$ magnification with CellSens Dimension software. The number of $\mathrm{Ki} 67^{+}$and the total number of nuclei were counted manually using AlphaView Q SA software. For small RMS a minimum of $6 \times 10^{3}$ nuclei were counted. The percentage of $\mathrm{Ki} 67^{+}$nuclei was calculated with GraphPad Prism 6 software.

\subsection{Animal experiments}

Experiments using animals were performed in compliance with all relevant legal and ethical requirements and have been approved by the Lower Saxony State Office for Consumer Protection and Food Safety experiments (file number 33.14-42502-04-13/1084). Research staff working with animals was trained according to the recommendations of Federation of European Laboratory Animal Science Associations (FELASA - Category B).

\subsubsection{Mouse lines}

Wildtype mice of the inbred strains C57BL/6N (B6) and BALB/C (Balb) were either bred in-house or purchased from Jackson Laboratories (Bar Harbor, USA) or Charles River Laboratories (Wilmington, USA). Balb-Ptch ${ }^{\text {del/t }}$ mice harbor a heterozygous deletion of exon 8 and 9 within the Ptch gene ${ }^{216}$. For in vivo studies and for isolation of primary RMS cells these mice were bred to B6 mice. The resulting BalbxB6-Ptch ${ }^{\text {del/t }}$ mice show a high susceptibility to $\mathrm{RMS}^{216}$ and were named Ptch $^{+/}$mice.

The in vivo study with HhAntag/pictilisib was performed with B6xBalb-Ptch ${ }^{\text {neo67/+ }}$ mice $^{227}$ that harbor a heterozygous deletion of exon 6 and 7 within the Ptch gene and were generated by breeding of B6-Ptch ${ }^{\text {neo67/+ }}$ mice with Balb mice (for further description and PCR-based genotyping $\left.\operatorname{se}^{228}\right)$. 


\subsubsection{Breeding of mice}

Breeding and housing of mice was done in the animal facility at the Institute of Human Genetics, University Medical Center Göttingen. Mice were housed in air-flow racks in Makrolon type 2 cages with a $12 \mathrm{~h}$ light-dark cycle at $22{ }^{\circ} \mathrm{C}+/-2{ }^{\circ} \mathrm{C}$ and $55 \%+/-10 \%$ relative humidity. Tap water and food pellets were sterilized for $20 \mathrm{~min}$ at $110{ }^{\circ} \mathrm{C}$ and provided ad libitum. All work performed with animals was done under a laminar flow system. For breeding, healthy animals with the desired genotype were used at an age of $10-35$ weeks.

\subsubsection{Tail biopsy and genotyping}

At the age of 4 weeks, mice underwent ear marking for numeration of each animal. In addition, a tail biopsy of approximately $0.2 \mathrm{~cm}$ length was taken from the tip of the tail and was used for gDNA isolation and PCR-based genotyping as described in sections 4.2.1 and 4.2.5. The DNA oligonucleotides that were used for genotyping of $\mathrm{Ptch}^{+/}$animals are listed in Table 11.

\subsubsection{Tumor monitoring and study design}

Once a week all $\mathrm{Ptch}^{+/}$mice were monitored for the occurrence of RMS. Prevalent sites for RMS were the extremities and the lower back region. In RMS-bearing animals the size of the tumor was estimated manually by palpation and careful visual observation. When a tumor reached a diameter of approximately $0.5 \mathrm{~cm}$, the animal was considered for in vivo drug treatment.

RMS-bearing animals were weighted before therapy onset and twice a week during the treatment period. The animals were monitored for tumor growth and their general health status twice daily. Animals were euthanized by cervical dislocation following $\mathrm{CO}_{2}$ anesthesia when the loss of body weight was $>20 \%$, when RMS reached a diameter $>1 \mathrm{~cm}$, when the animals showed bad health conditions (apathy, paralysis, ruffled fur) or if typical signs for tumors of the cerebellum (e.g. tumbling motion) occurred (please note that $\mathrm{Ptch}^{+/}$animals can develop medulloblastoma $\left.{ }^{216,227}\right)$.

At the end of the study, all animals were euthanized and RMS tissue was taken for RNA or protein isolation and immunohistochemistry as described in sections 4.2.3, 4.1.2 and 4.3.2, respectively. The identity of tumors as RMS was confirmed by HE staining according to section 4.3.1. 


\subsubsection{Drug formulation for in vivo treatment}

Drugs for in vivo studies were provided as powder by the manufacturers and are listed in Table 5. All drugs were applied systemically by oral gavage as described in section 4.4.6. For this purpose they were resuspended in methylcellulose tween (MCT). The dosage of each drug and concentrations of the prepared suspensions are listed in Table 5.

To prepare $100 \mathrm{~mL}$ of vehicle, $0.5 \mathrm{mg}$ methylcellulose were transferred into a sterile glass flask. While stirring at high speed, approximately $40 \mathrm{~mL}$ of $80{ }^{\circ} \mathrm{C}-90^{\circ} \mathrm{C}$ ultrapure $\mathrm{H}_{2} \mathrm{O}$ were added. When the mixture was dispersed, it was slowly filled up to $100 \mathrm{~mL}$ with cold ultrapure $\mathrm{H}_{2} \mathrm{O}$. Storage at $4{ }^{\circ} \mathrm{C}$ overnight or for several hours resulted in a clear solution. The solution was equilibrated to room temperature and $200 \mu \mathrm{L}$ of tween 80 were added while stirring. The MCT solution was filtered through a $0.4 \mu \mathrm{m}$ pore filter and could be stored at $4{ }^{\circ} \mathrm{C}$ for up to one month.

Drug suspensions were prepared according to manufacturer's recommendations. In brief, drug powder was weighed out on precision scales and transferred into a $2 \mathrm{~mL}$ reaction tube where it was mixed with the respective amount of vehicle to reach the concentrations listed in in Table 5. For preparation of the vismodegib, sonidegib or pictilisib suspensions, the vehicle was slowly added the day before use and tubes were kept at $4{ }^{\circ} \mathrm{C}$ without mixing. The next day, tubes were shaken at $1400 \mathrm{rpm}$ and $37^{\circ} \mathrm{C}$ for $3-5 \mathrm{~min}$. Powder clumps were triturated with a pipette tip in serial steps with short centrifugation at medium speed in between to collect all clumps at the bottom of the tube. For preparation of the HhAntag solution, the drug powder was triturated directly after addition of vehicle. Prepared mixtures were stored for a maximum of $48 \mathrm{~h}$ at $4{ }^{\circ} \mathrm{C}$.

\subsubsection{Oral gavage of SMO inhibitors and/or pictilisib}

RMS-bearing, but otherwise healthy $\mathrm{Ptch}^{+-}$mice with a tumor size of approximately $0.5 \mathrm{~cm}$ were used for the in vivo treatment studies. To avoid cross-contamination of the cohorts, all animals receiving the same treatment were kept in separate housing cages. Animals were treated twice daily with vehicle/vehicle, single drug/vehicle or drug/drug combinations by oral gavage. In between a time span of $5 \mathrm{~h}$ was left to prevent potential drug-drug interactions and complexations, which could have lowered the intestinal resorption and hence the therapeutic effectiveness of the combination treatment.

Drug suspension or vehicle was mixed thoroughly and pre-warmed to $37^{\circ} \mathrm{C}$ directly before oral treatment. The respective amount of drug suspension was aspirated with a sterile syringe. The feeding tube was attached and pre-filled with drug suspension/vehicle. Animals were restrained in the back, neck and tail region in an upright position so that the head and 
neck were fixed. The feeding tube was internalized into the esophagus of the mouse and the drug suspension/vehicle was released. Feeding tubes were wiped and rinsed once with $70 \%$ EtOH and several times with ultrapure $\mathrm{H}_{2} \mathrm{O}$ and allowed to dry before storing. In addition, feeding tubes were autoclaved monthly.

\subsubsection{Tumor size assessment by in vivo micro computed tomography ( $\mu \mathrm{CT})$}

The tumor growth was analyzed using a low dose in vivo $\mu \mathrm{CT}$ (QuantumFX, Perkin Elmer) at $90 \mathrm{kVp}$ tube voltage, $200 \mu \mathrm{A}$ tube current and a 2 min total acquisition time. Mice were anesthetized with 1 - $2 \%$ isoflurane in 1:1 air, oxygen mix before and during the scan. In order to visualize the tumors $5 \mathrm{ml} / \mathrm{kg}$ of Imeron 300 contrast agent were injected into the tail vein approximately $30 \mathrm{sec}$ prior imaging. Data sets were reconstructed with a voxel size of $80 \mu \mathrm{m}$ and analyzed using Scry v6.0 software. An example picture is shown in Fig. 4.

The contrast agent Imeron 300 contains a nonionic iodine compound called iomeprol. lodine compounds can enhance the absorption of $\mathrm{X}$-rays in vessels and tissues when injected intravenously. Delivered through the tumor vasculature, the contrast agent accumulates within the RMS and allows for proper monitoring of cancer structures, as shown in Fig. 4.

To calculate tumor volume the following equation was used, which assumes that the volume resembles an ellipsoid structure ${ }^{229}$. Tumor growth was calculated by scanning ERMS-bearing animals before therapy onset and at the end of treatment. For the animals in the study with HhAntag/pictilisib treatment a third scan at day 21 of treatment was performed.

$\mathrm{V}=\frac{\mathrm{a} \times \mathrm{b} \times \mathrm{c}}{2}$

V: tumor volume

a: width

b: height

c: length 


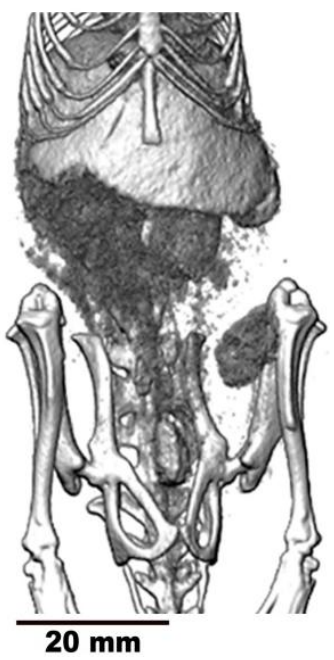

Figure 4: Low dose in vivo $\mu \mathrm{CT}$ of RMS. Picture shows one example of a $\mathrm{Ptch}^{+/}$mouse that has developed a RMS located at the inner knee. Tumor was visualized as described in the text and data acquisition was done with Scry software.

For data analysis the Response Evaluation Criteria in Solid Tumors (RECIST) were used $^{230,231}$. In short, the sum of tumor volumes of all ERMS lesions that were observed in one mouse was calculated. For each animal, the sum of tumor volumes at the end of study was normalized to the sum of tumor volumes at therapy onset. An increase in tumor volume of > $20 \%$ was defined as progressive disease (PD), a reduction in tumor volume of $>30 \%$ was defined as partial response (PR) and changes in tumor volume in-between PD and PR were defined as stable disease (SD).

\subsection{Statistics}

Statistical analysis was done with GraphPad Prism 6 software. Data were considered significant if $p$ values were $<0.05$. For statistical comparisons between two groups, a Student's t-test was performed. In order to compare more than two groups of data originating from in vitro experiments (considered following a Gaussian distribution), a one-way analysis of variance (ANOVA) was performed. For multiple testing between different treatments and control, Dunnett's test was performed. When different treatments groups were compared with each other, Tukey's test was done. In order to compare more than two groups of data originating from in vivo experiments (considered not following a Gaussian distribution), a one-way ANOVA with Dunn's test for multiple comparisons was performed.

Estimation of tumor growth in vivo and statistical analysis of group differences was performed with the help of Albert Rosenberger (Genetic Epidemiology, University Medical Center, Göttingen). Differences in tumor growth were analyzed using a mixed random effects 
model with repeated measures. Multiple testing was corrected by the method of Dunnett Hsu. All calculations were performed with SAS 9.4 software.

Correlation analysis between Gli1 expression levels and relative tumor size at the end of treatment was performed using GraphPad Prism 6 software. As tumor samples were not expected to follow a Gaussian distribution, a non-parametric Spearman test was applied. 


\section{Results}

\subsection{Targeting $\mathrm{HH}$ and $\mathrm{PI3K} / \mathrm{AKT} / \mathrm{mTOR}$ signaling pathways in human ERMS cell lines}

Previous studies have shown that SMO inhibitors can evoke anticancer effects in human ERMS cell lines ${ }^{121}$. These effects are highly concentration and cell line dependent. Surprisingly, the anticancer effects are not necessarily associated with a downregulation of $\mathrm{HH}$ signaling activity. For example the SMO inhibitor sonidegib significantly reduces proliferation of RD cells at a concentration of $30 \mu \mathrm{M}$ but at the same concentration does not affect expression of the $\mathrm{HH}$ signaling target gene GL/1. Additionally the SMO inhibitor vismodegib rather induces than reduces the proliferation of ERMS cell lines.

Here we tried to unravel if the anticancer effects of SMO inhibitors that were not associated with a downregulation of $\mathrm{HH}$ signaling activity were off-target effects. In addition, the impact of SMO inhibitors on cell cycle distribution and GLI transcriptional activity was investigated. Finally, and as the most important section of this part of the thesis, the importance of $\mathrm{PISK} / \mathrm{AKT} / \mathrm{mTOR}$ signaling in regulation of GLI transcriptional activity was elucidated and the effects of a combination treatment with SMO plus PI3K/AKT/mTOR inhibitors were analyzed.

\subsubsection{Cyclopamine, sonidegib or HhAntag, but not vismodegib, enhance anti- proliferative effects of cells with a low SMO expression level}

To investigate whether SMO inhibitors might evoke off-target effects in ERMS cell lines, their impact on RD cells with a stable SMO knockdown was analyzed. If the antitumoral effects of SMO inhibitors were indeed dependent on SMO, we expected that a SMO knockdown should prevent these effects.

The SMO knockdown cells were a gift from Prof. Dr. Beat Schaefer (University Children's Hospital of Zurich, Department of Oncology, Zurich, Switzerland) and were generated by expression of an exogenous small hairpin RNA targeting the SMO transcript (shSMO). Control cells were transfected with the respective empty vector ${ }^{118}$. To confirm the SMO knockdown, the expression level of SMO was investigated. RD cells transfected with shSMO showed a clear but incomplete downregulation of SMO on protein level (Fig. 5A) and on mRNA level (Fig. 5B). Hence, in our lab these cells were called RD SMOlow and control cells were called RD SMOhigh. Functionally the SMO knockdown reduced $\mathrm{HH}$ signaling activity as indicated by a downregulation of GLI1 and PTCH1 expression levels (Figs. 5C and 5D, respectively). 
A

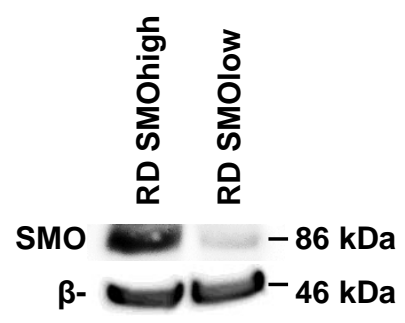

B

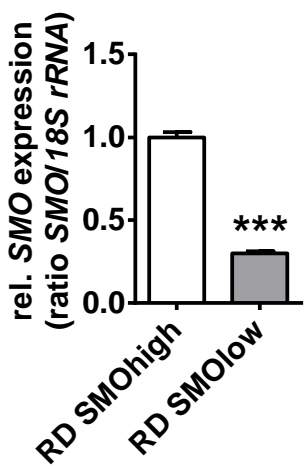

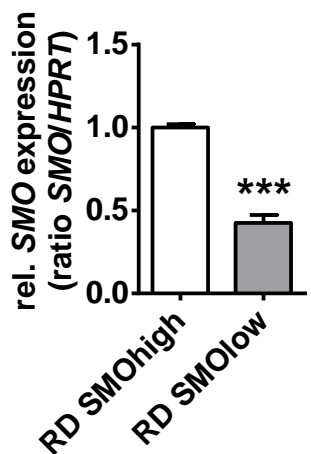

C
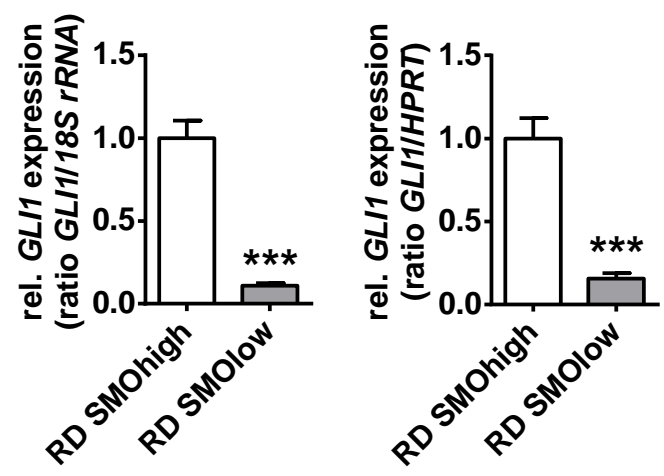

D
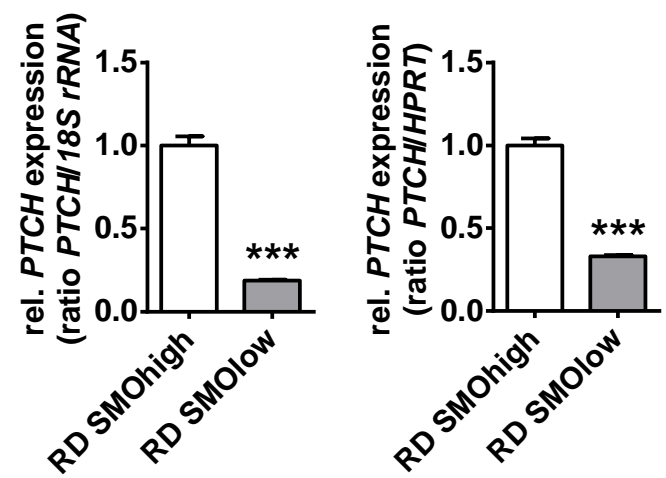

Figure 5: RD SMOlow cells show a clear but incomplete downregulation of SMO. SMO knockdown was confirmed by (A) Western Bot analysis with specific antibodies for SMO and the housekeeper protein B-actin and (B) qRT PCR. (C, D) Gene expression levels of the HH target genes GLI1 and PTCH1, which were normalized to $18 S$ rRNA and HPRT and are shown as fold expression to RD SMOhigh cells that were set to 1 . Bars represent the mean +standard error of the mean (SEM) of two independent experiments performed in duplicates. For statistical analysis a student's t test was performed. ${ }^{*} P<0.05,{ }^{* *} P<0.01,{ }^{* * *} P<0.001$ compared to expression levels of RD SMOhigh cells.

Upon knockdown confirmation, growth of RD SMOlow and RD SMOhigh cells was monitored by counting the number of living cells from treatment onset until $120 \mathrm{~h}$. As seen in Fig. 6A, cyclopamine, sonidegib and HhAntag reduced growth of RD SMOhigh in a concentration dependent manner. $30 \mu \mathrm{M}$ HhAntag nearly stopped growth and $30 \mu \mathrm{M}$ sonidegib even reduced cell numbers during treatment. In contrast, vismodegib did not affect cell growth of RD SMOhigh cells. Surprisingly, when RD SMOlow cells were incubated with $5 \mu \mathrm{M}$ cyclopamine cell growth was arrested and $10 \mu \mathrm{M}$ cyclopamine even induced cell death, indicated by a decreasing number of living cells. Similarly, $10 \mu \mathrm{M}$ sonidegib efficiently stopped cell growth and $30 \mu \mathrm{M}$ induced cell death. The same was true for HhAntag treatment, even though the decrease in cell number after treatment with $30 \mu \mathrm{M}$ was not as strong as it was seen for sonidegib treatment at the same concentration. In contrast and as also seen in RD SMOhigh cells, vismodegib did not affect growth of RD SMOlow cells. 
Additionally, the proliferative capacity and cellular viability of the cells was investigated by BrdU incorporation assay and by WST-1 assay, respectively, after treatment with SMO inhibitors for $24 \mathrm{~h}$.

When RD SMOhigh cells were treated with cyclopamine or vismodegib the cellular proliferation or viability was not affected (Fig. 6B). In contrast sonidegib enhanced cellular proliferation at a concentration of $10 \mu \mathrm{M}$ and reduced cellular proliferation and viability at a concentration of $30 \mu \mathrm{M}$. HhAntag enhanced cellular proliferation at a concentration of $10 \mu \mathrm{M}$ and reduced cellular viability at a concentration of $30 \mu \mathrm{M}$. Likewise in RD SMOlow cells, cyclopamine, vismodegib and $10 \mu \mathrm{M}$ sonidegib did not affect cellular proliferation and viability. In contrast $30 \mu \mathrm{M}$ sonidegib reduced both parameters to a similar extent as it was seen for RD SMOhigh cells. HhAntag indeed reduced proliferation and viability of $\mathrm{RD}$ SMOlow cells at both applied concentrations and at $30 \mu \mathrm{M}$ the reduction of cellular viability was stronger than it was seen for control cells. These results are in line with the observations made by counting the number of living cells after $24 \mathrm{~h}$ of treatment with SMO inhibitors (see Fig. 6A).

To sum up, RD cells with a stable but incomplete SMO knockdown are more sensitive towards the SMO inhibitors cyclopamine, sonidegib and HhAntag. These results might indicate that growth of ERMS cells is dependent on SMO activity. Hence, dual blockade of SMO activity by genetic downregulation of the basal expression level and pharmacologic inhibition of the remaining protein activity seems to be very efficient. As a consequence cyclopamine, sonidegib or HhAntag treatment induces stronger anti-proliferative effects in RD SMOlow compared to RD SMOhigh cells. However the lack of any effect of vismodegib is hard to explain. One possible explanation might be an acquired SMO mutation inducing selective resistance of RD cells against vismodegib. In literature, e.g. a D477G mutation in SMO has been described to cause resistance towards vismodegib while only mildly affecting the effectiveness of cyclopamine, sonidegib or HhAntag ${ }^{232,233}$. However, this is rather unlikely, since the parental RD cells do not harbor this mutation (personal communication of Heidi Hahn with Javed Khan, Genetic Branch, NIH). Finally, the different cellular response to one out of four investigated SMO inhibitors might indicate that the drugs indeed exert offtarget effects. Thus, if SMO would be the only target of all four drugs, one would expect similar cellular responses to either drug. 

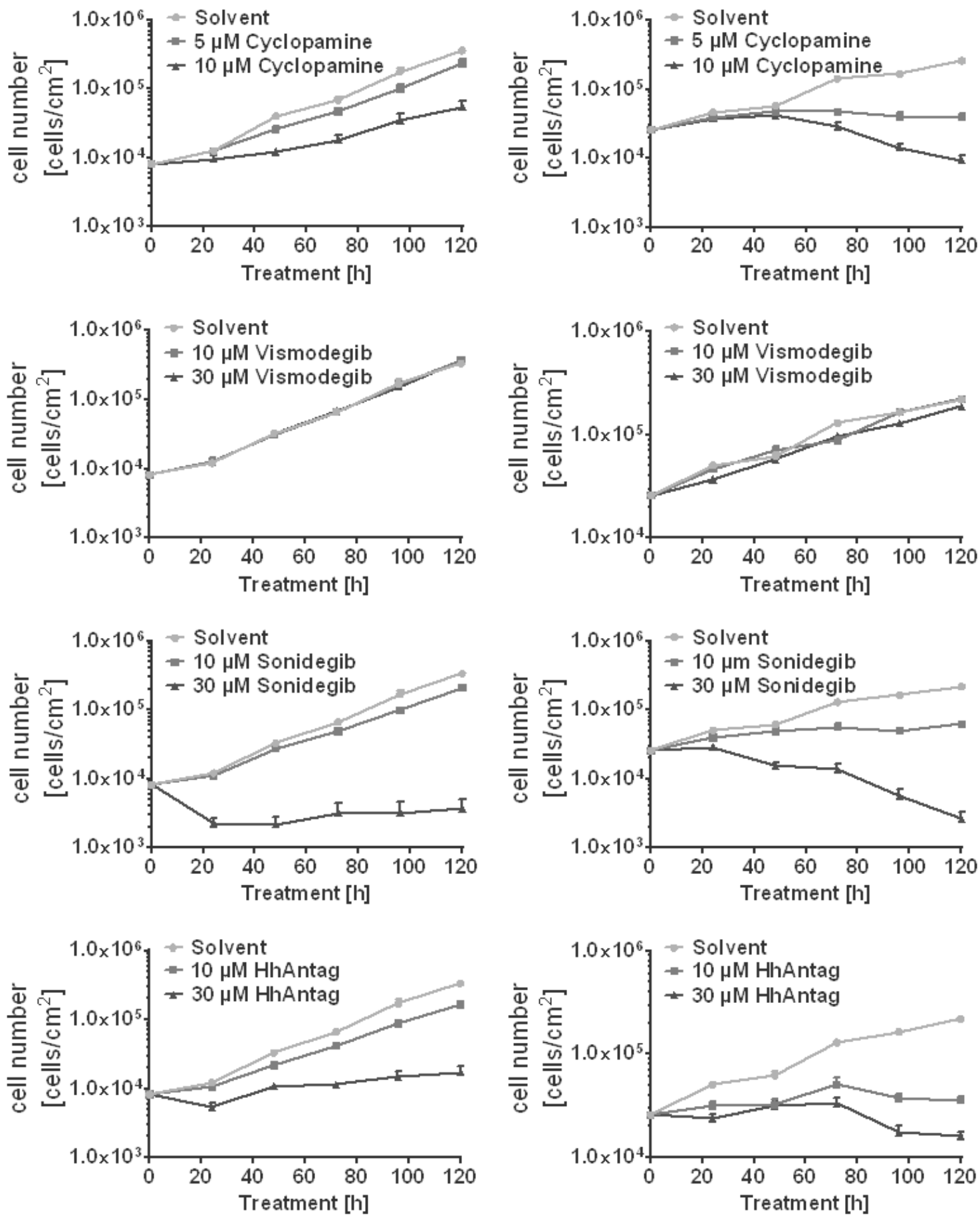
B

RD SMOhigh
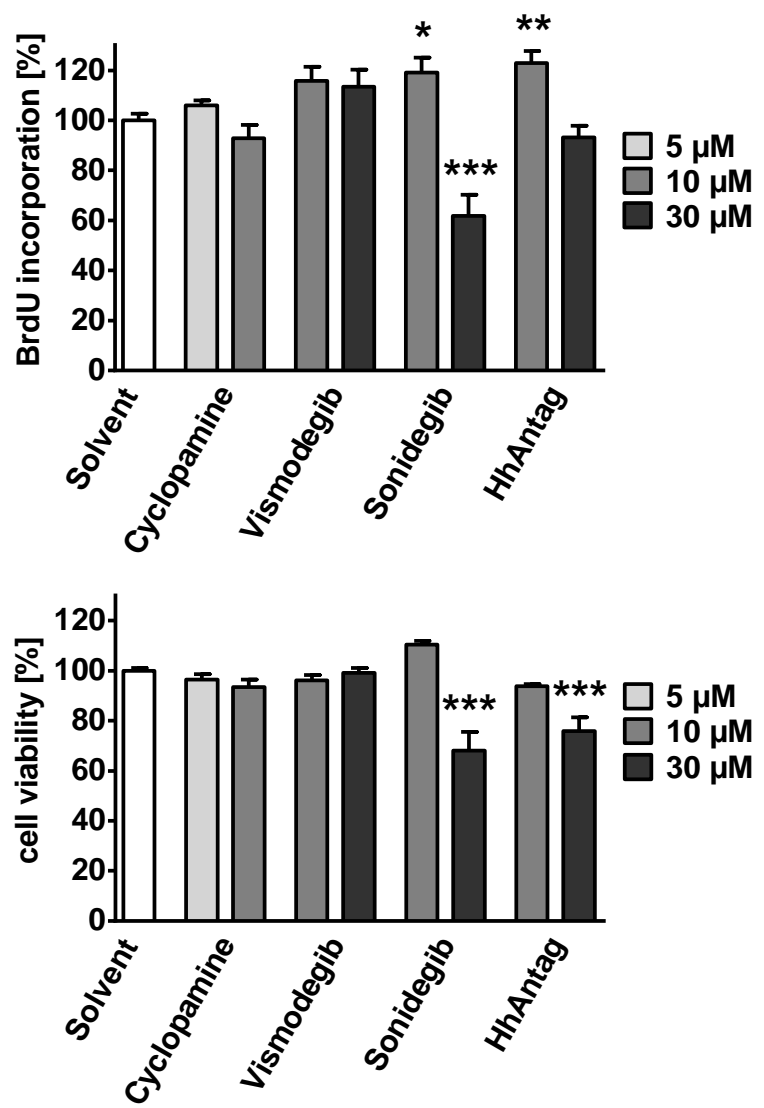

RD SMOlow
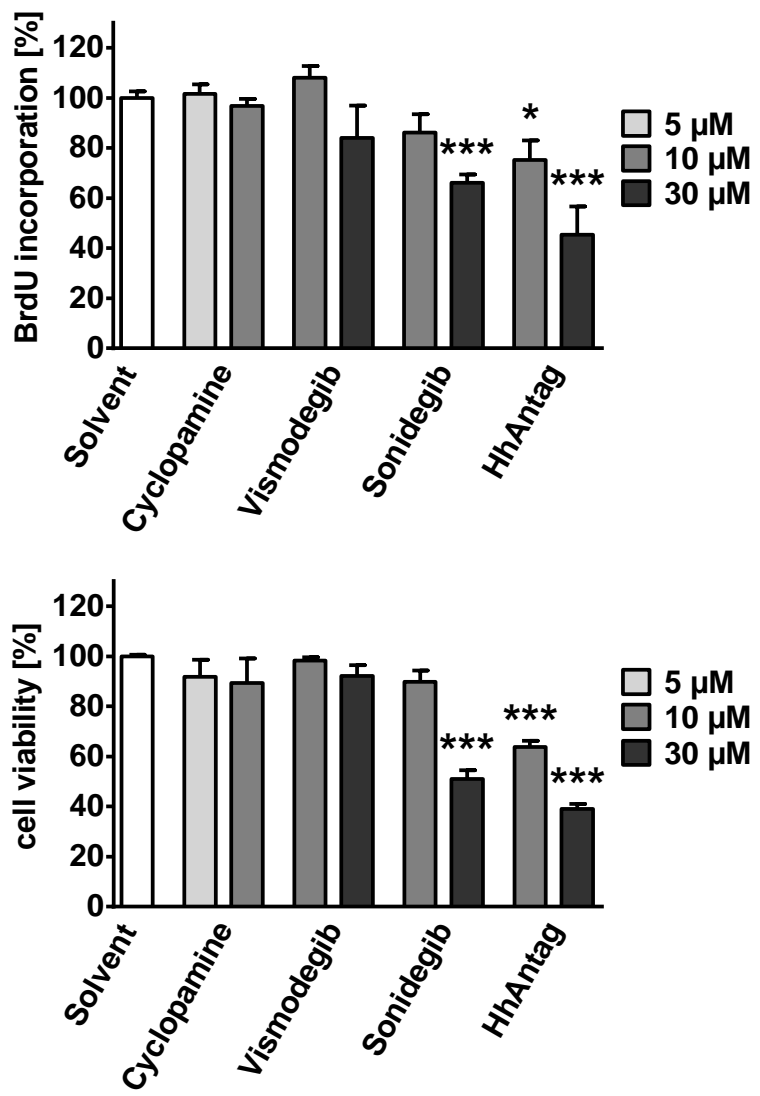

Figure 6: RD SMOlow cells are sensitiver towards cyclopamine, sonidegib or HhAntag compared to RD SMOhigh cells. (A) RD SMOlow and RD SMOhigh cells were treated with the indicated SMO inhibitors for up to $120 \mathrm{~h}$. Every $24 \mathrm{~h}$ cells were harvested, stained with toluidine blue and the number of living cells was counted. Data represent the mean +SEM of three independent experiments performed in duplicates. (B) RD SMOlow and RD SMOhigh cells were treated with the indicated SMO inhibitors for $24 \mathrm{~h}$. For BrdU incorporation assay, BrdU was added for $24 \mathrm{~h}$. Cell viability was analyzed with the help of WST-1 assay. Data are normalized to data from solvent treated cells that were set to $100 \%$ and bars represent the mean +SEM of two (cell viability) and three (BrdU incorporation assay) independent experiments performed in triplicates. Statistical analysis was performed according to one-way ANOVA and Dunnett's test for multiple comparisons. ${ }^{*} P<0.05$, ${ }^{\star \star} P<0.01,{ }^{* \star *} P<0.001$ compared to solvent treated cells.

\subsubsection{HhAntag, but not cyclopamine, vismodegib or sonidegib, induces a moderate G2/M arrest although it does not affect $\mathrm{HH}$ signaling activity}

As already mentioned above, the effects of the used SMO inhibitors on proliferation, measured with the help of BrdU incorporation assay, and on apoptosis, measured with the help of Annexin V/PI staining have been already published ${ }^{121}$. The data showed that the anticancer effects were not as strong as expected and were in parts not accompanied by a downregulation of $\mathrm{HH}$ target gene expression. Additionally, proliferation of ERMS cell lines was sometimes even enhanced by the drugs (e.g. by vismodegib). 
To complete these studies, changes in cell cycle distribution of RD and RUCH-2 cells treated with cyclopamine, vismodegib, sonidegib or HhAntag were investigated. In addition a GLI reporter assay system was utilized to test if SMO inhibitor treatment affects the activity of GLI transcription factors.

\subsubsection{Moderate G2/M arrest of RD cells upon incubation with HhAntag}

For cell cycle distribution analysis, RD and RUCH-2 cells were treated with the four SMO inhibitors for $24 \mathrm{~h}$ and $72 \mathrm{~h}$, respectively. Then the cells were fixed, stained with PI and analyzed by flow cytometry (Fig. 7).

In this setting, approximately $26 \%$ of RD cells were in G1/G0 phase (Fig. 7A), $9 \%$ in $S$ phase (Fig. 7B) and around $33 \%$ of cells resided in G2/M phase (Fig. 7C). In case of RUCH2 cells approximately $19 \%$ of cells were in G1/G0 phase (Fig. 7A), 2-3\% in S phase (Fig. 7B) and $48 \%$ in G2/M phase (Fig. 7C). Neither cyclopamine, nor vismodegib, nor sonidegib affected cell cycle distribution of the investigated cell lines. In contrast, $30 \mu \mathrm{M}$ HhAntag induced a significant G2/M arrest of RD cells. This was indicated by a significantly enhanced number of cells in G2/M phase (raise from $33 \%$ of solvent treated cells to $42 \%$ of cells treated with $30 \mu \mathrm{M}$ HhAntag) and a decrease in cell numbers in G1/G0 and S phase (not significant). Treatment of RUCH-2 cells with $30 \mu \mathrm{M}$ HhAntag likewise reduced the number of cells that reside in G1/G0 and S phase, but at the same time the number of cells in G2/M phase was unaffected. This might indicate an induction of apoptosis, which would lead to an increasing number of cells residing as Sub-G1/G0 cells. Indeed, the numbers of RUCH-2 cells in Sub-G1/G0 were moderately, but not significantly, enhanced after treatment with 30 $\mu \mathrm{M}$ HhAntag (data not shown).

The data showing that cyclopamine, vismodegib and sonidegib do not affect cell cycle distribution of $\mathrm{RD}$ and $\mathrm{RUCH}-2$ cells conflicts with previously published data showing that a $24 \mathrm{~h}$ treatment with $30 \mu \mathrm{M}$ sonidegib can reduce, and that a $24 \mathrm{~h}$ treatment with $5 \mu \mathrm{M}$ cyclopamine or $10 \mu \mathrm{M}$ vismodegib can even induce the proliferation rate of RD and RUCH-2 cells as analyzed by BrdU incorporation assay ${ }^{121}$. However, and in accordance with the proliferation assay ${ }^{121}, 24 \mathrm{~h}$ treatment with $30 \mu \mathrm{M}$ HhAntag can induce a significant cell cycle arrest of RD cells. 
RD

RUCH-2

A
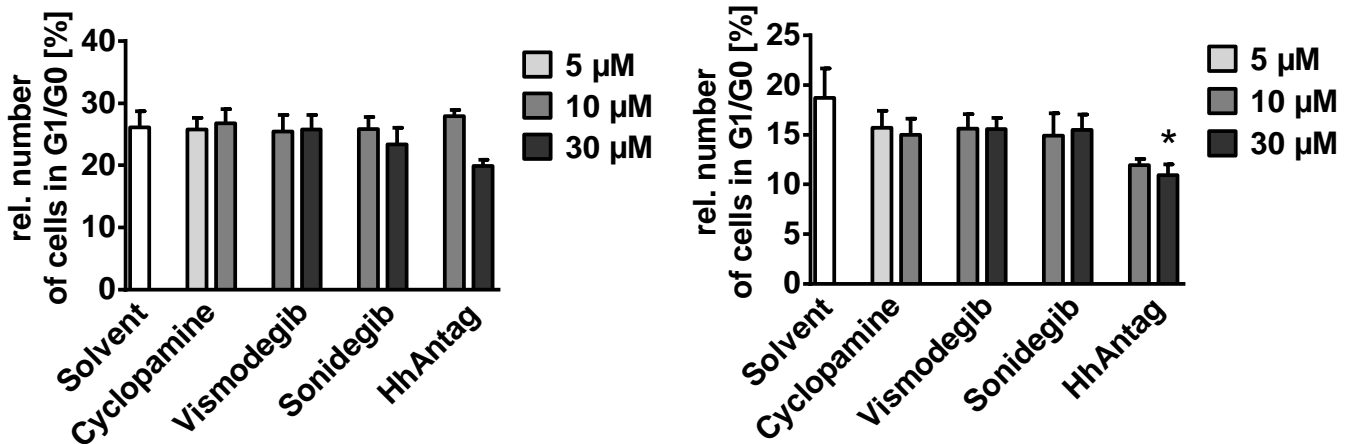

B
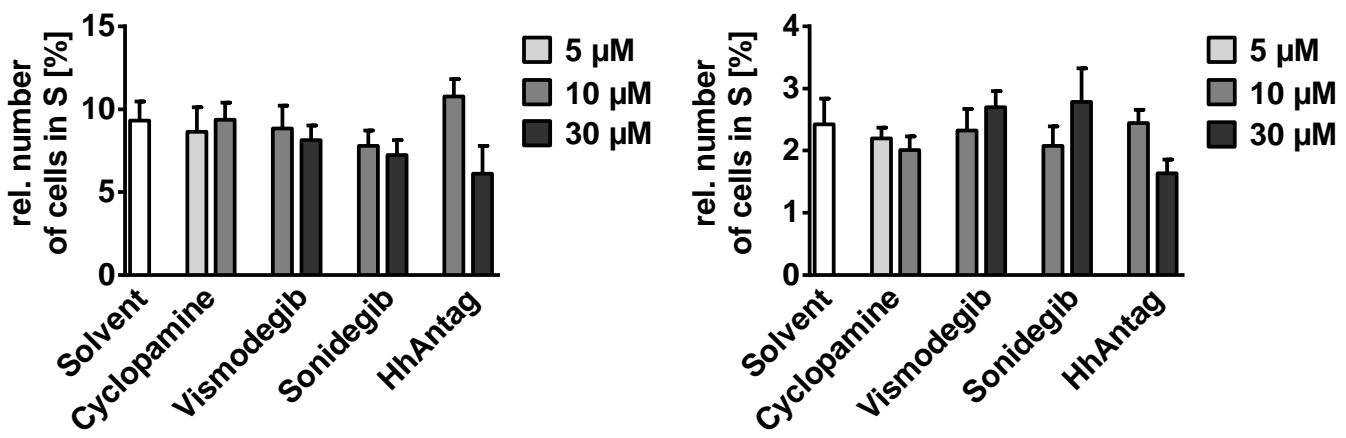

C
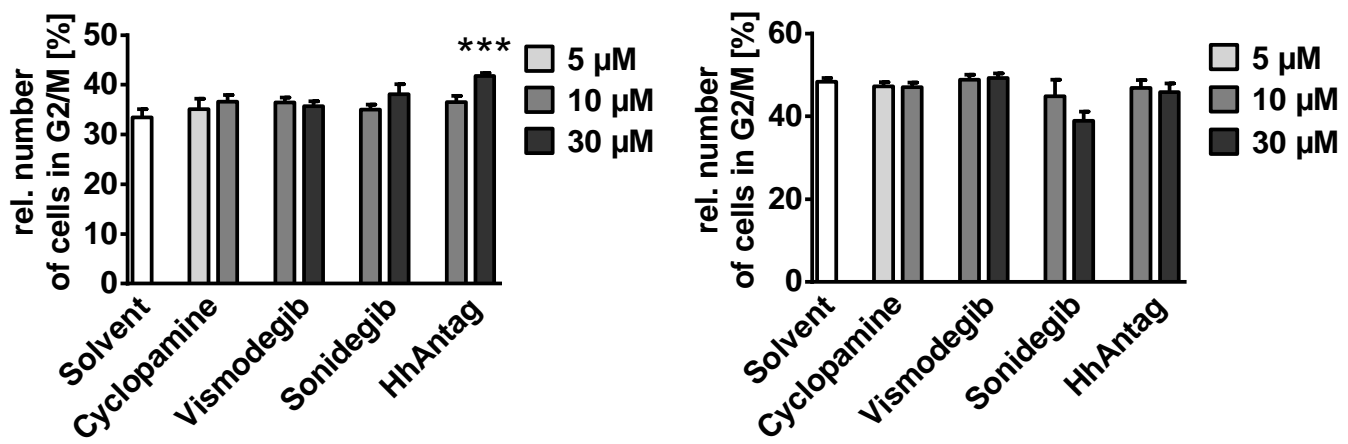

Figure 7: HhAntag induces a G2/M arrest of RD cells. Cells were treated for $24 \mathrm{~h}$ (RD cells) or $72 \mathrm{~h}$ (RUCH-2 cells) with SMO inhibitors as indicated. Fixed cells were stained with $\mathrm{PI}$, cell cycle distribution was analyzed by FACS and the relative amount of cells that resided in (A) G1/G0 phase, (B) S phase and (C) G2/M phase was calculated. Bars represent the mean +SEM of four (RD cells) or five (RUCH-2 cells) independent single experiments. Statistical analysis was performed according to one-way ANOVA and Dunnett's test for multiple comparisons. ${ }^{*} P<0.05,{ }^{* \star} P<0.01, \quad{ }^{* \star *} P<0.001$ compared to solvent treated cells.

\subsubsection{SMO inhibitors do not affect GLI transcriptional activity}

To investigate whether SMO inhibitors indeed block the activation status of $\mathrm{HH}$ signaling, a GLI reporter assay was performed (Fig. 8). For this purpose RD cells were transfected with a firefly luciferase whose expression is regulated by a GLI responsive promoter. For normalization of transfection efficiency, cells were co-transfected with a constitutively 
expressed Renilla luciferase. Transfected cells were treated with the four SMO inhibitors cyclopamine, vismodegib, sonidegib and HhAntag and with SMO agonist (SAG) that is expected to increase the $\mathrm{HH}$ signaling activity within the cells. As another positive control cells were also co-transfected with a Gli1 overexpression plasmid. As negative control cells were not transfected with the firefly luciferase plasmid but with an empty analogue plasmid.

A

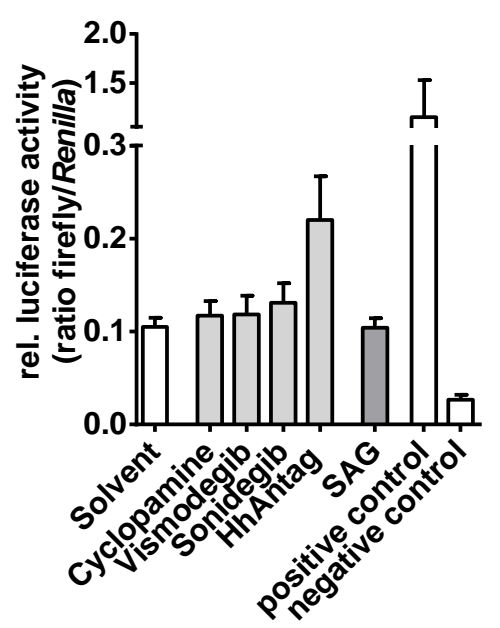

B

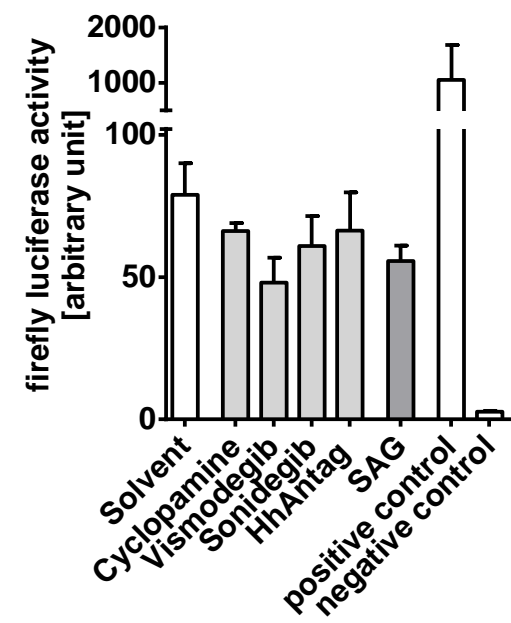

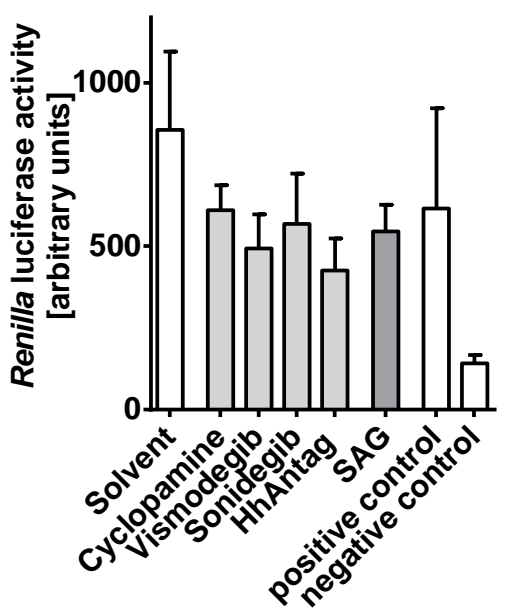

Figure 8: SMO inhibitors do not alter GLI reporter activity in RD cells. RD cells were transfected with a GLI-responsive firefly luciferase and treated with $1 \mu \mathrm{M}$ cyclopamine, $10 \mu \mathrm{M}$ vismodegib, $10 \mu \mathrm{M}$ sonidegib, $10 \mu \mathrm{M}$ HhAntag or $100 \mathrm{nM} \mathrm{SAG}$ for $48 \mathrm{~h}$. (A) Firefly luciferase activity normalized to the activity of a Renilla luciferase. (B) Raw data for firefly or Renilla luciferase activity. Bars represent the mean +SEM of three (vismodegib, HhAntag treatment), two (cyclopamine, sonidegib treatment) or one (SAG treatment) independent experiments performed in triplicates.

As seen in Fig. 8A neither cyclopamine, nor vismodegib, nor sonidegib, nor SAG were able to efficiently alter GLI reporter activity in RD cells. Surprisingly, HhAntag slightly enhanced the normalized GLI reporter activity. However, this effect was not based on a real upregulation of the firefly luciferase activity but rather on a lower Renilla luciferase activity upon treatment with HhAntag (Fig. 8B).

In summary, the data show that $\mathrm{HH}$ signaling activity is apparently not modulated by any of the four investigated SMO inhibitors or SAG when performing a luciferase-based GLI reporter assay. These data are in contrast with the downregulation of GLI1 expression level in RD cells treated with $10 \mu \mathrm{M}$ vismodegib, sonidegib or HhAntag and in contrast with the upregulation of GL/1 expression level in RD cells treated with $1 \mu \mathrm{M}$ cyclopamine ${ }^{121}$.

Together neither cyclopamine, nor vismodegib, nor sonidegib, nor HhAntag affect the GLI transcriptional activity in RD cells and, except HhAntag, also do not affect the cell cycle distribution of $\mathrm{RD}$ or $\mathrm{RUCH}-2$ cells. This experiment again indicates that the antitumoral 
effects of the SMO inhibitors (see ${ }^{121}$ ) may not result from SMO inhibition, but are rather offtarget effects of the drugs.

\subsubsection{Non-canonical regulation of $\mathrm{HH}$ signaling in ERMS cell lines}

\subsubsection{Marginal activation of $\mathrm{HH}$ signaling by $\mathrm{SHH}$}

As described above, the SMO inhibitors did not show the expected inhibitory effects on $\mathrm{HH}$ signaling activity (see section 5.1.2.2). In order to see whether $\mathrm{HH}$ signaling activity can be modulated in ERMS cells at all, the cells were next incubated with $\mathrm{SHH}$. For this purpose SHH conditioned medium from HEK293 cells that stably overexpress and secrete SHH was used. As control, ERMS cells were incubated with medium obtained from untransfected HEK293 cells. Murine B9 cells (also called Ptch $^{\text {floxfllox }}$ ERT2 $^{+/-}$cells ${ }^{214}$ ) that are responsive to $\mathrm{HH}$ signaling modulation served as control cells.

SHH containing medium did not regulate the expression of GLI1 and PTCH in RD cells, whereas HHIP expression seemed to be upregulated in dependency of the housekeeper gene (Fig. 9A). This was similar in $\mathrm{RUCH}-2$ cells, in which normalization to HPRT resulted in upregulation of GLI1 but in downregulation of HHIP. Normalization to $18 \mathrm{~S} r R N A$ resulted in upregulation of $\mathrm{PTCH}$. The functionality of the $\mathrm{SHH}$ conditioned medium was proven by a strong upregulation of Gli1 in B9 cells (Fig. 9B). Since changes of the GLI1, PTCH and HHIP expression levels in ERMS cells were extremely moderate and were also dependent on the housekeeper gene used for normalization, it was concluded that SHH does only marginally induce the $\mathrm{HH}$ signaling activity, if at all.

Together with the results described in section 5.1.2.2 these results show that canonical $\mathrm{HH}$ signaling activity is, if at all, only marginally adjustable in ERMS cells. 
A

RD

RUCH-2
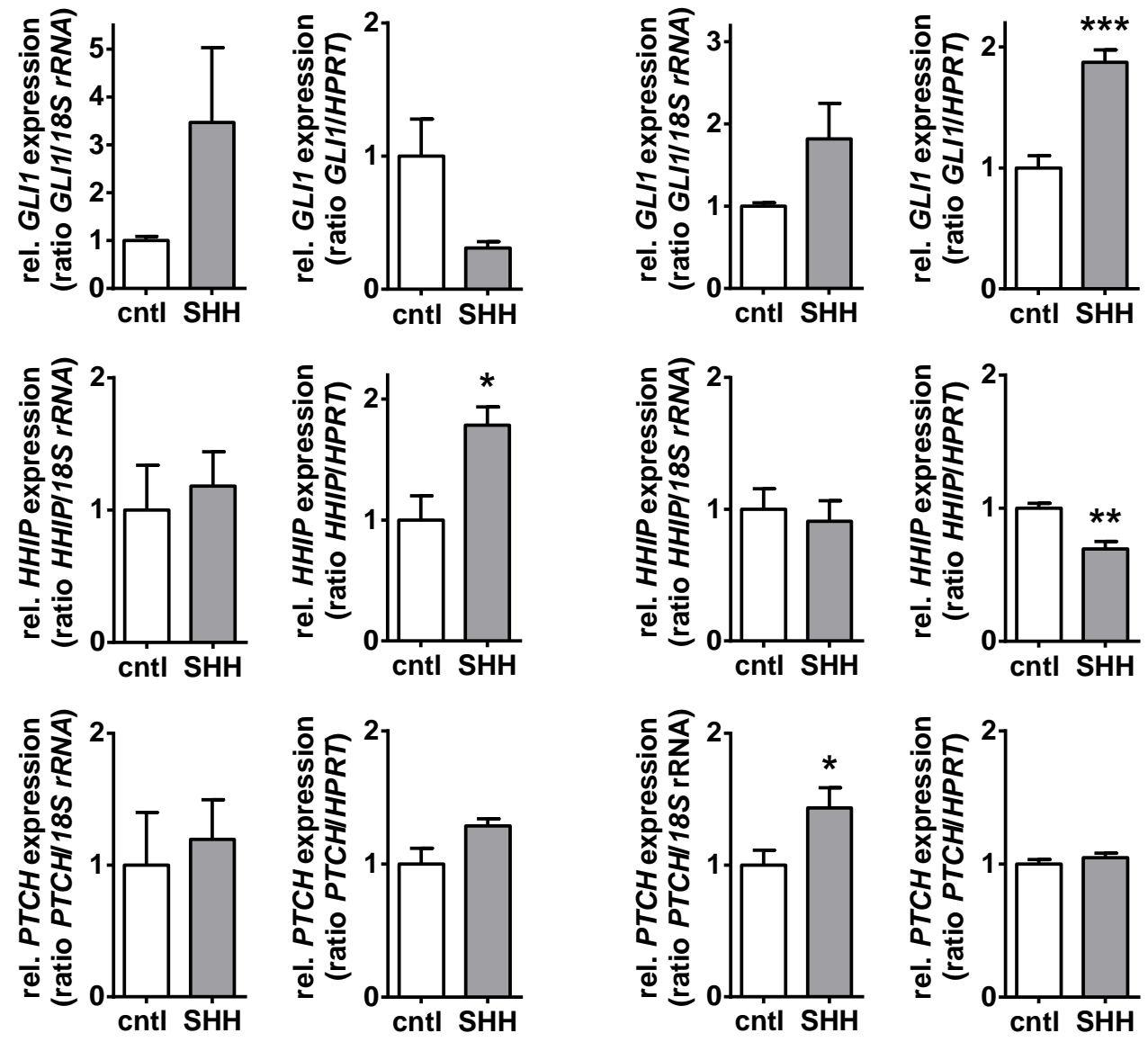

B

B9

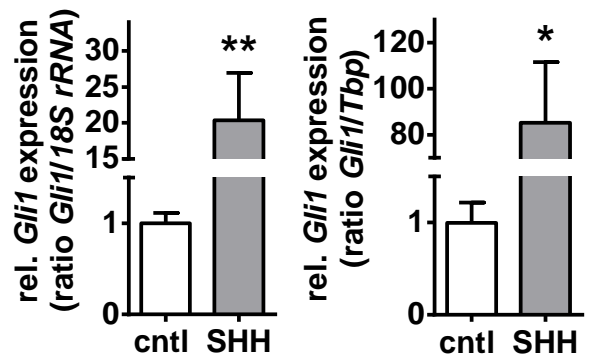

Figure 9: SHH may, if at all, only moderately regulate HH signaling in ERMS cell lines. (A) RD and $\mathrm{RUCH}-2$ cells were incubated for $24 \mathrm{~h}$ with medium obtained from HEK293 cells stably overexpressing $\mathrm{SHH}$. Cells that were incubated with medium obtained from untransfected HEK293 cells were considered as baseline (cntl). Data show qRT PCR analysis of the HH target genes GL/1, HHIP and PTCH. 18S rRNA and HPRT were used for normalization. The expression levels are shown as fold expression to cntl that were set to 1 . Bars represent the mean +SEM of two independent experiments performed in duplicates. Statistical analysis was done according to student's $t$ test. ${ }^{*} P<0.05,{ }^{* *} P<0.01,{ }^{* * *} P<0.001$ compared to cntl treated cells. (B) Murine B9 cells served as positive control. Gli1 expression levels were normalized to either $18 S$ rRNA or Tbp. 


\subsubsection{Potential non-canonical regulation of $\mathrm{HH}$ signaling by the PI3K/AKT/mTOR axis}

Next, it was investigated whether $\mathrm{HH}$ signaling activity can be regulated in a non-canonical way. From literature several oncogenic pathways are known to interact with $\mathrm{HH}$ signaling downstream of SMO. Thus, many tumors or tumor cell lines including RMS show convergence of $\mathrm{PI3K} / \mathrm{AKT} / \mathrm{mTOR}$ and $\mathrm{HH}$ signaling ${ }^{108,121,185,234,235}$. In addition, $\mathrm{PISK} / \mathrm{AKT} / \mathrm{mTOR}$ signaling plays an important role in $\mathrm{HH}$ signal potentiation for embryonic differentiation ${ }^{106}$. Furthermore, interactions between $\mathrm{HH}$ signaling and the RAS/MEK/ERK signaling pathway have been described in cancer. Examples are pancreatic cancer ${ }^{90,102,236}$ and melanoma ${ }^{76}$. Therefore, it was analyzed whether $\mathrm{HH}$ signaling activity might be regulated by one of these pathways in ERMS cell lines. To inhibit PI3K/AKT/mTOR signaling activity, RD and RUCH-2 cells were treated with the pure PI3K inhibitor pictilisib, the dual $\mathrm{PI3K} / \mathrm{mTOR}$ inhibitor PI-103, the pure AKT inhibitor MK-2206 and the mTOR inhibitors everolimus and rapamycin. In order to target the RAS/MEK/ERK signaling pathway, cells were treated with the MEK inhibitor UO126. Finally, AKT activity was modulated by overexpression of a constitutively active and a dominant negative AKT (AKT-CA and AKT$\mathrm{DN}$, respectively).

First, the functionality of the drugs was investigated. For this purpose the phosphorylation of AKT and S6 and that of ERK was analyzed upon application of PI3K/AKT/mTOR inhibitors and of UO126, respectively.

As expected, U0126 efficiently downregulated phosphorylation of ERK (Fig. 10A). Additionally and as already known from literature ${ }^{213}$ U0126 enhanced the phosphorylation of AKT.

PI-103, pictilisib or MK-2206 strongly reduced phosphorylation of AKT, whereas everolimus and rapamycin enhanced pAKT levels (Fig. 10B). This enhancement of pAKT levels by mTOR inhibitor treatment is an effect described as part of a mTOR feedback loop inhibition and occurs in different tumor cell lines ${ }^{237}$. $\mathrm{PI}-103$, pictilisib, everolimus or rapamycin efficiently reduced phosphorylation of the mTOR target S6. In contrast, MK-2206 did not affect pS6. A lack of pS6 reduction upon MK-2206 treatment is described for several human cancer cell lines ${ }^{238-240}$. 
A
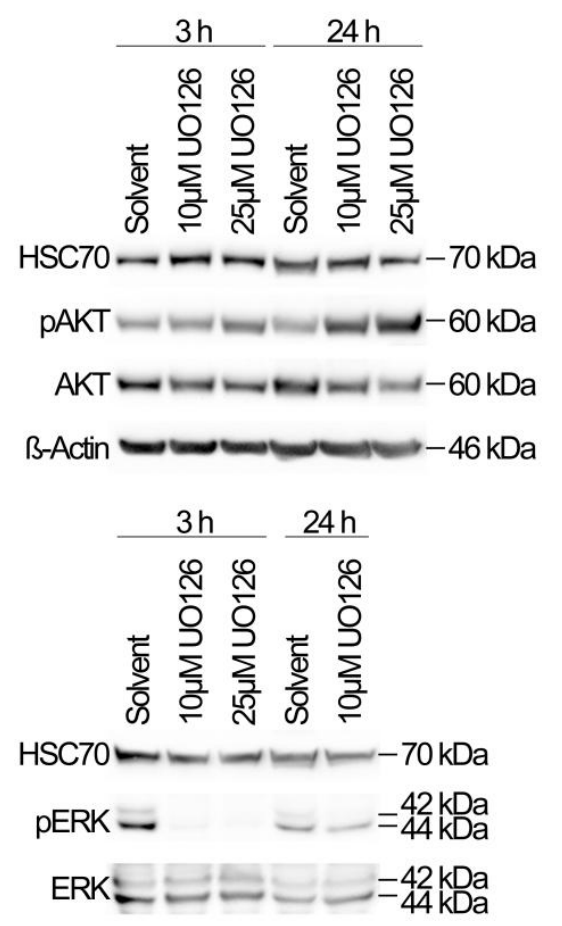

B

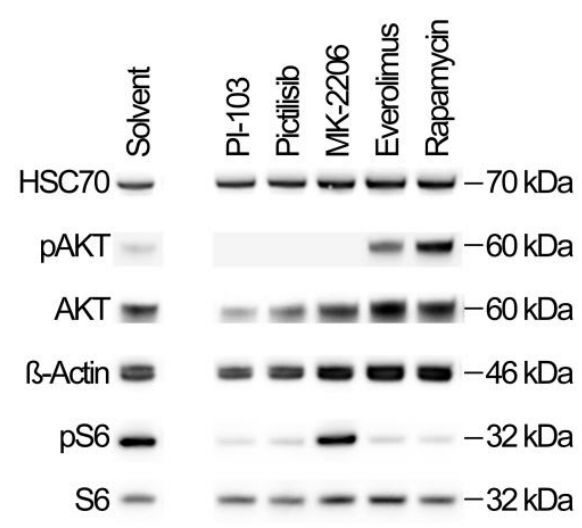

Figure 10: Proof of functionality of PI3K/AKT/mTOR and RAS/MEK/ERK inhibitors. RD cells were treated with (A) the ERK inhibitor U0126 as indicated and (B) PI-103 $(3 \mu \mathrm{M})$, pictilisib $(10 \mu \mathrm{M})$, MK$2206(5 \mu \mathrm{M})$, everolimus $(5 \mathrm{nM})$ and rapamycin $(100 \mathrm{nM})$ for $48 \mathrm{~h}$. Afterwards cell lysates were used for Western Blot analysis to detect the protein levels of pAKT/AKT, pERK/ERK and pS6/S6 with specific antibodies. HSC70 and B-Actin served as loading controls. Protein sizes in kDa are displayed on the right side of the blot. Shown is a representative blot out of two independent experiments.

Next, $\mathrm{HH}$ signaling activity was investigated. As shown in Fig. 11A, incubation of RD cells with U0126 upregulated GLI1 expression in a concentration dependent manner, whereas treatment with PI-103, pictilisib, MK-2206, everolimus or rapamycin efficiently downregulated GL/1 expression in these cells (Fig. 11B).

Together, the results depicted in Figs. 10 and 11 show a positive correlation between $\mathrm{PI} 3 \mathrm{~K} / \mathrm{AKT} / \mathrm{mTOR}$ and $\mathrm{HH}$ signaling. In addition, the results indicate that AKT might be a central factor within non-canonical regulation of $\mathrm{HH}$ signaling activity in ERMS cells. Thus, whereas inhibition of AKT (i.e. by PI-103, pictilisib, MK-2206) decreases HH signaling activity, activation of AKT (i.e. by U0126) increases it. Unfortunately it is not clear whether the impact of UO126 on $\mathrm{HH}$ signaling activity originates from AKT modulation. This effect could also be an off-target effect of UO126 or could originate from an AKT-independent interaction between RAS/MEK/ERK and GLI. Nevertheless incubation with UO126 is able to activate AKT and $\mathrm{HH}$ signaling activity. 
A
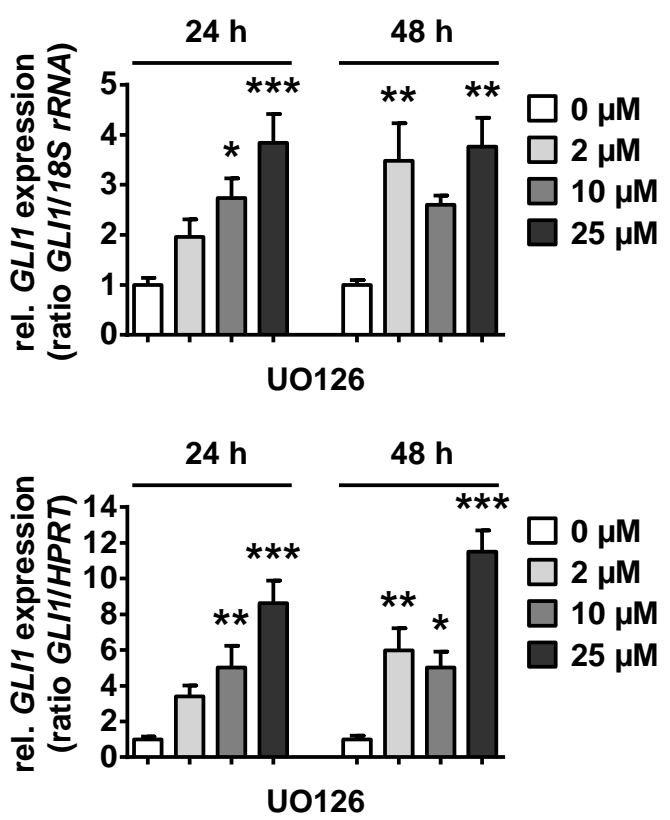

B

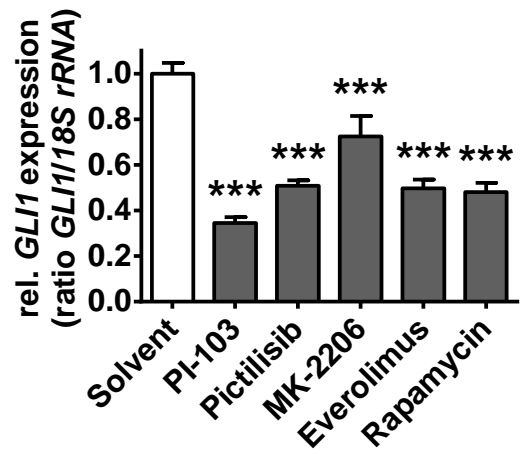

Figure 11: U0126 enhances and PI3K/AKT/mTOR inhibitors reduce HH activity. RD cells were treated with (A) the ERK inhibitor UO126 as indicated and (B) PI-103 $(3 \mu \mathrm{M})$, pictilisib $(10 \mu \mathrm{M})$, MK$2206(5 \mu \mathrm{M})$, everolimus $(5 \mathrm{nM})$ and rapamycin $(100 \mathrm{nM})$ for $24 \mathrm{~h}$. Afterwards cells were harvested for RNA isolation and qRT PCR of the HH target gene GL/1. GL/1 expression was normalized to $18 S$ rRNA and HPRT and is shown as fold expression to solvent treated cells that was set to 1. Bars represent the mean +SEM of three (UO126 treatment) and six (PI-103, pictilisib, MK-2206, everolimus, rapamycin treatment) independent experiments performed in duplicates. Statistical analysis was performed according to one-way ANOVA and Dunnett's test for multiple comparisons. ${ }^{*} P<0.05$, ${ }^{* *} P<0.01,{ }^{* \star *} P<0.001$ compared to solvent treated cells.

\subsection{Genetic modulation of AKT activity}

To test the hypothesis, whether AKT regulates $\mathrm{HH}$ signaling activity in ERMS, AKT activity was genetically modulated. For this purpose, RD cells were transfected with hemagglutinin (HA)-tagged AKT-CA and AKT-DN. The latter harbors a kinase inactivating K179M mutation within the catalytic domain). AKT-CA is characterized by a myristoylation signal targeting the protein to the cell membrane, which results in activation of downstream AKT/mTOR signaling ${ }^{221}$. Additionally, AKT-CA misses the pleckstrin homology domain, leading to a smaller protein size of approximately $50 \mathrm{kDa}$ compared to endogenous AKT and AKT-DN, which both are approximately $60 \mathrm{kDA}$ in size. Lysates of HEK293 cells transfected with AKTCA and AKT-DN were a gift from a former member of our group, J. Pyczek, and were used as control. The protein levels of AKT were analyzed with the help of specific antibodies against the HA-tag to see whether the exogenous proteins are expressed. In addition, antibodies against AKT and pAKT were used to see whether transfection has an influence on AKT activity. Additionally, since AKT can influence mTOR activity, phosphorylation of the 
mTOR target S6 was analyzed. The data showing overexpression of AKT-CA and AKT-DN in HEK293 cells have been already described in another thesis ${ }^{241}$.

In HEK293 cells, which show a very good transfectability, transfection with AKT-CA and AKT-DN resulted in a strong expression of the exogenous protein as shown with the help of antibodies detecting the HA tag or pAKT/AKT (Fig. 12). In addition, AKT-CA is highly phosphorylated, indicating its functionality. Transfection with the dominant negative form of AKT, AKT-DN, decreased the level of endogenous pAKT. However, no obvious difference in phosphorylation of S6 could be detected. These results show that the exogenous AKT proteins act, as expected, on phosphorylation of AKT, but apparently do not act on the AKT downstream effector mTOR in HEK293 cells.

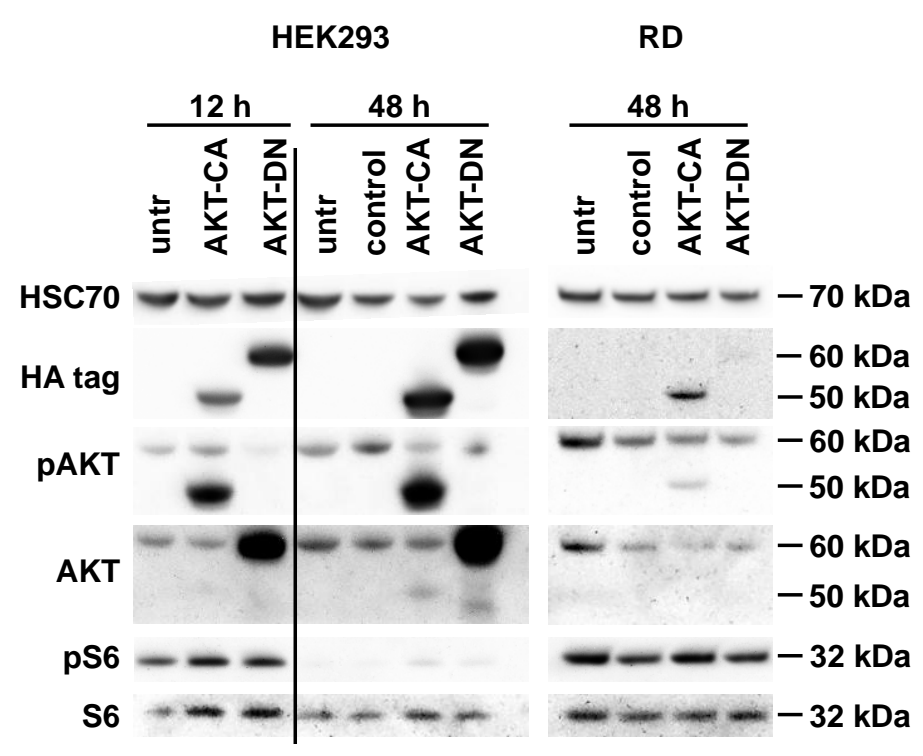

Figure 12: Overexpression of AKT variants in RD and HEK293 cells. RD and HEK293 cells were transfected with plasmids carrying either a HA-tagged constitutively active (AKT-CA) or dominant negative (AKT-DN) AKT. In parallel, cells were also transfected with EGFP to confirm transfectability (control). $12 \mathrm{~h}$ and $48 \mathrm{~h}$ after transfection cells were harvested and lysates from transfected and untransfected (untr) cells were analyzed by Western Blot with specific antibodies against HA, AKT, pAKT, S6 and pS6. HSC70 served as loading control. Estimated protein sizes in $\mathrm{kDa}$ are indicated on the right side of the blot.

In RD cells, AKT-CA was expressed and phosphorylated, as indicated by a HA and pAKT signal at the expected size of $50 \mathrm{kDa}$ (exogenous protein). Comparable to the observations that have been made in HEK293 cells, pS6 remained unaffected. The HA tag detection of AKT-DN was very weak and also the general AKT level was apparently not altered in cells transfected with AKT-DN, indicating a weak expression of the AKT-DN protein. In addition, phosphorylation of $\mathrm{S} 6$ remained unaffected by AKT-DN transfection as well. 
To sum it up, it was possible to transfect RD cells with AKT-CA and AKT-DN. However, the expression of AKT-DN was very weak and both exogenous proteins did not affect phosphorylation of the AKT/mTOR downstream target S6.

\subsection{No impact of genetic AKT modulation on HH signaling activity}

Even though phosphorylation of S6 was not affected in RD cells and AKT-DN was merely expressed, it was investigated, whether the expression of AKT-CA or AKT-DN has an impact on $\mathrm{HH}$ signaling activity in RD cells (Fig. 13).
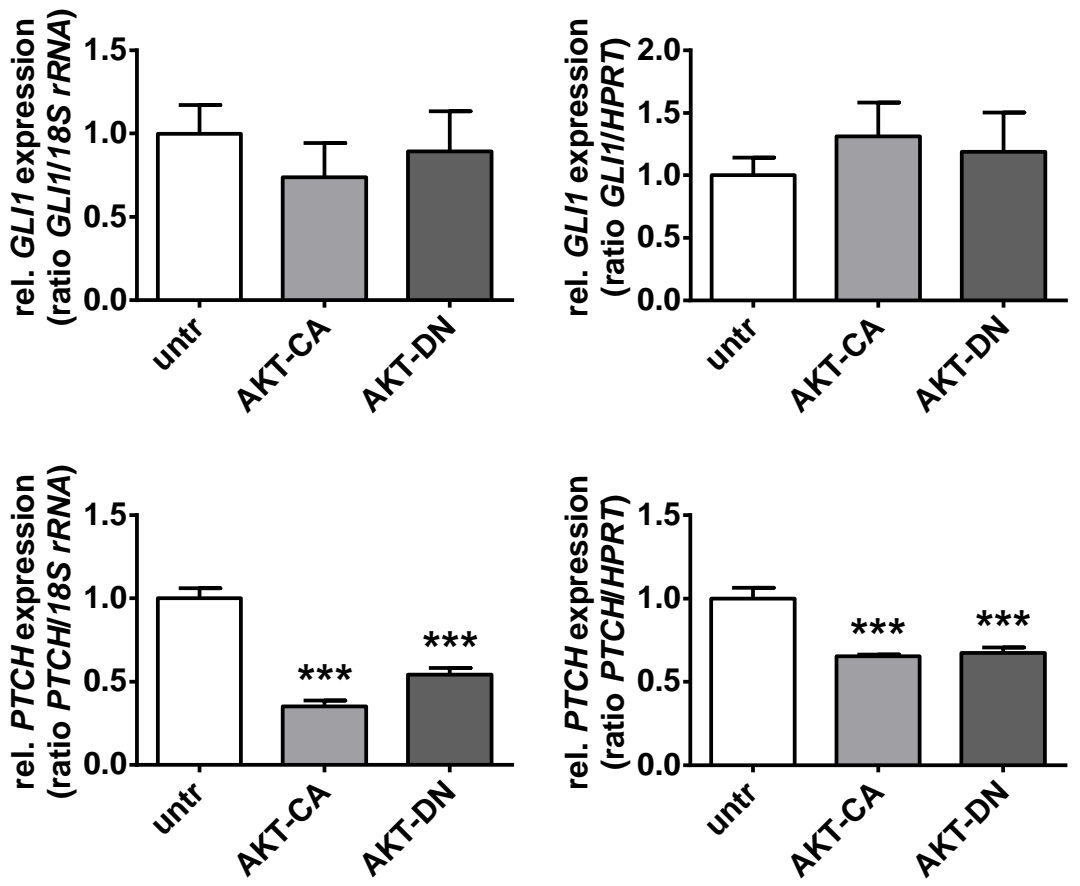

Figure 13: Impact of AKT variants on HH signaling activity. RD cells were transfected with plasmids carrying constitutive active (AKT-CA) or dominant negative (AKT-DN) forms of AKT. $48 \mathrm{~h}$ after transfection cells were harvested for RNA isolation and subsequent qRT PCR analysis for the HH target genes GLI1 and PTCH1. 18S rRNA (left panel) and HPRT (right panel) were used for normalization. Expression levels are shown as fold expression of untransfected (untr) cells that were set to 1. Bars indicate the mean +SEM of one biological replicate performed in duplicates. Statistical analysis was performed according to one-way ANOVA and Dunnett's test for multiple comparisons. ${ }^{\star} P<0.05,{ }^{* *} P<0.01,{ }^{* * *} P<0.001$ compared to untransfected cells.

The expression level of GLI1 was not altered upon expression of AKT-CA or AKT-DN, whereas PTCH expression was reduced (Fig. 13). Although this experiment has been performed only once, it was not repeated. This was due to the fact, that according to the literature AKT-CA should have decreased pS6 levels in control cells or ERMS cells ${ }^{221}$, which however was not the case. Therefore it is not clear whether the missing GLI1 upregulation upon transfection with AKT-CA and the missing downregulation upon transfection with AKT$\mathrm{DN}$ are due to lack of activity of the plasmid-derived proteins. 


\subsubsection{SMO inhibitors can induce cooperative anticancer effects when combined with PI3K/AKT/mTOR inhibitors}

Because PI3K/AKT/mTOR inhibitors significantly reduced HH signaling activity in ERMS cells (see Fig. 11B) it next was investigated whether a combination of SMO and PI3K/AKT/mTOR inhibitors may enhance the anticancer effects of the SMO inhibitors.

The experiments were performed with vismodegib, sonidegib and HhAntag and with the $\mathrm{PIOK} / \mathrm{AKT} / \mathrm{mTOR}$ inhibitors described in section 5.1.3.2.

\subsubsection{No cooperative inhibition of $\mathrm{HH}$ signaling activity upon combination of SMO and PI3K/AKT/mTOR inhibitors}

First it was tested if the combination of SMO inhibitors with PI3K/AKT/mTOR inhibitors cooperates in reduction of $\mathrm{HH}$ signaling activity in the ERMS cell lines RD and RUCH-2. For this purpose the expression level of the $\mathrm{HH}$ target gene GL/1 was quantified. (Parts of the results already have been shown in Fig. 11.)

In the applied concentrations vismodegib (Fig. 14A), sonidegib (Fig. 14B) and HhAntag (Fig. 14C) alone reduced the $\mathrm{HH}$ signaling activity in RD cells, even though the reduction was only moderate when vismodegib or sonidegib were applied. In $\mathrm{RUCH}-2$ cells vismodegib and sonidegib did not affect $\mathrm{HH}$ signaling activity and HhAntag only moderately reduced it. All applied PI3K/AKT/mTOR inhibitors reduced the $\mathrm{HH}$ signaling activity in both cell lines. The reduction was most efficient upon treatment with $\mathrm{PI}-103$ or pictilisib.

However, when the SMO inhibitors were combined with PI3K/AKT/mTOR inhibitors, the effects on GLI1 suppression were not strengthened (Figs. 14A - 14C). 
A

RD
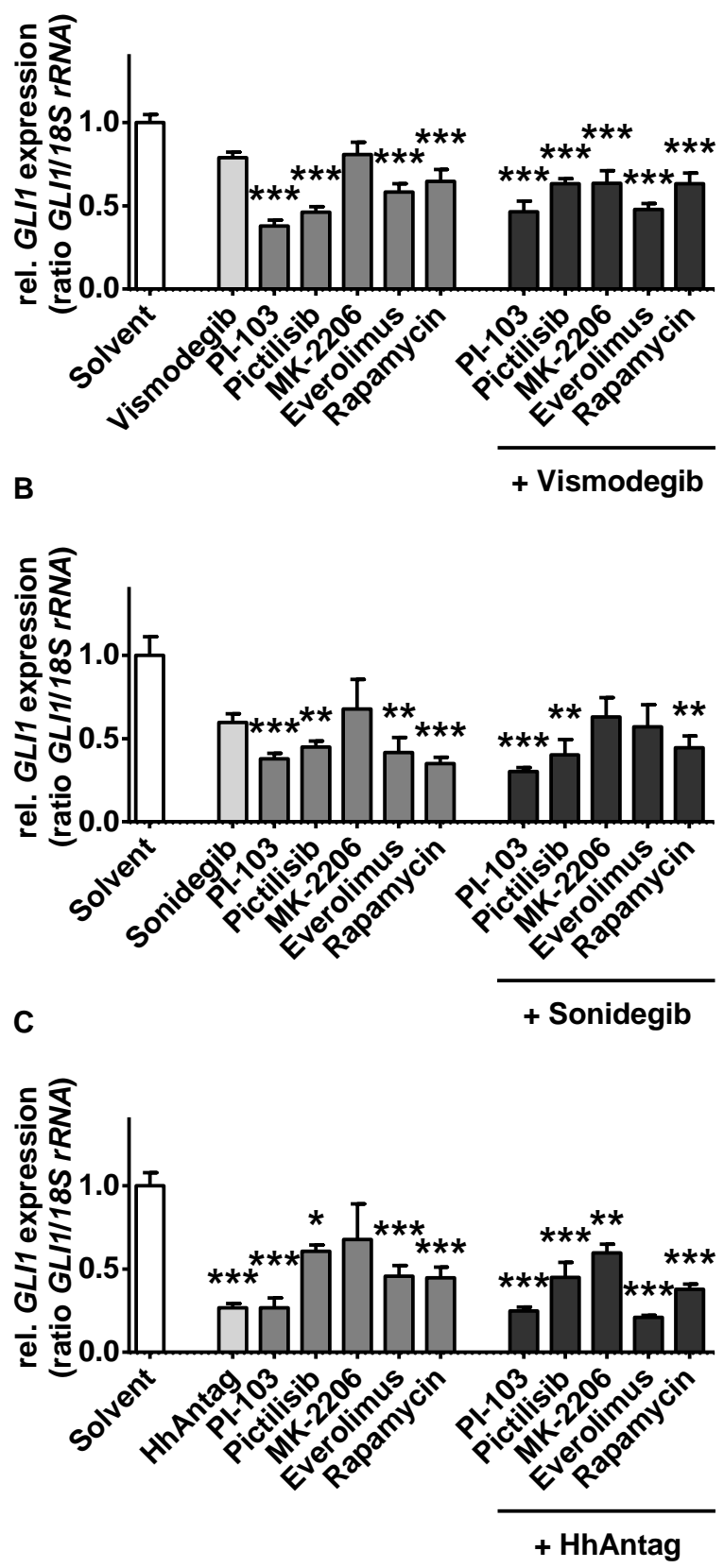

RUCH-2
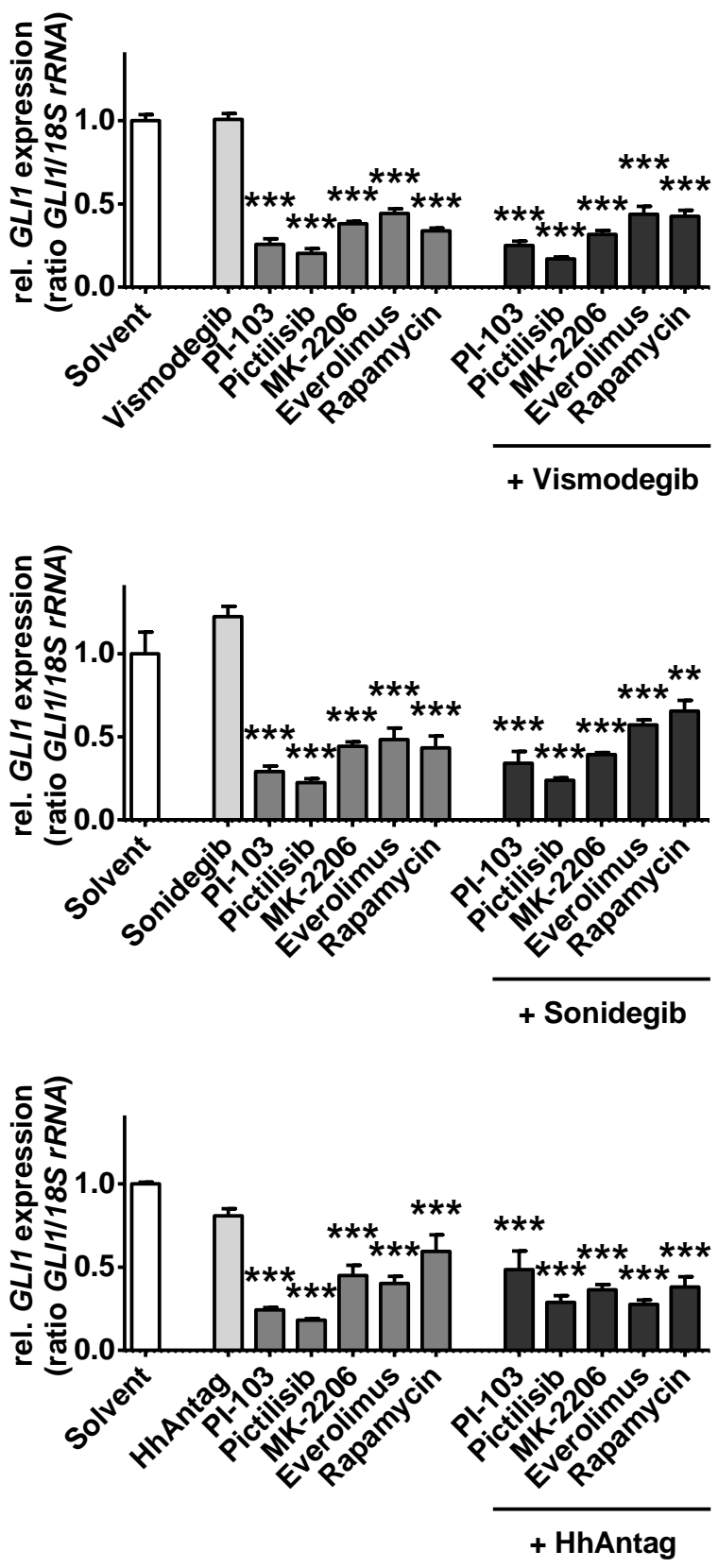

Figure 14: Impact of SMO and PI3K/AKT/mTOR inhibitors on HH signaling activity. RD and $\mathrm{RUCH}-2$ cells were treated for $24 \mathrm{~h}$ with the indicated drugs. Concentration of vismodegib, sonidegib or HhAntag was $10 \mu \mathrm{M}$, those of PI-103, pictilisib, MK-2206, everolimus and rapamycin were $3 \mu \mathrm{M}, 10$ $\mu \mathrm{M}, 5 \mu \mathrm{M}, 5 \mathrm{nM}$ and $100 \mathrm{nM}$, respectively. Afterwards cells were harvested and qRT PCR for the HH target gene GLI1 was performed. GLI1 expression was normalized to $18 S$ rRNA and is shown as fold expression to solvent treated cells that were set to 1 . Bars represent the mean +SEM of at least two independent experiments performed in duplicates. Statistical analysis was performed according to one-way ANOVA and Tukey's test for multiple comparisons. ${ }^{*} P<0.05,{ }^{* \star} P<0.01,{ }^{* * *} P<0.001$ compared to solvent treated cells. (A), (B) and (C) show the gene expression levels after treatment with vismodegib, sonidegib, HhAntag and/or PI3K/AKT/mTOR inhibitors, respectively. 


\subsubsection{Moderate cooperative effects on pAKT/AKT, pS6/S6 or caspase 3 cleavage upon combination of SMO and PI3K/AKT/mTOR inhibitors}

As a next step, the impact of SMO inhibitors alone and in combination with PI3K/AKT/mTOR inhibitors on pAKT/AKT and pS6/S6 levels as well as on cleaved caspase 3 as a marker for apoptosis was investigated. For this purpose cell lysates were subjected to Western Blot analysis and analyzed with specific antibodies. (Parts of the results already have been shown in Fig. 10).

Vismodegib or sonidegib did not evoke any obvious effects on pAKT or pS6/S6 levels in RD and $\mathrm{RUCH}-2$ cells, but seem to enhance the total level of AKT in RUCH-2 cells (Figs. 15A and 15B). As already published by our lab ${ }^{121}$ HhAntag reduced PAKT in RD and RUCH-2 cells, but did not affect AKT or pS6/S6 levels (Fig. 15C). None of the SMO inhibitors affected caspase 3 cleavage. As already described (see Fig. 10B), PI-103, pictilisib and MK-2206 efficiently reduced pAKT in RD and $\mathrm{RUCH}-2$ cells. In contrast to MK-2206, PI-103 and pictilisib additionally reduced pS6. Everolimus and rapamycin reduced pS6 in both cell lines as expected, but enhanced pAKT, as already shown in Fig. 10B. Furthermore PI-103, pictilisib and MK-2206 induced cleavage of caspase 3 in RD cells. Similar results were obtained with RUCH-2 cells in two out of three blots.

In RD cells, the combination of vismodegib, sonidegib and HhAntag with PI3K/AKT/mTOR inhibitors did not change the protein pattern. The only and obvious exception was the combination of HhAntag plus MK-2206, which induced cleavage of caspase 3. Similarly, in RUCH-2 cells many of the combinations did not enhance the effects that were observed upon treatment with either drug alone. However, exceptions were the combination of vismodegib plus MK-2206 that reduced the protein level of AKT while enhancing the level of cleaved caspase 3 and the combinations of HhAntag plus pictilisib and HhAntag plus MK2206 that reduced the level of pS6 more efficiently than either single drug alone. In addition the combination of HhAntag plus pictilisib more efficiently induced cleavage of caspase 3 when compared to single drug treatment. 
RD

A

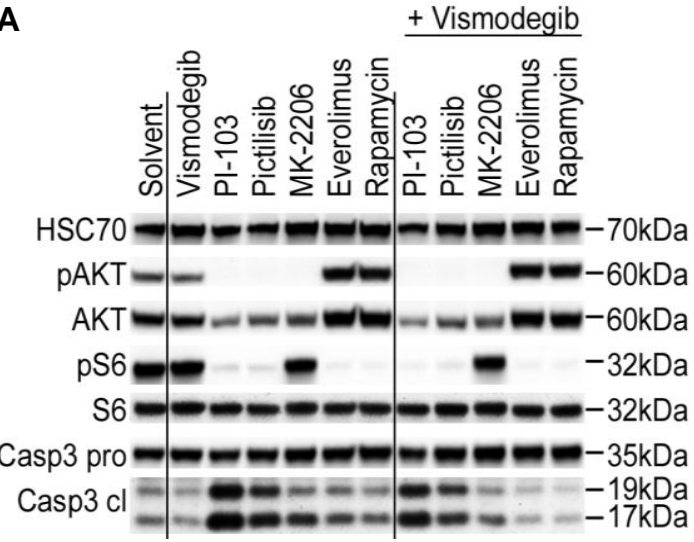

B

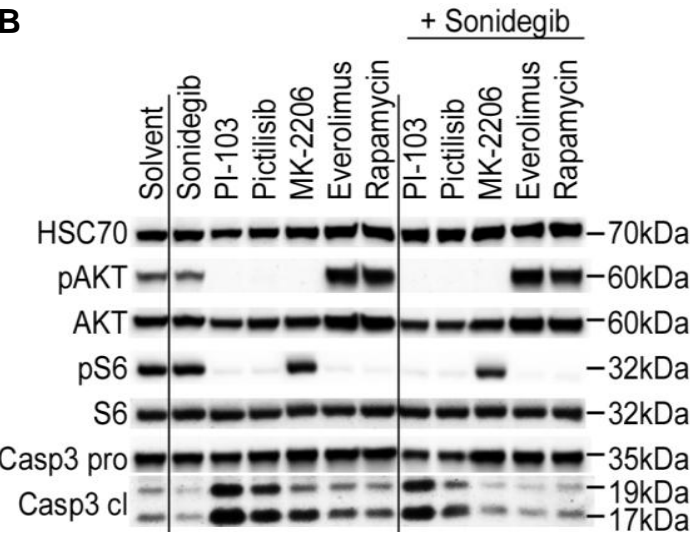

RUCH-2

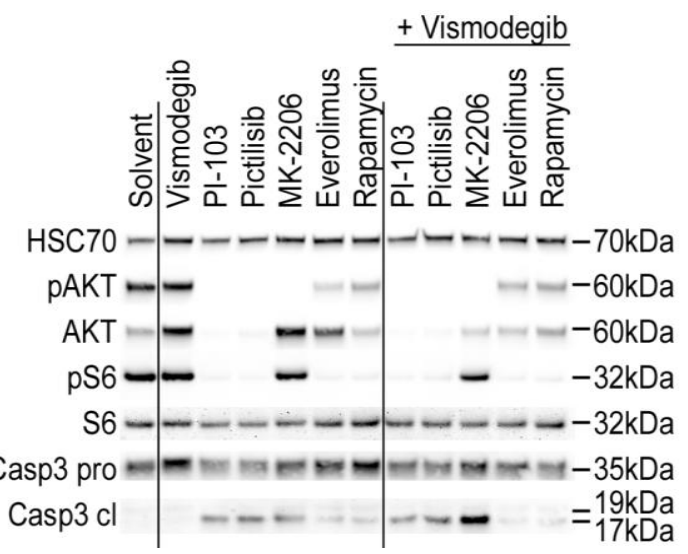

C

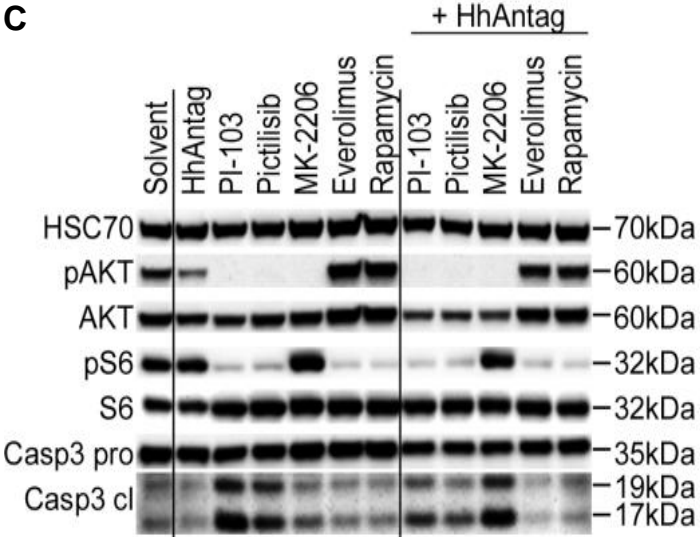

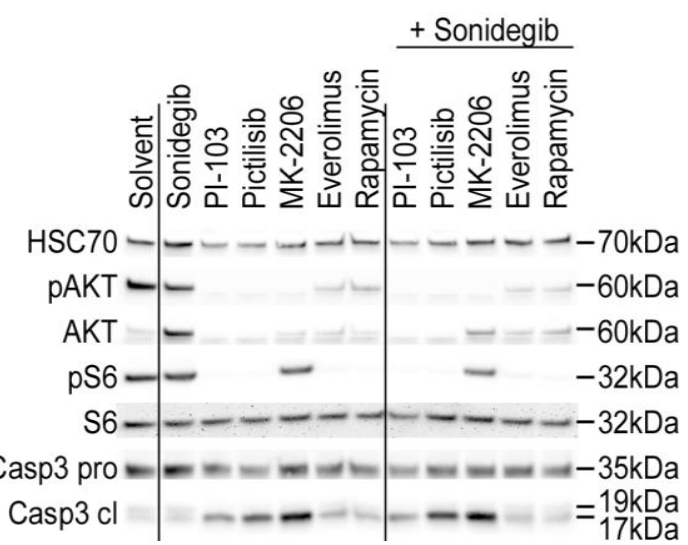

+ HhAntag

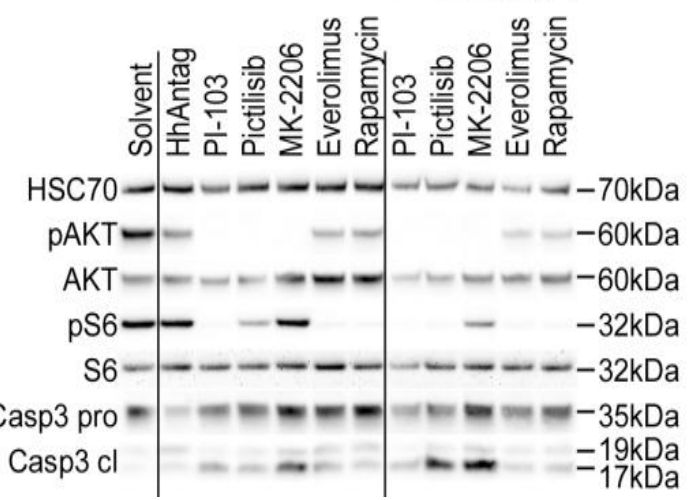

Figure 15: Impact of SMO and PI3K/AKT/mTOR inhibitors on phosphorylation of AKT, S6 and the cleavage of caspase 3. RD and RUCH-2 cells were treated with the indicated drugs for $48 \mathrm{~h}$. Concentration of vismodegib, sonidegib or HhAntag was $10 \mu \mathrm{M}$, those of PI-103, pictilisib, MK-2206, everolimus and rapamycin were $3 \mu \mathrm{M}, 10 \mu \mathrm{M}, 5 \mu \mathrm{M}, 5 \mathrm{nM}$ and $100 \mathrm{nM}$, respectively. Afterwards cells were harvested for Western Blot analysis to detect the levels of pAKT/AKT, pS6/S6 and caspase 3 (Casp3) in its pro and cleaved (Cl) form with the help of specific antibodies. HSC70 served as loading control and protein sizes in $\mathrm{kDa}$ are indicated on the right side. (A), (B) and (C) show Western Blots after treatment with vismodegib, sonidegib, HhAntag and/or PI3K/AKT/mTOR inhibitors, respectively. 


\subsubsection{Sonidegib and HhAntag, but not vismodegib, can evoke cooperative anti- proliferative effects when combined with PI3K/AKT/mTOR inhibitors}

Even though no cooperative effects of combined treatment with SMO plus PI3K/AKT/mTOR inhibitors on $\mathrm{HH}$ signaling and only a few cooperative effects on pAKT/AKT, pS6/S6 or caspase 3 cleavage have been observed, the impact of SMO inhibitors alone and in combination with PI3K/AKT/mTOR inhibitors on cellular proliferation of RD and RUCH-2 cells was investigated. Proliferation of the cells was quantified by BrdU incorporation assay.

Vismodegib (Fig. 16A) and sonidegib (Fig. 16B) did not show any effects on proliferation of RD and RUCH-2 cells, whereas HhAntag (Fig. 16C) reduced it. Similarly, PI-103 and pictilisib alone reduced cellular proliferation of both cell lines. MK-2206 did not affect proliferation of $\mathrm{RD}$ cells but reduced proliferation of $\mathrm{RUCH}-2$ cells. Everolimus and rapamycin did not affect proliferation of either cell line.

When vismodegib was combined with PI3K/AKT/mTOR inhibitors, no changes were generally observed compared to the single treatments. In contrast, the combination of sonidegib plus rapamycin induced a cooperative anti-proliferative effect in $\mathrm{RUCH}-2$ cells. A cooperative effect was defined as a decrease in proliferation upon combination treatment that was significant compared to solvent treated cells and that was significantly lower than the decrease with either drug alone. Cooperative effects were also seen when HhAntag was combined with PI3K/AKT/mTOR inhibitors. Thus, the combination of HhAntag plus pictilisib induced cooperative anti-proliferative effects in RD cells. In RUCH-2 cells cooperative antiproliferative effects were also seen for HhAntag plus either PI-103, MK-2206 or rapamycin. 

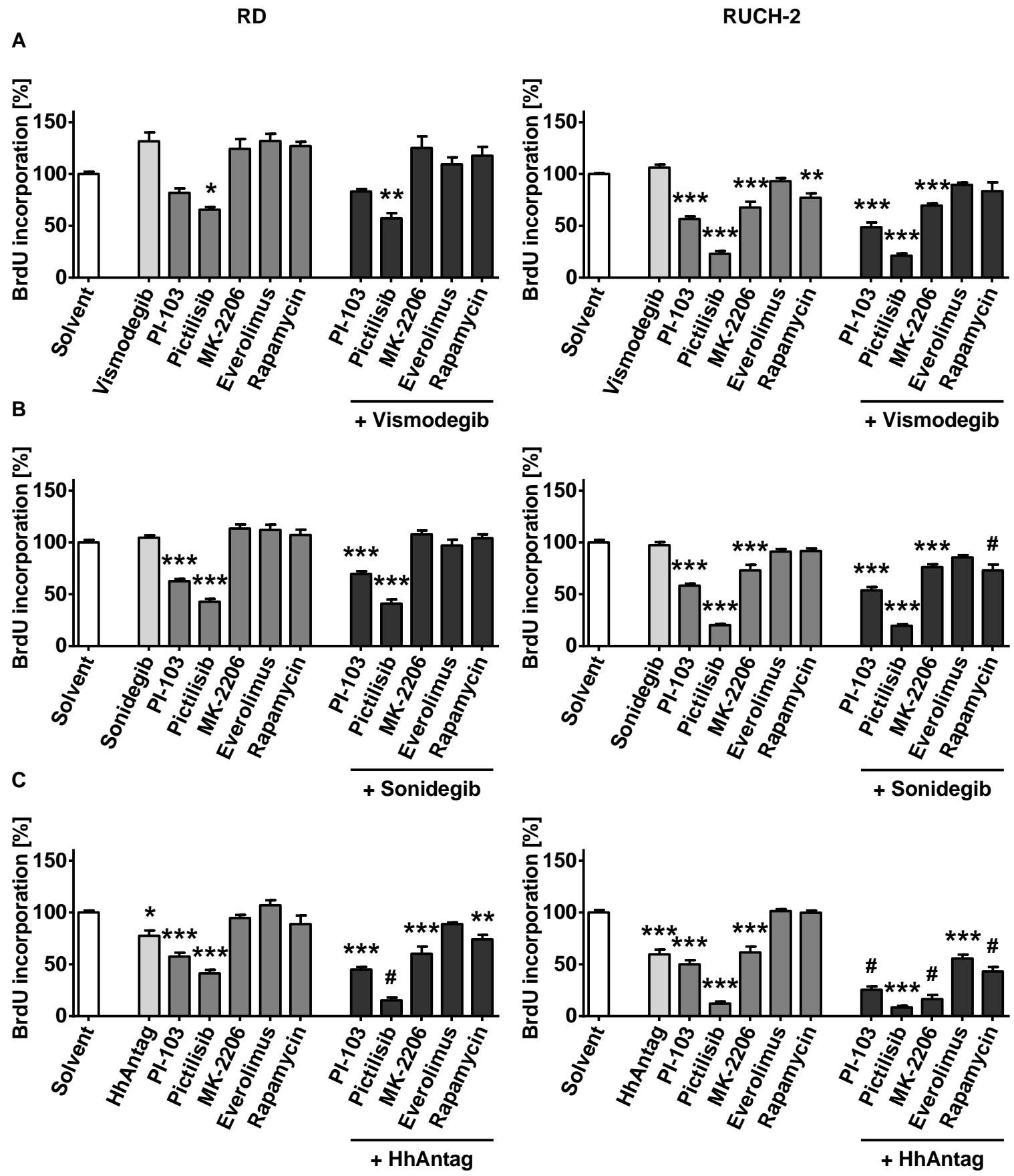

Figure 16: Impact of SMO and PI3K/AKT/mTOR inhibitors on proliferation. RD and RUCH-2 cells were treated for $24 \mathrm{~h}$ with drugs supplied in BrdU containing medium. Concentration of vismodegib, sonidegib and HhAntag was $10 \mu \mathrm{M}$ and those of PI-103, pictilisib, MK-2206, everolimus and rapamycin were $3 \mu \mathrm{M}, 10 \mu \mathrm{M}, 5 \mu \mathrm{M}, 50 \mathrm{nM}$ and $100 \mathrm{nM}$, respectively. BrdU incorporation of solvent treated cells was set to $100 \%$. Bars represent the mean +SEM of three independent experiments performed in triplicates. For statistical analysis a one-way ANOVA with Tukey's test for multiple comparisons was performed. ${ }^{*} P<0.05,{ }^{* *} P<0.01,{ }^{* \star *} P<0.001$ compared to solvent treated cells and $\# P<0.05$ compared to solvent treated cells and to cells treated with either single drug. (A), (B) and (C) show BrdU incorporation after treatment with vismodegib, sonidegib, HhAntag and/or $\mathrm{PI}$ IK/AKT/mTOR inhibitors, respectively. 


\subsubsection{Combinations of SMO inhibitors with pictilisib can induce synergistic anti- proliferative effects}

As some of the combinations were indeed able to intensify the anticancer effect of either single drug, it was investigated whether this intensification was synergistic or rather additive. For this purpose the PI3K inhibitor pictilisib was employed and combined with vismodegib, sonidegib or HhAntag. Pictilisib was chosen, because it targets the PI3K/AKT/mTOR pathway most upstream and is used in clinical studies. RD cells were incubated with five different concentrations of vismodegib, sonidegib, HhAntag and/or five different concentrations of pictilisib. BrdU incorporation during treatment was measured and the combination index $(\mathrm{Cl})$ was calculated with the help of CompuSyn software.

As already described by our lab ${ }^{121}$ and as seen in Fig. 6B vismodegib alone rather induced the proliferation of RD cells (Fig. 17A). In contrast sonidegib, HhAntag as well as pictilisib treatment inhibited the proliferation of RD cells in a concentration dependent manner (Figs. 17B and 17C).

When vismodegib, sonidegib or HhAntag were combined with pictilisib, a moderate enhancement of the anti-proliferative effects of either single drug was seen at some concentrations. Thus, the combination of $50 \mu \mathrm{M}$ vismodegib plus $10 \mu \mathrm{M}$ pictilisib led to a stronger reduction in proliferation than either single drug. With a $\mathrm{Cl}$ of 0.69 this effect was synergistic. Additionally, the combination of $25 \mu \mathrm{M}$ and $50 \mu \mathrm{M}$ sonidegib plus $5 \mu \mathrm{M}$ and 10 $\mu \mathrm{M}$ pictilisib, respectively, led to a stronger reduction in proliferation than either single drug. Out of these two combinations only the latter showed synergistic behavior with a $\mathrm{Cl}$ of 0.61 . When HhAntag was applied in concentrations above $12.5 \mu \mathrm{M}$ (corresponding to pictilisib concentrations above $2.5 \mu \mathrm{M}$ ) a stronger anti-proliferative effect of the combined treatment was observed compared to the anti-proliferative affects after treatment with either drug alone. Of these treatments the combination of $12.5 \mu \mathrm{M}$ HhAntag plus $2.5 \mu \mathrm{M}$ showed a synergistic behavior with a $\mathrm{Cl}$ of 0.74 .

Together the data show that vismodegib alone rather induces than reduces proliferation of ERMS cells, which is in accordance with published data ${ }^{121}$. In addition, the combination of SMO inhibitors $>12.5 \mu \mathrm{M}$ plus pictilisib $>2.5 \mu \mathrm{M}$ results in an enhancement of the antiproliferative effects that sometimes is synergistic. 


\begin{tabular}{|c|c|c|}
\hline $0.1-0.3$ & $0.3-0.7$ & $0.7-0.85$ \\
\hline $\begin{array}{c}\text { strong } \\
\text { synergism }\end{array}$ & synergism & $\begin{array}{l}\text { moderate } \\
\text { synergism }\end{array}$ \\
\hline
\end{tabular}

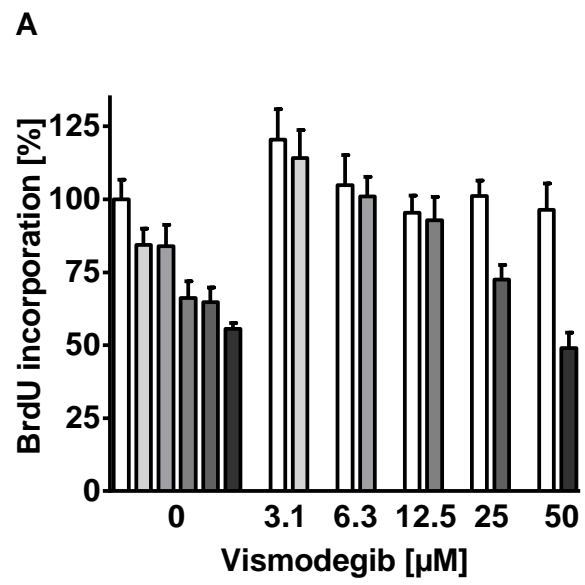

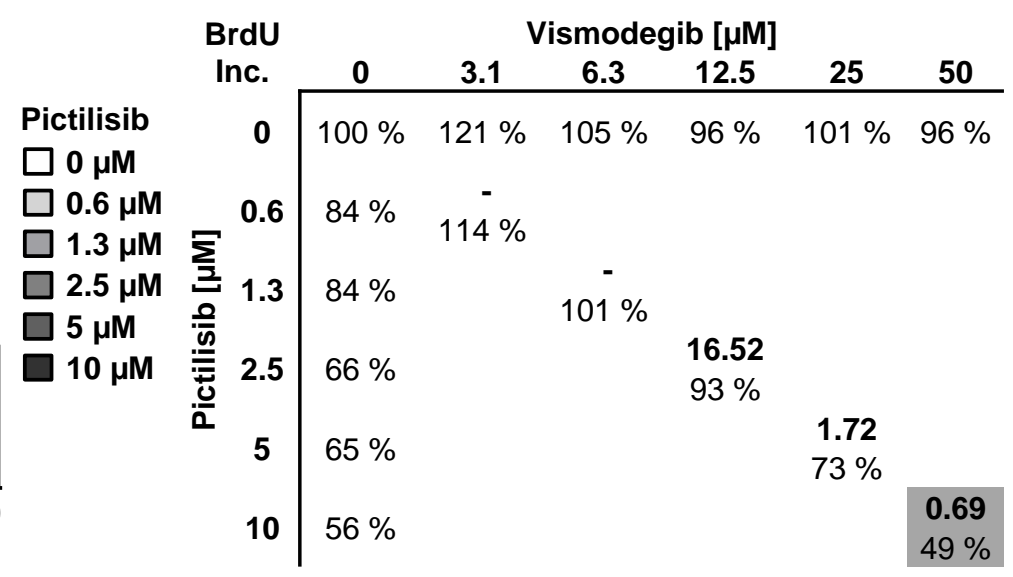
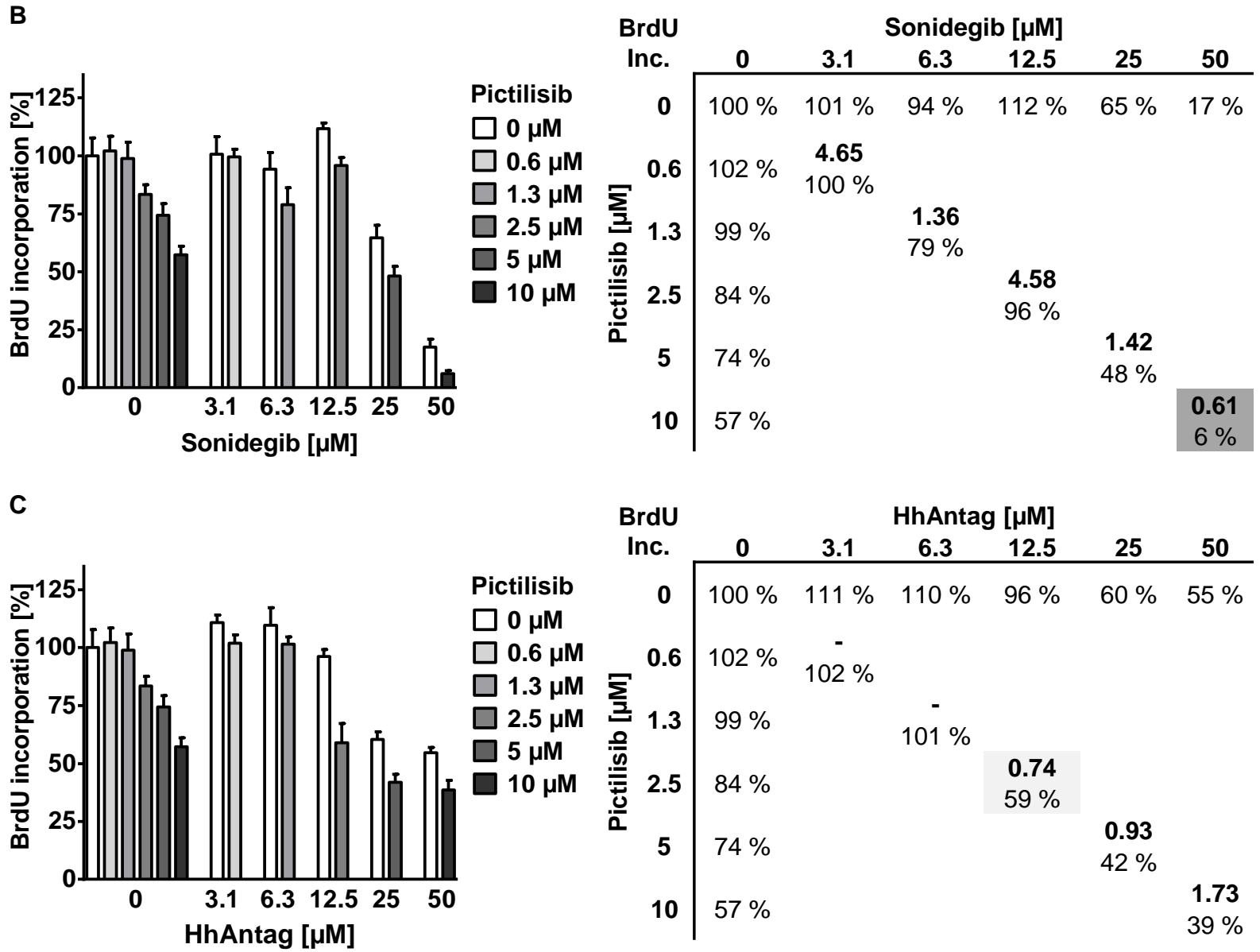

Figure 17: Synergistic anti-proliferative effects of combined SMO and PI3K inhibition. RD cells were treated with the indicated drugs for $48 \mathrm{~h}$. For the last $24 \mathrm{~h}$ BrdU was added and then BrdU incorporation (Inc.) was measured. Left: Bars represent the mean +SEM of three independent experiments performed in triplicates. Solvent treated cells were set to $100 \%$. Right: Combination Indices $(\mathrm{Cl})$ calculated with CompuSyn software. (A), (B) and (C) show BrdU incorporation and $\mathrm{Cl}$ after treatment with vismodegib, sonidegib, HhAntag and/or pictilisib, respectively. 


\subsubsection{Sonidegib or HhAntag, but not vismodegib, can induce cooperative pro- apoptotic effects when combined with PI3K/AKT/mTOR inhibitors}

Next apoptosis was investigated in RD cells that have been treated with SMO inhibitors alone or in combination with PI3K/AKT/mTOR inhibitors. For this purpose $10 \mu \mathrm{M}$ and $30 \mu \mathrm{M}$ of the SMO inhibitors vismodegib, sonidegib and HhAntag were applied alone or in combination with $\mathrm{PISK} / \mathrm{AKT} / \mathrm{mTOR}$ inhibitors (the concentrations are indicated in the figure legend of Fig. 16). For quantification of apoptosis, Annexin $V$ staining of living cells was performed and the number of apoptotic cells was measured with the help of flow cytometry.

Vismodegib alone did not induce apoptosis (Fig. 18A). In contrast, sonidegib and HhAntag significantly induced apoptosis when applied at a concentration of $30 \mu \mathrm{M}$ (Figs. 18B and $18 \mathrm{C})$. This is identical to data described in the thesis of R. Ridzewski ${ }^{228}$. Additionally, PI-103 and pictilisib significantly induced apoptosis, whereas MK-2206, everolimus and rapamycin did not.

Upon combination of SMO and PI3K/AKT/mTOR inhibitors, several combinations induced cooperative pro-apoptotic effects, meaning that the increase in apoptotic cells was significant compared to solvent treated cells and compared to the increase after treatment with either drug alone. The combinations of $30 \mu \mathrm{M}$ sonidegib plus pictilisib, PI-103 or MK-2206 cooperatively induced apoptosis. The same was true for the combinations of 10 or $30 \mu \mathrm{M}$ HhAntag plus MK-2206.

To sum up, sonidegib and HhAntag as well as PI-103 and pictilisib induce apoptosis in RD cells. In addition, the combinations of sonidegib plus PI-103, pictilisib or MK-2206 or the combination of HhAntag plus MK-2206 provoke cooperative pro-apoptotic effects. 
A

$\square 0 \mu \mathrm{M}$ Vismodegib $\square 10 \mu \mathrm{M}$ Vismodegib $\square 30 \mu \mathrm{M}$ Vismodegib

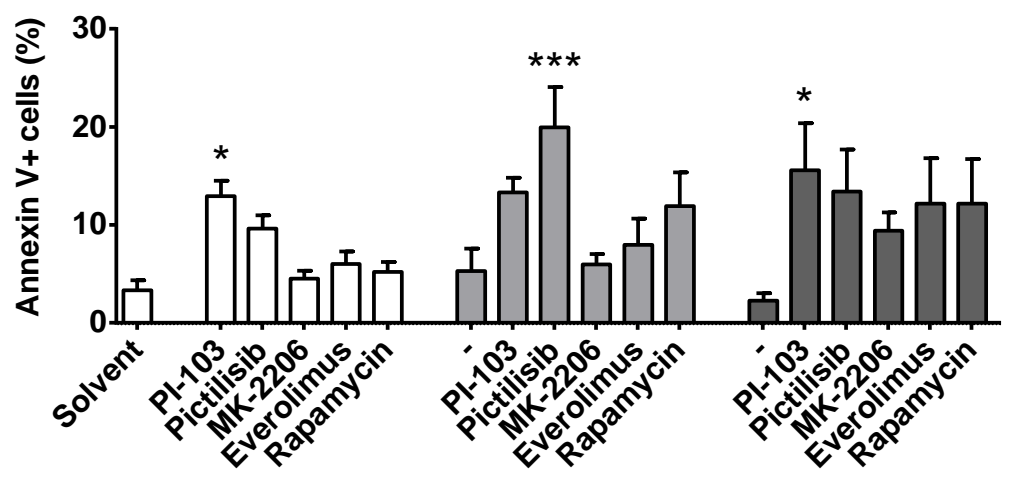

B

$\square 0 \mu \mathrm{M}$ Sonidegib $\square 10 \mu \mathrm{M}$ Sonidegib $\square 30 \mu \mathrm{M}$ Sonidegib

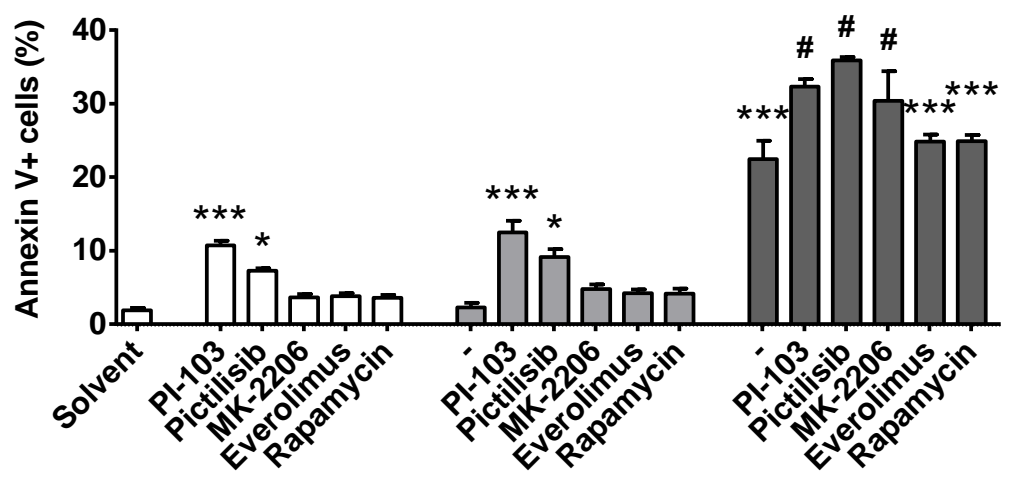

C

$\square 0 \mu \mathrm{M}$ HhAntag $\quad \square 10 \mu \mathrm{M}$ HhAntag $\square 30 \mu \mathrm{M}$ HhAntag

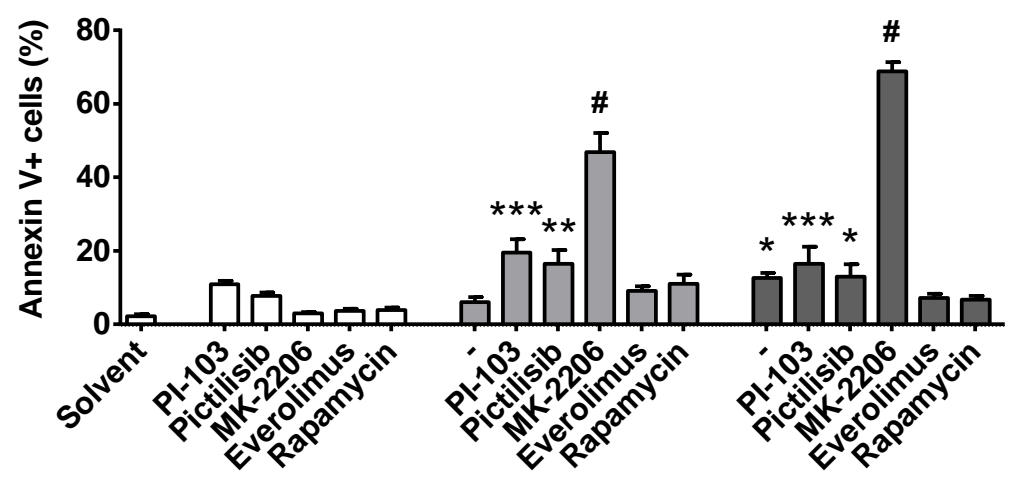

Figure 18: Impact of SMO and PI3K/AKT/mTOR inhibitors on apoptosis. RD cells were treated for $48 \mathrm{~h}$ with the indicated drugs. Concentrations of vismodegib, sonidegib or HhAntag were $10 \mu \mathrm{M}$ or 30 $\mu \mathrm{M}$, those of $\mathrm{PI}-103$, pictilisib, MK-2206, everolimus and rapamycin were $3 \mu \mathrm{M}, 10 \mu \mathrm{M}, 5 \mu \mathrm{M}, 5 \mathrm{nM}$ and $100 \mathrm{nM}$, respectively. Apoptotic cells were quantified by Annexin $\mathrm{V}$ staining and subsequent FACS analysis. Bars represent the mean percentage of apoptotic cells +SEM of two independent experiments performed in duplicates. For statistical analysis a one-way ANOVA with Tukey's test for multiple comparisons was performed. ${ }^{*} P<0.05,{ }^{* *} P<0.01,{ }^{* * *} P<0.001$ compared to solvent treated cells; \#P<0.05 compared to solvent treated cells and to cells treated with either single drug. (A), (B) and (C) show percentage of Annexin $V_{+}$cells for vismodegib, sonidegib, HhAntag and/or $\mathrm{PISK} / \mathrm{AKT} / \mathrm{mTOR}$ inhibitors, respectively. 


\subsubsection{Chapter summary}

In summary the results of this chapter show that ERMS cells are rather unresponsive to stimulation by the SHH ligand or SMO agonist and that SMO inhibitors do not inhibit HH/GLI activity in ERMS cells. In contrast, GLI activity is inhibited by the PI3K/AKT/mTOR inhibitors $\mathrm{PI}-103$, pictilisib, MK-2206, everolimus and rapamycin. Although we were not able to track this interaction down to any component of the PI3K/AKT/mTOR pathway (e.g. AKT), these drugs were combined with SMO inhibitors and potential cooperative effects on $\mathrm{HH}$ signaling, cellular proliferation and apoptosis were investigated. Whereas $\mathrm{HH}$ signaling activity is not affected, some of the combinations induce cooperative anticancer effects. Thus, the combinations of HhAntag plus PI-103, pictilisib, MK-2206 or rapamycin can induce strong cooperative anti-proliferative effects and the combinations of sonidegib plus $\mathrm{PI}-103$, pictilisib or MK-2206 as well as the combination of HhAntag plus MK-2206 induce strong cooperative pro-apoptotic effects.

The fact that ERMS cell lines were only moderately responsive to SHH or SMO inhibitors was at the first glance very surprising. This is due to the fact that patient-derived ERMS express high levels of $\mathrm{HH}$ ligands and of the downstream targets $G L / 1$ and $P T C H^{21,120}$. This discrepancy thus could indicate that human ERMS cell lines simply do not reflect the in vivo situation or that canonical $\mathrm{HH}$ signaling does not play a crucial role in ERMS. In addition it is possible that SMO inhibitors are only useful in those ERMS that are caused by mutations upstream of SMO i.e. by mutations in PTCH that are found in rare cases of ERMS. To approach these hypotheses, we next employed ERMS that are caused by PTCH mutations. Due to the non-canonical activation of $\mathrm{HH}$ signaling in human ERMS cell lines and since a knock-down of $\mathrm{PTCH}$ in these cells would not have adequately reflected the patient's situation, we used primary tumor cell cultures from Ptch mutant mice for the experiments. Like patients with heterozygous $\mathrm{PTCH}$ mutations these mice develop ERMS-like tumors that like human ERMS show active $\mathrm{HH}$ signaling and increased activity of $A K T^{34,242}$. Due to the latter fact and due to the interaction between the PI3K/AKT/mTOR and the $\mathrm{HH}$ signaling pathway, we also combined SMO inhibitors with PI3K/AKT/mTOR inhibitors.

\subsection{Targeting $\mathrm{Hh}$ and $\mathrm{Pi} 3 \mathrm{k} / \mathrm{Akt} / \mathrm{mTor}$ signaling pathways in murine Ptch $^{+/}$ERMS cells}

Due to a heterozygous deletion of Ptch exon 8 and 9, Ptch $^{+-}$mice on a BALB/c background develop ERMS-like tumors with highly active $\mathrm{Hh}$ signaling ${ }^{216,243}$. From these ERMS primary cultures were established and used to investigate the impact of the SMO inhibitors vismodegib, sonidegib and HhAntag alone or in combination with the PI3K inhibitor pictilisib 
on Hh signaling activity, Pi3k/Akt/mTor signaling activity, apoptosis and proliferation. The experiments focused on pictilisib as this drug is the most upstream of the ones investigated in the previous chapters and because it efficiently downregulated pAKT/AKT as well as pS6/S6 and evoked anticancer effects in human ERMS cell lines (see above).

\subsubsection{SMO inhibitors as well as pictilisib efficiently inhibit Gli1 expression}

At first the impact of SMO inhibitors alone and in combination with pictilisib on $\mathrm{Hh}$ signaling activity was investigated in Ptch ${ }^{+/}$ERMS cells by measurement of the expression level of the major Hh target gene Gli1 and two additional target genes Hhip and Gli2.

As expected and in contrast to human ERMS cell lines, all three SMO inhibitors significantly reduced the expression level of Gli1 in murine $\mathrm{Ptch}^{+-}$ERMS cells (Fig. 19). However, the drugs did not affect the expression level of Hhip or Gli2. As also seen in human ERMS cell lines, pictilisib reduced Gli1 expression. However, this drug concomitantly induced Hhip and Gli2 expression, which could be a sign for an Akt-dependent epigenetic silencing of Hhip in the $\mathrm{Ptch}^{+/}$ERMS. This hypothesis is discussed in section 6.5.2.

Upon combination of the SMO inhibitors with pictilisib the decrease in Gli1 expression levels was enhanced. When sonidegib or HhAntag were combined with pictilisib this effect was even cooperative upon normalization of the data to Tbp. With respect to the pictilisibmediated upregulation of Hhip and Gli2 it was interesting to see that some SMO inhibitors were able to rescue the pictilisib-induced expression levels. Whereas vismodegib did not affect Hhip and Gli2 expression (the only exception was a slight rescue of Hhip expression when normalized to $T b p$ ), sonidegib rescued the expression level of Hhip back to basal levels and HhAntag rescued the pictilisib-induced Hhip expression level by $50 \%$. Sonidegib additionally rescued the expression level of Gli2 back to basal level (when normalized to Tbp).

To sum up, SMO inhibitors as well as pictilisib reduce Gli1 expression levels and the combination of SMO inhibitors plus pictilisib can be more efficient than either drug alone. Surprisingly, pictilisib upregulates the expression levels of Hhip and Gli2. However, this upregulation is partly rescued when pictilisib is combined with SMO inhibitors. 

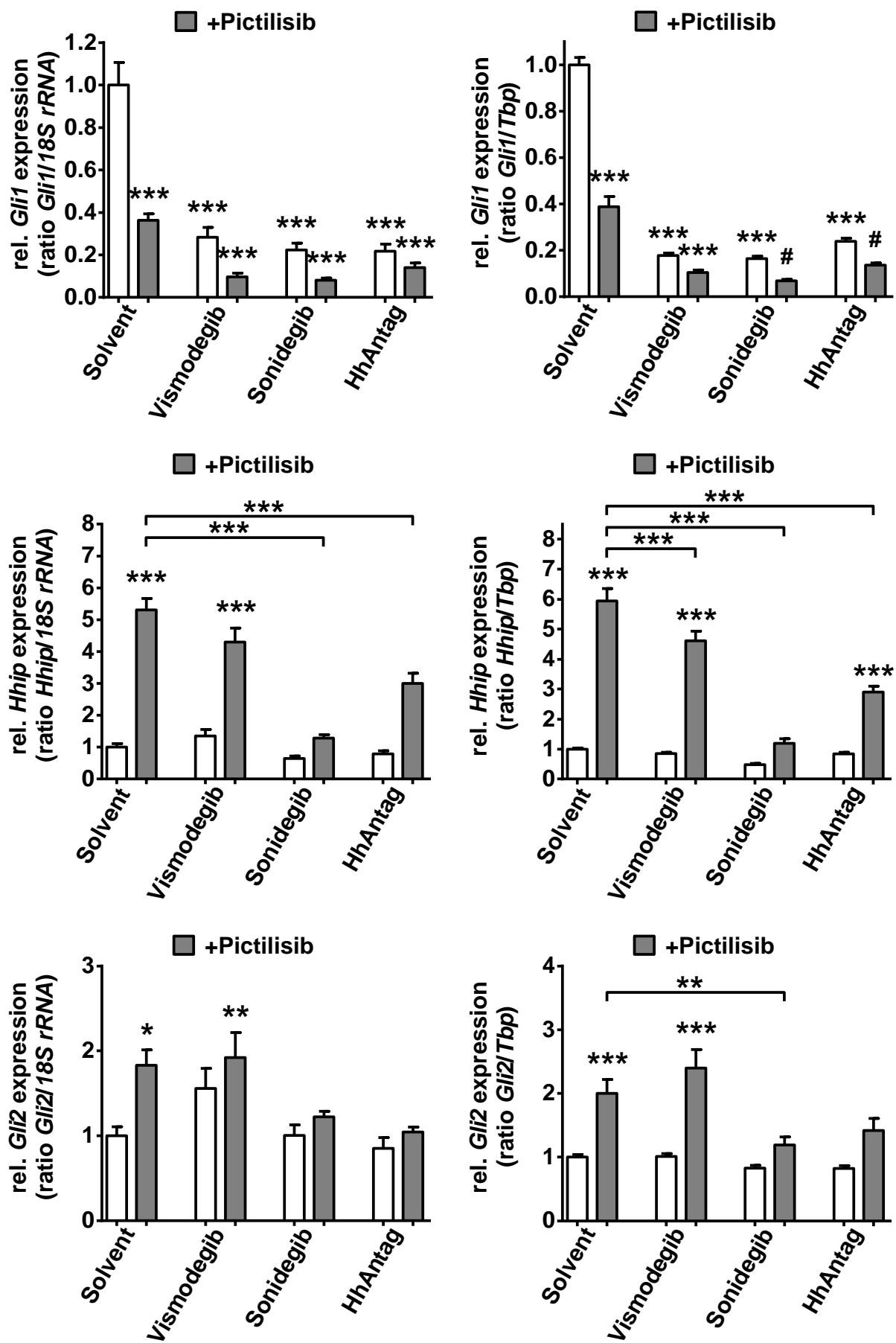

Figure 19: SMO inhibitors reduce Gli1 and can rescue the upregulation of Hhip occurring upon pictilisib treatment. Primary cultures from ERMS tissue of $\mathrm{Ptch}^{+-}$mice were treated with the indicated drugs for $48 \mathrm{~h}$. Concentration of vismodegib, sonidegib and HhAntag was $10 \mu \mathrm{M}$ and that of pictilisib was $5 \mu \mathrm{M}$. After treatment RNA was isolated and subjected to qRT PCR analysis for Gli1, Hhip and Gli2. Expression levels were normalized to 18S rRNA (left) and Tbp (right) and are shown as fold expression to solvent treated cells that was set to 1. Bars represent the mean +SEM of three independent experiments performed in duplicates. For statistical analysis a one-way ANOVA with Tukey's test for multiple comparisons was performed. ${ }^{\star} P<0.05$, ${ }^{* \star} P<0.01$, ${ }^{* \star *} P<0.001$ compared to solvent treated cells or as indicated; $\# P<0.05$ compared to solvent treated cells and cells treated with either single drug. 


\subsubsection{Pictilisib inhibits Akt phosphorylation and induces cleavage of caspase 3}

In the next step, the impact of SMO inhibitors alone or in combination with pictilisib on $\mathrm{Pi} 3 \mathrm{k} / \mathrm{Akt} / \mathrm{mTor}$ activity and apoptosis was investigated. For this purpose phosphorylation of Akt and caspase 3 cleavage were measured by Western Blot analysis and quantified.

Whereas none of the SMO inhibitors showed any effect on Akt or pAkt levels, pictilisib treatment efficiently downregulated pAkt levels in a concentration dependent manner as expected (Fig. 20). $1 \mu \mathrm{M}$ pictilisib additionally downregulated the total Akt level in $\mathrm{Ptch}^{+-}$ ERMS cells and these pictilisib-mediated changes in Akt/pAkt were not affected by SMO inhibitors.

Likewise, none of the SMO inhibitors significantly enhanced cleavage of caspase 3 in Ptch ${ }^{+1-}$ ERMS cells. In contrast, treatment with pictilisib led to a concentration dependent enhancement of caspase 3 cleavage (Fig. 20B). However, the combination of SMO inhibitors plus pictilisib did not further strengthen the induction of caspase 3 cleavage. Whereas pictilisib slightly reduced the level of caspase 3 in its pro form, none of the SMO inhibitors significantly affected it.

In summary, SMO inhibitors do not affect phosphorylation of Akt and thus the activity of $\mathrm{Pi} 3 \mathrm{k} / \mathrm{Akt} / \mathrm{mTor}$ signaling in $\mathrm{Ptch}^{+-}$ERMS cells. They also do not alter pictilisib-induced inhibition of Akt phosphorylation. Pictilisib induces cleavage of caspase 3 in these cells, which, however, is also not strengthened when combined with SMO inhibitors.

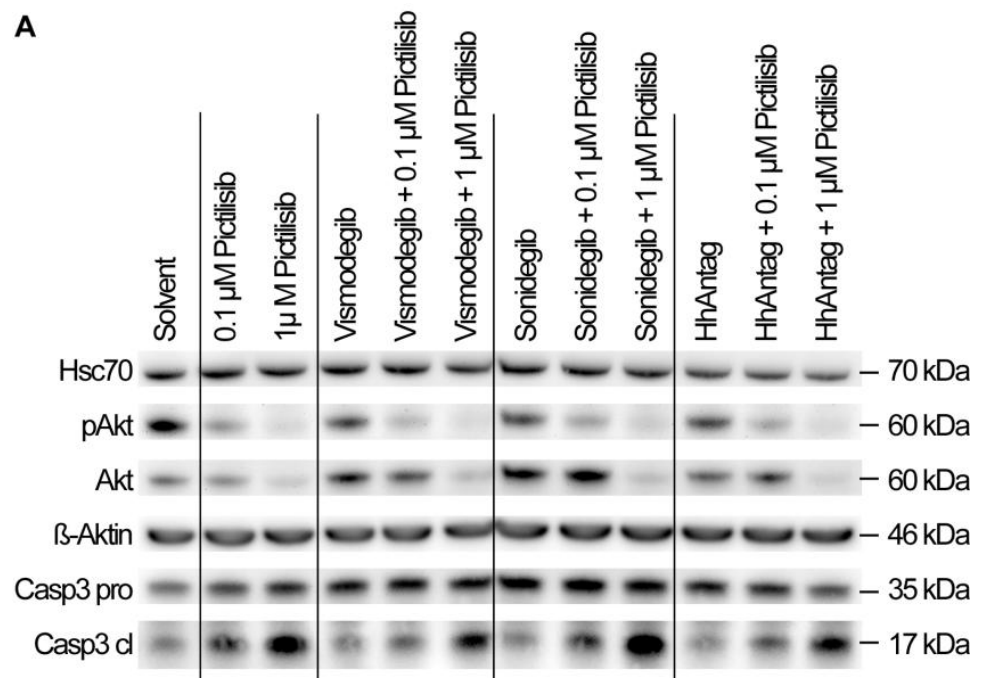



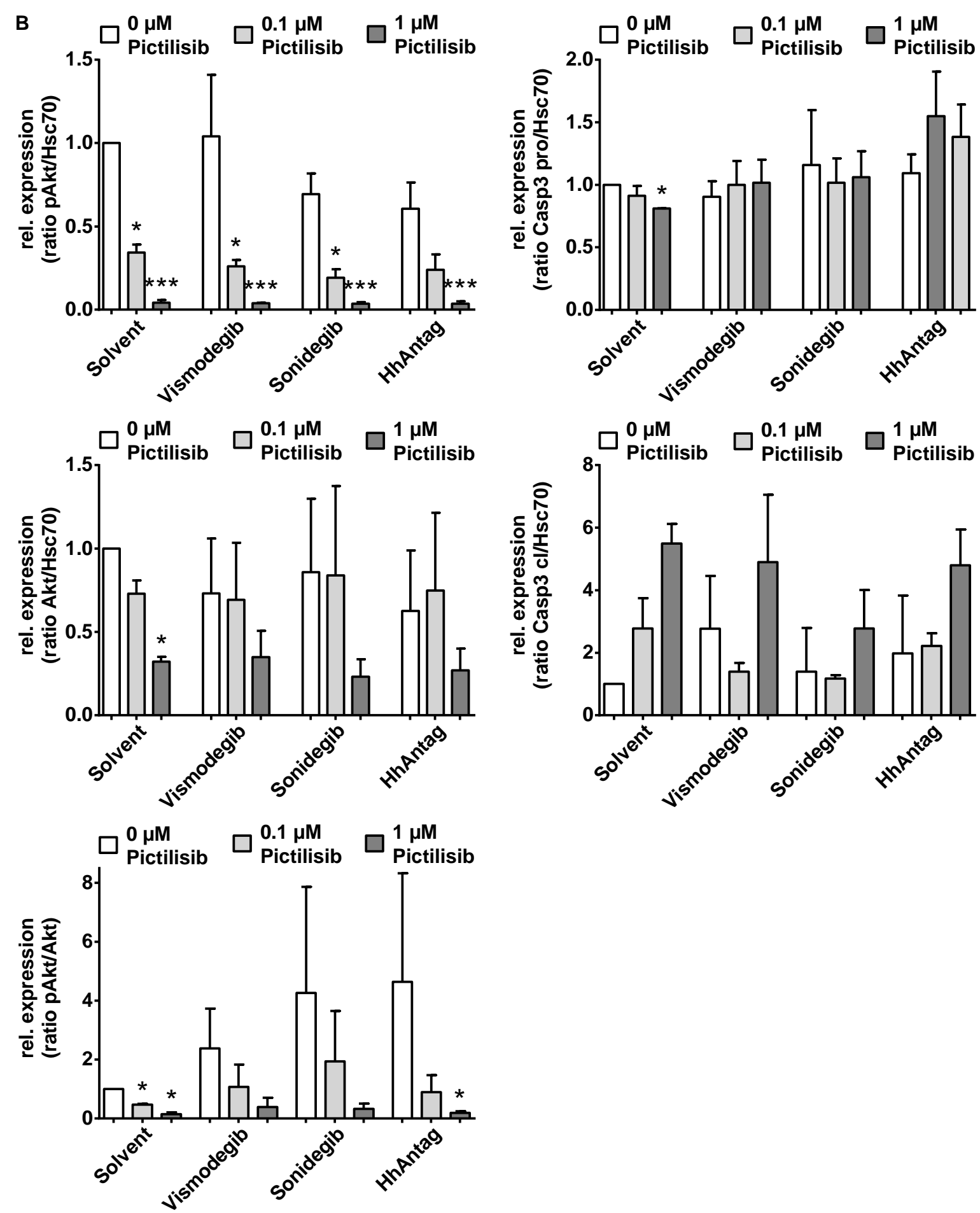

Figure 20: Impact of Smo and Pi3k inhibition on Pi3k/Akt/mTor activity and caspase 3 cleavage in primary $\mathrm{Ptch}^{+/}$ERMS cells. Primary cells from ERMS of $\mathrm{Ptch}^{+/}$mice were treated with the indicated drugs for $12 \mathrm{~h}$. Concentration of vismodegib, sonidegib or HhAntag was $5 \mu \mathrm{M}$. After treatment cells were harvested and cell lysates were used for Western Blot analysis to detect the level of pAkt, Akt, and caspase 3 (pro and cleaved (cl) form) with specific antibodies. Hsc70 served as loading control. (A) One representative blot out of three independent experiments is shown. Protein sizes in $\mathrm{kDa}$ are indicated on the right side. (B) Semi-quantitative densitometry. Bars represent the mean +SEM of three (pAkt/Akt) or two (caspase 3) independent experiments and protein levels of solvent treated cells were set to 1 . For statistical analysis a one-way ANOVA with Tukey's test for multiple comparisons was performed. ${ }^{*} P<0.05,{ }^{* *} P<0.01,{ }^{* * *} P<0.001$ compared to solvent treated cells. 


\subsubsection{Synergistic anti-proliferative effects of SMO inhibitors in combination with pictilisib}

As a next step it was investigated whether SMO inhibitors alone and in combination with pictilisib were able to affect proliferation of $\mathrm{Ptch}^{+/}$cells. ERMS cultures were incubated with five different concentrations of vismodegib, sonidegib, HhAntag and/or five different concentrations of pictilisib. BrdU incorporation during treatment was measured and the combination index $(\mathrm{Cl})$ was calculated with the help of CompuSyn software.

Vismodegib (Fig. 21A), sonidegib (Fig. 21B) or HhAntag (Fig. 21C) reduced the proliferation of $\mathrm{Ptch}^{+/}$ERMS cells in a concentration dependent manner. Sonidegib and HhAntag were more effective than vismodegib. Pictilisib treatment likewise reduced the proliferation in a concentration dependent manner. The combination of either SMO inhibitor plus pictilisib enhanced the anti-proliferative effects of the single drugs. By calculation of the $\mathrm{Cl}$, all combinations turned out to be synergistic. In case of vismodegib, the $\mathrm{Cl}$ was between 0.3 and 0.7 for all concentrations (synergism) with the exception of the lowest concentration that showed strong synergism ( $\mathrm{Cl}$ between 0.1 and 0.3 ). The combination of sonidegib plus pictilisib showed synergism at concentrations $>18 \mu \mathrm{M}$ sonidegib and $>5 \mu \mathrm{M}$ pictilisib. Concentrations beneath these showed moderate synergism ( $\mathrm{Cl}$ between 0.7 and 0.85 ). The combination of HhAntag plus pictilisib showed synergism at all concentrations. The exception was the highest concentration of $36 \mu \mathrm{M}$ HhAntag and $8 \mu \mathrm{M}$ pictilisib that showed moderate synergism.

In summary, all SMO inhibitors synergistically cooperated with pictilisib to inhibit proliferation of Ptch $^{+/-}$ERMS cells. 


\begin{tabular}{cc|c|c|}
\multicolumn{1}{c}{} & $0.1-0.3$ & $0.3-0.7$ & $0.7-0.85$ \\
\cline { 2 - 4 } & $\begin{array}{c}\text { strong } \\
\text { synergism }\end{array}$ & synergism & $\begin{array}{c}\text { moderate } \\
\text { synergism }\end{array}$ \\
\hline
\end{tabular}

A
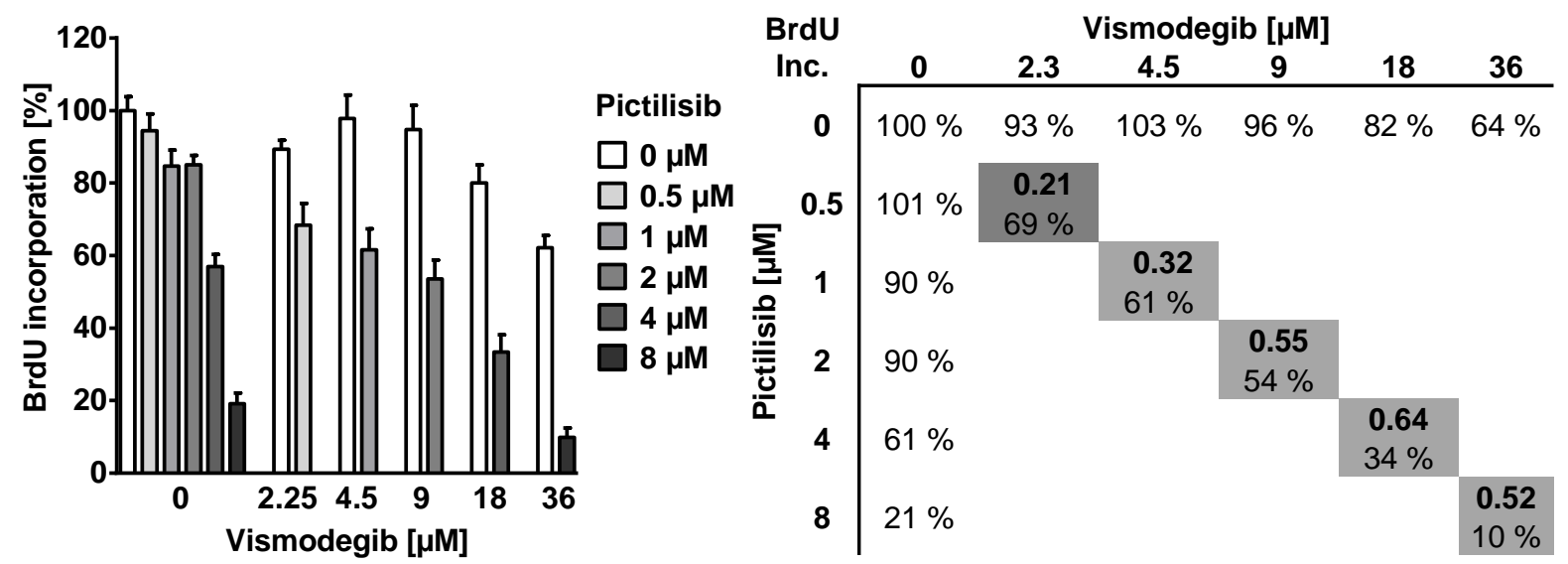

B
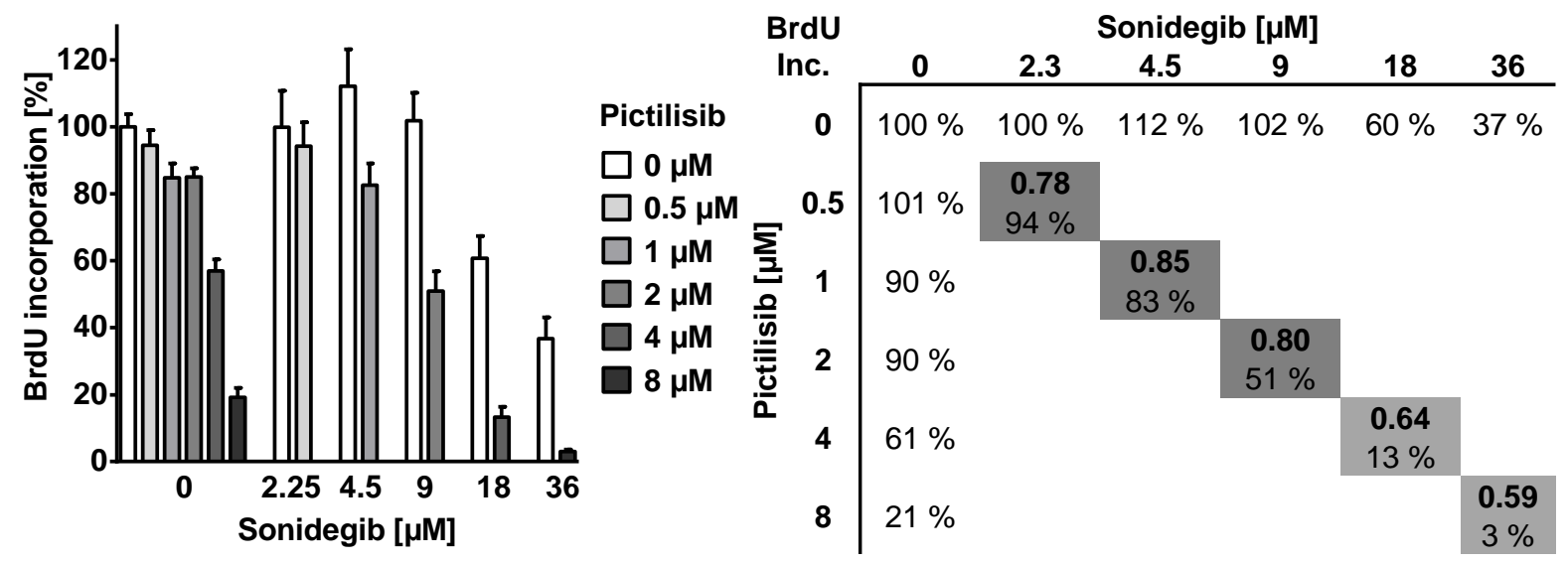

C
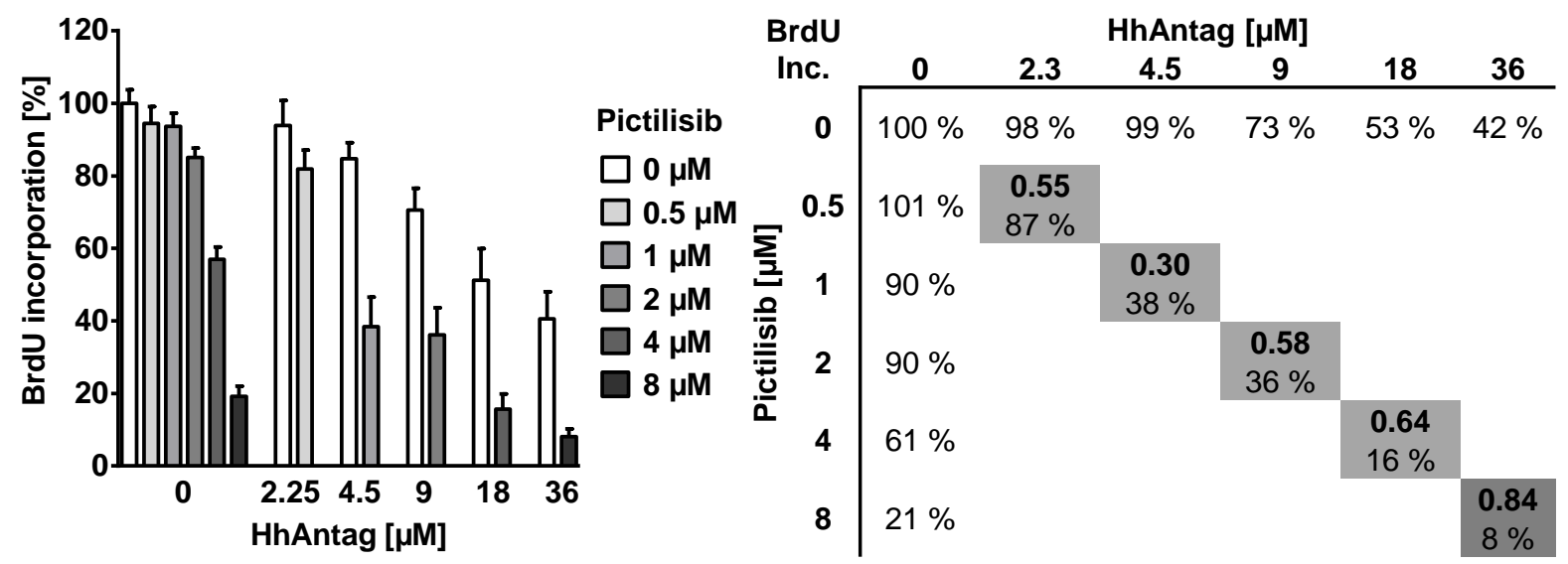
Figure 21: Synergistic anti-proliferative effects of SMO and PI3K inhibitors in Ptch ${ }^{+/}$ERMS cells. Primary cells from ERMS of $\mathrm{Ptch}^{+/}$mice were treated with the drugs as indicated for $48 \mathrm{~h}$. For the last $24 \mathrm{~h} \mathrm{BrdU}$ was added and BrdU incorporation (Inc.) was measured. Left: Bars represent the mean + SEM of three independent experiments performed in quadruplicates. Solvent treated cells were set to $100 \%$. Right: Combination indices (Cl) calculated with CompuSyn software. (A - C) shows $\mathrm{BrdU}$ incorporation and $\mathrm{Cl}$ for vismodegib, sonidegib, HhAntag and/or pictilisib.

\subsubsection{Chapter summary}

To sum up the second chapter, $\mathrm{Ptch}^{+-}$ERMS cells respond to SMO inhibitors alone and in combination with pictilisib. This response is more pronounced and much more solid than that of the cell lines derived from human sporadic ERMS. Thus, SMO inhibitors clearly reduce the $\mathrm{Hh}$ signaling activity of $\mathrm{Ptch}^{+-}$cells and this reduction can be enhanced when combined with pictilisib, which itself also reduces $\mathrm{Hh}$ signaling activity. Although pictilisib-induced proapoptotic effects are not enhanced by addition of either of the SMO inhibitors, all three investigated SMO inhibitors evoke synergistic anti-proliferative effects when they are combined with pictilisib. Together, the combination of SMO inhibitors plus pictilisib cooperatively induces anticancer effects that are associated with a strong inhibition of $\mathrm{Hh}$ signaling activity (Gli1 expression) in $\mathrm{Ptch}^{+/}$ERMS cells.

As all drugs alone or in combination were very effective in cultured $\mathrm{Ptch}^{+/}$ERMS cells, they were also applied in vivo in the established $\mathrm{Ptch}^{+/-}$mouse model for ERMS.

\subsection{Targeting $\mathrm{Hh}$ and Pi3k/Akt/mTor signaling pathways in ERMS of $\mathrm{Ptch}^{+/}$mice}

As mentioned above $\mathrm{Ptch}^{+/}$mice develop tumors that resemble human ERMS. ERMSbearing animals were treated with the SMO inhibitors vismodegib, sonidegib or HhAntag alone or in combination with pictilisib. All animals were treated twice a day with vehicle/vehicle (controls), drug/vehicle or drug/drug combinations. Tumor growth was monitored with the help of in vivo $\mu \mathrm{CT}$ analysis. At the end of the study RMS were analyzed with respect to proliferation, apoptosis and $\mathrm{Hh}, \mathrm{Pi} 3 \mathrm{k} / \mathrm{Akt} / \mathrm{mTor}$ activation status.

\subsubsection{SMO inhibitors and pictilisib can reduce ERMS tumor growth and their combination can enhance the antitumoral effects}

ERMS-bearing $\mathrm{Ptch}^{+/}$mice were treated daily with HhAntag and/or pictilisib for a period of 35 days. Tumor size was monitored before therapy onset, at day 21 and at the end of treatment. As shown in Figs. $22 \mathrm{C}$ and $22 \mathrm{~F}$, the treatment with HhAntag plus pictilisib resulted in extremely small tumors at the end of treatment, which precluded protein and RNA isolation. Therefore the treatment period for vismodegib and sonidegib in combination with pictilisib was reduced to 21 days. The tumor size in these studies was monitored before therapy onset 
and at the end of treatment. The amount of drugs used in the studies was based on recommendations given by the manufacturer and were $100 \mathrm{mg} / \mathrm{kg}$ vismodegib or HhAntag, $80 \mathrm{mg} / \mathrm{kg}$ sonidegib and/or $75 \mathrm{mg} / \mathrm{kg}$ pictilisib. The analysis of HhAntag and/or pictilisib treated tumors is already described in the thesis of R. Ridzewski ${ }^{228}$.

As shown in Figs. 22A - 22C and Table 18, treatment with vismodegib, HhAntag or pictilisib enhanced the number of mice that showed stable disease (SD) or partial response (PR) compared to vehicle treatment. Sonidegib alone or in combination with pictilisib and also vismodegib in combination with pictilisib resulted in PR in the majority of mice. According to RECIST analysis, HhAntag in combination with pictilisib was the most effective therapy, leading to PR in all mice. However, one must note that animals treated in context of the HhAntag/pictilisib study received the drugs for 35 days whereas animals of the vismodegib/pictilisib and sonidegib/pictilisib studies have been treated only for 21 days.

The results are also summarized in the tumor growth curves (Figs. 22D - 22F) that show the expected tumor growth for each treatment group calculated with a "mixed random effects" model. Thus, treatment with vismodegib or HhAntag alone is expected to efficiently stop tumor growth, leading to an estimated relative tumor volume of approximately 1 at the end of therapy. Sonidegib and pictilisib are expected to induce tumor regression, resulting in a significantly reduced estimated tumor volume at the end of therapy compared to vehicle. When vismodegib or sonidegib are combined with pictilisib, tumor regression is expected to be similar as for pictilisib treatment alone, whereas the combination of HhAntag plus pictilisib is expected to result in tumor regression that is more efficient than the single treatments.

To sum up, treatment with SMO inhibitors and/or pictilisib can induce efficient tumor regression in the $\mathrm{Ptch}^{+/}$mouse model for ERMS, which was strongest for sonidegib monotherapy and the HhAntag plus pictilisib combination therapy. 
A

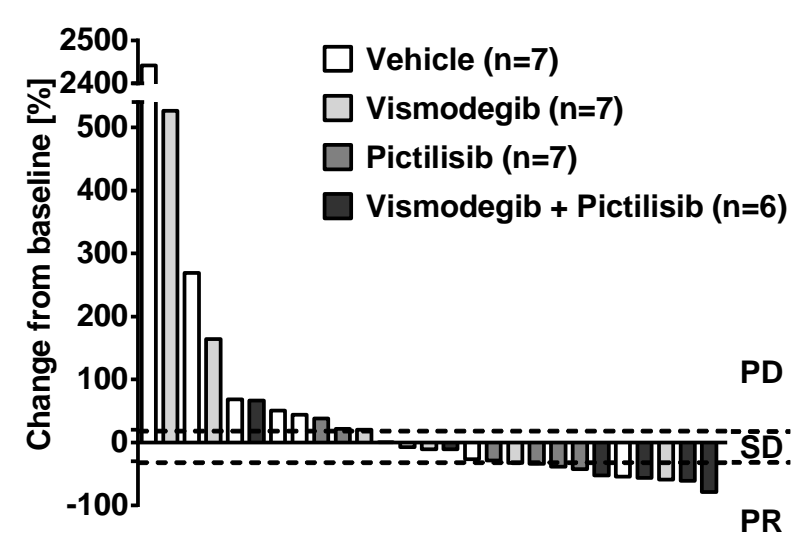

B

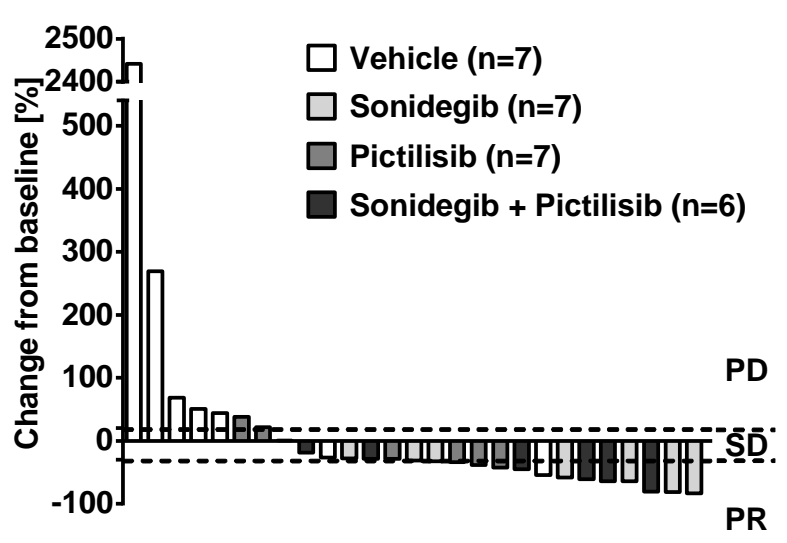

C

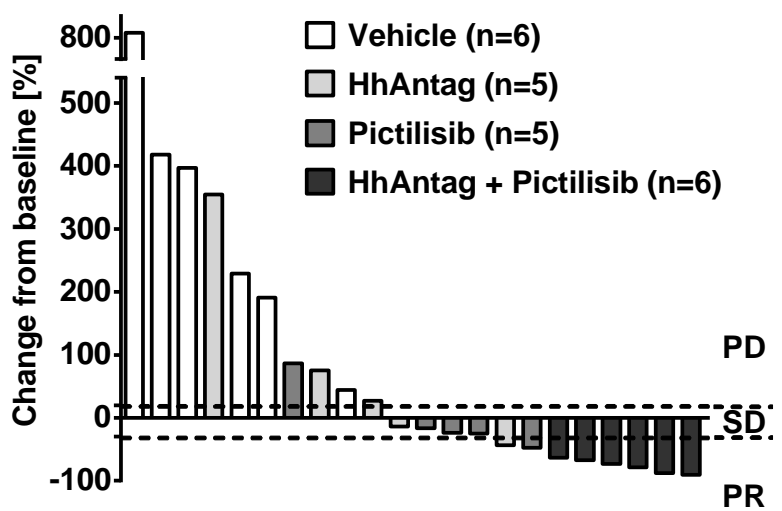

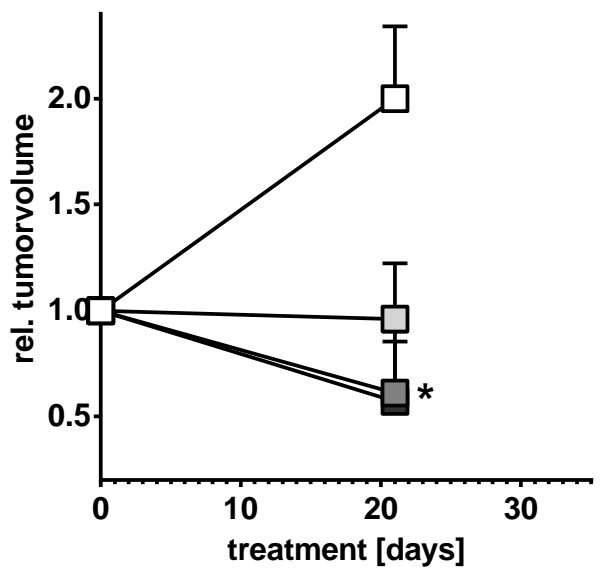

E

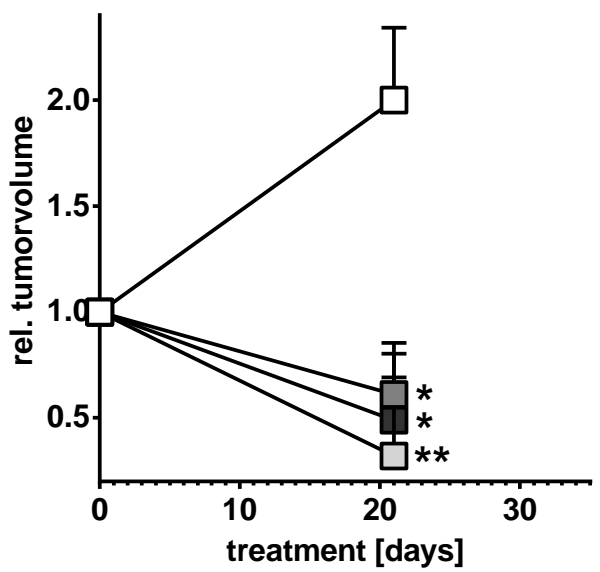

$\mathbf{F}$

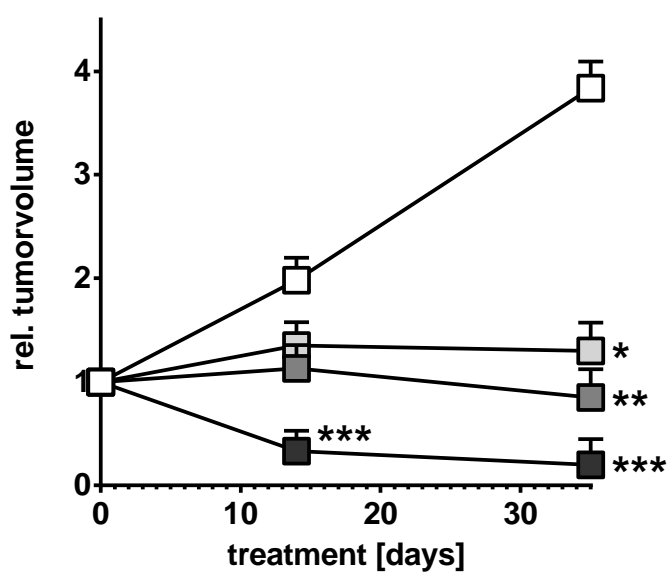

Figure 22: Impact of SMO inhibitors and/or pictilisib on ERMS tumor growth. RMS-bearing $\mathrm{Ptch}^{+/}$mice received $100 \mathrm{mg} / \mathrm{kg}$ vismodegib, $80 \mathrm{mg} / \mathrm{kg}$ sonidegib or $100 \mathrm{mg} / \mathrm{kg}$ HhAntag alone or in combination with $75 \mathrm{mg} / \mathrm{kg}$ pictilisib daily for 21 (vismodegib/pictilisib or sonidegib/pictilisib) or 35 (HhAntag/pictilisib) days. Drugs were supplied by oral gavage, suspended in methylcellulose tween vehicle. Tumor growth was monitored by low dose in vivo $\mu \mathrm{CT}$. (A) - (C) Bars represent changes in tumor size normalized to starting point. PD: progressive disease, SD: stable disease, PR: partial response according to RECIST analysis. (D) - (F) Shown is the expected tumor growth for each treatment group calculated with a mixed random effects model. For statistical analysis multiple testing was performed by the method of Dunnett-Hsu. ${ }^{*} P<0.05$, ${ }^{* *} P<0.01,{ }^{* * *} P<0.001$ compared to vehicle. 
Table 18: Analysis of data shown in Figs. 22A - 22C according to RECIST analysis. PD: progressive disease, SD: stable disease, PR: partial response. Values at therapy onset and end were evaluated.

\begin{tabular}{l|ccc|l} 
& PD & SD & PR & \\
\hline Vehicle & 5 & 1 & 1 & \\
Pictilisib & 2 & 2 & 3 & \\
Vismodegib & 3 & 2 & 2 & \\
Vismodegib + Pictilisib & 1 & 1 & 4 & \\
\hline & & & & Total: 27
\end{tabular}

\begin{tabular}{l|ccc|l} 
& PD & SD & PR & \\
\hline Vehicle & 5 & 1 & 1 & \\
Pictilisib & 2 & 2 & 3 & \\
Sonidegib & 0 & 1 & 6 & \\
Sonidegib + Pictilisib & 0 & 2 & 4 & \\
\hline & & & & Total: 27
\end{tabular}

\begin{tabular}{l|ccc|l} 
& PD & SD & PR & \\
\hline Vehicle & 6 & 0 & 0 & \\
Pictilisib & 1 & 3 & 1 & \\
HhAntag & 3 & 1 & 1 & \\
HhAntag + Pictilisib & 0 & 0 & 6 & \\
\hline & & & & Total: 22
\end{tabular}

\subsubsection{SMO inhibitors and/or pictilisib can reduce the number of $\mathrm{Ki}^{6} 7^{+}$tumor cells}

At the end of treatment, paraffin sections of tumor tissue were used to analyze the amount of $\mathrm{Ki} 67^{+}$nuclei by immunohistochemistry. The analysis of HhAntag and/or pictilisib treated tumors are already described in the thesis of R. Ridzewski ${ }^{228}$.

In vehicle treated tumors the amount of $\mathrm{Ki}^{+} 7^{+}$nuclei ranged between $4 \%$ and $8 \%$ of all nuclei (Fig. 23). Treatment with either SMO inhibitor or with pictilisib seems to reduce the number of $\mathrm{Ki}^{+} 7^{+}$nuclei and in case of sonidegib the reduction was significant compared to vehicle. When the SMO inhibitors were combined with pictilisib the reduction of $\mathrm{Ki}^{+} 7^{+}$nuclei was enhanced and the reduction was significant compared to vehicle. 

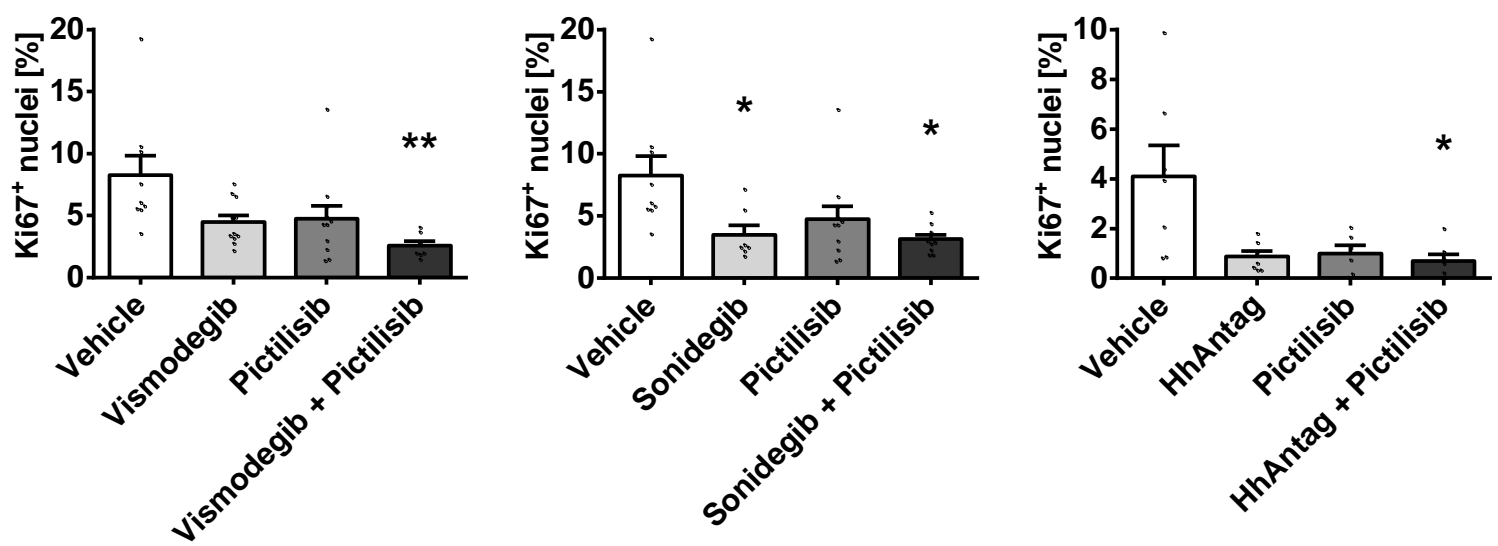

Figure 23: Percentage of $\mathrm{Ki}^{+}$cells in $\mathrm{Ptch}^{+/}$ERMS treated with SMO inhibitors and/or pictilisib. ERMS from the study shown in Figs. 22A - 22C were stained with an antibody specific for the proliferation marker Ki67. 6000-10000 nuclei were counted within each tumor. Bars represent the mean +SEM of 6-11 tumors. For statistical analysis a one-way ANOVA with Dunn's test for multiple comparisons was performed. ${ }^{*} P<0.05,{ }^{* *} P<0.01$ compared to vehicle.

To sum up, all three investigated SMO inhibitors as well as pictilisib reduce proliferation of $\mathrm{Ptch}^{+/}$ERMS. The combinations of vismodegib plus pictilisib and HhAntag plus pictilisib enhance the anti-proliferative effects of either single treatment whereas sonidegib alone is as efficient as the combination of sonidegib plus pictilisib. This is in line with the results shown in Figs. $22 \mathrm{~A}-22 \mathrm{C}$ and Table 18 demonstrating that vismodegib/pictilisib, sonidegib/pictilisib, HhAntag/pictilisib or sonidegib alone increase the number of mice showing PR and almost completely prevent PD. However, these results do not perfectly match with the estimated growth curves depicted in Figs. 22D - 22F as the latter model shows that pictilisib alone will reduce tumor growth in a similar manner as vismodegib/pictilisib and sonidegib/pictilisib. Differences between the growth estimation model and the data shown in Fig. 23 might be due to the small number of animals that were analyzed. Finally, the more pronounced decrease in $\mathrm{Ki}^{+} 7^{+}$cells in HhAntag/pictilisib treated tumors compared to either single treatment is in line with the estimated tumor growth reduction.

\subsubsection{SMO inhibitors, but not pictilisib, strongly reduce Gli1 expression}

Next, the expression level of the major Hh target Gli1 and of another target Hhip was analyzed in the tumor tissues (Fig. 24). Since ERMS that have been treated with HhAntag and/or pictilisib for 35 days were too small for protein or mRNA isolation (see section 5.3.1), a new cohort of mice was set up. ERMS-bearing mice were only treated for 14 days with HhAntag and/or pictilisib and then the tumors were isolated for molecular analysis (according to the tumor growth model shown in Fig. 22F, HhAntag and/or pictilisib already reduce tumor growth at around 14 days after therapy onset). 

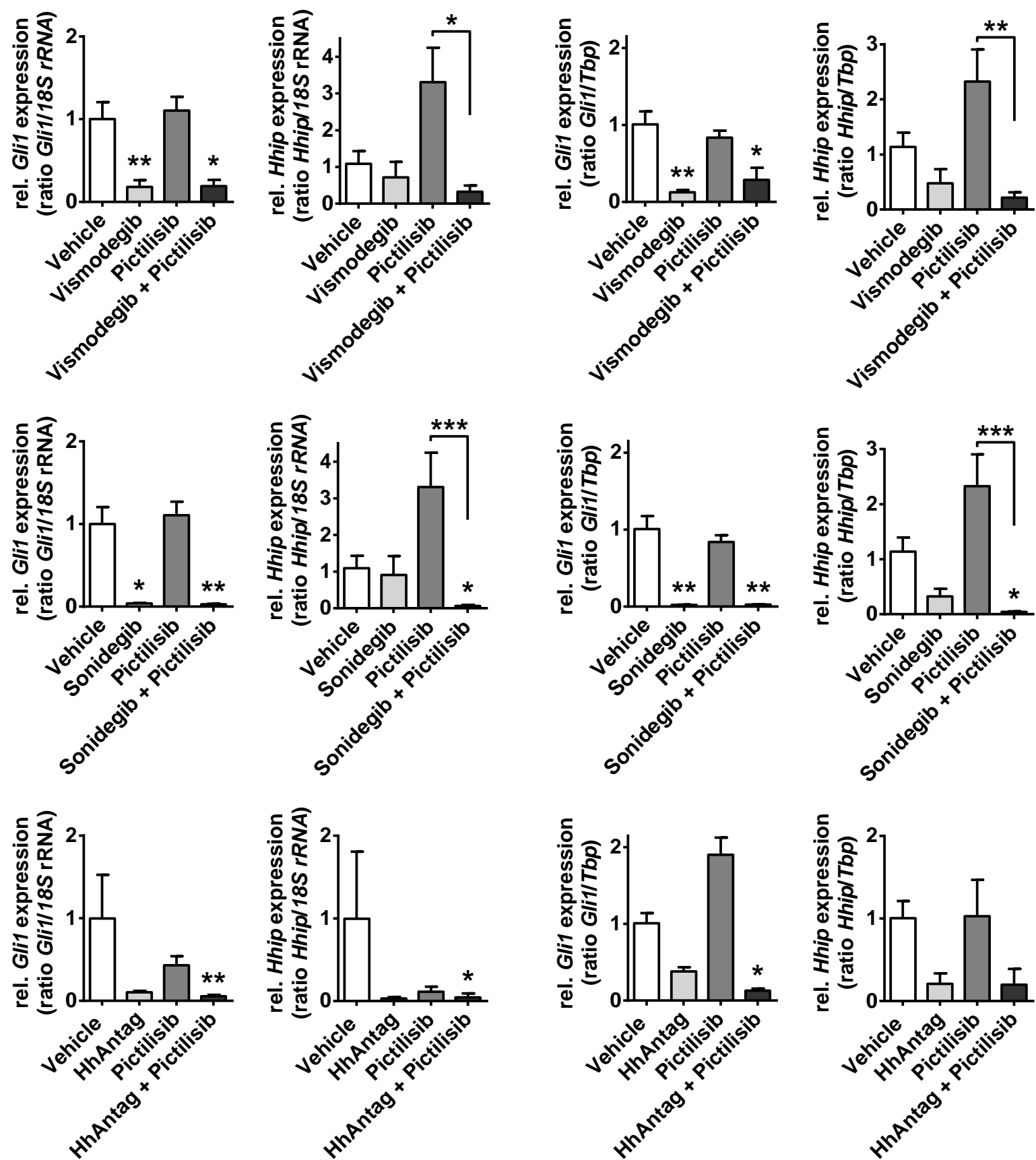

Figure 24: Effect of SMO and/or PI3K inhibitors on Hh signaling activity. Ptch $^{\text {t/ }}$ ERMS from studies shown in Figs. 22A and 22B and ERMS from $\mathrm{Ptch}^{+/}$mice treated with $100 \mathrm{mg} / \mathrm{kg}$ HhAntag and/or $75 \mathrm{mg} / \mathrm{kg}$ pictilisib for 14 days were used for RNA isolation and qRT PCR analysis to assess the expression levels of Gli1 and Hhip. Expression levels were normalized to 18S rRNA (left) or Tbp (right) and are shown as fold expression to vehicle treated cells that were set to 1. For statistical analysis a Kruskal-Wallis test with Dunn's test for multiple comparisons was performed. ${ }^{*} P<0.05$, ${ }^{* \star} P<0.01,{ }^{* \star *} P<0.001$ compared to vehicle or as indicated.

As shown in Fig. 24 vismodegib, sonidegib and HhAntag reduced the expression levels of Gli1 and Hhip. In contrast to the human ERMS cell lines and primary Ptch ${ }^{+-}$ERMS cells, pictilisib did not significantly reduce or induce the expression of Gli1 or Hhip. Please also note the difference in gene expression when $18 S$ rRNA or Tbp were used for normalization. 
This difference could be due to intertumoral differences in housekeeper gene expression as RMS tissues are known to have a very heterogeneous cellular composition (experience of our group).

The combination treatment with vismodegib or sonidegib plus pictilisib reduced Gli1 expression to a similar extent as vismodegib or sonidegib alone. When sonidegib was combined with pictilisib the reduction of Hhip expression was pronounced and, in the case of sonidegib plus pictilisib, the reduction was significant compared to vehicle. Similarly, the reduction of Gli1 and Hhip expression was pronounced when HhAntag was combined with pictilisib and became significant compared to vehicle.

Next, the Gli1 expression level of each tumor was correlated with the tumor growth pattern from the study shown in Figs. $22 \mathrm{~A}$ and $22 \mathrm{~B}$ to see if the relative tumor size at the end of treatment is associated with $\mathrm{Hh}$ signaling activity. Due to the fact that Gli1 expression data for the tumors of the combination study HhAntag and/or pictilisib shown in Fig. $22 \mathrm{C}$ were not available, the correlation analysis could not be performed for this cohort.

The correlation analysis showed that the reduction of tumor size is associated with a downregulation of $\mathrm{Hh}$ signaling activity in the tumors that were treated with vismodegib or sonidegib alone or in combination with pictilisib (Fig. 25A). In contrast, in the cohorts that received vehicle or pictilisib, Gli1 expression levels were not positively correlated with tumor size (Fig. 25B), showing that tumor size in these cohorts is not associated with inhibition of Hh signaling activity. The latter is also true for the pictilisib cohort alone (Fig. 25C).

In summary, all three SMO inhibitors reduce $\mathrm{Hh}$ signaling activity in $\mathrm{Ptch}^{+/}$tumors, whereas pictilisib has no effect. In addition, pictilisib may enhance the inhibitory effect of HhAntag. Furthermore, the level of $\mathrm{Hh}$ signaling inhibition by vismodegib or sonidegib (alone and in combination with pictilisib; data for HhAntag are unfortunately not available, see above) correlates with reduction of tumor growth. 
A
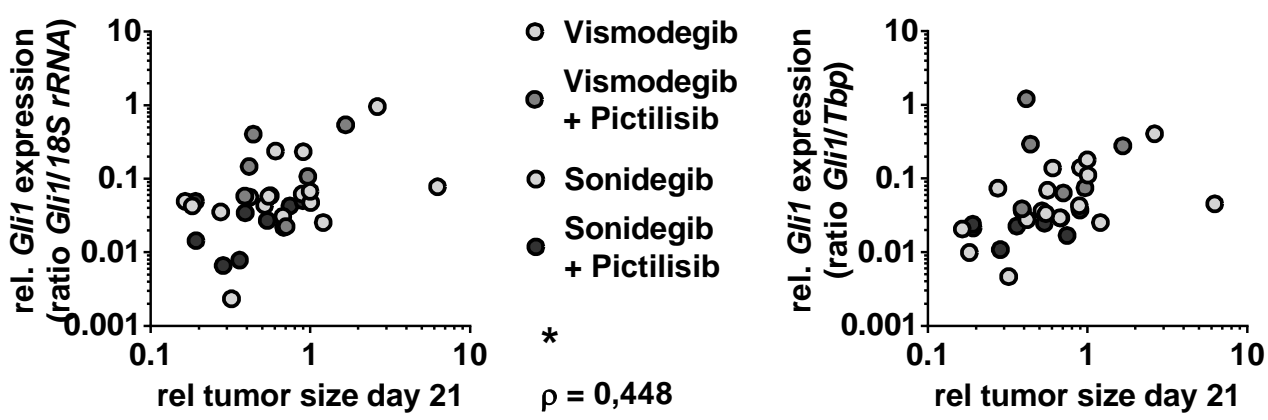

- Vismodegib

Vismodegib

+ Pictilisib

- Sonidegib

Sonidegib

+ Pictilisib

$\star \star \star$

$\rho=0,561$

B

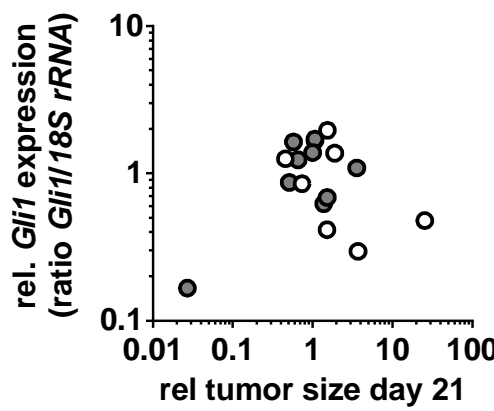

- Vehicle

- Pictilisib

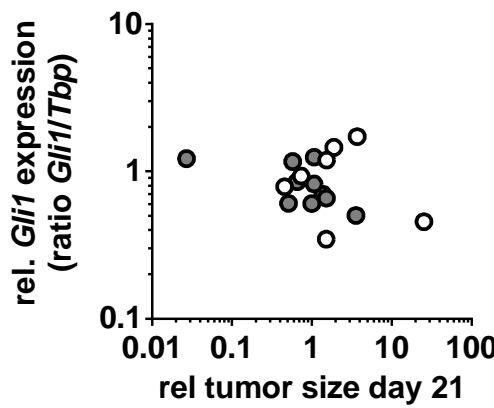

- Vehicle

- Pictilisib

$\rho=-0,118$

C
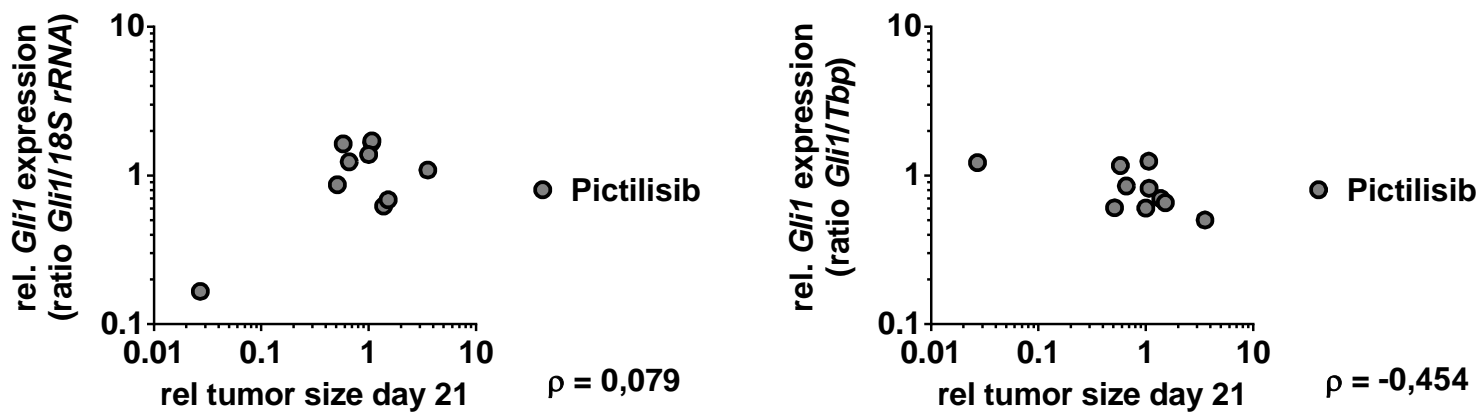

Figure 25: Vismodegib and sonidegib, but not pictilisib, reduce tumor growth in Ptch $^{+/-}$mice in dependency on $\mathrm{Hh}$ signaling activity. Shown is the correlation analysis of Gli1 expression levels shown in Fig. 24 and the corresponding relative (rel) tumor size. Spearman coefficient $\rho$ is indicated for each pair of data. ${ }^{*} P<0.05,{ }^{* *} P<0.01,{ }^{* *} P<0.001$. Analysis was performed for cohorts treated with (A) vismodegib, vismodegib/pictilisib, sonidegib and sonidegib/pictilisib, (B) vehicle and pictilisib or (C) pictilisib. 


\subsubsection{Effects of SMO inhibitors and pictilisib on Pi3k/Akt/mTor signaling and caspase 3 cleavage}

In addition, the influence of the drugs on Pi3k/Akt/mTor signaling activity and on caspase 3 cleavage was investigated. For this purpose the phosphorylation level of Akt and the protein levels of caspase 3 in its pro and cleaved forms were analyzed in tumor tissue (Figs. 26A 26C show representative Western Blots; the results for the combination treatment with HhAntag plus pictilisib, shown in Fig. 26C, are also described in the thesis of $R$. Ridzewski ${ }^{228}$ ). Although the results were very heterogeneous, they were quantified by semiquantitative densitometric analysis (Fig. 27).

As shown in Fig. 27, phosphorylation of Akt was only moderately reduced by the SMO inhibitors, whereas pictilisib significantly reduced pAkt/Akt levels as expected. Surprisingly, the combinations of either SMO inhibitor with pictilisib seem to rescue pAkt/Akt levels back to basal level or to the level, which was reached upon treatment with SMO inhibitors alone.

Unfortunately, the results with respect to caspase 3 cleavage were very heterogeneous (see Figs. $26 \mathrm{~A}-26 \mathrm{C}$ ) and therefore a distinct quantification did not make sense.

In summary, all three SMO inhibitors moderately reduce phosphorylation of Akt in Ptch ${ }^{+-}$ ERMS tissue, whereas pictilisib has a strong and significant effect. However, the combination of either SMO inhibitor with pictilisib seem to rescue pAkt/Akt levels back to basal level or to the level upon treatment with SMO inhibitors alone. 
A

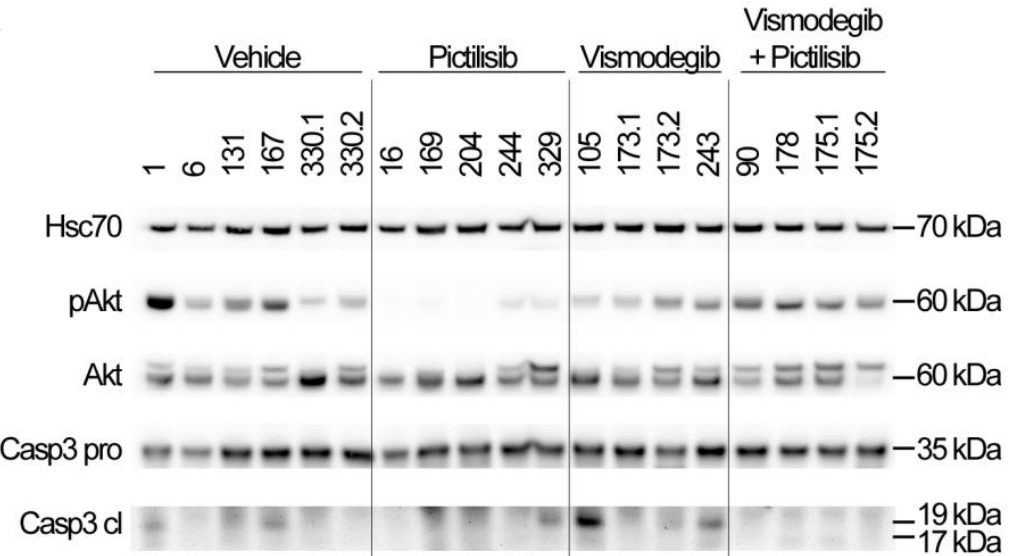

B

Vehicle $\quad$ Pictilisib $\longrightarrow$ Sonidegib $\begin{aligned} & \begin{array}{l}\text { Sonidegib } \\ + \text { Pictilisib }\end{array} \\ & \text { + }\end{aligned}$

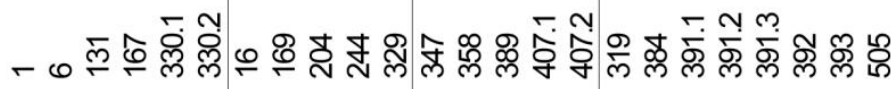

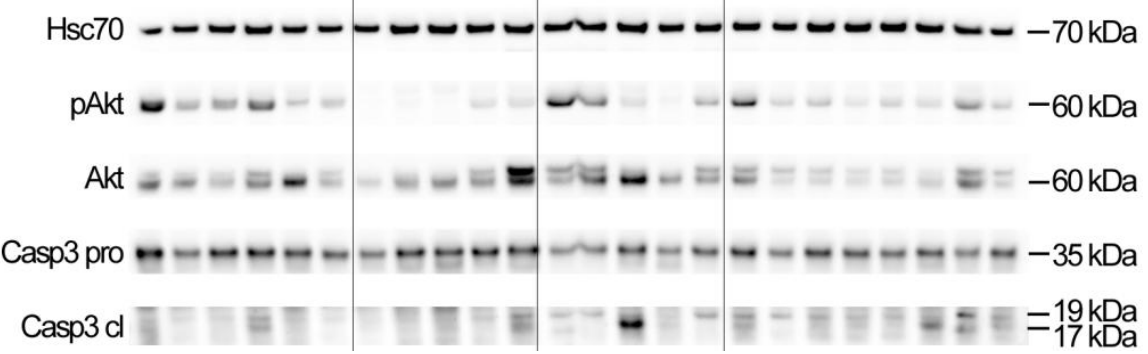

C

Vehicle $\quad$ HhAntag - Pictilisib $-\begin{aligned} & \text { HhAntag } \\ & + \text { Pictilisib }\end{aligned}$

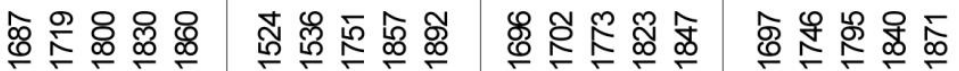

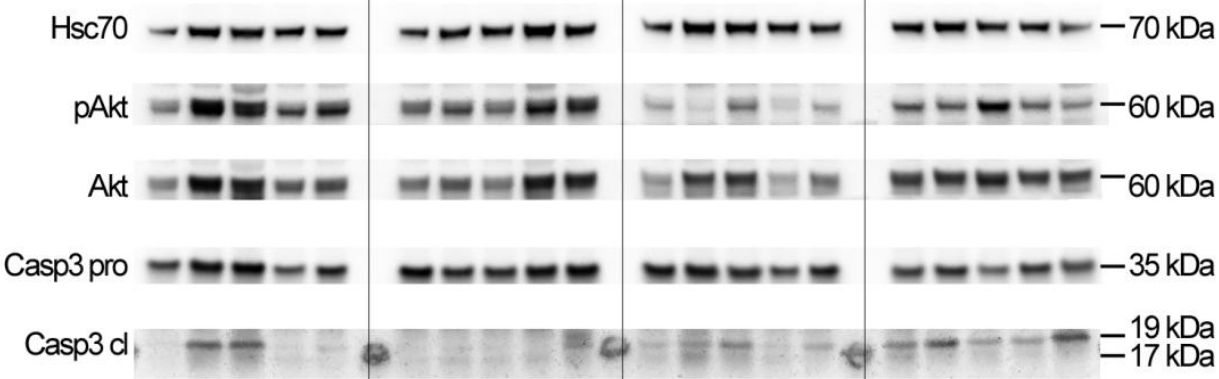

Figure 26: Impact of vismodegib, sonidegib, HhAntag and/or pictilisib on Pi3k/Akt/mTor activity and caspase 3 cleavage in tumors of Ptch $^{+/}$mice. Protein of ERMS from the study shown in Figs. 22A and 22B and ERMS from Ptch $^{+/}$mice treated with $100 \mathrm{mg} / \mathrm{kg} \mathrm{HhAntag}$ and $/ \mathrm{or} 75 \mathrm{mg} / \mathrm{kg}$ pictilisib for 14 days were used for Western Blot analysis. The protein levels of pAkt, Akt, Caspase 3 (Casp3 pro and cleaved (cl) form) were detected with specific antibodies. Hsc70 served as loading control. The blots are representative for at least 2 independent blots and (A), (B) and (C) show the data for vismodegib, sonidegib, HhAntag and/or pictilisib, respectively. Protein sizes in $\mathrm{kDa}$ are indicated on the right side of the blots. 

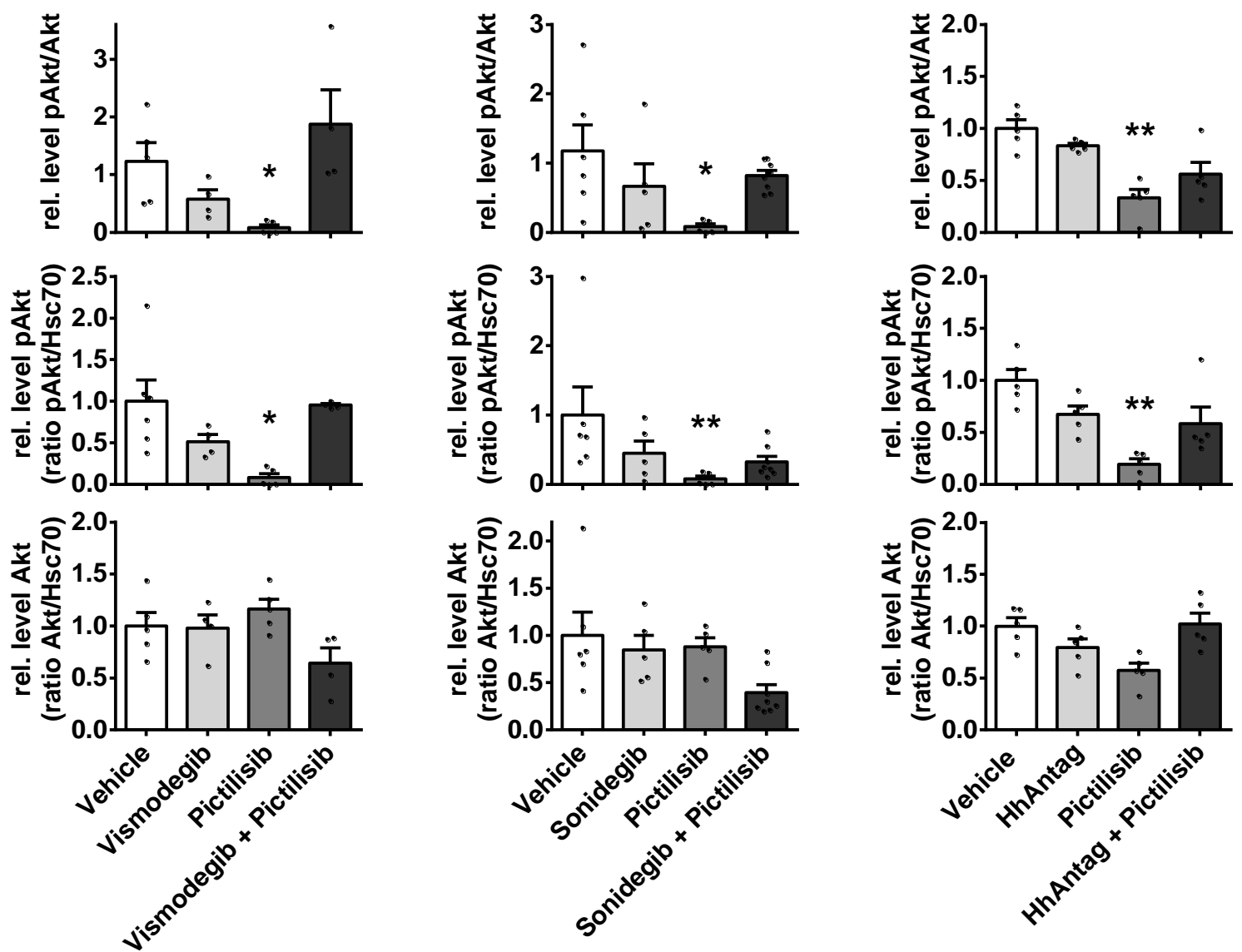

Figure 27: Quantification of pAkt levels shown in Fig. 26. Densitometric analysis of data shown in Figs. 26A - 26C. Bars represent the mean +SEM protein levels of pAkt/Akt ratio, pAkt and Akt normalized to Hsc70. Protein levels of vehicle treated tumors were set to 1. For statistical analysis a Kruskal-Wallis test with Dunn's test for multiple comparisons was performed. ${ }^{*} P<0.05,{ }^{* *} P<0.01$, ${ }^{* * *} P<0.001$ compared to vehicle treated tumors.

\subsubsection{Chapter summary}

In the third chapter the anticancer effects of SMO inhibitors alone and in combination with pictilisib in the $\mathrm{Ptch}^{+/}$mouse model for ERMS are described. In this model SMO inhibitors as well as pictilisib stop tumor growth. Sonidegib is the most efficient SMO inhibitor when used as a single agent and HhAntag plus pictilisib seem to be the most efficient combination. Additionally SMO inhibitors, especially sonidegib, as well as pictilisib reduce the proliferation rate of the tumors and this effect is strengthened in the combination treatments. Furthermore, as in cultured $\mathrm{Ptch}^{+/}$ERMS cells, Hh signaling activity is significantly reduced by either SMO inhibitor. Moreover the downregulation of $\mathrm{Hh}$ signaling activity seen upon vismodegib and sonidegib treatment correlates with reduction of tumor size, indicating a direct dependency of tumor growth on Hh signaling in this model. But in contrast to cultured Ptch ${ }^{+/}$ERMS cells and 
human ERMS cell lines, pictilisib does not affect Hh signaling activity when applied alone or in combination with SMO inhibitors. Additionally the functionality of pictilisib was proven by a downregulation of pAkt within the tumor tissue.

Together, these data show that RMS growth in the $\mathrm{Ptch}^{+-}$mouse model is dependent on active canonical Hh signaling. Hence, the effective downregulation of $\mathrm{Hh}$ signaling by SMO inhibitors goes along with strong anticancer effects. The most effective drug was sonidegib. Pictilisib treatment also reduced tumor growth, but in an Hh-independent manner. In addition, the effectiveness of a combination treatment with SMO inhibitors and pictilisib seems to be drug-dependent. Whereas the effectiveness of vismodegib and sonidegib cannot be enhanced by pictilisib the effectiveness of HhAntag apparently is. These results are partly contradictory to the results obtained from cultured $\mathrm{Ptch}^{+/}$ERMS cells (e.g. all SMO inhibitors evoke synergistic anti-proliferative effects when combined with pictilisib) and could depend on drug pharmacokinetics or the tumor microenvironment that is missing in cell cultures. 


\section{Discussion}

The importance of $\mathrm{HH}$ signaling in RMS was first discovered when the $P T C H$ germline mutations were found to be causal for the development of multiple tumors in patients with Gorlin syndrome, among them ERMS ${ }^{56-58}$. Until now expression of $\mathrm{HH}$ signaling components was shown in the majority of all sporadic RMS with higher degree of pathway activation in ERMS and fusion-gene negative ARMS compared to fusion-gene positive ARMS $^{21,22,113}$. However, in sporadic RMS the $\mathrm{HH}$ signaling activity is most likely driven by other mechanisms than mutations in components of the $\mathrm{HH}$ pathway. Two clinical trials investigating the effectiveness of SMO inhibitors in RMS were performed and showed that the drugs are generally tolerated. Follow-up trials are missing so far.

Our group has shown that the effectiveness of SMO inhibitors in cell lines derived from sporadic RMS strongly depends on the cell line investigated and that effectiveness is not necessarily associated with a downregulation of $\mathrm{HH}$ signaling activity ${ }^{121}$. Therefore, it was first hypothesized that besides canonical $\mathrm{HH}$ signaling, non-canonical activation via $\mathrm{PI} 3 \mathrm{~K} / \mathrm{AKT} / \mathrm{mTOR}$ signaling may play a role in sporadic RMS tumorigenesis and maintenance. Indeed, the majority of sporadic RMS show phosphorylation of AKT or S6 $6^{207-209}$ and cross-talk between PI3K/AKT/mTOR and $\mathrm{HH}$ signaling is well described ${ }^{108}$. Second, it was hypothesized that the antitumoral effects of SMO inhibitors may rely on off-target effects.

Here, we investigated these hypotheses in more depth and we analyzed the effectiveness of SMO inhibitors alone and in combination with PI3K/AKT/mTOR inhibitors in cell lines derived from sporadic ERMS and in the $\mathrm{Ptch}^{+/-}$mouse model for ERMS. Together, we show that the effectiveness of SMO inhibitors depends on the mode of $\mathrm{HH}$ signaling activation. Whereas the drugs rather induce GL/1-independent antitumoral effects in cell lines derived from sporadic ERMS, their anticancer effects correlate with Gli1 expression levels in Ptch ${ }^{+/}$ERMS cells and in vivo in ERMS of the Ptch $^{+-}$mouse model. In either case combination with $\mathrm{PI}$ IK/AKT/mTOR inhibitors can be beneficial.

\subsection{Effectiveness of SMO inhibitors on ERMS cell lines with low HH activity}

Previous work of our group showed that SMO inhibitors can induce apoptosis and reduce proliferation of RMS cell lines. Whereas sonidegib and HhAntag showed strong antitumoral effects, cyclopamine as well as vismodegib did either not affect or even enhance proliferation of the cell lines ${ }^{121}$. However, the observed antitumoral effects were not always associated with a downregulation of $\mathrm{HH}$ signaling activity, e.g. $30 \mu \mathrm{M}$ sonidegib reduced proliferation 
and induced apoptosis of RD cells but did not affect GLI1 expression. Since this was indicative for off-target effects, a RD cell line with a stable SMO knockdown ${ }^{118}$ was incubated with the SMO inhibitors cyclopamine, vismodegib, sonidegib and HhAntag.

So far, a SMO knockdown was described in CCA and Rh36 cells where it did not affect proliferation ${ }^{168}$. However, the SMO knockdown in RD cells apparently reduced tumor growth in xenograft models and sphere formation in vitro ${ }^{118}$. When analyzing the latter model, we found a strong, but incomplete reduction of SMO protein levels (see Fig. 5). This was accompanied by reduced $\mathrm{HH}$ signaling activity. Because this cell line showed very low basal levels of SMO expression, we expected that SMO inhibitors would be less effective compared to control cells with higher basal SMO expression. However, against this expectation, the experiments revealed that RD SMOlow cells are more sensitive towards cyclopamine, sonidegib or HhAntag compared to RD SMOhigh cells. Indeed, RD SMOlow cells stopped to grow or even died when they were incubated with these SMO inhibitors. Thus, pharmacological inhibition of the remaining SMO activity in RD SMOlow cells induced strong anti-proliferative effects. This could reflect a situation, in which cells with very low $\mathrm{HH}$ signaling activity (i.e. RD SMOlow cells) are more sensitive to small changes in $\mathrm{HH}$ signaling. In other words, in tumor cells with low $\mathrm{HH}$ signaling activity even a small pharmacological inhibition of signaling leads to dramatic induction of effectiveness. A similar behavior was shown in vivo for vismodegib in preclinical models for medulloblastoma and colorectal cancer $^{135}$, for the B-RAF inhibitor PLX4032 in melanoma ${ }^{244}$ and for the B-RAF inhibitor GDC0879 in melanoma and colorectal cancer ${ }^{245}$. A possibility to prove this hypothesis would require the measurement of SMO activity. This could for example be done with a phosphospecific SMO antibody that shows the activation status of SMO as described ${ }^{246}$.

The lack of any effect of vismodegib in both RD SMOlow cells and RD SMOhigh cells is hard to explain, because it is opposite to previous observed data from our group showing that vismodegib enhances BrdU incorporation of RD cells ${ }^{121}$. It is also opposite to another report showing that vismodegib reduces viability of $\mathrm{RD}$ cells ${ }^{120}$. However, one possible explanation might be an acquired SMO mutation in the RD subclone used for generation of the SMO knockdown, which might induce a selective resistance against vismodegib. Indeed, in the literature a D477G mutation in SMO has been described that causes resistance towards vismodegib while only mildly reducing the effectiveness of cyclopamine, sonidegib or HhAntag ${ }^{232,233}$. However, the explanation is rather unlikely, since the parental RD cells do not harbor this mutation (personal communication of Heidi Hahn with Javed Khan, Genetic Branch, NIH). Finally, the different cellular response to one out of four investigated SMO inhibitors might indicate that these drugs indeed exert off-target effects. Thus, vismodegib as all other SMO inhibitors - downregulated GL/1 expression moderately (see Fig. 14A) but 
did not affect proliferation of RD cells. If SMO would be the only target for all four drugs, one would expect similar cellular responses to either drug.

Another explanation for the lack of effectiveness of vismodegib is the fact that it binds to other structures in the binding pocket of SMO, which might be compromised in the used cell lines $^{41,247}$. Another possibility might be that proliferation of RD cells is not only regulated by the SMO/GLI axis but by other mechanisms that were not further investigated here. In contrast to vismodegib, cyclopamine, sonidegib and HhAntag, vismodegib might influence these mechanisms.

\subsection{Modulation of canonical HH signaling in ERMS cell lines}

Our data here demonstrates that it is not possible to strongly activate canonical $\mathrm{HH}$ signaling in $\mathrm{RD}$ and $\mathrm{RUCH}-2$ cells by stimulation with $\mathrm{SHH}$. This was surprising, because human sporadic RMS samples express $\mathrm{HH}$ ligands and show activity of $\mathrm{HH}$ signaling ${ }^{21,120}$. However, in human RMS, $\mathrm{DHH}$ and $\mathrm{IHH}$ are the predominant $\mathrm{HH}$ ligands and $\mathrm{DHH}$ and $\mathrm{IHH}$ depletion downregulates GLI1 protein levels in RD cells ${ }^{120}$. Thus, these two $\mathrm{HH}$ ligands would have been more reliable for the experiment. Nevertheless, the fact that SAG, which binds to the upper part of the ligand binding pocket of $\mathrm{SMO}^{41}$, also did not activate $\mathrm{HH}$ signaling activity, rather argues for a relative unresponsiveness of $\mathrm{RD}$ and $\mathrm{RUCH}-2$ cells towards ligand-based stimulation of the pathway. Furthermore, autocrine secretion of $\mathrm{DHH}$ and $\mathrm{IHH}$ should have stimulated the $\mathrm{HH}$ pathway in an autocrine loop. However, the incubation of the cells with SMO inhibitors did in general not block the pathway. Similarly, when investigating the impact of SMO inhibitors on the transcriptional activity of GLI proteins using a luciferase-based GLI reporter system in RD cells, we found that none of the compounds inhibited the expression of the reporter (see Fig. 8). These data are furthermore in contrast to the data showing that vismodegib or sonidegib moderately and HhAntag significantly reduced GLI1 expression in RD cells (see Fig. 14).

Together, our data - although partly in contrast to the current literature - strongly suggest that canonical $\mathrm{HH}$ signaling does not play a major role in cell lines that are derived from sporadic human ERMS. In addition, the fact that some SMO inhibitors i.e. HhAntag significantly inhibited GLI1 transcription, but did not affect GLI activity, argues for an offtarget effect of this compound. Furthermore, the observation that vismodegib - in contrast to cyclopamine, sonidegib or HhAntag - does not affect growth of RD SMOlow and RD SMOhigh cells, also indicates off-target effects as already described above. 


\subsection{Non-canonical modulation of $\mathrm{HH}$ signaling via PI3K/AKT/mTOR in ERMS cell lines}

In general it was shown that GLI1 expression and thus $\mathrm{HH}$ signaling activity can be regulated in sporadic ERMS, as also shown above. Furthermore it is known that the RAS/RAF/MEK/ERK and PI3K/AKT/mTOR pathways, that are active in RMS, can regulate $\mathrm{HH}$ signaling. Due to these facts we next investigated the potential cross-talk between the $\mathrm{HH}, \mathrm{RAS} / \mathrm{RAF} / \mathrm{MEK} / \mathrm{ERK}$ and PI3K/AKT/mTOR pathways in cell lines derived from sporadic ERMS.

In order to analyze the impact of RAS/RAF/MEK/ERK signaling, RD cells were treated with the MEK inhibitor U0126. The drug significantly upregulated GL/1 expression level in a concentration-dependent manner (see Fig. 11A). Similar results have been described for pancreas carcinoma, in which RAS signaling negatively regulates GLI2 and GLI3 through DYRK1B $^{97}$. In contrast, treatment of RD cells with PI3K/AKT/mTOR inhibitors efficiently downregulated GLI1 expression (see Fig. 11B). This could be explained by an AKT-mediated inactivation of PKA and GSK3 $\beta$, which inhibits the negative influence of these proteins on GLI activity ${ }^{54,248}$. Another possible explanation is that S6K1 phosphorylates and thereby releases GLI1 from its negative regulator SUFU ${ }^{108}$.

To sum up, non-canonically regulated $\mathrm{HH}$ signaling in human ERMS cell lines by both RAS/RAF/MEK/ERK and PI3K/AKT/mTOR signaling is more pronounced than canonical activation. Since the MEK inhibitor UO126 induced AKT phosphorylation, which might have contributed to the upregulation of GLI1 (see results section 5.1.3.2), we here tried to analyze a potential regulation of $\mathrm{HH}$ signaling by AKT in more detail. Indeed, a correlation between PISK/AKT and $\mathrm{HH}$ signaling has also been demonstrated in esophageal adenocarcinoma $^{108,184,235}$, melanoma ${ }^{76}$, breast cancer $^{185}$ and during osteoblast differentiation ${ }^{107}$. However, in RD cells that were transfected with constitutively active and dominant negative forms of AKT, overexpression of either protein did not modulate GLI1 expression (see Fig. 13). Since no changes in phosphorylation of the mTOR target S6 were observed as described in the literature, and since the general expression of exogenous proteins in RD cells was quite low (see Fig. 12), we currently think that this experiment should be repeated using a retroviral transduction system for stable expression of the AKT isoforms. 


\subsection{Effects of SMO and/or PI3K/AKT/mTOR inhibitors in ERMS cell lines}

\subsubsection{Functionality of PI3K/AKT/mTOR signaling inhibitors depends on feedback regulatory loops}

At first, all PI3K/AKT/mTOR inhibitors were functional. PI-103, pictilisib and MK-2206 efficiently downregulated pAKT levels, and everolimus and rapamycin efficiently inhibited the phosphorylation of the mTOR target S6 (see Figs.10B and 15).

Furthermore, everolimus and rapamycin enhanced phosphorylation of AKT in RD cells. This phenomenon has already been described ${ }^{237}$. Thus, upon mTOR inhibition, an IGF-1Rdependent activation of PI3K and subsequent phosphorylation of AKT at Ser473 occurs. Due to this negative feedback loop, the use of mTOR inhibitors for RMS clinical trials (phase II and III clinical trials are ongoing, as described in section 1.1.1) should be carefully reconsidered.

PI-103 and pictilisib efficiently inhibited the phosphorylation of S6 in RD and RUCH-2 cells. However, MK-2206 lacked this effect as was observed for several other cancer cell lines ${ }^{238-}$ 240 . One possible explanation of the missing inhibition of S6 phosphorylation is the possibility of an AKT-independent regulation of mTORC1. However, this would be contrary to what was observed upon pictilisib treatment, which efficiently downregulated pAKT and pS6. Together, the two PI3K inhibitors $\mathrm{PI}-103$ and pictilisib showed higher functionality than AKT or mTOR inhibitors.

\subsubsection{Anticancer effects of SMO inhibitors alone and in combination with $\mathrm{PI3K} / \mathrm{AKT} / \mathrm{mTOR}$ inhibitors}

Next, the impact of a combined treatment with SMO and PI3K/AKT/mTOR inhibitors on $\mathrm{HH}$ signaling activity and on proliferation and apoptosis was investigated in RD and $\mathrm{RUCH}-2$ cells. As already stated, PI3K/AKT/mTOR inhibitors more efficiently reduced $\mathrm{HH}$ signaling compared to SMO inhibitors (see Fig. 14). These data indicate that non-canonical $\mathrm{HH}$ signaling via the PI3K/AKT/mTOR signaling pathway plays a more prominent role in both ERMS cell lines compared to canonical $\mathrm{HH}$ signaling. In addition the data showed that inhibition of canonical $\mathrm{HH}$ signaling was not strengthened when SMO inhibitors were combined with PI3K/AKT/mTOR inhibitors. Similar results have been shown in a recent paper when using vismodegib in combination with $\mathrm{PI}-103^{249}$.

We next investigated the impact of the drugs on proliferation (see Figs. 16 and 17) and apoptosis (see Fig. 18). In the settings where cells were treated with single drugs, 
vismodegib or sonidegib did not affect proliferation, whereas HhAntag reduced it. In addition, sonidegib and HhAntag - in contrast to vismodegib - induced apoptosis in RD cells. PI-103 and pictilisib efficiently blocked proliferation of RD and $\mathrm{RUCH}-2$ cells and induced apoptosis in RD cells. MK-2206 blocked proliferation of RUCH-2 cells. In contrast, everolimus and rapamycin did not affect proliferation of either cell line. Although these effects are very hard to explain with the markers used in this thesis, it is possible that downregulation of PAKT and pS6 are required for efficient growth inhibition of RD cells. Thus, MK-2206 or everolimus and rapamycin, that did not reduce pS6 or PAKT, respectively, had no anti-proliferative or proapoptotic effects in RD cells. On the other hand, MK-2206 blocks proliferation of RUCH-2 cells but not of RD cells, which goes along with a reduction of GL/1 expression in RUCH-2, but not in RD. This may indicate that the lack of pS6 reduction might be compensated by GLI1 reduction in RUCH-2 cells. However, this is pure speculation.

When SMO inhibitors were combined with PI3K/AKT/mTOR inhibitors, cooperative antitumoral effects were observed for several combination treatments. However, these were dependent on the used SMO inhibitor and on the cell line investigated. Thus, in RD cells, combination treatments with vismodegib generally did not evoke cooperative anti-proliferative or pro-apoptotic effects, whereas the combination sonidegib plus pictilisib induced a synergistic reduction of proliferation at concentrations of $50 \mu \mathrm{M}$ plus $10 \mu \mathrm{M}$. Additionally, combinations of $30 \mu \mathrm{M}$ sonidegib plus $\mathrm{PI}-103$, pictilisib or MK-2206 evoked strong and cooperative pro-apoptotic effects. Unfortunately, these effects were not observed at a concentration of $10 \mu \mathrm{M}$ sonidegib and GLI1 expression, pAKT and pS6 levels and caspase 3 cleavage were only measured in samples treated with $10 \mu \mathrm{M}$ sonidegib. Thus, it was not possible to correlate these factors with the cooperative pro-apoptotic effects. Nevertheless, single treatment of RD cells with $\mathrm{PI}-103$, pictilisib or MK-2206 induced cleavage of caspase 3 and apoptosis (see Figs. 15 and 18), suggesting that the cooperative pro-apoptotic effects may be caspase-dependent.

Also the combination of HhAntag plus pictilisib evoked cooperative anti-proliferative effects and the combination of $12.5 \mu \mathrm{M}$ HhAntag plus $2.5 \mu \mathrm{M}$ pictilisib acted synergistically (see Fig. 17C). However, the cooperative anti-proliferative effects were not accompanied by any changes in GL/1 expression, PAKT, pS6 or cleavage of caspase 3. Thus, the reason for the cooperative effects has to be based on other factors. HhAntag also evoked strong proapoptotic effects when combined with MK-2206. This was indeed accompanied by an enhanced cleavage of caspase 3. However, it remains unclear why the pro-apoptotic effects only occurred upon combination treatment with MK-2206 and not with $\mathrm{PI}-103$ or pictilisib. 
Similar to what was seen in RD cells, combination of vismodegib plus PI3K/AKT/mTOR inhibitors did not enhance the anti-proliferative effects in $\mathrm{RUCH}-2$ cells (see Fig. 16). This was also true for sonidegib. Although the combination of sonidegib plus rapamycin cooperatively reduced proliferation, the overall effect of this combination was rather weak compared to e.g. single treatment with pictilisib. In contrast, combination of HhAntag plus $\mathrm{PI}$ 103 induced strong and cooperative anti-proliferative effects. However, this effect also could not be traced back to GL/1, pAKT or pS6 levels and remains to be analyzed in the future. Furthermore the combination of HhAntag plus pictilisib did not enhance the anti-proliferative effects of either single treatment in $\mathrm{RUCH}-2$. However, since pictilisib already reduced proliferation towards the lower detection limit and since the combination of HhAntag plus pictilisib enhanced cleavage of caspase 3 (see Fig. 15C), this combination may indeed exert very potent antitumoral effects, at least in $\mathrm{RUCH}-2$ cells. Furthermore, the combination of HhAntag plus MK-2206 induced strong and cooperative anti-proliferative effects (see Fig. $16 \mathrm{C})$. Because this went along with a more pronounced reduction of pS6 levels and an increase in cleavage of caspase 3 compared to either single treatment (Fig. 15C), the cooperative effects could be due to enhancement of apoptosis. This is similar to a recently published observation showing that MK-2206, which alone does not affect pS6 levels, cooperatively reduces pS6 levels in mouse embryonic fibroblasts when combined with rapamycin ${ }^{240}$. In addition, the authors of this report also state that, similar to what we have observed, only the parallel reduction of pAKT and pS6 inhibits cell growth. In RUCH-2 cells, cooperative anti-proliferative effects were also seen when HhAntag was combined with rapamycin (see Fig. 16C). This was accompanied by a reduction of pAKT (see Fig. 15C). Since rapamycin only mildly reduced PAKT levels and HhAntag strengthened this effect, HhAntag may enhance effectiveness of rapamycin via downregulation of AKT activity. However, the combination HhAntag plus everolimus, which also reduced the level of pAKT, did not show cooperative anti-proliferative effects. Thus, the cooperative anti-proliferative effect of the combination rapamycin plus HhAntag may be based on other mechanisms than pAKT levels.

Together, cell lines derived from sporadic ERMS show PI3K/AKT/mTOR-mediated noncanonical activation of $\mathrm{HH}$ signaling. In addition, antitumoral effects in these cells are generally induced by PI3K/AKT/mTOR inhibitors, but not by SMO inhibitors. Although the antitumoral effects of $\mathrm{PI} 3 \mathrm{~K} / \mathrm{AKT} / \mathrm{mTOR}$ inhibitors are accompanied by inhibition of noncanonical $\mathrm{HH}$ signaling, inhibition of the latter pathway is most probably not much involved in the antitumoral effects. Thus, HhAntag, MK-2006 and the mTOR inhibitors rapamycin or everolimus strongly inhibited GL/1 expression but did not affect proliferation. This is similar to another study showing that application of the GLI1/2 inhibitor GANT-61 is not effective in RD 
cells $^{249}$. Together these data indicate that targeting the $\mathrm{HH}$ pathway alone is not very useful in therapy of sporadic ERMS.

In addition, the combination of SMO inhibitors plus PI3K/AKT/mTOR inhibitors is generally not superior to single drug treatment in cell lines derived from sporadic ERMS. The exceptions were the combinations of HhAntag plus PI-103, MK-2206 or rapamycin, which cooperatively inhibited cellular proliferation of at least $\mathrm{RUCH}-2$ cells. This fact also indicates that cooperative antitumoral effects of SMO inhibitors and PI3K/AKT/mTOR inhibitors are highly drug- and cell line-specific.

\subsection{Effects of SMO and/or PI3K inhibitors on Ptch ${ }^{+/}$ERMS cells and tumors}

So far, the data showed that human cell lines that are derived from sporadic ERMS are rather unresponsive to activation or inhibition of canonical $\mathrm{HH}$ signaling. These cell lines in most likelihood do not harbor mutations that cause activation of $\mathrm{HH}$ signaling upstream of SMO, because $\mathrm{PTCH}$ mutations or mutations in other components of the $\mathrm{HH}$ pathway are very rare in sporadic ERMS or $\mathrm{ARMS}^{22,115,116}$ (see also section 1.2.4; RD cells are PTCH wildtype $^{168}$ ). Therefore, we next investigated the effects of SMO inhibitors and also of PI3K inhibitors in ERMS that are caused by mutations upstream of SMO in e.g. PTCH. PTCH germline mutations in patients with Gorlin syndrome are causal for the development of several $\mathrm{HH}$-associated cancer types, among them $\mathrm{RMS}^{34,57,58}$. Thus, canonical $\mathrm{HH}$ signaling is probably a driver for RMS in some cases. Since we had no access to a human ERMS cell line with a PTCH driver mutation and since a knockdown of PTCH in ERMS e.g. RD cells, in which non-canonical $\mathrm{HH}$ signaling is predominant, would not have reflected the situation in vivo, we used ERMS-like tumors of $\mathrm{Ptch}^{+/}$mice ${ }^{34}$. In addition to active $\mathrm{Hh}$ signaling, this model shows active Pi3k/Akt/mTor signaling ${ }^{242}$. Tumors derived from this mouse model were used to assess the effectiveness of SMO inhibitors and also of the PI3K inhibitor pictilisib alone or in combination. For this purpose, primary short-term ERMS cultures were incubated in vitro and ERMS-bearing Ptch ${ }^{+/-}$mice were treated orally with the drugs.

\subsubsection{Effects of different SMO inhibitors in vitro and in vivo}

In contrast to RD cells that are wildtype for PTCH and also to RUCH-2 cells (which are in all likelihood also PTCH wildtype), treatment of primary Ptch $^{+/}$ERMS cells with vismodegib, sonidegib or HhAntag significantly reduced Gli1 expression levels (see Fig. 19). This shows that the canonical Hh signaling pathway can be efficiently modulated in this model and that all three drugs indeed inhibit Smo to a similar extent. The SMO inhibitors also strongly reduced Gli1 expression in vivo (see Fig. 24). This proves favorable bioavailability and 
functionality of all drugs when applied orally, at least in mice. In contrast to primary ERMS cells, sonidegib seems to be more potent than vismodegib in the mouse, although its dosage was lower (80 mg/kg daily) than that of vismodegib (100 mg/kg daily). This may indicate an enhanced bioavailability of sonidegib when compared to vismodegib. A recent comparison between the two drugs in a preclinical mouse model for basal cell carcinoma showed similar results. Although mice underwent topical drug administration, this report suggests a more favorable uptake of sonidegib into the bloodstream compared to vismodegib, indicated by a higher plasma concentration ${ }^{232}$. This could explain the stronger inhibition of Gli1 expression by sonidegib when compared to vismodegib in ERMS isolated from treated mice (please note that a direct comparison of Gli1 expression between vismodegib- or sonidegib- and HhAntag-treated ERMS was not possible, because vismodegib or sonidegib were given for 21 days, whereas HhAntag was given for only 14 days; see also section 5.3.1).

Additionally, vismodegib, sonidegib and HhAntag efficiently reduced cell growth in vitro (see Fig. 21) and tumor growth in vivo (see Fig. 22). In primary ERMS cells vismodegib was less effective than sonidegib and HhAntag. In contrast, vismodegib and HhAntag showed a similar predicted tumor growth inhibition in vivo, whereas sonidegib was more effective and induced tumor regression. Although the treatment duration of the HhAntag cohorts was longer than that of the vismodegib or sonidegib cohorts (drugs were given for 35 and 21 days, respectively), the vehicle-treated tumors of all cohorts show a similar growth behavior in the prediction model. This suggests that the predicted tumor growth of all cohorts can probably be compared with each other. Thus, sonidegib seems to be more effective in vivo than vismodegib or HhAntag. This was also reflected by the analysis of $\mathrm{Ki} 67^{+}$cells that were significantly downregulated in the sonidegib-treated tumors compared to the vehicle control (see Fig. 23).

Besides the growth prediction models, the effectiveness of the drugs was evaluated by RECIST analysis (PD: progressive disease, SD: stable disease, PR: partial response) $)^{230,231}$. The analysis showed that all three SMO inhibitors reduced the number of animals showing PD and enhanced the number of animals showing SD or PR. Also in this analysis, sonidegib was the most effective drug (see Table 18), and thus the results are in line with the growth prediction models. The effectiveness of sonidegib and vismodegib can be explained by $\mathrm{Hh}$ signaling inhibition (see Fig. 24). Indeed, a positive correlation between Gli1 expression levels and tumor growth was found for ERMS of all animals treated with vismodegib or sonidegib (see Fig. 25A, analysis could not be performed for HhAntag because no tumor material was available at the end of treatment; please see section 5.3.1). However, this correlation was not found in primary Ptch ${ }^{+/}$ERMS cells. In cultured ERMS cells, vismodegib or sonidegib reduced Gli1 expression levels to a similar extend (see Fig. 19), but sonidegib 
had a more pronounced anti-proliferative potential when compared to vismodegib (see Fig. 21). There are several explanations for this difference. First, in the in vitro setting the concentrations of the drugs were all the same, whereas in the in vivo setting the administered doses and most probably the bioavailability of vismodegib and sonidegib is different, as already described above.

Furthermore, vismodegib or sonidegib apparently moderately reduced pAkt levels in vivo (see Fig. 27; not significant). The same was seen for sonidegib or HhAntag in vitro (see Fig. 20; not significant). Thus, it is possible that $\mathrm{Hh}$ signaling interacts with $\mathrm{Pi3k} / \mathrm{Akt} / \mathrm{mTor}$ signaling. On the other hand the decreased Akt phosphorylation could reflect off-target effects of the drugs.

In summary, all SMO inhibitors show a very strong antitumoral potency in ERMS that show canonical Hh signaling activity due to Ptch mutations.

\subsubsection{Pictilisib-mediated effects on Hh signaling and growth of Ptch $^{+/-}$ERMS}

Because the PI3K inhibitor pictilisib efficiently downregulated $\mathrm{HH}$ signaling and proliferation in $\mathrm{RD}$ and $\mathrm{RUCH}-2$ cells (see chapter 5.1.4 and ${ }^{228}$ ), this drug was also employed in $\mathrm{Ptch}^{+/}$ ERMS. As expected, the drug efficiently downregulated PAKT in vitro and in vivo (see Figs. 20 and 27). Similar to RD and $\mathrm{RUCH}-2$ cells, pictilisib also reduced Gli1 expression in cultured $\mathrm{Ptch}^{+/}$ERMS cells (see Fig. 19). Thus, we hypothesized that Hh signaling in $\mathrm{Ptch}^{+/}$ ERMS is not only activated by the Ptch mutation but also by the Pi3k/Akt/mTor pathway. However, this was different in the in vivo situation where pictilisib did not affect Gli1 expression at all (see Fig. 24). One possible explanation for this difference could be external stimuli from the tumor microenvironment that hamper the Pi3k/Akt/mTor-mediated $\mathrm{Hh}$ signaling regulation in vivo. If e.g. immune cells or endothelial cells secrete these stimuli they are probably missing when the $\mathrm{Ptch}^{+-}$ERMS cells are cultured in vitro.

Beyond that, pictilisib enhanced the expression level of the negative $\mathrm{Hh}$ regulator Hhip in vitro and in vivo (see Figs. 19 and 24). The upregulation of Hhip expression and downregulation of Gli1 expression is at the first glance contradictory, because both genes are positively regulated by $\mathrm{Hh}$ signaling. However, we also did not observe a correlation between Gli1 and Hhip expression levels in Ptch $^{+-}$ERMS cells and tissue samples that were treated with SMO inhibitors. In addition, Hhip can be epigenetically silenced in Hh-associated cancer types ${ }^{250-253}$. Thus, it is possible that Hhip is also epigenetically silenced in $\mathrm{Ptch}^{+/}$ ERMS, e.g. by DNA methyltransferase 1 (Dnmt1)-mediated hypermethylation of its promoter region. Furthermore, in bladder $^{254}$, lung ${ }^{255}$ and liver cancer ${ }^{256}$ active Pi3k/Akt signaling stabilizes Dnmt1, e.g. through inhibition of GSK3 $\beta$. Hence, pictilisib treatment may decrease 
Dnmt1 levels in ERMS, which could result in upregulation of Hhip expression. Because hypermethylation of the Hhip promoter region would prevent Gli transcription factors from binding, this hypothesis would also explain two additional observations. First, it would explain the discrepancy between Gli1 and Hhip expression levels in pictilisib-treated Ptch ${ }^{+-}$ERMS cells and tumors. Second, it would also explain why SMO inhibitors did not affect Hhip expression levels although they were in general shown to be functional (see Figs. 19 and 24). To proof this hypothesis one should assess Dnmt1 protein levels in pictilisib-treated ERMS (tissue and cells) and methylation marks in the Hhip promoter region by bisulfite sequencing. One could also perform chromatin immunoprecipitation (ChIP) with sequencing to analyze potential binding of Gli transcription factors at the Hhip promoter under solvent- or pictilisib-treated conditions.

Treatment with pictilisib additionally upregulated the expression level of Gli2, at least in the in vitro settings (see Fig. 19). As the Gli2 promoter is methylated and can even be hypermethylated $^{257}$, Gli2 expression upon pictilisib treatment could also be the result of an inhibition of the Akt-Dnmt1 axis.

Similar to SMO inhibitors, pictilisib also reduced proliferation (see Fig. 21) and induced caspase 3 cleavage (see Fig. 20) in cultured ERMS cells in a concentration-dependent manner. In line with that, the drug reduced tumor growth in vivo. Regarding to RECIST analysis, the effectiveness of pictilisib was similar to that of vismodegib or HhAntag (see Table 18). In line with the latter result, pictilisib treatment reduced the number of $\mathrm{Ki} 67^{+}$cells within the tumor to a similar extent as vismodegib or HhAntag (see Fig. 23).

Whereas caspase 3 cleavage was enhanced by pictilisib treatment in cultured cells, it was not affected in vivo (see Fig. 26). However, pictilisib efficiently downregulated pAkt levels in both settings. Thus, again, signals from the tumor microenvironment may have prevented pictilisib-mediated apoptosis induction in the in vivo setting. Indeed, the tumor microenvironment is often characterized by e.g. hypoxic conditions that also can prevent RMS cell lines from drug-induced apoptosis ${ }^{258}$.

Together the data indicate that pictilisib is also an efficient anticancer drug for ERMS that are caused by Ptch mutations, although its effectiveness is independent of $\mathrm{Hh}$ signaling modulation. We have shown that the anticancer effects of pictilisib in vivo are based on an inhibition of cancer cell proliferation. In combination with the high effectiveness of this drug in cell lines derived from sporadic ERMS (see section 6.4), our data support the idea that, indeed, inhibition of PI3K may be superior to SMO inhibition. This is mainly based on the fact that anticancer effects of pictilisib are independent of the existence of PTCH mutations in ERMS. 


\subsubsection{Combination effects of SMO inhibitors plus pictilisib}

Both SMO inhibitors and pictilisib evoked strong antitumoral effects in Ptch $^{+/}$ERMS. To see whether the combination of the drugs was more potent, they were also applied together. This could be important e.g. for patients with PTCH-associated RMS, because the use of SMO inhibitors in the clinics is frequently accompanied by severe side effects and is therefore especially problematic for young patients (see also introduction section 1.3.2). An enhanced effectiveness in the frame of a combination therapy may thus allow for lowering the dose of SMO inhibitors and for avoiding adverse effects. Furthermore, SMO inhibitors can induce tumor resistance, either by activating canonical (e.g. SMO mutations) or non-canonical (e.g. $\mathrm{PI3K} / \mathrm{AKT} / \mathrm{mTOR}$-mediated) $\mathrm{HH}$ signaling ${ }^{160,165}$. Therefore, the combination of SMO inhibitors with the PI3K inhibitor pictilisib may potentially circumvent some of these resistance mechanisms.

When cultured ERMS cells were treated with SMO inhibitors plus pictilisib, the reduction of Gli1 expression was strengthened and was even cooperative for sonidegib or HhAntag plus pictilisib (see Fig. 19). This fostered the hypothesis that $\mathrm{Hh}$ signaling in $\mathrm{Ptch}^{+/}$ERMS is also regulated by the Pi3k/Akt/mTor signaling cascade. However, this effect was not observed in vivo (see Fig. 24). Because pictilisib alone also does not affect Gli1 expression in vivo, $\mathrm{Pi} 3 \mathrm{k} / \mathrm{Akt} / \mathrm{mTor}$-signaling probably does not regulate $\mathrm{Hh}$ signaling in this setting (already discussed above; see section 6.5.2).

Furthermore, combination treatment with sonidegib plus pictilisib rescued the pictilisibmediated upregulation of Hhip expression back to basal level in cultured Ptch $^{+/}$ERMS cells (see Fig.19). Combination treatments with vismodegib or HhAntag plus pictilisib also lowered the pictilisib-mediated upregulation of Hhip expression, but to a lesser extent. Similar results were obtained in the in vivo setting (see Fig. 24). This phenomenon can be explained with the aforementioned hypothesis of Akt/Dnmt1-mediated epigenetic silencing described in section 6.5.2. Thus, pictilisib may induce demethylation of the Hhip promoter region, which subsequently becomes accessible for Gli repressor isoforms that are generated upon treatment with SMO inhibitors. A similar scenario can be suggested for the pictilisib-mediated upregulation of Gli2 expression, which was reduced to basal level upon the combination treatments with sonidegib or HhAntag plus pictilisib (see Fig. 19). However, this hypothesis remains pure speculation so far.

Besides Hh signaling inhibition, all combination treatments were generally very effective regarding tumor growth reduction. In the prediction model, sonidegib alone or HhAntag plus pictilisib were the most potent treatments (see Figs. 22D - 22F). This was also shown by RECIST analysis, which indicated that combination treatment with HhAntag plus pictilisib 
was the most effective among all treatments (see Table 18). These data are basically also in line with the reduced number of proliferating $\mathrm{Ki} 67^{+}$tumor cells (see Fig. 23), and with the synergistic anti-proliferative effects in vitro (see Fig. 21).

Furthermore, in tumors that have been treated with pictilisib alone the Gli1 expression level did not correlate with tumor growth inhibition (Fig. 25C). Thus, the anticancer effects of pictilisib in vivo must be driven in an Hh-independent way. In contrast, all $\mathrm{Ptch}^{+/}$ERMS treated with SMO inhibitors or with SMO inhibitors plus pictilisib showed a significant correlation between Gli1 expression and tumor growth inhibition (see Fig. 25A). This correlation indicates the impact of $\mathrm{Hh}$ signaling on proliferation of $\mathrm{Ptch}^{+-}$ERMS. Furthermore, in those tumors in which $\mathrm{Hh}$ signaling and proliferation were strongly suppressed by a SMO inhibitor, addition of pictilisib was of no benefit (e.g. the anticancer effects of sonidegib were not enhanced when combined with pictilisib). In contrast, in tumors in which Hh signaling and proliferation were only moderately suppressed by a SMO inhibitor, pictilisib was beneficial (e.g. the combination of HhAntag plus pictilisib was more efficient than HhAntag alone). This implicates that SMO inhibitors could indeed be used in low doses for clinical trials - at least in $\mathrm{Ptch}^{+/}$ERMS - when they are combined with PI3K inhibitors.

Finally, the data may indicate that pictilisib targets a different cancer cell population than the SMO inhibitors. Thus, whereas SMO inhibitors reduce growth of cells showing canonical Hh pathway activation, pictilisib may reduce growth of cells that show active Pi3k signaling. Perhaps pictilisib also reduces growth of tumor cells that show non-canonical Hh signaling. However, these cells must be very rare in Ptch $^{+-}$ERMS, because pictilisib does not block Gli1 expression in the in vivo setting. It is also possible that these cells have a growth advantage in the in vitro setting e.g. mediated by factors in the culture medium, because the effect of pictilisib on non-canonical Hh signaling in cultured $\mathrm{Ptch}^{+-}$ERMS is very strong.

Together these results show that SMO inhibitors can be very effective anticancer drugs for $\mathrm{Ptch}^{+-}$ERMS. Those drugs, which strongly inhibit $\mathrm{HH}$ signaling, are especially effective. In addition, when the respective SMO inhibitor only moderately inhibits $\mathrm{HH}$ signaling and proliferation, the combination with pictilisib is beneficial. The latter fact also implies that pictilisib may be beneficial to attenuate side effects of SMO inhibitors, because the SMO inhibitors could be applied at a lower dose when combined with pictilisib. However, the effectiveness of SMO inhibitors in $\mathrm{Ptch}^{+/}$ERMS cannot be translated to $\mathrm{PTCH}$ wildtype cell lines from sporadic ERMS (see section 6.4). Thus, the use of SMO inhibitors in ERMS patients, especially in those without $P T C H$ mutation, should be very carefully considered and requires thorough pretesting, e.g. in patient-derived xenograft models. 


\section{Bibliography}

1 Ward, E., DeSantis, C., Robbins, A., Kohler, B. \& Jemal, A. Childhood and adolescent cancer statistics, 2014. CA: a cancer journal for clinicians 64, 83-103, doi:10.3322/caac.21219 (2014).

2 Steliarova-Foucher, E. et al. International incidence of childhood cancer, 2001-10: a populationbased registry study. The Lancet. Oncology 18, 719-731, doi:10.1016/S1470-2045(17)30186-9 (2017).

3 Drummond, C. J. et al. Hedgehog Pathway Drives Fusion-Negative Rhabdomyosarcoma Initiated From Non-myogenic Endothelial Progenitors. Cancer cell 33, 108-124 e105, doi:10.1016/j.ccell.2017.12.001 (2018).

4 Hatley, M. E. et al. A mouse model of rhabdomyosarcoma originating from the adipocyte lineage. Cancer cell 22, 536-546, doi:10.1016/j.ccr.2012.09.004 (2012).

5 McDowell, H. P. Update on childhood rhabdomyosarcoma. Archives of disease in childhood 88, 354-357 (2003).

6 Parham, D. M. Pathologic classification of rhabdomyosarcomas and correlations with molecular studies. Modern pathology : an official journal of the United States and Canadian Academy of Pathology, Inc 14, 506-514, doi:10.1038/modpathol.3880339 (2001).

7 Douglass, E. C. et al. A specific chromosomal abnormality in rhabdomyosarcoma. Cytogenetics and cell genetics 45, 148-155, doi:10.1159/000132446 (1987).

8 Barr, F. G. Gene fusions involving PAX and FOX family members in alveolar rhabdomyosarcoma. Oncogene 20, 5736-5746, doi:10.1038/sj.onc.1204599 (2001).

9 Skapek, S. X. et al. PAX-FOXO1 fusion status drives unfavorable outcome for children with rhabdomyosarcoma: a children's oncology group report. Pediatric blood \& cancer 60, 14111417, doi:10.1002/pbc.24532 (2013).

10 Koufos, A. et al. Loss of heterozygosity in three embryonal tumours suggests a common pathogenetic mechanism. Nature 316, 330-334 (1985).

11 Xia, S. J., Pressey, J. G. \& Barr, F. G. Molecular pathogenesis of rhabdomyosarcoma. Cancer biology \& therapy 1, 97-104 (2002).

12 Merlino, G. \& Helman, L. J. Rhabdomyosarcoma--working out the pathways. Oncogene 18, 5340-5348, doi:10.1038/sj.onc.1203038 (1999).

13 Chen, X. et al. Targeting oxidative stress in embryonal rhabdomyosarcoma. Cancer cell 24, 710-724, doi:10.1016/j.ccr.2013.11.002 (2013).

14 Kohsaka, S. et al. A recurrent neomorphic mutation in MYOD1 defines a clinically aggressive subset of embryonal rhabdomyosarcoma associated with PI3K-AKT pathway mutations. Nature genetics 46, 595-600, doi:10.1038/ng.2969 (2014).

15 Williamson, D. et al. Fusion gene-negative alveolar rhabdomyosarcoma is clinically and molecularly indistinguishable from embryonal rhabdomyosarcoma. Journal of clinical oncology : official journal of the American Society of Clinical Oncology 28, 2151-2158, doi:10.1200/JCO.2009.26.3814 (2010).

16 Arndt, C. A. et al. Vincristine, actinomycin, and cyclophosphamide compared with vincristine, actinomycin, and cyclophosphamide alternating with vincristine, topotecan, and cyclophosphamide for intermediate-risk rhabdomyosarcoma: children's oncology group study D9803. Journal of clinical oncology : official journal of the American Society of Clinical Oncology 27, 5182-5188, doi:10.1200/JCO.2009.22.3768 (2009).

17 Malempati, S. \& Hawkins, D. S. Rhabdomyosarcoma: review of the Children's Oncology Group (COG) Soft-Tissue Sarcoma Committee experience and rationale for current COG studies. Pediatric blood \& cancer 59, 5-10, doi:10.1002/pbc.24118 (2012).

18 Chisholm, J. C. et al. Open-label, multicentre, randomised, phase II study of the EpSSG and the ITCC evaluating the addition of bevacizumab to chemotherapy in childhood and adolescent patients with metastatic soft tissue sarcoma (the BERNIE study). Eur $J$ Cancer 83, 177-184, doi:10.1016/j.ejca.2017.06.015 (2017).

19 Pappo, A. S. et al. A phase 2 trial of R1507, a monoclonal antibody to the insulin-like growth factor-1 receptor (IGF-1R), in patients with recurrent or refractory rhabdomyosarcoma, osteosarcoma, synovial sarcoma, and other soft tissue sarcomas: results of a Sarcoma Alliance 
for Research Through Collaboration study. Cancer 120, 2448-2456, doi:10.1002/cncr.28728 (2014).

20 Knowling, M. et al. A phase II study of perifosine (D-21226) in patients with previously untreated metastatic or locally advanced soft tissue sarcoma: A National Cancer Institute of Canada Clinical Trials Group trial. Investigational new drugs 24, 435-439, doi:10.1007/s10637-0066406-7 (2006).

21 Zibat, A. et al. Activation of the hedgehog pathway confers a poor prognosis in embryonal and fusion gene-negative alveolar rhabdomyosarcoma. Oncogene 29, 6323-6330, doi:10.1038/onc.2010.368 (2010).

22 Tostar, U. et al. Deregulation of the hedgehog signalling pathway: a possible role for the PTCH and SUFU genes in human rhabdomyoma and rhabdomyosarcoma development. The Journal of pathology 208, 17-25, doi:10.1002/path.1882 (2006).

23 Nusslein-Volhard, C. \& Wieschaus, E. Mutations affecting segment number and polarity in Drosophila. Nature 287, 795-801 (1980).

24 Ingham, P. W. \& McMahon, A. P. Hedgehog signaling in animal development: paradigms and principles. Genes \& development 15, 3059-3087, doi:10.1101/gad.938601 (2001).

25 Jiang, J. \& Hui, C. C. Hedgehog signaling in development and cancer. Developmental cell 15, 801-812, doi:10.1016/j.devcel.2008.11.010 (2008).

26 Rohatgi, R., Milenkovic, L. \& Scott, M. P. Patched1 regulates hedgehog signaling at the primary cilium. Science 317, 372-376, doi:10.1126/science.1139740 (2007).

27 Ingham, P. W., Nakano, Y. \& Seger, C. Mechanisms and functions of Hedgehog signalling across the metazoa. Nature reviews. Genetics 12, 393-406, doi:10.1038/nrg2984 (2011).

28 Ruiz i Altaba, A., Mas, C. \& Stecca, B. The Gli code: an information nexus regulating cell fate, stemness and cancer. Trends in cell biology 17, 438-447, doi:10.1016/j.tcb.2007.06.007 (2007).

29 Chuang, P. T. \& McMahon, A. P. Vertebrate Hedgehog signalling modulated by induction of a Hedgehog-binding protein. Nature 397, 617-621, doi:10.1038/17611 (1999).

30 Nguyen, V., Chokas, A. L., Stecca, B. \& Ruiz i Altaba, A. Cooperative requirement of the Gli proteins in neurogenesis. Development 132, 3267-3279, doi:10.1242/dev.01905 (2005).

31 Allen, B. L. et al. Overlapping roles and collective requirement for the coreceptors GAS1, CDO, and $\mathrm{BOC}$ in SHH pathway function. Developmental cell 20, 775-787, doi:10.1016/j.devcel.2011.04.018 (2011).

32 Izzi, L. et al. Boc and Gas1 each form distinct Shh receptor complexes with Ptch1 and are required for Shh-mediated cell proliferation. Developmental cell 20, 788-801, doi:10.1016/j.devcel.2011.04.017 (2011).

$33 \mathrm{Kim}, \mathrm{J}$. et al. The role of ciliary trafficking in Hedgehog receptor signaling. Science signaling 8 , ra55, doi:10.1126/scisignal.aaa5622 (2015).

34 Hahn, $\mathrm{H}$. et al. Rhabdomyosarcomas and radiation hypersensitivity in a mouse model of Gorlin syndrome. Nature medicine 4, 619-622 (1998).

35 Goodrich, L. V., Milenkovic, L., Higgins, K. M. \& Scott, M. P. Altered neural cell fates and medulloblastoma in mouse patched mutants. Science 277, 1109-1113 (1997).

36 Arensdorf, A. M., Marada, S. \& Ogden, S. K. Smoothened Regulation: A Tale of Two Signals. Trends in pharmacological sciences 37, 62-72, doi:10.1016/j.tips.2015.09.001 (2016).

37 Chen, Y. et al. Sonic Hedgehog dependent phosphorylation by CK1alpha and GRK2 is required for ciliary accumulation and activation of smoothened. PLoS biology 9, e1001083, doi:10.1371/journal.pbio.1001083 (2011).

38 Zhao, Y., Tong, C. \& Jiang, J. Hedgehog regulates smoothened activity by inducing a conformational switch. Nature 450, 252-258, doi:10.1038/nature06225 (2007).

$39 \mathrm{Li}, \mathrm{S}$., Wang, B. \& Jiang, J. Hedgehog reciprocally controls trafficking of Smo and Ptc through the Smurf family of E3 ubiquitin ligases. Science signaling 11, doi:10.1126/scisignal.aan8660 (2018).

40 Chen, J. K. I only have eye for ewe: the discovery of cyclopamine and development of Hedgehog pathway-targeting drugs. Natural product reports 33, 595-601, doi:10.1039/c5np00153f (2016).

41 Wang, C. et al. Structural basis for Smoothened receptor modulation and chemoresistance to anticancer drugs. Nature communications 5, 4355, doi:10.1038/ncomms5355 (2014). 
42 Myers, B. R. et al. Hedgehog pathway modulation by multiple lipid binding sites on the smoothened effector of signal response. Developmental cell 26, 346-357, doi:10.1016/j.devcel.2013.07.015 (2013).

43 Zhang, X. M., Ramalho-Santos, M. \& McMahon, A. P. Smoothened mutants reveal redundant roles for Shh and Ihh signaling including regulation of L/R asymmetry by the mouse node. Cell 105, 781-792 (2001).

44 Xie, J. et al. Activating Smoothened mutations in sporadic basal-cell carcinoma. Nature 391, 9092, doi:10.1038/34201 (1998).

45 Lam, C. W. et al. A frequent activated smoothened mutation in sporadic basal cell carcinomas. Oncogene 18, 833-836, doi:10.1038/sj.onc.1202360 (1999).

46 Pavletich, N. P. \& Pabo, C. O. Crystal structure of a five-finger GLI-DNA complex: new perspectives on zinc fingers. Science 261, 1701-1707 (1993).

47 Kinzler, K. W. \& Vogelstein, B. The GLI gene encodes a nuclear protein which binds specific sequences in the human genome. Molecular and cellular biology 10, 634-642 (1990).

48 Chen, M. H. et al. Cilium-independent regulation of Gli protein function by Sufu in Hedgehog signaling is evolutionarily conserved. Genes \& development 23, 1910-1928, doi:10.1101/gad.1794109 (2009).

49 Humke, E. W., Dorn, K. V., Milenkovic, L., Scott, M. P. \& Rohatgi, R. The output of Hedgehog signaling is controlled by the dynamic association between Suppressor of Fused and the Gli proteins. Genes \& development 24, 670-682, doi:10.1101/gad.1902910 (2010).

50 Svard, J. et al. Genetic elimination of Suppressor of fused reveals an essential repressor function in the mammalian Hedgehog signaling pathway. Developmental cell 10, 187-197, doi:10.1016/j.devcel.2005.12.013 (2006).

51 Cooper, A. F. et al. Cardiac and CNS defects in a mouse with targeted disruption of suppressor of fused. Development 132, 4407-4417, doi:10.1242/dev.02021 (2005).

52 Lee, Y. et al. Loss of suppressor-of-fused function promotes tumorigenesis. Oncogene 26, 6442-6447, doi:10.1038/sj.onc.1210467 (2007).

53 Taylor, M. D. et al. Mutations in SUFU predispose to medulloblastoma. Nature genetics 31, 306310, doi:10.1038/ng916 (2002).

54 Niewiadomski, P. et al. Gli protein activity is controlled by multisite phosphorylation in vertebrate Hedgehog signaling. Cell reports 6, 168-181, doi:10.1016/j.celrep.2013.12.003 (2014).

55 Aberger, F. \& Ruiz, I. A. A. Context-dependent signal integration by the GLI code: the oncogenic load, pathways, modifiers and implications for cancer therapy. Seminars in cell \& developmental biology 33, 93-104, doi:10.1016/j.semcdb.2014.05.003 (2014).

56 Hahn, $\mathrm{H}$. et al. Mutations of the human homolog of Drosophila patched in the nevoid basal cell carcinoma syndrome. Cell 85, 841-851 (1996).

57 Johnson, R. L. et al. Human homolog of patched, a candidate gene for the basal cell nevus syndrome. Science 272, 1668-1671 (1996).

58 Gorlin, R. J. Nevoid basal cell carcinoma syndrome. Dermatologic clinics 13, 113-125 (1995).

59 Pandolfi, S. \& Stecca, B. Cooperative integration between HEDGEHOG-GLI signalling and other oncogenic pathways: implications for cancer therapy. Expert reviews in molecular medicine 17, e5, doi:10.1017/erm.2015.3 (2015).

60 Clement, V., Sanchez, P., de Tribolet, N., Radovanovic, I. \& Ruiz i Altaba, A. HEDGEHOG-GLI1 signaling regulates human glioma growth, cancer stem cell self-renewal, and tumorigenicity. Current biology : CB 17, 165-172, doi:10.1016/j.cub.2006.11.033 (2007).

61 Takezaki, T. et al. Essential role of the Hedgehog signaling pathway in human glioma-initiating cells. Cancer science 102, 1306-1312, doi:10.1111/j.1349-7006.2011.01943.x (2011).

62 Braun, S. et al. Hedgehog signaling in glioblastoma multiforme. Cancer biology \& therapy 13, 487-495, doi:10.4161/cbt.19591 (2012).

63 O'Toole, S. A. et al. Hedgehog overexpression is associated with stromal interactions and predicts for poor outcome in breast cancer. Cancer research 71, 4002-4014, doi:10.1158/00085472.CAN-10-3738 (2011).

64 Duan, Z. H. et al. Cooperatively transcriptional and epigenetic regulation of sonic hedgehog overexpression drives malignant potential of breast cancer. Cancer science 106, 1084-1091, doi:10.1111/cas.12697 (2015). 
65 Thayer, S. P. et al. Hedgehog is an early and late mediator of pancreatic cancer tumorigenesis. Nature 425, 851-856, doi:10.1038/nature02009 (2003).

66 Berman, D. M. et al. Widespread requirement for Hedgehog ligand stimulation in growth of digestive tract tumours. Nature 425, 846-851, doi:10.1038/nature01972 (2003).

67 Bailey, J. M. et al. Sonic hedgehog promotes desmoplasia in pancreatic cancer. Clinical cancer research : an official journal of the American Association for Cancer Research 14, 5995-6004, doi:10.1158/1078-0432.CCR-08-0291 (2008).

$68 \mathrm{Li}, \mathrm{X}$. et al. Sonic hedgehog paracrine signaling activates stromal cells to promote perineural invasion in pancreatic cancer. Clinical cancer research : an official journal of the American Association for Cancer Research 20, 4326-4338, doi:10.1158/1078-0432.CCR-13-3426 (2014).

69 Bailey, J. M., Mohr, A. M. \& Hollingsworth, M. A. Sonic hedgehog paracrine signaling regulates metastasis and lymphangiogenesis in pancreatic cancer. Oncogene 28, 3513-3525, doi:10.1038/onc.2009.220 (2009).

70 Sheng, T. et al. Activation of the hedgehog pathway in advanced prostate cancer. Molecular cancer 3, 29, doi:10.1186/1476-4598-3-29 (2004).

71 Sanchez, P. et al. Inhibition of prostate cancer proliferation by interference with SONIC HEDGEHOG-GLI1 signaling. Proceedings of the National Academy of Sciences of the United States of America 101, 12561-12566, doi:10.1073/pnas.0404956101 (2004).

72 Karhadkar, S. S. et al. Hedgehog signalling in prostate regeneration, neoplasia and metastasis. Nature 431, 707-712, doi:10.1038/nature02962 (2004).

73 Shigemura, K. et al. Active sonic hedgehog signaling between androgen independent human prostate cancer cells and normal/benign but not cancer-associated prostate stromal cells. The Prostate 71, 1711-1722, doi:10.1002/pros.21388 (2011).

74 Fan, L. et al. Hedgehog signaling promotes prostate xenograft tumor growth. Endocrinology 145, 3961-3970, doi:10.1210/en.2004-0079 (2004).

75 Wilkinson, S. E. et al. Hedgehog signaling is active in human prostate cancer stroma and regulates proliferation and differentiation of adjacent epithelium. The Prostate 73, 1810-1823, doi:10.1002/pros.22720 (2013).

76 Stecca, B. et al. Melanomas require HEDGEHOG-GLI signaling regulated by interactions between GLI1 and the RAS-MEK/AKT pathways. Proceedings of the National Academy of Sciences of the United States of America 104, 5895-5900, doi:10.1073/pnas.0700776104 (2007).

77 Krauthammer, M. et al. Exome sequencing identifies recurrent somatic RAC1 mutations in melanoma. Nature genetics 44, 1006-1014, doi:10.1038/ng.2359 (2012).

78 Chinchilla, P., Xiao, L., Kazanietz, M. G. \& Riobo, N. A. Hedgehog proteins activate proangiogenic responses in endothelial cells through non-canonical signaling pathways. Cell Cycle 9, 570-579, doi:10.4161/cc.9.3.10591 (2010).

79 Mille, F. et al. The Patched dependence receptor triggers apoptosis through a DRAL-caspase-9 complex. Nature cell biology 11, 739-746, doi:10.1038/ncb1880 (2009).

80 Ogden, S. K. et al. G protein Galphai functions immediately downstream of Smoothened in Hedgehog signalling. Nature 456, 967-970, doi:10.1038/nature07459 (2008).

81 Shen, F., Cheng, L., Douglas, A. E., Riobo, N. A. \& Manning, D. R. Smoothened is a fully competent activator of the heterotrimeric $\mathrm{G}$ protein $\mathrm{G}(\mathrm{i})$. Molecular pharmacology 83, 691-697, doi:10.1124/mol.112.082511 (2013).

82 Belgacem, Y. H. \& Borodinsky, L. N. Sonic hedgehog signaling is decoded by calcium spike activity in the developing spinal cord. Proceedings of the National Academy of Sciences of the United States of America 108, 4482-4487, doi:10.1073/pnas.1018217108 (2011).

83 Belgacem, Y. H. \& Borodinsky, L. N. Inversion of Sonic hedgehog action on its canonical pathway by electrical activity. Proceedings of the National Academy of Sciences of the United States of America 112, 4140-4145, doi:10.1073/pnas.1419690112 (2015).

84 Teperino, R. et al. Hedgehog partial agonism drives Warburg-like metabolism in muscle and brown fat. Cell 151, 414-426, doi:10.1016/j.cell.2012.09.021 (2012).

85 D'Amico, D. et al. Non-canonical Hedgehog/AMPK-Mediated Control of Polyamine Metabolism Supports Neuronal and Medulloblastoma Cell Growth. Developmental cell 35, 21-35, doi:10.1016/j.devcel.2015.09.008 (2015). 
86 Polizio, A. H., Chinchilla, P., Chen, X., Manning, D. R. \& Riobo, N. A. Sonic Hedgehog activates the GTPases Rac1 and RhoA in a Gli-independent manner through coupling of smoothened to Gi proteins. Science signaling 4, pt7, doi:10.1126/scisignal.2002396 (2011).

87 Gu, D. \& Xie, J. Non-Canonical Hh Signaling in Cancer-Current Understanding and Future Directions. Cancers 7, 1684-1698, doi:10.3390/cancers7030857 (2015).

88 Dennler, S. et al. Induction of sonic hedgehog mediators by transforming growth factor-beta: Smad3-dependent activation of Gli2 and Gli1 expression in vitro and in vivo. Cancer research 67, 6981-6986, doi:10.1158/0008-5472.CAN-07-0491 (2007).

89 Dennler, S., Andre, J., Verrecchia, F. \& Mauviel, A. Cloning of the human GLI2 Promoter: transcriptional activation by transforming growth factor-beta via SMAD3/beta-catenin cooperation. The Journal of biological chemistry 284, 31523-31531, doi:10.1074/jbc.M109.059964 (2009).

90 Nolan-Stevaux, O. et al. GLI1 is regulated through Smoothened-independent mechanisms in neoplastic pancreatic ducts and mediates PDAC cell survival and transformation. Genes \& development 23, 24-36, doi:10.1101/gad.1753809 (2009).

91 Mazza, D. et al. PCAF ubiquitin ligase activity inhibits Hedgehog/Gli1 signaling in p53dependent response to genotoxic stress. Cell death and differentiation 20, 1688-1697, doi:10.1038/cdd.2013.120 (2013).

92 Malek, R., Matta, J., Taylor, N., Perry, M. E. \& Mendrysa, S. M. The p53 inhibitor MDM2 facilitates Sonic Hedgehog-mediated tumorigenesis and influences cerebellar foliation. PloS one 6, e17884, doi:10.1371/journal.pone.0017884 (2011).

93 Stecca, B. \& Ruiz i Altaba, A. A GLI1-p53 inhibitory loop controls neural stem cell and tumour cell numbers. The EMBO journal 28, 663-676, doi:10.1038/emboj.2009.16 (2009).

94 Abe, Y. et al. Hedgehog signaling overrides p53-mediated tumor suppression by activating Mdm2. Proceedings of the National Academy of Sciences of the United States of America 105, 4838-4843, doi:10.1073/pnas.0712216105 (2008).

95 Varjosalo, M. et al. Application of active and kinase-deficient kinome collection for identification of kinases regulating hedgehog signaling. Cell 133, 537-548, doi:10.1016/j.cell.2008.02.047 (2008).

96 Mao, J. et al. Regulation of Gli1 transcriptional activity in the nucleus by Dyrk1. The Journal of biological chemistry 277, 35156-35161, doi:10.1074/jbc.M206743200 (2002).

97 Lauth, M. et al. DYRK1B-dependent autocrine-to-paracrine shift of Hedgehog signaling by mutant RAS. Nature structural \& molecular biology 17, 718-725, doi:10.1038/nsmb.1833 (2010).

98 Singh, R., Dhanyamraju, P. K. \& Lauth, M. DYRK1B blocks canonical and promotes noncanonical Hedgehog signaling through activation of the mTOR/AKT pathway. Oncotarget 8 , 833-845, doi:10.18632/oncotarget.13662 (2017).

99 Gruber, W. et al. DYRK1B as therapeutic target in Hedgehog/GLI-dependent cancer cells with Smoothened inhibitor resistance. Oncotarget 7, 7134-7148, doi:10.18632/oncotarget.6910 (2016).

100 Whisenant, T. C. et al. Computational prediction and experimental verification of new MAP kinase docking sites and substrates including Gli transcription factors. PLOS computational biology 6, doi:10.1371/journal.pcbi.1000908 (2010).

101 Riobo, N. A., Haines, G. M. \& Emerson, C. P., Jr. Protein kinase C-delta and mitogen-activated protein/extracellular signal-regulated kinase-1 control GLI activation in hedgehog signaling. Cancer research 66, 839-845, doi:10.1158/0008-5472.CAN-05-2539 (2006).

102 Ji, Z., Mei, F. C., Xie, J. \& Cheng, X. Oncogenic KRAS activates hedgehog signaling pathway in pancreatic cancer cells. The Journal of biological chemistry 282, 14048-14055, doi:10.1074/jbc.M611089200 (2007).

103 Seto, M. et al. Regulation of the hedgehog signaling by the mitogen-activated protein kinase cascade in gastric cancer. Molecular carcinogenesis 48, 703-712, doi:10.1002/mc.20516 (2009).

104 Eberl, M. et al. Hedgehog-EGFR cooperation response genes determine the oncogenic phenotype of basal cell carcinoma and tumour-initiating pancreatic cancer cells. EMBO molecular medicine 4, 218-233, doi:10.1002/emmm.201100201 (2012).

105 Schnidar, H. et al. Epidermal growth factor receptor signaling synergizes with Hedgehog/GLI in oncogenic transformation via activation of the MEK/ERK/JUN pathway. Cancer research 69, 1284-1292, doi:10.1158/0008-5472.CAN-08-2331 (2009). 
106 Riobo, N. A., Lu, K., Ai, X., Haines, G. M. \& Emerson, C. P., Jr. Phosphoinositide 3-kinase and Akt are essential for Sonic Hedgehog signaling. Proceedings of the National Academy of Sciences of the United States of America 103, 4505-4510, doi:10.1073/pnas.0504337103 (2006).

107 Shi, Y., Chen, J., Karner, C. M. \& Long, F. Hedgehog signaling activates a positive feedback mechanism involving insulin-like growth factors to induce osteoblast differentiation. Proceedings of the National Academy of Sciences of the United States of America 112, 4678-4683, doi:10.1073/pnas.1502301112 (2015).

108 Wang, Y. et al. The crosstalk of mTOR/S6K1 and Hedgehog pathways. Cancer cell 21, 374387, doi:10.1016/j.ccr.2011.12.028 (2012).

109 Paul, P., Volny, N., Lee, S., Qiao, J. \& Chung, D. H. Gli1 transcriptional activity is negatively regulated by AKT2 in neuroblastoma. Oncotarget 4, 1149-1157, doi:10.18632/oncotarget.1074 (2013).

110 Kappler, R. et al. Profiling the molecular difference between Patched- and p53-dependent rhabdomyosarcoma. Oncogene 23, 8785-8795, doi:10.1038/sj.onc.1208133 (2004).

111 Hahn, H. et al. Patched target Igf2 is indispensable for the formation of medulloblastoma and rhabdomyosarcoma. The Journal of biological chemistry 275, 28341-28344, doi:10.1074/jbc.C000352200 (2000).

112 Krskova, L. et al. Rhabdomyosarcoma: molecular analysis of Igf2, MyoD1 and Myogenin expression. Neoplasma 58, 415-423 (2011).

113 Pressey, J. G., Anderson, J. R., Crossman, D. K., Lynch, J. C. \& Barr, F. G. Hedgehog pathway activity in pediatric embryonal rhabdomyosarcoma and undifferentiated sarcoma: a report from the Children's Oncology Group. Pediatric blood \& cancer 57, 930-938, doi:10.1002/pbc.23174 (2011).

114 Shern, J. F. et al. Comprehensive genomic analysis of rhabdomyosarcoma reveals a landscape of alterations affecting a common genetic axis in fusion-positive and fusion-negative tumors. Cancer discovery 4, 216-231, doi:10.1158/2159-8290.CD-13-0639 (2014).

115 Teot, L. A. et al. Clinical and mutational spectrum of highly differentiated, paired box 3 :forkhead box protein 01 fusion-negative rhabdomyosarcoma: A report from the Children's Oncology Group. Cancer, doi:10.1002/cncr.31286 (2018).

116 Bridge, J. A. et al. Novel genomic imbalances in embryonal rhabdomyosarcoma revealed by comparative genomic hybridization and fluorescence in situ hybridization: an intergroup rhabdomyosarcoma study. Genes, chromosomes \& cancer 27, 337-344 (2000).

117 Calzada-Wack, J. et al. Analysis of the PTCH coding region in human rhabdomyosarcoma. Human mutation 20, 233-234, doi:10.1002/humu.9056 (2002).

118 Satheesha, S. et al. Targeting hedgehog signaling reduces self-renewal in embryonal rhabdomyosarcoma. Oncogene 35, 2020-2030, doi:10.1038/onc.2015.267 (2016).

119 Oue, T., Yoneda, A., Uehara, S., Yamanaka, H. \& Fukuzawa, M. Increased expression of the hedgehog signaling pathway in pediatric solid malignancies. Journal of pediatric surgery $\mathbf{4 5}$, 387-392, doi:10.1016/j.jpedsurg.2009.10.081 (2010).

120 Almazan-Moga, A. et al. Ligand-dependent Hedgehog pathway activation in Rhabdomyosarcoma: the oncogenic role of the ligands. British journal of cancer, doi:10.1038/bjc.2017.305 (2017).

121 Ridzewski, R. et al. Hedgehog Inhibitors in Rhabdomyosarcoma: A Comparison of Four Compounds and Responsiveness of Four Cell Lines. Frontiers in oncology 5, 130, doi:10.3389/fonc.2015.00130 (2015).

122 Lauth, M., Bergstrom, A., Shimokawa, T. \& Toftgard, R. Inhibition of GLI-mediated transcription and tumor cell growth by small-molecule antagonists. Proceedings of the National Academy of Sciences of the United States of America 104, 8455-8460, doi:10.1073/pnas.0609699104 (2007).

123 Chen, Q. et al. Down-regulation of Gli transcription factor leads to the inhibition of migration and invasion of ovarian cancer cells via integrin beta4-mediated FAK signaling. PloS one 9, e88386, doi:10.1371/journal.pone.0088386 (2014).

124 Shahi, M. H., Holt, R. \& Rebhun, R. B. Blocking signaling at the level of GLI regulates downstream gene expression and inhibits proliferation of canine osteosarcoma cells. PloS one 9, e96593, doi:10.1371/journal.pone.0096593 (2014). 
125 Srivastava, R. K. et al. GLI inhibitor GANT-61 diminishes embryonal and alveolar rhabdomyosarcoma growth by inhibiting Shh/AKT-mTOR axis. Oncotarget 5, 12151-12165 (2014).

126 Wickstrom, M. et al. Targeting the hedgehog signal transduction pathway at the level of GLI inhibits neuroblastoma cell growth in vitro and in vivo. International journal of cancer 132, 15161524, doi:10.1002/ijc.27820 (2013).

127 Lauth, M. et al. Antipsychotic drugs regulate hedgehog signaling by modulation of 7dehydrocholesterol reductase levels. Molecular pharmacology 78, 486-496, doi:10.1124/mol.110.066431 (2010).

128 Rimkus, T. K., Carpenter, R. L., Qasem, S., Chan, M. \& Lo, H. W. Targeting the Sonic Hedgehog Signaling Pathway: Review of Smoothened and GLI Inhibitors. Cancers 8, doi:10.3390/cancers8020022 (2016).

129 Reifenberger, J. et al. Somatic mutations in the PTCH, SMOH, SUFUH and TP53 genes in sporadic basal cell carcinomas. The British journal of dermatology 152, 43-51, doi:10.1111/j.1365-2133.2005.06353.x (2005).

130 Heretsch, P., Tzagkaroulaki, L. \& Giannis, A. Cyclopamine and hedgehog signaling: chemistry, biology, medical perspectives. Angew Chem Int Ed Engl 49, 3418-3427, doi:10.1002/anie.200906967 (2010).

131 Feldmann, G. et al. Hedgehog inhibition prolongs survival in a genetically engineered mouse model of pancreatic cancer. Gut 57, 1420-1430, doi:10.1136/gut.2007.148189 (2008).

132 Olive, K. P. et al. Inhibition of Hedgehog signaling enhances delivery of chemotherapy in a mouse model of pancreatic cancer. Science 324, 1457-1461, doi:10.1126/science.1171362 (2009).

133 Sasaki, K. et al. Phase II evaluation of IPI-926, an oral Hedgehog inhibitor, in patients with myelofibrosis. Leukemia \& lymphoma 56, 2092-2097, doi:10.3109/10428194.2014.984703 (2015).

134 Mak, I. W., Evaniew, N. \& Ghert, M. Lost in translation: animal models and clinical trials in cancer treatment. American journal of translational research 6, 114-118 (2014).

135 Wong, $\mathrm{H}$. et al. Pharmacokinetic-pharmacodynamic analysis of vismodegib in preclinical models of mutational and ligand-dependent Hedgehog pathway activation. Clinical cancer research : an official journal of the American Association for Cancer Research 17, 4682-4692, doi:10.1158/1078-0432.CCR-11-0975 (2011).

136 Sekulic, A. et al. Efficacy and safety of vismodegib in advanced basal-cell carcinoma. The New England journal of medicine 366, 2171-2179, doi:10.1056/NEJMoa1113713 (2012).

137 Robinson, G. W. et al. Vismodegib Exerts Targeted Efficacy Against Recurrent Sonic Hedgehog-Subgroup Medulloblastoma: Results From Phase II Pediatric Brain Tumor Consortium Studies PBTC-025B and PBTC-032. Journal of clinical oncology : official journal of the American Society of Clinical Oncology 33, 2646-2654, doi:10.1200/JCO.2014.60.1591 (2015).

138 Chang, A. L. et al. Safety and efficacy of vismodegib in patients with basal cell carcinoma nevus syndrome: pooled analysis of two trials. Orphanet journal of rare diseases 11, 120, doi:10.1186/s13023-016-0506-z (2016).

139 Basset-Seguin, N. et al. Vismodegib in patients with advanced basal cell carcinoma (STEVIE): a pre-planned interim analysis of an international, open-label trial. The Lancet. Oncology 16, 729736, doi:10.1016/S1470-2045(15)70198-1 (2015).

140 Maughan, B. L. et al. Pharmacodynamic study of the oral hedgehog pathway inhibitor, vismodegib, in patients with metastatic castration-resistant prostate cancer. Cancer chemotherapy and pharmacology 78, 1297-1304, doi:10.1007/s00280-016-3191-7 (2016).

141 Berlin, J. et al. A randomized phase II trial of vismodegib versus placebo with FOLFOX or FOLFIRI and bevacizumab in patients with previously untreated metastatic colorectal cancer. Clinical cancer research : an official journal of the American Association for Cancer Research 19, 258-267, doi:10.1158/1078-0432.CCR-12-1800 (2013).

142 Kaye, S. B. et al. A phase II, randomized, placebo-controlled study of vismodegib as maintenance therapy in patients with ovarian cancer in second or third complete remission. Clinical cancer research : an official journal of the American Association for Cancer Research 18, 6509-6518, doi:10.1158/1078-0432.CCR-12-1796 (2012). 
143 Skvara, H. et al. Topical treatment of Basal cell carcinomas in nevoid Basal cell carcinoma syndrome with a smoothened inhibitor. The Journal of investigative dermatology 131, 17351744, doi:10.1038/jid.2011.48 (2011).

144 Rodon, J. et al. A phase I, multicenter, open-label, first-in-human, dose-escalation study of the oral smoothened inhibitor Sonidegib (LDE225) in patients with advanced solid tumors. Clinical cancer research : an official journal of the American Association for Cancer Research 20, 19001909, doi:10.1158/1078-0432.CCR-13-1710 (2014).

145 Zhou, J., Quinlan, M., Hurh, E. \& Sellami, D. Exposure-Response Analysis of Sonidegib (LDE225), an Oral Inhibitor of the Hedgehog Signaling Pathway, for Effectiveness and Safety in Patients With Advanced Solid Tumors. Journal of clinical pharmacology 56, 1406-1415, doi:10.1002/jcph.749 (2016)

146 Kieran, M. W. et al. Phase I study of oral sonidegib (LDE225) in pediatric brain and solid tumors and a phase II study in children and adults with relapsed medulloblastoma. Neuro-oncology 19, 1542-1552, doi:10.1093/neuonc/nox109 (2017).

147 Casey, D. et al. FDA Approval Summary: Sonidegib for Locally Advanced Basal Cell Carcinoma. Clinical cancer research : an official journal of the American Association for Cancer Research, doi:10.1158/1078-0432.CCR-16-2051 (2017).

148 Dummer, R. et al. The 12-month analysis from Basal Cell Carcinoma Outcomes with LDE225 Treatment (BOLT): A phase II, randomized, double-blind study of sonidegib in patients with advanced basal cell carcinoma. Journal of the American Academy of Dermatology 75, 113-125 e115, doi:10.1016/j.jaad.2016.02.1226 (2016).

149 Filbin, M. G. et al. Coordinate activation of Shh and PI3K signaling in PTEN-deficient glioblastoma: new therapeutic opportunities. Nature medicine 19, 1518-1523, doi:10.1038/nm.3328 (2013).

150 Jalili, A. et al. NVP-LDE225, a potent and selective SMOOTHENED antagonist reduces melanoma growth in vitro and in vivo. PloS one 8, e69064, doi:10.1371/journal.pone.0069064 (2013).

151 Irvine, D. A. et al. Deregulated hedgehog pathway signaling is inhibited by the smoothened antagonist LDE225 (Sonidegib) in chronic phase chronic myeloid leukaemia. Scientific reports 6, 25476, doi:10.1038/srep25476 (2016).

152 Dijkgraaf, G. J. et al. Small molecule inhibition of GDC-0449 refractory smoothened mutants and downstream mechanisms of drug resistance. Cancer research 71, 435-444, doi:10.1158/0008-5472.CAN-10-2876 (2011).

153 Romer, J. T. et al. Suppression of the Shh pathway using a small molecule inhibitor eliminates medulloblastoma in Ptc1(+/-)p53(-/-) mice. Cancer cell 6, 229-240, doi:10.1016/j.ccr.2004.08.019 (2004).

154 Hanke, C. W. et al. Vismodegib Use in Clinical Practice: Analysis of a United States Medical Claims Database. Journal of drugs in dermatology : JDD 17, 143-148 (2018).

155 Sofen, H. et al. A phase II, multicenter, open-label, 3-cohort trial evaluating the efficacy and safety of vismodegib in operable basal cell carcinoma. Journal of the American Academy of Dermatology 73, 99-105 e101, doi:10.1016/j.jaad.2015.03.013 (2015).

156 Amakye, D., Jagani, Z. \& Dorsch, M. Unraveling the therapeutic potential of the Hedgehog pathway in cancer. Nature medicine 19, 1410-1422, doi:10.1038/nm.3389 (2013).

157 Demirci, H., Worden, F., Nelson, C. C., Elner, V. M. \& Kahana, A. Efficacy of Vismodegib (Erivedge) for Basal Cell Carcinoma Involving the Orbit and Periocular Area. Ophthalmic plastic and reconstructive surgery 31, 463-466, doi:10.1097/IOP.0000000000000388 (2015).

158 Ally, M. S. et al. Effect of Calcium Channel Blockade on Vismodegib-Induced Muscle Cramps. JAMA dermatology 151, 1132-1134, doi:10.1001/jamadermatol.2015.1937 (2015).

159 Rudin, C. M. et al. Treatment of medulloblastoma with hedgehog pathway inhibitor GDC-0449. The New England journal of medicine 361, 1173-1178, doi:10.1056/NEJMoa0902903 (2009).

160 Yauch, R. L. et al. Smoothened mutation confers resistance to a Hedgehog pathway inhibitor in medulloblastoma. Science 326, 572-574, doi:10.1126/science.1179386 (2009).

161 Petrirena, G. J. et al. Recurrent extraneural sonic hedgehog medulloblastoma exhibiting sustained response to vismodegib and temozolomide monotherapies and inter-metastatic molecular heterogeneity at progression. Oncotarget 9, 10175-10183, doi:10.18632/oncotarget.23699 (2018). 
162 Atwood, S. X. et al. Smoothened variants explain the majority of drug resistance in basal cell carcinoma. Cancer cell 27, 342-353, doi:10.1016/j.ccell.2015.02.002 (2015).

163 Sharpe, H. J. et al. Genomic analysis of smoothened inhibitor resistance in basal cell carcinoma. Cancer cell 27, 327-341, doi:10.1016/j.ccell.2015.02.001 (2015).

164 Asklund, T. et al. Early and persisting response to vismodegib in a patient with bone metastasizing medulloblastoma. Acta Oncol 52, 862-866, doi:10.3109/0284186X.2012.724537 (2013).

165 Buonamici, S. et al. Interfering with resistance to smoothened antagonists by inhibition of the PI3K pathway in medulloblastoma. Science translational medicine 2, 51ra70, doi:10.1126/scitranslmed.3001599 (2010).

166 Kawabata, N. et al. Pharmacological inhibition of the Hedgehog pathway prevents human rhabdomyosarcoma cell growth. International journal of oncology 39, 899-906, doi:10.3892/ijo.2011.1076 (2011).

167 Ecke, I. et al. Cyclopamine treatment of full-blown Hh/Ptch-associated RMS partially inhibits Hh/Ptch signaling, but not tumor growth. Molecular carcinogenesis 47, 361-372, doi:10.1002/mc.20394 (2008).

168 Tostar, U., Toftgard, R., Zaphiropoulos, P. G. \& Shimokawa, T. Reduction of human embryonal rhabdomyosarcoma tumor growth by inhibition of the hedgehog signaling pathway. Genes \& cancer 1, 941-951, doi:10.1177/1947601910385449 (2010).

169 Dienstmann, R., Rodon, J., Serra, V. \& Tabernero, J. Picking the point of inhibition: a comparative review of PI3K/AKT/mTOR pathway inhibitors. Molecular cancer therapeutics 13, 1021-1031, doi:10.1158/1535-7163.MCT-13-0639 (2014).

170 Weigelt, B. \& Downward, J. Genomic Determinants of PI3K Pathway Inhibitor Response in Cancer. Frontiers in oncology 2, 109, doi:10.3389/fonc.2012.00109 (2012).

171 Huang, J. \& Manning, B. D. A complex interplay between Akt, TSC2 and the two mTOR complexes. Biochemical Society transactions 37, 217-222, doi:10.1042/BST0370217 (2009).

172 Kovacina, K. S. et al. Identification of a proline-rich Akt substrate as a 14-3-3 binding partner. The Journal of biological chemistry 278, 10189-10194, doi:10.1074/jbc.M210837200 (2003).

173 Vander Haar, E., Lee, S. I., Bandhakavi, S., Griffin, T. J. \& Kim, D. H. Insulin signalling to mTOR mediated by the Akt/PKB substrate PRAS40. Nature cell biology 9, 316-323, doi:10.1038/ncb1547 (2007).

174 Harrington, L. S. et al. The TSC1-2 tumor suppressor controls insulin-PI3K signaling via regulation of IRS proteins. The Journal of cell biology 166, 213-223, doi:10.1083/jcb.200403069 (2004).

$175 \mathrm{Um}, \mathrm{S}$. H. et al. Absence of S6K1 protects against age- and diet-induced obesity while enhancing insulin sensitivity. Nature 431, 200-205, doi:10.1038/nature02866 (2004).

176 Tzatsos, A. \& Kandror, K. V. Nutrients suppress phosphatidylinositol 3-kinase/Akt signaling via raptor-dependent mTOR-mediated insulin receptor substrate 1 phosphorylation. Molecular and cellular biology 26, 63-76, doi:10.1128/MCB.26.1.63-76.2006 (2006).

177 Julien, L. A., Carriere, A., Moreau, J. \& Roux, P. P. mTORC1-activated S6K1 phosphorylates Rictor on threonine 1135 and regulates mTORC2 signaling. Molecular and cellular biology 30, 908-921, doi:10.1128/MCB.00601-09 (2010).

178 Manning, B. D. \& Cantley, L. C. AKT/PKB signaling: navigating downstream. Cell 129, 12611274, doi:10.1016/j.cell.2007.06.009 (2007).

179 Datta, S. R. et al. Akt phosphorylation of BAD couples survival signals to the cell-intrinsic death machinery. Cell 91, 231-241 (1997).

180 del Peso, L., Gonzalez-Garcia, M., Page, C., Herrera, R. \& Nunez, G. Interleukin-3-induced phosphorylation of BAD through the protein kinase Akt. Science 278, 687-689 (1997).

181 Mayo, L. D. \& Donner, D. B. A phosphatidylinositol 3-kinase/Akt pathway promotes translocation of Mdm2 from the cytoplasm to the nucleus. Proceedings of the National Academy of Sciences of the United States of America 98, 11598-11603, doi:10.1073/pnas.181181198 (2001).

182 Zhou, B. P. et al. HER-2/neu induces p53 ubiquitination via Akt-mediated MDM2 phosphorylation. Nature cell biology 3, 973-982, doi:10.1038/ncb1101-973 (2001).

183 Beurel, E., Grieco, S. F. \& Jope, R. S. Glycogen synthase kinase-3 (GSK3): regulation, actions, and diseases. Pharmacology \& therapeutics 148, 114-131, doi:10.1016/j.pharmthera.2014.11.016 (2015). 
184 Wei, L. \& Xu, Z. Cross-signaling among phosphinositide-3 kinase, mitogen-activated protein kinase and sonic hedgehog pathways exists in esophageal cancer. International journal of cancer 129, 275-284, doi:10.1002/ijc.25673 (2011).

185 Ramaswamy, B. et al. Hedgehog signaling is a novel therapeutic target in tamoxifen-resistant breast cancer aberrantly activated by PI3K/AKT pathway. Cancer research 72, 5048-5059, doi:10.1158/0008-5472.CAN-12-1248 (2012).

186 Sharma, N. et al. PI3K/AKT/mTOR and sonic hedgehog pathways cooperate together to inhibit human pancreatic cancer stem cell characteristics and tumor growth. Oncotarget 6, 3203932060, doi:10.18632/oncotarget.5055 (2015).

187 Chu, Q. S. et al. 4450 - Dose-escalation study of sonidegib (LDE225) plus buparlisib (BKM120) in patients (pts) with advanced solid tumors. Annals of Oncology 25 (suppl_4), iv146-iv164, doi:https://doi.org/10.1093/annonc/mdu331.5 (2014).

188 LoPiccolo, J., Blumenthal, G. M., Bernstein, W. B. \& Dennis, P. A. Targeting the PI3K/Akt/mTOR pathway: effective combinations and clinical considerations. Drug resistance updates : reviews and commentaries in antimicrobial and anticancer chemotherapy 11, 32-50, doi:10.1016/j.drup.2007.11.003 (2008).

189 Porta, C., Paglino, C. \& Mosca, A. Targeting PI3K/Akt/mTOR Signaling in Cancer. Frontiers in oncology 4, 64, doi:10.3389/fonc.2014.00064 (2014).

190 Sehgal, S. N., Baker, H. \& Vezina, C. Rapamycin (AY-22,989), a new antifungal antibiotic. II. Fermentation, isolation and characterization. The Journal of antibiotics 28, 727-732 (1975).

191 Douros, J. \& Suffness, M. New antitumor substances of natural origin. Cancer treatment reviews 8, 63-87 (1981).

192 Kwitkowski, V. E. et al. FDA approval summary: temsirolimus as treatment for advanced renal cell carcinoma. The oncologist 15, 428-435, doi:10.1634/theoncologist.2009-0178 (2010).

193 Franz, D. N. et al. Everolimus for subependymal giant cell astrocytoma in patients with tuberous sclerosis complex: 2-year open-label extension of the randomised EXIST-1 study. The Lancet. Oncology 15, 1513-1520, doi:10.1016/S1470-2045(14)70489-9 (2014).

194 Witzig, T. E. et al. Adjuvant everolimus in high-risk diffuse large B-cell lymphoma: final results from the PILLAR-2 randomized phase III trial. Annals of oncology : official journal of the European Society for Medical Oncology 29, 707-714, doi:10.1093/annonc/mdx764 (2018).

195 Yao, J. C. et al. Everolimus for the treatment of advanced, non-functional neuroendocrine tumours of the lung or gastrointestinal tract (RADIANT-4): a randomised, placebo-controlled, phase 3 study. Lancet 387, 968-977, doi:10.1016/S0140-6736(15)00817-X (2016).

196 Martin, M. et al. A randomized adaptive phase II/III study of buparlisib, a pan-class I PI3K inhibitor, combined with paclitaxel for the treatment of HER2- advanced breast cancer (BELLE4). Annals of oncology : official journal of the European Society for Medical Oncology 28, 313320, doi:10.1093/annonc/mdw562 (2017).

197 Vansteenkiste, J. F. et al. Safety and Efficacy of Buparlisib (BKM120) in Patients with PI3K Pathway-Activated Non-Small Cell Lung Cancer: Results from the Phase II BASALT-1 Study. Journal of thoracic oncology : official publication of the International Association for the Study of Lung Cancer 10, 1319-1327, doi:10.1097/JTO.0000000000000607 (2015).

198 Raynaud, F. I. et al. Biological properties of potent inhibitors of class I phosphatidylinositide 3kinases: from PI-103 through PI-540, PI-620 to the oral agent GDC-0941. Molecular cancer therapeutics 8, 1725-1738, doi:10.1158/1535-7163.MCT-08-1200 (2009).

199 Sarker, D. et al. First-in-human phase I study of pictilisib (GDC-0941), a potent pan-class I phosphatidylinositol-3-kinase (PI3K) inhibitor, in patients with advanced solid tumors. Clinical cancer research : an official journal of the American Association for Cancer Research 21, 77-86, doi:10.1158/1078-0432.CCR-14-0947 (2015).

200 Vuylsteke, P. et al. Pictilisib PI3Kinase inhibitor (a phosphatidylinositol 3-kinase [PI3K] inhibitor) plus paclitaxel for the treatment of hormone receptor-positive, HER2-negative, locally recurrent, or metastatic breast cancer: interim analysis of the multicentre, placebo-controlled, phase II randomised PEGGY study. Annals of oncology : official journal of the European Society for Medical Oncology 27, 2059-2066, doi:10.1093/annonc/mdw320 (2016).

201 Krop, I. E. et al. Pictilisib for oestrogen receptor-positive, aromatase inhibitor-resistant, advanced or metastatic breast cancer (FERGI): a randomised, double-blind, placebo-controlled, phase 2 trial. The Lancet. Oncology 17, 811-821, doi:10.1016/S1470-2045(16)00106-6 (2016). 
202 Schmid, P. et al. Phase II Randomized Preoperative Window-of-Opportunity Study of the PI3K Inhibitor Pictilisib Plus Anastrozole Compared With Anastrozole Alone in Patients With Estrogen Receptor-Positive Breast Cancer. Journal of clinical oncology : official journal of the American Society of Clinical Oncology 34, 1987-1994, doi:10.1200/JCO.2015.63.9179 (2016).

203 Do, K. et al. Biomarker-driven phase 2 study of MK-2206 and selumetinib (AZD6244, ARRY142886) in patients with colorectal cancer. Investigational new drugs 33, 720-728, doi:10.1007/s10637-015-0212-z (2015).

204 Lara, P. N., Jr. et al. Phase II Study of the AKT Inhibitor MK-2206 plus Erlotinib in Patients with Advanced Non-Small Cell Lung Cancer Who Previously Progressed on Erlotinib. Clinical cancer research : an official journal of the American Association for Cancer Research 21, 4321-4326, doi:10.1158/1078-0432.CCR-14-3281 (2015).

205 Jonasch, E. et al. A randomized phase 2 study of MK-2206 versus everolimus in refractory renal cell carcinoma. Annals of oncology : official journal of the European Society for Medical Oncology 28, 804-808, doi:10.1093/annonc/mdw676 (2017).

206 Renshaw, J. et al. Dual blockade of the PI3K/AKT/mTOR (AZD8055) and RAS/MEK/ERK (AZD6244) pathways synergistically inhibits rhabdomyosarcoma cell growth in vitro and in vivo. Clinical cancer research : an official journal of the American Association for Cancer Research 19, 5940-5951, doi:10.1158/1078-0432.CCR-13-0850 (2013).

207 Cen, L. et al. Phosphorylation profiles of protein kinases in alveolar and embryonal rhabdomyosarcoma. Modern pathology : an official journal of the United States and Canadian Academy of Pathology, Inc 20, 936-946, doi:10.1038/modpathol.3800834 (2007).

208 Cen, L. et al. PDK-1/AKT pathway as a novel therapeutic target in rhabdomyosarcoma cells using OSU-03012 compound. British journal of cancer 97, 785-791, doi:10.1038/sj.bjc.6603952 (2007).

209 Petricoin, E. F., 3rd et al. Phosphoprotein pathway mapping: Akt/mammalian target of rapamycin activation is negatively associated with childhood rhabdomyosarcoma survival. Cancer research 67, 3431-3440, doi:10.1158/0008-5472.CAN-06-1344 (2007).

210 Seki, M. et al. Integrated genetic and epigenetic analysis defines novel molecular subgroups in rhabdomyosarcoma. Nature communications 6, 7557, doi:10.1038/ncomms8557 (2015).

211 Kilic-Eren, M., Boylu, T. \& Tabor, V. Targeting PI3K/Akt represses Hypoxia inducible factor1alpha activation and sensitizes Rhabdomyosarcoma and Ewing's sarcoma cells for apoptosis. Cancer cell international 13, 36, doi:10.1186/1475-2867-13-36 (2013).

212 Geoerger, B. et al. Phase II trial of temsirolimus in children with high-grade glioma, neuroblastoma and rhabdomyosarcoma. Eur $J$ Cancer 48, 253-262, doi:10.1016/j.ejca.2011.09.021 (2012).

213 Guenther, M. K., Graab, U. \& Fulda, S. Synthetic lethal interaction between PI3K/Akt/mTOR and Ras/MEK/ERK pathway inhibition in rhabdomyosarcoma. Cancer letters 337, 200-209, doi:10.1016/j.canlet.2013.05.010 (2013).

214 Uhmann, A. et al. Antitumoral effects of calcitriol in basal cell carcinomas involve inhibition of hedgehog signaling and induction of vitamin $\mathrm{D}$ receptor signaling and differentiation. Molecular cancer therapeutics 10, 2179-2188, doi:10.1158/1535-7163.MCT-11-0422 (2011).

215 Chen, J. K., Taipale, J., Young, K. E., Maiti, T. \& Beachy, P. A. Small molecule modulation of Smoothened activity. Proceedings of the National Academy of Sciences of the United States of America 99, 14071-14076, doi:10.1073/pnas.182542899 (2002).

216 Zibat, A. et al. Time-point and dosage of gene inactivation determine the tumor spectrum in conditional Ptch knockouts. Carcinogenesis 30, 918-926, doi:10.1093/carcin/bgp068 (2009).

217 Fritsch, A. Analysen zu Interaktionen zwischen dem Vitamin-D-Rezeptor Signalweg und der Hedgehog-Signalkaskade., Georg-August-Universität Göttingen, (2014).

218 Beer, C., Buhr, P., Hahn, H., Laubner, D. \& Wirth, M. Gene expression analysis of murine cells producing amphotropic mouse leukaemia virus at a cultivation temperature of 32 and 37 degrees C. The Journal of general virology 84, 1677-1686, doi:10.1099/vir.0.18871-0 (2003).

219 Zhou, B. P. et al. HER-2/neu blocks tumor necrosis factor-induced apoptosis via the Akt/NFkappaB pathway. The Journal of biological chemistry 275, 8027-8031 (2000).

220 Zhou, H., Li, X. M., Meinkoth, J. \& Pittman, R. N. Akt regulates cell survival and apoptosis at a postmitochondrial level. The Journal of cell biology 151, 483-494 (2000). 
221 Kohn, A. D., Takeuchi, F. \& Roth, R. A. Akt, a pleckstrin homology domain containing kinase, is activated primarily by phosphorylation. The Journal of biological chemistry 271, 21920-21926 (1996).

222 Smith, P. K. et al. Measurement of protein using bicinchoninic acid. Analytical biochemistry 150, 76-85 (1985).

223 Mahmood, T. \& Yang, P. C. Western blot: technique, theory, and trouble shooting. North American journal of medical sciences 4, 429-434, doi:10.4103/1947-2714.100998 (2012).

224 Towbin, H., Staehelin, T. \& Gordon, J. Electrophoretic transfer of proteins from polyacrylamide gels to nitrocellulose sheets: procedure and some applications. Proceedings of the National Academy of Sciences of the United States of America 76, 4350-4354 (1979).

225 Renart, J., Reiser, J. \& Stark, G. R. Transfer of proteins from gels to diazobenzyloxymethylpaper and detection with antisera: a method for studying antibody specificity and antigen structure. Proceedings of the National Academy of Sciences of the United States of America 76, 3116-3120 (1979).

226 Rio, D. C., Ares, M., Jr., Hannon, G. J. \& Nilsen, T. W. Purification of RNA using TRIzol (TRI reagent). Cold Spring Harbor protocols 2010, pdb prot5439, doi:10.1101/pdb.prot5439 (2010).

227 Hahn, H. et al. Genetic mapping of a Ptch1-associated rhabdomyosarcoma susceptibility locus on mouse chromosome 2. Genomics 84, 853-858, doi:10.1016/j.ygeno.2004.07.002 (2004).

228 Ridzewski, R. Improving Therapies of Rhabdomyosarcoma, Georg-August-Universität Göttingen, (2015)

229 Tomayko, M. M. \& Reynolds, C. P. Determination of subcutaneous tumor size in athymic (nude) mice. Cancer chemotherapy and pharmacology 24, 148-154 (1989).

230 Therasse, P. et al. New guidelines to evaluate the response to treatment in solid tumors. European Organization for Research and Treatment of Cancer, National Cancer Institute of the United States, National Cancer Institute of Canada. Journal of the National Cancer Institute 92, 205-216 (2000).

231 Eisenhauer, E. A. et al. New response evaluation criteria in solid tumours: revised RECIST guideline (version 1.1). Eur J Cancer 45, 228-247, doi:10.1016/j.ejca.2008.10.026 (2009).

232 Lauressergues, E. et al. Pharmacological evaluation of a series of smoothened antagonists in signaling pathways and after topical application in a depilated mouse model. Pharmacology research \& perspectives 4, e00214, doi:10.1002/prp2.214 (2016).

233 Metcalfe, C. \& de Sauvage, F. J. Hedgehog fights back: mechanisms of acquired resistance against Smoothened antagonists. Cancer research 71, 5057-5061, doi:10.1158/00085472.CAN-11-0923 (2011).

234 Morton, J. P. et al. Sonic hedgehog acts at multiple stages during pancreatic tumorigenesis. Proceedings of the National Academy of Sciences of the United States of America 104, 51035108, doi:10.1073/pnas.0701158104 (2007).

235 Kebenko, M. et al. ErbB2 signaling activates the Hedgehog pathway via PI3K-Akt in human esophageal adenocarcinoma: identification of novel targets for concerted therapy concepts. Cellular signalling 27, 373-381, doi:10.1016/j.cellsig.2014.11.022 (2015).

236 Pasca di Magliano, M. et al. Hedgehog/Ras interactions regulate early stages of pancreatic cancer. Genes \& development 20, 3161-3173, doi:10.1101/gad.1470806 (2006).

237 O'Reilly, K. E. et al. mTOR inhibition induces upstream receptor tyrosine kinase signaling and activates Akt. Cancer research 66, 1500-1508, doi:10.1158/0008-5472.CAN-05-2925 (2006)

238 Li, Z., Yan, S., Attayan, N., Ramalingam, S. \& Thiele, C. J. Combination of an allosteric Akt Inhibitor MK-2206 with etoposide or rapamycin enhances the antitumor growth effect in neuroblastoma. Clinical cancer research : an official journal of the American Association for Cancer Research 18, 3603-3615, doi:10.1158/1078-0432.CCR-11-3321 (2012).

239 Hirai, H. et al. MK-2206, an allosteric Akt inhibitor, enhances antitumor efficacy by standard chemotherapeutic agents or molecular targeted drugs in vitro and in vivo. Molecular cancer therapeutics 9, 1956-1967, doi:10.1158/1535-7163.MCT-09-1012 (2010).

$240 \mathrm{Ji}$, S. et al. Combined Targeting of mTOR and Akt Using Rapamycin and MK-2206 in The Treatment of Tuberous Sclerosis Complex. Journal of Cancer 8, 555-562, doi:10.7150/jca.17205 (2017).

241 Pyczek, J. Hedgehog signaling in cutaneous squamous cell carcinoma, Georg-AugustUniversität Göttingen, (2017). 
242 Kappler, R. et al. Molecular characterization of Patched-associated rhabdomyosarcoma. The Journal of pathology 200, 348-356, doi:10.1002/path.1361 (2003).

243 Nitzki, F. et al. Uncommitted precursor cells might contribute to increased incidence of embryonal rhabdomyosarcoma in heterozygous Patched1-mutant mice. Oncogene 30, 44284436, doi:10.1038/onc.2011.157 (2011).

244 Bollag, G. et al. Clinical efficacy of a RAF inhibitor needs broad target blockade in BRAF-mutant melanoma. Nature 467, 596-599, doi:10.1038/nature09454 (2010).

245 Wong, H. et al. Pharmacodynamics of 2-[4-[(1E)-1-(hydroxyimino)-2,3-dihydro-1H-inden-5-yl]-3(pyridine-4-yl)-1H-pyraz ol-1-yl]ethan-1-ol (GDC-0879), a potent and selective B-Raf kinase inhibitor: understanding relationships between systemic concentrations, phosphorylated mitogen-activated protein kinase kinase 1 inhibition, and efficacy. The Journal of pharmacology and experimental therapeutics 329, 360-367, doi:10.1124/jpet.108.148189 (2009).

246 Fan, J., Liu, Y. \& Jia, J. Hh-induced Smoothened conformational switch is mediated by differential phosphorylation at its C-terminal tail in a dose- and position-dependent manner. Developmental biology 366, 172-184, doi:10.1016/j.ydbio.2012.04.007 (2012).

247 Wang, C. et al. Structure of the human smoothened receptor bound to an antitumour agent. Nature 497, 338-343, doi:10.1038/nature12167 (2013).

248 Fang, X. et al. Phosphorylation and inactivation of glycogen synthase kinase 3 by protein kinase A. Proceedings of the National Academy of Sciences of the United States of America 97, 11960-11965, doi:10.1073/pnas.220413597 (2000).

249 Graab, U., Hahn, H. \& Fulda, S. Identification of a novel synthetic lethality of combined inhibition of hedgehog and PI3K signaling in rhabdomyosarcoma. Oncotarget 6, 8722-8735, doi:10.18632/oncotarget.2726 (2015).

250 Lin, E. H. et al. Hedgehog pathway maintains cell survival under stress conditions, and drives drug resistance in lung adenocarcinoma. Oncotarget 7, 24179-24193, doi:10.18632/oncotarget.8253 (2016).

251 Shahi, M. H. et al. Epigenetic regulation of human hedgehog interacting protein in glioma cell lines and primary tumor samples. Tumour biology : the journal of the International Society for Oncodevelopmental Biology and Medicine 36, 2383-2391, doi:10.1007/s13277-014-2846-4 (2015).

252 Tada, M. et al. Down-regulation of hedgehog-interacting protein through genetic and epigenetic alterations in human hepatocellular carcinoma. Clinical cancer research : an official journal of the American Association for Cancer Research 14, 3768-3776, doi:10.1158/1078-0432.CCR07-1181 (2008).

253 Taniguchi, $\mathrm{H}$. et al. Transcriptional silencing of hedgehog-interacting protein by CpG hypermethylation and chromatic structure in human gastrointestinal cancer. The Journal of pathology 213, 131-139, doi:10.1002/path.2216 (2007).

254 Sun, L. et al. Phosphatidylinositol 3-kinase/protein kinase B pathway stabilizes DNA methyltransferase I protein and maintains DNA methylation. Cellular signalling 19, 2255-2263, doi:10.1016/j.cellsig.2007.06.014 (2007).

255 Lin, R. K. et al. The tobacco-specific carcinogen NNK induces DNA methyltransferase 1 accumulation and tumor suppressor gene hypermethylation in mice and lung cancer patients. The Journal of clinical investigation 120, 521-532, doi:10.1172/JCI40706 (2010).

256 Fang, Q. L. et al. Mechanistic and biological significance of DNA methyltransferase 1 upregulated by growth factors in human hepatocellular carcinoma. International journal of oncology 46, 782-790, doi:10.3892/ijo.2014.2776 (2015).

257 Lu, X. L. et al. Sonic Hedgehog Signaling Affected by Promoter Hypermethylation Induces Aberrant Gli2 Expression in Spina Bifida. Molecular neurobiology 53, 5413-5424, doi:10.1007/s12035-015-9447-0 (2016).

258 Kilic, M., Kasperczyk, H., Fulda, S. \& Debatin, K. M. Role of hypoxia inducible factor-1 alpha in modulation of apoptosis resistance. Oncogene 26, 2027-2038, doi:10.1038/sj.onc.1210008 (2007). 


\section{Abbreviations}

\begin{tabular}{|c|c|}
\hline$\mu \mathrm{CT}$ & Micro computed tomography \\
\hline AKT & Protein kinase B \\
\hline AKT-CA & Constitutively active AKT \\
\hline AKT-DN & Dominant negative AKT \\
\hline AMPK & 5'Adenosine monophosphate-activated protein kinase \\
\hline ANOVA & Analysis of variance \\
\hline ARMS & Alveolar RMS \\
\hline ATCC & American type culture collection \\
\hline B6 & C57BL/6N \\
\hline BAD & Bcl-2-associated death promoter \\
\hline Balb & $\mathrm{BALB} / \mathrm{c}$ \\
\hline $\mathrm{BCA}$ & Bicinchoninic acid \\
\hline $\mathrm{Bcl}-2$ & B-cell lymphoma 2 \\
\hline $\mathrm{BOC}$ & Brother of CDO \\
\hline BrdU & 5-Bromo-2'-deoxyuridine \\
\hline BSA & Bovine serum albumin \\
\hline BSA & Bovine serum albumin \\
\hline Casp3 cl & Cleaved form of caspase 3 \\
\hline Casp3 pro & Pro form of caspase 3 \\
\hline cDNA & Complementary DNA \\
\hline CDO & Cell adhesion molecule-related/down-regulated by oncogenes \\
\hline ChIP & Chromatin immunoprecipitation \\
\hline $\mathrm{Cl}$ & Combination index \\
\hline CK1 & Casein kinase 1 \\
\hline CMV & Cytomegalovirus \\
\hline Control-CM & Control conditioned medium \\
\hline $\mathrm{Cu}^{2+}$ & Cupric ions \\
\hline DAB & Diaminobenzidine \\
\hline dATP & Deoxyadenosine triphosphate \\
\hline $\mathrm{dCTP}$ & Deoxycytidine triphosphate \\
\hline dGTP & Deoxyguanosine triphosphate \\
\hline $\mathrm{DHH}$ & Desert $\mathrm{HH}$ \\
\hline DMEM & Dulbecco's Modified Eagle Medium \\
\hline DMSO & Dimethyl sulfoxide \\
\hline DNA & Desoxyribonucleic acid \\
\hline DNMT1 & DNA methyltransferase 1 \\
\hline dNTPs & Deoxyribonucleotide triphosphates \\
\hline DTT & Dithiothreitol \\
\hline dTTP & Deoxythymidine triphosphate \\
\hline DYRK & Dual-specificity tyrosine-phosphorylation-regulated kinase \\
\hline E. coli & Escherichia coli \\
\hline EDTA & Ethylendiaminetetraacetic acid \\
\hline
\end{tabular}




\begin{tabular}{|c|c|}
\hline EGF & Epidermal growth factor \\
\hline EGFP & Enhanced green fluorescent protein \\
\hline EGFR & EGF receptor \\
\hline EMA & European medicines agency \\
\hline ERK & Extracellular signal-regulated kinase \\
\hline ERMS & Embryonal RMS \\
\hline $\mathrm{EtOH}$ & Ethanol \\
\hline FCS & Fetal calf serum \\
\hline FDA & Food and drug administration \\
\hline FELASA & Federation of european laboratory animal science associations \\
\hline FGF & Fibroblast growth factor \\
\hline FGFR & FGF receptor \\
\hline FITC & Fluorescein isothiocyanate \\
\hline FOXO1 & Forkhead box protein $\mathrm{O} 1$ \\
\hline GAS1 & Growth arrest-specific 1 \\
\hline gDNA & Genomic DNA \\
\hline GLI & Glioma-associated oncogene homolog \\
\hline $\mathrm{GLI}^{\mathrm{R}}$ & GLI repressor form \\
\hline GSK3ß & Glycogen synthase kinase $3 \beta$ \\
\hline $\mathrm{HA}$ & Hemagglutinin \\
\hline HE & Haematoxylin and eosin \\
\hline $\mathrm{HH}$ & Hedgehog \\
\hline HHIP & $\mathrm{HH}$ interacting protein \\
\hline HPRT & Hypoxanthine-guanine phosphoribosyltransferase \\
\hline HRP & Horse radish peroxidase \\
\hline HSC70 & Heat-shock protein 70 \\
\hline IGF1/2 & Insulin-like growth factor $1 / 2$ \\
\hline IGF-1R & IGF factor 1 receptor \\
\hline $\lg G$ & Immunoglobulin G \\
\hline $\mathrm{IHH}$ & Indian $\mathrm{HH}$ \\
\hline IRS1 & Insulin receptor substrate 1 \\
\hline JNK & c-Jun N-terminal kinases \\
\hline LB & Lysogeny broth \\
\hline $\mathrm{LOH}$ & Loss of heterozygosity \\
\hline $\mathrm{mAb}$ & Monoclonal antibody \\
\hline MAPK & Mitogen-activated protein kinase \\
\hline MCT & Methylcellulose tween \\
\hline MDM2 & Mouse double minute 2 homolog \\
\hline MEK & Mitogen-activated protein kinase kinase \\
\hline MolTaq & Taq polymerase (named after Thermus aquaticus) \\
\hline mRNA & Messenger RNA \\
\hline mTOR & Mammalian target of rapamycin \\
\hline mTORC1/2 & mTOR complex \\
\hline $\mathrm{NC}$ & Nitrocellulose \\
\hline $\mathrm{P} / \mathrm{S}$ & Penicillin, Streptomycin \\
\hline
\end{tabular}




\begin{tabular}{ll} 
PAb & Polyclonal antibody \\
PAKT & Phosphorylated AKT \\
PAX & Paired box \\
PBS & Phosphate buffered saline \\
PBST & PBS-tween \\
PCR & Polymerase chain reaction \\
PD & Progressive disease \\
PDK & 3-phosphoinositide-dependent protein kinase \\
PDNA & Plasmid DNA \\
pERK & Phosphorylated ERK \\
PFA & Paraformaldehyde \\
PI & Propidium iodide \\
PI3K & Phosphatidylionsitide 3-kinase \\
PIP2 & Phosphatidylinositol-4,5-bisphosphate \\
PIP3 & Phosphatidylinositol-3,4,5-trisphosphate \\
PKA & Protein kinase A \\
PR & Partial response \\
PRAS40 & Proline-rich AKT substrate of 40 kDa \\
pS6 & Phosphorylated S6 \\
PTCH & Patched \\
PTEN & Phosphatase and tensin homolog \\
PVDF & Polyvinylidene \\
qRT PCR & Quantitative real-time PCR \\
Rac1 & RAS-related C3 botulinum toxin substrate 1 \\
RAF & Rapidly accelerated fibrosarcoma \\
RAS & Rat sarcoma \\
RECIST & Response evaluation criteria in solid tumors \\
RhoA & RAS homolog gene family member A \\
RMS & Rhabdomyosarcoma \\
RNA & Ribonucleic acid \\
rRNA & Ribosomal RNA \\
RTK & Receptor typrosine kinase \\
S6K1 & S6 kinase 1 \\
SAG & SMO agonist \\
SD & Stable disease \\
SDS & Sodiumdodecylsulfate \\
SEM & Standard error of the mean \\
SHH & Sonic HH \\
SHH-CM & SHH conditioned medium \\
SMO & Smoothened \\
SOX & Sex-determining region Y-related high mobility group-box \\
SUFU & Suppressor of fused \\
TBE & Tris-boric acid-EDTA \\
TBP & TATA-box binding protein \\
TBS & Tris-buffered saline \\
\hline &
\end{tabular}


TBST TBS-triton

TGF $\beta \quad$ Transforming Growth Factor- $\beta$

TSC1/2 Tuberous sclerosis protein

UV ultraviolet

VAC Vincristine, actinomycin D and cyclophosphamide

VEGF Vascular endothelial growth factor

VEGFR VEGF receptor

WST-1 Water soluble tetrazolium salt-1 


\section{Acknowledgement}

Now that my time as a PhD student is coming towards an end, I am very proud of all the help I was allowed to experience. This thesis would not have been possible without the people surrounding me.

First of all, I would like to thank Prof. Dr. Heidi Hahn for her kind supervision and the possibility of learning from her experience. Thank you for your permanent assistance throughout the time and for always being available for questions. It was great to develop new ideas together.

Furthermore I would like to thank Prof. Dr. Matthias Dobbelstein and Prof. Dr. Dieter Kube for the lively discussions and helpful comments at the thesis committee meetings. They were very important to go one step back and see the project as a whole.

Thank you Dr. Kai Dittmann for your help with flow cytometry and the kind conversations, it was always good to see you around. I would also like to thank Dr. Christian Dullin, Dr. Verena Reupke and Christina Malowsky for their competent work and all the nice hours we spent together during the $\mu \mathrm{CT}$ measurements. Many thanks to the animal caretakers, it was very supportive to know that the mice are in such good hands.

In addition, I would like to express my gratitude to all the former and present members of our group. Thank you, Dr. Anja Uhmann for the broad help with all the small problems. Many thanks to my direct supervisor Dr. Rosalie Ridzewski, you are great and I'm very happy that we met. Additionally I would like to thank Dr. Julia Dräger, Dr. Marco Becker, Dr. Benedikt Linder, Dr. Nicole Cuvelier, Julia Heise, Dominik Botermann and Nadine Brandes. It was a real pleasure working with you. Special thanks to Ina Heß and Anke Frommhold for all your help, support and the nice atmosphere you created.

Dr. Joanna Pyczek, thank you so much for everything. It is wonderful having you as a friend.

Many thanks go to my family and friends for always being around, for your unlimited support and for your encouragement. Especially I would like to thank my grandma and my parents, my brothers (plus family) and my parents-in-law. Special thanks to the youngest member of our family, we are so happy and proud to welcome you soon.

Most important: Thank you my dear husband and best friend, Kevin. It is not possible to express how grateful I am to have you in my life. Your love is the greatest support I could ever imagine. 


\section{Curriculum Vitae}

4/2015 - hitherto

PhD candidate within the Molecular Medicine Study Program, Georg-August University Göttingen

$\mathrm{PhD}$ thesis at the Institute of Human Genetics, University Medical Center Göttingen

Title: Targeting the Hedgehog and PI3K/AKT/mTOR signaling pathways in rhabdomyosarcoma

10/2014 - 3/2015 Research assistant

Biophysics division, GSI Helmholtzzentrum für Schwerionenforschung, Darmstadt

11/2012-9/2014 M.Sc. Technical Biology, Technical University Darmstadt (Grade: very good)

Master thesis at the GSI Helmholtzzentrum für Schwerionenforschung, Darmstadt

Title: Impact of ionizing radiation on the differentiation of hematopoietic progenitor cells into osteoclasts and $\mathrm{T}$ cell subpopulations

11/2009-08/2012 B.Sc. Biotechnology, Darmstadt University of Applied Science (Grade: very good)

Bachelor thesis at the Institute of Physiological Chemistry, University Medical Center Mainz

Title: Gene expression analysis of carbonic anhydrase from Petroselinum crispum (parsley) by Real-Time-PCR

Manuscripts submitted for publication

Viehweger, F., Ragab, N., Geyer, N., Heise, J., Yang, M., Seils, A., Belharazem, D., Schildhaus, H.U., Marx, A., Hahn, H., Simon-Keller, K. Subordinate role of canonical WNT/ßCATENIN signaling in alveolar and embryonal rhabdomyosarcomas. Sarcoma, submitted.

\section{$\underline{\text { Publications }}$}

Müller, W.E., Qiang, L., Schröder, H.C., Hönig, N., Yuan, D., Grebenjuk, V.A., Mussino, F., Giovine, M., Wang, X. Carbonic anhydrase: a key regulatory and detoxifying enzyme for Karst plants. Planta 239, 213-229, doi:10.1007/s00425-013-1981-2 (2014). 